\title{
Essays on the Importance of Gender, Sectoral Assignment and Post-Migration Education for Earnings Dynamics
}

\author{
by \\ Michelle G. Laing \\ A thesis submitted to the Faculty of Graduate and Postdoctoral Affairs in partial \\ fulfillment of the requirements for the degree of \\ Doctor of Philosophy \\ in \\ Economics \\ Carleton University \\ Ottawa, Ontario
}

(C) 2021

Michelle G. Laing 


\section{Abstract}

This thesis is comprised of three essays which aim to contribute to a deeper understanding of the factors influencing the experiences of different individuals in the labour market as well as the impact of diversity for firm performance.

Chapter 1 explores whether having more female executive directors on a corporate board deters opportunistic behaviour in financial reporting in periods of uncertainty. This

opportunistic behaviour, termed earnings management, arises because the accrual accounting method used by many corporations leads to the possibility that earnings will be presented in a way which gives an excessively positive view of a firm's activities and financial position due to compensation contracts of inside directors being based on the value of the share price of the firm. To address issues of endogeneity and determine whether board gender diversity has a causal effect on earnings quality, I use a firm fixed effects model with two way clustered standard errors based on the firm and year. I find that having two female directors is associated with lower discretionary accruals and, thus, greater corporate income. Yet, the presence of female directors does not always deter opportunistic behaviour in financial reporting during periods of uncertainty when $\mathrm{CEO} / \mathrm{CFO}$ wealth is tied to the value of a firm's shares. A major implication of my findings is that the equity-based rationale for increasing the share of women on corporate boards should get more weight. If male and female directors behave in a similar fashion in some aspects of corporate decision making, then men and women must not be treated as monolithic groups but there should be a focus on fairly assessing female directors based on their skills and accomplishments by holding 
them to the same and not higher expectations as their male counterparts.

Chapter 2 examines the existence of a public-private sector wage differential in Canada. Given that empirical work on the topic with a strong time series component is virtually non-existent, I contribute to the literature by using longitudinal data from all waves of the Survey of Labour and Income Dynamics (SLID) to explore wage differentials across the public and private sectors in the period from 1993 to 2010. My estimations provide strong evidence for the existence of a public sector wage premium. They also show that controlling for union coverage or firm size can reduce the estimated public-private sector wage differential. Additionally, the public sector pays some workers who are likely to experience discrimination based on their race or sex relatively more than they would have earned if they had worked in the private sector.

Chapter 3 uses data from the Canadian Employer-Employee Dynamics Database (CEEDD) to analyze the earnings returns immigrants obtain from investments in post-secondary education (PSE) after their arrival in Canada. Our findings indicate that PSE is an important part of the labour market adjustment process for new immigrants. Specifically, post-migration PSE enrollment is found to increase the annual earnings of both men and women. The earnings effects of PSE are larger for immigrants admitted in the Skilled Worker category relative to Family Class immigrants and Refugees, and are increasing in the level of education at landing. Also, immigrants from non-traditional source countries generally have larger returns to PSE than immigrants from English language source countries such as the US and the countries of Northwestern Europe. Further, earnings returns are higher when immigrants build human capital through both PSE and work experience; returns from PSE rise with time since the most recent study period; and earnings growth from PSE is not biased by out-migration. 


\section{Dedication}

\section{To God}

"who is able to do exceedingly abundantly above all that we ask or think,

..., to Him be glory..., forever and ever. Amen."

(Ephesians 3:20-21, The New King James Version) 


\section{Acknowledgements}

First and foremost, I would like to express my sincere gratitude to my supervisor Prof. Christopher Worswick for his invaluable and endless guidance and support. As my mentor, he has taught me more than I could ever give him credit for. He went beyond the call of duty and has inspired me by his hard-working and passionate attitude. I have learnt to always aim for the best both in and out of my career as an Economist and, above all, also to believe in myself.

I am also grateful to the members of my thesis committee: Prof. Matthew D. Webb and Prof. Louis-Philippe Morin; my external external examiner, Prof. Mikal Skuterud; and my internal external examiner, Prof. Luciara Nardon. They provided the crucial and constructive feedback to raise the standard of my work. I would also like to express my gratitude to Prof. M. Omair Shafiq who chaired my Ph.D. defence, to Prof. Hashmat Khan who provided feedback on the first chapter of the thesis, and to the co-authors of the final chapter of my thesis: Wen Ci (an alumna of the Carleton University Ph.D. Economics program), Prof. Marcel Voia and Prof. Christopher Worswick. I am also very thankful to the Ottawa - Outaouais Research Data Centre at the University of Ottawa and the Canadian Centre for Data Development and Economic Research (CDER) at Statistics Canada for 
providing me with secure access to data from the Survey of Labour and Income Dynamics (SLID) and Canadian Employer-Employee Dynamics Database (CEEDD) which I used for my second and third chapters.

I also wish to thank Prof. Patrick Coe (Ph.D. Economics Program Director, Carleton University) and the entire faculty and staff as well as my fellow classmates from the Department of Economics at Carleton University for their continuous encouragement. I am also deeply grateful to Prof. Robert W. Dimand (Brock University) who supported my career goals both financially and with a great deal of encouragement, and Prof. Tomson Ogwang (Brock University) who has provided me with helpful advice along the way.

Finally, I would like to thank my family and friends who showered me with consistent unconditional love, patience and endless moral support especially my parents, Michael and Elizabeth; my brothers, Emmanuel and Mark; and my best friend, Clarence D. Kalitsi. I also thank Rebekah Owusu (an alumna of the University of Ottawa Ph.D. Economics program); the late Emeritus Prof. Ebenezer Laing and the entire Laing family; the Armah family (Ghana); the Wood family (U.K.); the Otoo family (Canada); and members of the Parchmore Methodist Church (U.K.). The depth of my gratitude for them is impossible to put in words as this would definitely not have been accomplished without them. They have all inspired, supported and encouraged me throughout this very intense journey, and for that I say a big "thank you". 


\section{Contents}

$\begin{array}{ll}\text { Abstract } & \text { ii }\end{array}$

Dedication $\quad$ iv

Acknowledgements $\quad$ v

1 Do Corporate Boards with Women Deter Opportunistic Behaviour in Financial Reporting? 1

1.1 Introduction . . . . . . . . . . . . . . . . . . 1

1.2 Literature Review . . . . . . . . . . . . . . . . . . . 5

1.3 Data and Empirical Framework . . . . . . . . . . . . . . 9

1.3.1 Sample Selection . . . . . . . . . . . . . . . . . . . . . 9 9

1.3.2 Measuring Earnings Management . . . . . . . . . . . . . . . . 10

1.3.3 Model Specification . . . . . . . . . . . . . . . . . . . . . . 12

1.4 Empirical Results . . . . . . . . . . . . . . . . . . . . . 16

1.4.1 CEO Incentives, Boardroom Gender Diversity, and Reported Earnings . . . . . . . . . . . . . . 16

1.4.2 CFO Incentives, Boardroom Gender Diversity, and Reported Earnings . . . . . . . . . . . . . . . 17

1.4 .3 Robustness Checks . . . . . . . . . . . . . . . . . . . . 18

1.5 Concluding Remarks . . . . . . . . . . . . . . . . . . . . . 23

2 The Implications of Sectoral Assignment for Wages: Longitudinal Evidence for Canada $\quad 26$

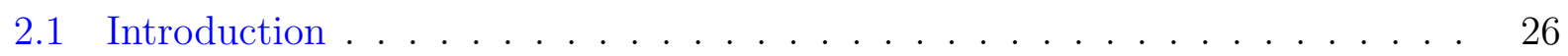

2.2 Literature Review . . . . . . . . . . . . . . . . . . . . . . . . . . . . . . . . 29

2.3 Empirical Framework . . . . . . . . . . . . . . . . . . . . . . 33

2.3 .1 Data . . . . . . . . . . . . . . . . . . . 33

2.3 .2 Model Specification . . . . . . . . . . . . . . . . . . . . 37

2.4 Empirical Results . . . . . . . . . . . . . . . . . . . . . . . . 42 
2.4.1 Cross-sectional and Pooled OLS Models . . . . . . . . . . . . . 42

2.4 .2 Fixed Effects Model . . . . . . . . . . . . . . . . . . 46

2.5 Robustness Checks and Extensions . . . . . . . . . . . . . . 54

2.5.1 Controlling for Residence in the National Capital Region . . . . . . . 54

2.5 .2 The Role of Union Membership . . . . . . . . . . . . . . . . 55

2.5.3 Does the Public Sector Pay Visible Minorities More? . . . . . . . . . 57

2.6 Concluding Remarks . . . . . . . . . . . . . . . . 63

3 Immigrant Earnings Returns to Post-Migration Education:

$\begin{array}{ll}\text { Evidence for Canada, } 1999-2013 & 67\end{array}$

3.1 Introduction . . . . . . . . . . . . . . . . . 67

3.2 Literature Review . . . . . . . . . . . . . . . . . . . . 70

3.2.1 Post-Migration Human Capital Investments . . . . . . . . . . 71

3.2 .2 Wage Effects of Adult Mid-Career Training . . . . . . . . . . . . 73

3.3 Empirical Framework . . . . . . . . . . . . . . . . . . . . . 74

3.3 .1 Data and Sample Selection . . . . . . . . . . . . . . 74

3.3 .2 Methodology . . . . . . . . . . . . . . . . 78

3.4 Empirical Results . . . . . . . . . . . . . . . . . . . . . . . 79

3.5 Extensions . . . . . . . . . . . . . . . . . . . . 82

3.5 .1 Propensity Score Matching . . . . . . . . . . . . . . . . 82

3.5 .2 Fixed Effects Estimation _ . . . . . . . . . . . . . 86

3.5.3 Robustness Checks and Other Extensions . . . . . . . . . . . . . . . 91

3.6 Concluding Remarks . . . . . . . . . . . . . . . . . . . . . . . . . . . . . . . . 99

$\begin{array}{lll}\text { A Appendix for Chapter 1 } & 104\end{array}$

$\begin{array}{ll}\text { B Appendix for Chapter 2 } & 122\end{array}$

$\begin{array}{ll}\text { C Appendix for Chapter 3 } & 163\end{array}$

$\begin{array}{lr}\text { References } & 189\end{array}$ 


\section{List of Tables}

A.1 Variable Descriptions . . . . . . . . . . . . . . . . . . . . . 105

A.2 Sample Selection Process . . . . . . . . . . . . . . . . . . 106

A.3 Descriptive Statistics for the CEO Sample . . . . . . . . . . . . . 107

A.4 Descriptive Statistics for the CFO Sample . . . . . . . . . . . . . . 107

A.5 CEO Incentives, Gender Diversity, and Reported Earnings . . . . . . . . 108

A.6 CFO Incentives, Gender Diversity, and Reported Earnings . . . . . . . . . 110

A.7 Robustness Check Results: CEO Sample - Without Dynamic Effects . . . . . 112

A.8 Robustness Check Results: CFO Sample - Without Dynamic Effects . . . . . 113

A.9 Robustness Check Results: CEO Sample - Unregulated Firms . . . . . . . . 114

A.10 Robustness Check Results: CFO Sample - Unregulated Firms . . . . . . . 115

A.11 Robustness Check Results: CEO Sample - Winsorization . . . . . . . . . 116

A.12 Robustness Check Results: CFO Sample - Winsorization . . . . . . . . . . 117

A.13 Robustness Check Results: CEO Sample - Alternative Estimation of Discretionary Accruals . . . . . . . . . . . . . . . . . . . . 118

A.14 Robustness Check Results: CFO Sample - Alternative Estimation of Discretionary Accruals . . . . . . . . . . . . . . . . . . . . . . . . 119

A.15 Robustness Check Results: CEO Sample - Positive and Negative Discretionary Accruals . . . . . . . . . . . . . . . . . . . . . . 120

A.16 Robustness Check Results: CFO Sample - Positive and Negative Discretionary Accruals . . . . . . . . . . . . . . . . . . . . . . . . 121

B.1 Summary of Key Findings of Existing Literature . . . . . . . . . . . . 123

B.2 Variable Descriptions . . . . . . . . . . . . . . . . . . . . . . . . 125

B.3 Descriptive Statistics by Sector of Employment . . . . . . . . . . . . 127

B.4 Non-wage Benefits by Sector of Employment . . . . . . . . . . . . . . 128

B.5 Raw Wage Public-Private Sector Wage Differentials . . . . . . . . . . . . . 132

B.6 Cross-sectional Wage Regressions - Males . . . . . . . . . . . . . . . . 133

B.7 Cross-sectional Wage Regressions - Females . . . . . . . . . . . . . . . 134

B.8 A Comparison of Raw Public-Private Sector Wage Differentials and Estimates from Cross-sectional Regressions . . . . . . . . . . . . . . . . . . . . 135 
B.9 Pooled OLS Wage Regressions - Baseline . . . . . . . . . . . . . . 136

B.10 Pooled OLS Wage Regressions - Controlling for the Number of Children . . . 137

B.11 Pooled OLS Wage Regressions - Public Administration . . . . . . . . . 138

B.12 Pooled OLS Wage Regressions - Controlling for Firm Size . . . . . . . . . . 138

B.13 Pooled OLS Wage Regressions - Excluding Observations Associated With

Wages Above $\$ 1,000 \ldots \ldots$. . . . . . . . . . . . . . 139

B.14 Pooled OLS Wage Regressions - Winsorization . . . . . . . . . . . . . . 139

B.15 Fixed Effects Wage Regressions - Baseline . . . . . . . . . . . . . . . 140

B.16 Fixed Effects Wage Regressions - Controlling for the Number of Children . . 141

B.17 Fixed Effects Wage Regressions - Public Administration . . . . . . . . . . . 142

B.18 Fixed Effects Wage Regressions - Controlling for Firm Size . . . . . . . . . 142

B.19 Fixed Effects Wage Regressions - Excluding Observations Associated With Wages Above $\$ 1,000 \ldots \ldots$. . . . . . . . . . . . . . . . 143

B.20 Fixed Effects Wage Regressions - Winsorization (Top 1\%) . . . . . . . . . 143

B.21 Fixed Effects Wage Regressions - Winsorization (Top and Bottom 1\%) . . 144

B.22 First Difference OLS Wage Regressions . . . . . . . . . . . . . . . . 145

B.23 First Difference OLS Wage Regressions with Indicators for the Direction of Sector Switching . . . . . . . . . . . . . . . . . . 146

B.24 Fixed Effects Wage Regressions - Without Private to Public Sector Switches 147

B.25 Fixed Effects Wage Regressions - Without Public to Private Sector Switches 147

B.26 Fixed Effects Wage Regressions - Sector Switches Accompanied by Job Switches148

B.27 Fixed Effects Wage Regressions - Sector Switches Accompanied by Involuntary

Job Switches . . . . . . . . . . . . . . . . . . . . . . . . . . . . 148

B.28 Fixed Effects Wage Regressions - Balanced Panel . . . . . . . . . . . . . 149

B.29 Pooled OLS and Fixed Effects Wage Regressions - Trend Across Time . . . . 150

B.30 Pooled OLS Wage Regressions - With Time Trend and Detrended Unemployment Rate . . . . . . . . . . . . . . . . . . . . . . . . 152

B.31 Fixed Effects Wage Regressions - With Time Trend and Detrended Unemployment Rate . . . . . . . . . . . . . . . . . . . . . . 153

B.32 Distribution of Workers by Census Metropolitan Area (CMA) and Sector of Employment . . . . . . . . . . . . . . . . . . . . 154

B.33 Fixed Effects Wage Regressions Controlling for Residence in the National Capital Region . . . . . . . . . . . . . . . . . . . . . . . 154

B.34 Pooled OLS and Fixed Effects Wage Regressions Controlling for Residence in the National Capital Region - Trend Across Time . . . . . . . . . . . . . 155

B.35 Fixed Effects Wage Regressions Not Controlling for Union Coverage . . . . . 156 
B.36 Pooled OLS and Fixed Effects Wage Regressions Not Controlling for Union Coverage - Trend Across Time . . . . . . . . . . . . . . . . 157

B.37 Distribution of Workers by Visible Minority Group and Sector of Employment 158

B.38 Pooled OLS Wage Regressions Controlling for Belonging to a Visible Minority Group . . . . . . . . . . . . . . . . . . . . . 158

B.39 Pooled OLS Wage Regressions Controlling for Belonging to a Visible Minority Group and Time Since Migration . . . . . . . . . . . . . . . 160

B.40 Fixed Effects Wage Regressions Controlling for Belonging to a Visible Minority Group . . . . . . . . . . . . . . . . . . . . . 162

C.1 Descriptive Statistics of Immigrant Characteristics by Enrollment in Post-Secondary Education . . . . . . . . . . . . . . . . . . . . . . . . 164

C.2 Descriptive Statistics (Variables Used in the Parametric Long-Difference Model) 165

C.3 Earnings Return to Full-Time PSE Investment of Immigrants Within the 6-Year Window Since Their Arrival . . . . . . . . . . . . . . . 166

C.4 Earnings Return to Part-Time PSE Investment of Immigrants Within the 6-Year Window Since Their Arrival . . . . . . . . . . . . . . . 167

C.5 Earnings Return to Months of Full-Time PSE Investment of Immigrants Within the 6-Year Window Since Their Arrival . . . . . . . . . . . . . 168

C.6 Earnings Return to Months of Part-Time PSE Investment of Immigrants Within the 6-Year Window Since Their Arrival . . . . . . . . . . . . . 169

C.7 Determinants of Immigrant PSE Enrollment Within the 6-Year Window Since Their Arrival, Linear Probability Model . . . . . . . . . . . . . . . . . 170

C.8 Propensity Score Matching Estimates for the Effect of Full-Time Study (Nearest Neighbour Matching Using the Euclidean Distance Metric) . . . . . 171

C.9 Propensity Score Matching Estimates for the Effect of Part-Time Study (Nearest Neighbour Matching Using the Euclidean Distance Metric) . . . . . 171

C.10 Descriptive Statistics of Immigrant Characteristics by Enrollment in Post-Secondary Education (Sample Used for the Fixed Effects Estimation) . 172

C.11 Descriptive Statistics (Variables Used in the Fixed Effects Estimation) . . . 173

C.12 Fixed Effects Estimation of the Earnings Return to PSE Investment of Immigrants . . . . . . . . . . . . . . . . . . . . . . . 174

C.13 Second Stage of the Fixed Effects Estimation of the Earnings Return to PSE Investment of Immigrants _ . . . . . . . . . . . . . . 175

C.14 Fixed Effects Estimation of the Earnings Return to Months of PSE Investment of Immigrants . . . . . . . . . . . . . . . . . . . . . 176 
C.15 Fixed Effects Estimation of the Earnings Return to PSE Investment of Immigrants by Admission Category . . . . . . . . . . . . . . . . 177

C.16 Fixed Effects Estimation of the Earnings Return to PSE Investment of Immigrants by Source Region . . . . . . . . . . . . . . . . 178

C.17 Fixed Effects Estimation of the Earnings Return to PSE Investment of Immigrants by Education Level at Landing . . . . . . . . . . . . . . 179

C.18 Fixed Effects Estimation of the Earnings Return to PSE Investment of Immigrants - Including Immigrants Enrolled in Both Full-time and Part-time

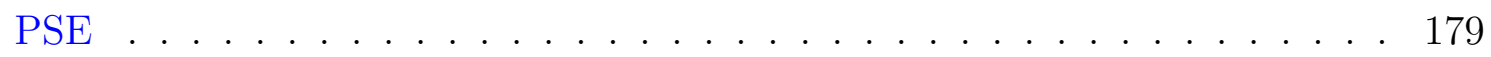

C.19 Fixed Effects Estimation of the Earnings Return to PSE Investment of Immigrants With Earnings Levels as the Outcome Variable . . . . . . . . 180

C.20 Fixed Effects Estimation of the Earnings Return to PSE Investment of Immigrants Including Immigrants Who Had Positive Earnings in Each of the First Full 8 Years Since Migration . . . . . . . . . . . . . . . . . . . 180

C.21 Fixed Effects Estimation of the Earnings Return to PSE Investment of Immigrants Including Immigrants Who Had Positive Earnings in Each of the First Full 8 Years Since Migration: The Timing of the PSE Investment . . . 181

C.22 Fixed Effects Estimation of the Earnings Return to PSE Investment of Immigrants: The Non-Linear Effects of Post-Migration Education . . . . . . 182

C.23 Shares of Immigrants Absent from the Tax Records by Landing Cohort . . . 183

C.24 Probit Estimation for the Incidence of Male Immigrants Being Absent from the Tax Records for Four or More Consecutive Years . . . . . . . . . . . . 184

C.25 Probit Estimation for the Incidence of Female Immigrants Being Absent from the Tax Records for Four or More Consecutive Years . . . . . . . . . . . 186

C.26 Fixed Effects Estimation of the Earnings Return to PSE Investment of Immigrants Excluding Immigrants Who Were Ever Absent . . . . . . . . 188 


\section{List of Figures}

B.1 Proportion of Workers in the Public Sector by Gender Canada, 1993 to 2010129

B.2 Wages of Workers in the Public and Private Sectors (Conditional on Sample Restrictions) Canada, 1993 to 2010 . . . . . . . . . . . . . . . . . . 129

B.3 Wages of Workers in the Public and Private Sectors Canada, 1993 to 2010 . 129

B.4 Wages of Workers in the Public and Private Sectors (Without Outliers) Canada, 1993 to 2010 . . . . . . . . . . . . . . . . . . . . 130

B.5 Wages of Workers in the Public and Private Sectors (Conditional on Sample Restrictions and Without Outliers) Canada, 1993 to 2010 . . . . . . . . . . . 130

B.6 Raw Public-Private Sector Wage Differential by Gender Canada, 1993 to 2010131

B.7 Proportion of Workers Who Switched Sectors by Gender Canada, 1993 to 2010131

B.8 Proportion of Switchers Who Switched to the Public Sector by Gender Canada, 1993 to 2010 . . . . . . . . . . . . . . . . . . . . 131

B.9 Estimates of the Public-Private Sector Wage Differential from Cross-Sectional Models by Gender Canada, 1993 to 2010 . . . . . . . . . . . . . . . . . . . . 135

B.10 Proportion of Workers who were Union Members by Sector and Gender Canada, 1993 to $2010 \ldots \ldots$. . . . . . . . . . . . . 156 


\section{Chapter 1}

\section{Do Corporate Boards with Women}

\section{Deter Opportunistic Behaviour in}

\section{Financial Reporting?}

\section{$1.1 \quad$ Introduction}

The rise in female executive directors and the push for greater diversity in boardrooms has led to a desire to understand the role of gender for corporate board decision making. Decisions in the financial reporting of earnings are one example.

Many public corporations in Canada, the US and many other countries are required by law to use the accrual accounting method whereby adjustments are made to financial statements for earned revenues and incurred expenses for which cash has not yet been received or paid out. The adjustments are recorded on financial statements as total current accruals. However, in reality, part of the total accruals is non-discretionary and the other is discretionary. Non-discretionary accruals reflect business conditions while discretionary 
accruals reflect management choices and judgement.

To maximise shareholder value, several modern corporations have adopted a two-tier corporate hierarchy where the first tier is a board of directors elected by the shareholders and the second tier is the upper management hired by the board of directors. Consequently, although discretionary accruals may be used to smooth earnings intertemporally, the separation of ownership and management leads to the possibility of 'earnings management' i.e. the opportunistic reporting of earnings through a manipulation of discretionary accruals to present an excessively positive view of a firm's activities and financial position. Earnings management may occur in firms whose management is less closely monitored and inside directors, e.g. Chief Executive Officers (CEOs) and Chief Financial Officers (CFOs), tend to have compensation contracts that are based on the value of the firm's share price (Bergstresser and Philippon (2006)). Shareholders who are not inside directors may not be privy to information about the firm's true income leading to the share price being stable or higher than it may have been prior to earnings management. As a result, the wealth of the inside directors may be increased at the expense of the other shareholders of the company who have invested their funds in the firm but are less informed about the true value of the shares.

Although CFOs are primarily responsible for a company's financial statements and financial information, the incentives of both CFOs and CEOs to engage in such behaviour may be a cause for concern. Hambrick and Mason (1984) suggest that strategic choices and organizational outcomes reflect the characteristics of top management including both CEOs and CFOs. CEOs have larger and more influential incentives; CFOs report to CEOs; and CFOs may have to act according to the wishes of their CEOs in order not to be replaced (Jiang et al. (2010)). The CEO may often serve on the nomination committee during the board appointment process (Bertrand (2009)).

Recent evidence suggests that opportunistic earnings management may vary with the degrees of both unsystematic and systematic risk (e.g. Francis et al. (2015); Stein and 
Wang (2016) and Gassen and Markarian (2009)). The aforementioned strand of literature has highlighted that the relationship between opportunistic behaviour and uncertainty may stem from the perception that one may be less fortunate during uncertain times and luckier in periods of lower uncertainty. Incidentally, evidence from experimental economics and psychology lends support to the idea that decision making under uncertainty can systematically differ across genders based on their perceived evaluations of risk (e.g. Graham et al. (2002); Barber and Odean (2001)). It is such differences in risk attitudes which Francis et al. (2015) hold accountable for their finding that female CFOs of S\&P 1500 companies cautiously report earnings in the face of higher systematic risk thereby reducing a possible overstatement of earnings. ${ }^{1}$ Despite finding evidence that female CFOs have less preference for equity-based compensation, Francis et al. (2015) do not consider the potential effects of CFO compensation and wealth on financial reporting.

Therefore, I investigate whether having female executive directors on a corporate board deters opportunistic behaviour in financial reporting in periods of uncertainty. Some authors in the Accounting and Finance literature have found that having female executive directors can improve the general quality of reported earnings (e.g. Gul et al. (2011); Aguir et al. (2015)). These benefits are typically observed when there are at least three women on the board (e.g. Konrad and Kramer (2006); Erkut et al. (2008); Gyapong et al. (2016)). However, given that women are more risk averse and tend to be more resilient to catastrophic events (e.g. Dohmen et al. (2011); Dormady et al. (2017)), we should expect a priori that earnings management in firms with female directors on their boards will be negatively correlated with uncertainty.

From an econometrics perspective, one immediate empirical challenge in answering this question is the problem of endogeneity. To address the issue of endogeneity and determine whether board gender diversity has a causal effect on earnings quality, I use a firm fixed effects model with two way clustered standard errors based on the firm and year. In

\footnotetext{
${ }^{1}$ Systematic risk is measured as the beta of the firm computed by regressing the firms monthly stock returns on the corresponding NYSE/AMEX/NASDAQ Value-Weighted Index.
} 
particular, I estimate earnings management as a function of firm female representation, uncertainty (as measured by the Chicago Board of Exchange Volatility Index (VIX)), and director incentives among other firm characteristics typically used as regression controls in the earnings management literature. Using balance sheet data of firms from the CRSP/Compustat Merged Fundamentals Annual database, I proxy earnings management with discretionary accruals computed using the modified-Jones model of Dechow et al. (1995) augmented with a firm's lagged, current and future operating cash flow. I acquire other firm data used in the computation of regression controls from Bloomberg and take data on board characteristics and executive compensation and economic uncertainty from the ExecuComp and FRED databases, respectively. The ExecuComp database only contains information on the biological sex of board directors represented by a binary variable with male or female categories. $^{2}$

Consistent with the Accounting and Finance literature on gender and earnings management, I find that having two female directors on the board is associated with lower discretionary accruals and, thus, greater corporate income relative to firms with male-only boards. Yet, my results do not render statistical support to the idea that having female directors on the board is associated with lower discretionary accruals during periods of uncertainty when CEO / CFO wealth is tied to the value of a firm's shares. Thus, I conclude that corporate board gender diversity does not always mitigate accounting discretion and improve financial reporting.

In Section 1.2, I review the extant literature on earnings management; and the experimental economics and psychology literature on gender differences in risk perception and decision making. Section 1.3 describes the data and methodology used. This is followed by a review of the results in Section 1.4; and ultimately, the conclusions (Section 1.5) recapitulate the main results and their implications.

\footnotetext{
${ }^{2}$ Although I use the words gender and sex interchangeably, I do not consider the gender of a director which refers to the socially constructed identity of an individual and encompasses a wider range of identities than the binary male or female sex categories.
} 


\subsection{Literature Review}

The first strand of literature relevant for my paper is the work in the Accounting and Finance literature which explores the link between executive compensation and earnings management. Bergstresser and Philippon (2006) show that when a CEO's wealth is tied to the value of their firm's shares then the CEO has incentives to engage in earnings management. Jiang et al. (2010) illustrate that the magnitude of accruals and likelihood of beating analyst forecasts are more sensitive to CFO equity incentives than to those of the CEO. In addition, Duong and Evans (2015) claim that the higher the non-cash compensation received by a CFO, the lower the accruals quality.

Other related papers in the earnings management literature have investigated the relationship between the biological sex of board directors and opportunistic behaviour. Some authors have found that an increased proportion of women on the corporate board is beneficial for improving the general quality of reported earnings. Gul et al. (2011) study US corporations between 2001 and 2007 and find that gender diverse boards and audit committees are associated with higher earnings quality (lower discretionary accruals). Francis et al. (2015) reveal that there are improvements in accounting conservatism for S\&P 1500 companies in the period after transition from a male to female CFO. They highlight that the compensation of female CFOs consists of less equities than that of men and firms with female CFOs pay smaller dividends. On the other hand, Aguir et al. (2015) find that a female $\mathrm{CEO}$ or CFO does not significantly influence earnings. Instead, some papers have emphasised that the proportion of female directors on the board matters more than having a female CEO or CFO. For example, Gyapong et al. (2016) and Erkut et al. (2008) disclose that the connection between having at least three women and earnings management is negative.

Recent evidence suggests that opportunistic earnings management may vary with both firm level and economy-wide uncertainty (e.g. Francis et al. (2015); Stein and Wang (2016) and Gassen and Markarian (2009)). For example, Francis et al. (2015) obtain evidence to suggest that female CFOs of S\&P 1500 companies cautiously report earnings in the face 
of higher systematic risk thereby reducing a possible overstatement of earnings. Though they investigate the influence of CFO's risk preferences on their choice of compensation, they do not consider the potential effects of CFO incentives on the reporting of earnings in situations of risk. They also do not consider CEOs or delve into the relationship between investor sentiment, as measured by the VIX, and financial reporting quality.

Gassen and Markarian (2009) find a positive and significant correlation between investor sentiment and discretionary accruals; and show that the VIX leads financial reporting decisions. According to their analysis, CEOs with share holdings are more likely to behave opportunistically than those with option holdings in order to gain from share price stability. Stein and Wang (2016) explore the relationship between firm level uncertainty, as given by the implied volatility of a firm's equity, and earnings management. They suggest that the ability of directors to engage in opportunistic behaviour varies with uncertainty since more negative accruals (losses) during more uncertain times are attributed to luck rather than firm performance; and positive accruals (higher earnings) during periods of lower uncertainty are attributed to performance rather than luck. However, Gassen and Markarian (2009) and Stein and Wang (2016) both neglect to consider the gender of CFOs in their papers.

Evidence from experimental economics and psychology lends support to the idea that decision making under uncertainty can systematically differ across genders based on their perceived evaluations of risk (e.g. Graham et al. (2002); Barber and Odean (2001)). Perceptions of risk can vary contingent on gender, socio-economic class, age, ethnicity and disability (e.g. Orr and West (2007); Dormady et al. (2017)). According to Croson and Gneezy (2009), gender differences in risk preferences exist because of differences in emotions, confidence and sensitivity to social cues. Fehr-Duda et al. (2006) propose that gender differences in risk aversion can be attributed to differences in the valuations of possible outcomes and the probabilities used in decision making. For example, they find that although different genders value monetary outcomes in the same way, risk taking depends on the probabilities they attach to lotteries with different outcomes. A woman's higher degree 
of risk aversion may be a valuable trait for good firm performance (e.g. Bernile et al. (2016); Loukil and Yousfi (2016); Parotta and Smith (2013)). The presence of women may limit risk taking, lead to more calculated risks being taken, and foster a forum where actions are well discussed and monitored.

The higher risk aversion of women may, however, potentially be one factor hindering the representation of women in the higher end of the income distribution. For example, Dohmen et al. (2011) showed that gender can reduce one's self-assessed willingness to take risk. Women in a large representative sample of the German population were found to exhibit a higher risk aversion than men. According to their research, women may consequently be under-represented in occupations which pay more due to the positive correlation between earnings and earnings volatility. A similar finding is also obtained in other studies. For example, in a field experiment by Flory et al. (2015), subjects are given the choice to express interest in a job offering one of six different compensation regimes. The experiment is conducted on an advertisement for two versions of the job. One of the advertisements was designed such that a job-seeker would perceive the job as more 'male' (a sports job) while the other was for a general genderless job. Female job-seekers were found to be less likely to apply when the job ad mentioned that they have to compete with a co-worker for their bonus, or when there was uncertainty about the conditions under which their bonus will be paid. These findings were more pronounced for the 'male' job suggesting that gender differences in attitudes towards uncertainty and competition may be a factor driving the under-representation of women particularly in jobs that are considered to be more 'male'. For such reasons, Bertrand (2018, p.227) suggests that the gender quotas that many countries have set in response to an under-representation of women at the higher end of the earnings distribution are not successful because they do not tackle issues with job design. ${ }^{3}$ Some

\footnotetext{
${ }^{3}$ Canada set a national goal to have $30 \%$ women on boards by 2019 (Status of Women Canada (2016)). Similarly, Isidro and Sobral (2015) report that many European countries have passed regulations to increase the number of women on the board. For example, in 2007, the Spanish parliament passed the Gender Equality Act which recommended that public companies with 250 or more employees should have at least $40 \%$ of each gender on their boards by 2015 .
} 
other popular explanations for the glass ceiling in the corporate world include discrimination against women; failure of male-dominated boards to recognize the talents of and train female workers to be their future successors; beliefs about the ability of female CEOs; and the fact that the share of women studying for a Master of Business Administration (MBA) degree has been relatively low until recently (Bertrand (2009)).

Some papers advocate that men and women process information differently. Women are more likely than men to make decisions based on a comprehensive set of information from internal, external, objective and subjective sources (e.g. Byrne and Worthy (2015); Graham et al. (2002)). Decisions made by women may also be due to their sentiments or perceptions (Dormady et al. (2017)). ${ }^{4}$ The results of Dormady et al. (2017) suggest that female middle market managers make greater resilience investments than their male counterparts since their perception of the likelihood that a catastrophic event will occur is much higher.

There are a few findings from the aforementioned literature which are of fundamental importance to this paper. First, the literature illustrates that earnings management should be lower when there are at least three women on the corporate board. Second, the literature highlights that earnings management varies with uncertainty. Third, the literature suggests that decision making under uncertainty can differ across genders. My paper combines these insights in order to investigate whether having female executive directors on a corporate board deters opportunistic behaviour in financial reporting in periods of uncertainty.

\footnotetext{
${ }^{4}$ The samples of individuals used in these studies suggests that this finding is true at the top of the ability distribution. While Graham et al. (2002) focuses on financial investors and Dormady et al. (2017) on managers from firms with annual revenues of between $\$ 10$ million and $\$ 1$ billion in the US, Byrne and Worthy (2015) use a sample of undergraduate students from a university in Texas.
} 


\subsection{Data and Empirical Framework}

\subsubsection{Sample Selection}

The goal of this paper is to study how corporate boardroom gender diversity affects earnings management during periods of investor uncertainty. I do this using data from a variety of sources used in the extant literature.

I assemble observations from reportings in financial statements from the CRSP/Compustat Merged - Fundamentals Annual database. ${ }^{5}$ Next, for the CEO sample, I merge this data with CEO related data on executive-compensation and board characteristics obtained from the ExecuComp database. I indentify the CEO for each firm as a value of "CEO" in the annual CEO flag (CEOANN) variable, which indicates that the associated individual was the CEO for all or most of the indicated fiscal year. I only include firm-years with positive discretionary accruals since I focus only on firms which present an excessively positive view of their financial position in my analysis. ${ }^{6}$ This procedure allows me to obtain data on fiscal periods from April 1994 to December 2015 for an unbalanced panel of 927 unique firms with an average of 5 annual observations per firm for the analysis. In total, there are 6,024 firm-year observations in the sample. A summary of the "CEO sample" selection process is provided in Table A.2.

I follow the same procedure to obtain my "CFO sample" ensuring that I have the same companies as for the CEOs in my sample. To identify the CFO for each firm, I use the annual CFO flag (CFOANN) variable in the ExecuComp database. I obtain a sample of

\footnotetext{
${ }^{5}$ Note that the CRSP/Compustat Merged - Fundamentals Annual database has coverage of companies from the NYSE, AMEX and NASDAQ. Therefore, the data I use in my paper is representative of publicly traded firms in the US.

${ }^{6}$ Including both negative and positive discretionary accruals only allows one to understand whether or not a firm managed earnings as opposed to whether or not they increased their discretionary accruals. Negative discretionary accruals constitute $37 \%$ of the merged data for the CEO sample (without dropping missing data in necessary variables and duplicates and observations associated with negative discretionary accruals as shown in Table A.2) while the proportion is $42 \%$ for the CFO sample. The results in Tables A.15 and A.16 using both positive and negative discretionary accruals suggest that corporate boardroom gender diversity has no significant impact on earnings management during periods of uncertainty. This result remains true when using only the positive discretionary accruals.
} 
3,190 firm-years for use in analysing firms with CFOs whose wealth is tied to the value of their firm's shares. This data corresponds to fiscal periods from January 2008 to December 2015 for an unbalanced panel of 907 unique firms with an average of 3 annual observations per firm.

\subsubsection{Measuring Earnings Management}

I proxy a firm's earnings management using the value of its discretionary accruals. The norm is to compute discretionary accruals using a two-stage procedure. The first step is to compute the total accruals using data from either a firm's balance sheet or statement of cash flows; and then regress them on a set of firm-level controls. The fitted values of this regression are regarded as the non-discretionary accruals while the residuals are regarded as the discretionary accruals.

I compute Total Current Accruals $\left(T C A C C_{i, t}\right)$, using data from the balance sheet, as the change in Current Assets from time $t-1$ to $t\left(\Delta C A_{i, t}\right)$ minus the change in Current Liabilities (excluding the change in short-term Debt in Current Liabilities $\left(\Delta D L C_{i, t}\right)$ ) from time $t-1$ to $t\left(\Delta C L_{i, t}\right)$ and the Cash Holdings from time $t-1$ to $t\left(\Delta C H E_{i, t}\right)$ scaled by the Total Assets of the firm at time $t-1\left(A T_{i, t-1}\right)$ :

$$
T C A C C_{i, t}=\frac{\Delta C A_{i, t}-\left(\Delta C L_{i, t}-\Delta D L C_{i, t}\right)-\Delta C H E_{i, t}}{A T_{i, t-1}}
$$

Note that the subscripts $i$ and $t$ represent sample firm $i$ in year $t .^{7}$

McNichols (2002), Kim and Qi (2010), and Gul et al. (2011) employ a Jones model augmented with the lagged, current and future operating cash flow. I employ the modified-Jones model version of that used by the aforementioned papers. The regression

\footnotetext{
${ }^{7}$ Following Kim and Qi (2010, p. 941) and a specification used in Stein and Wang (2016, p. 22).
} 
used to compute the estimated total current accruals is thus given as:

$$
\begin{aligned}
T C A C C_{i, t} & =\beta_{0}+\beta_{1} \frac{1}{A T_{i, t-1}}+\beta_{2} \frac{\Delta R E V_{i, t}-\Delta A R_{i, t}}{A T_{i, t-1}}+\beta_{3} \frac{P P E_{i, t}}{A T_{i, t-1}}+\beta_{4} \frac{O C F_{i, t-1}}{A T_{i, t-1}} \\
& +\beta_{5} \frac{O C F_{i, t}}{A T_{i, t-1}}+\beta_{6} \frac{O C F_{i, t+1}}{A T_{i, t-1}}+\varepsilon_{i, t}
\end{aligned}
$$

where $\triangle R E V_{i, t}-\Delta A R_{i, t}$ is the difference between the change in revenue from time $t-1$ to $t$ and the change in accounts receivable from time $t-1$ to $t ; P P E_{i, t}$ is the gross value of Plant, Property and Equipment; and $O C F_{i, t}$ is Operating Cash Flow. $O C F_{i, t}$ is calculated as the difference between Net Income Before Extraordinary items $\left(N I B E_{i, t}\right)$ and Total Accruals $\left(T A_{i, t}\right)$ where $T A_{i, t}$ is estimated as $\Delta C A_{i, t}-\left(\Delta C L_{i, t}-\Delta D L C_{i, t}\right)-\Delta C H E_{i, t}-D P_{i, t}$, where $D P_{i, t}$ is Depreciation and Amortization. All terms are scaled by total assets lagged one period $\left(A T_{i, t-1}\right)$.

In line with Kothari et al. (2005), Stein and Wang (2016) and Kim and Qi (2010), I estimate the model separately for each period and in the cross section based on the two-digit Standard Industry Classification (SIC) code based industry. ${ }^{8}$ To ensure that there are enough observations per industry year grouping, I only use two-digit SIC code based industries with at least 15 observations for the computation. This estimation procedure implicitly assumes that all firms within the two-digit SIC code based industry have the same relationship between the non-discretionary accruals as given by $\widehat{T C A C C_{i, t}}=E\left[T C A C C_{i, t}\right]$ and the explanatory variables in the regression. As stated earlier, the discretionary accruals are given as the residuals $\left(\varepsilon_{i, t}\right)$ from the cross-sectional regressions:

$$
D A C C_{i, t}=T C A C C_{i, t}-T \widehat{C A C C}_{i, t}
$$

\footnotetext{
${ }^{8} \mathrm{~A}$ list of the SIC codes and associated industry group is available on the United States Department of Labor website at https://www.osha.gov/pls/imis/sic_manual.html
} 


\subsubsection{Model Specification}

Past papers in the corporate finance literature have emphasized a key issue that arises in the modelling of the relationship between board characteristics and firm performance. This issue is the problem of endogeneity which arises as a consequence of unobserved heterogeneity where omitted variables are correlated with both the dependent $(\mathrm{Y})$ and independent $(\mathrm{X})$ variables of a regression model; or because of simultaneity causality bias where the dependent and independent variables cause each other (i.e. $\mathrm{X}$ determines $\mathrm{Y}$ and $\mathrm{Y}$ determines $\mathrm{X}$ ).

Hermalin and Weisbach (1998) stress that board characteristics are endogenously chosen in order to ensure that they are effective in their business environment. For instance, high levels of past firm performance will lead to an incumbent CEO having greater bargaining power than their potential replacement thereby allowing them to maintain their role and possibly earn a higher salary. One measure of the performance of the firm is the reported accruals / earnings which it makes at the end of each accounting period. At the time of the appointment decision, the board is likely to only have access to information about earnings reported in previous periods. Good performance may also warrant less monitoring of the executive directors which may increase the likelihood of them acting in their own interests. Moreover, in addition to the idea raised by Hermalin and Weisbach (1998), it is also possible that directors may self-select, by way of recruitment, into a firm with good earnings quality suggesting that there may be factors other than the personal characteristics of the directors that may influence financial reporting quality.

To deal with endogeneity issues, I estimate a firm fixed effects regression model defined as:

$$
\begin{aligned}
D_{A C C_{i, t}} & =\gamma_{0}+\gamma_{1} \text { FDir }_{i, t}+\gamma_{2} \text { DACC }_{i, t-1}+\gamma_{3} \text { VIX } X_{i, t}+\gamma_{4} \text { Incentive }_{i, t-1} \\
& +\Lambda_{1} X_{i, t}+\Lambda_{2} G_{i, t}+\eta_{i}+\xi_{i, t}
\end{aligned}
$$

where $X_{i, t}$ is a vector of firm level controls and year dummy variables while $G_{i, t}$ is a vector 
of board level controls. ${ }^{9}$ FDir $_{i, t}$ is equal to 1 for firms with at least one female director on their corporate board. To control for firm level determinants of discretionary accruals, as is typically done in the literature, I include the firm's return-on-assets ratio; Tobin's Q lagged by one period; firm size (natural logarithm of total assets) lagged by one period; debt-to-asset ratio; board size; standard deviation of daily stock returns (total risk); and sales growth over the preceding three years.

I also control for the current CEO / CFO's incentive to manage earnings opportunistically using a lag of the manipulation incentive measure proposed by Bergstresser and Philippon (2006). This measure is based on the effect of a $1 \%$ increase in the firm's share price on the dollar value of an executive director's wealth in terms of their share and options holdings under an assumption that their option holdings have a delta of one: ${ }^{10}$

$$
\text { OnePercent }_{i, t-1}=\left(0.01 \times \text { Price }_{i, t-1}\right)\left(\text { Shares }_{i, t-1}+\text { Options }_{i, t-1}\right)
$$

The manipulation incentive is then defined as the fraction of the total annual gains (wealth effect plus compensation) arising from this $1 \%$ share price increase:

$$
\text { Incentive }_{i, t-1}=\frac{\text { OnePercent }_{i, t-1}}{\text { OnePercent }_{i, t-1}+\text { Salary }_{i, t-1}+\text { Bonus }_{i, t-1}}
$$

The average incentive ratio for CEOs (0.265) is more than double that for CFOs (0.133) suggesting CEOs would benefit more from earnings management.

In the baseline model, I proxy uncertainty using the level of the Chicago Board Options Exchange Volatility Index (VIX), also referred to as the fear index, at the associated fiscal year end month for each firm. Data for the VIX is available from the FRED database. The

\footnotetext{
${ }^{9}$ Tables A.1 in the Appendix for Chapter 1 provides a summary of all the variables involved in the estimation. Descriptive statistics are reported in Tables (A.3) and (A.4) in the Appendix for Chapter 1.

${ }^{10}$ In this equation Shares and Options refers to the number of shares and options (the sum of unexercised exercisable options and unexercised unexercisable options) held (not the dollar value). Delta is the amount an option price is expected to move based on a $\$ 1$ change in the share price. Therefore, a delta of one implies that the option price and share price adjust with the same magnitude and direction.
} 
index is an approximation of investor expectations regarding the near-term volatility of the stock market conveyed by the annualized implied volatility of 30 calendar-day options on the S\&P 500 stock market index.

By construction, the regression equation implies that the discretionary accruals at time $t$ are also a function of past realisations of discretionary accruals. This is not an unrealistic assumption. Earnings are expected to be somewhat persistent because stability is valued by shareholders (see Easton and Zmijewski, 1989; Kormendi and Lipe, 1987; Penman and Zhang, 2002; Richardson et al., 2005).

The residual term $\left(\xi_{i, t}\right)$ captures both random variation in discretionary accruals that is independent across time; and $\eta_{i}$ captures firm-specific fixed effects. One example of a characteristic captured in $\eta_{i}$, assuming no changes in the executive directors, is the personality traits of the CEOs and CFOs. Graham et al. (2013) find that CEOs are more optimistic and less risk averse than CFOs; and Kaplan and Sorensen (2017) state that risk-taking is positively correlated with execution and charisma which are traits they discover CEOs to have more. In particular, Kaplan and Sorensen (2017) find CEOs tend to have superior managerial talent, execution ability, charisma, and strategic ability than CFOs.

In this specification, if the estimate of the coefficient $\gamma_{1}$ is negative then corporate boardroom gender diversity leads to lower discretionary accruals. ${ }^{11}$ Additionally, if the estimate of the coefficient $\gamma_{3}$ is positive then a rise in the value of the VIX leads to an increase in discretionary accruals; and if the estimate of the coefficient $\gamma_{4}$ is positive then executive incentives lead to earnings management.

To investigate my research equation, I consider extensions of the regression specified in Equation (1.3.4) in which I include some interaction variables. Specifically, I first estimate

\footnotetext{
${ }^{11}$ Timing may not be exogenous if when a firm has high discretionary accruals it makes them more or less likely to hire a female director. In that case, no matter what the female directors do, discretionary accruals could be lower. However, regressing discretionary accruals on a binary variable equal to 1 if the firm appointed a female director between two consecutive periods, I found that there is no statistically significant relationship between the lag of discretionary accruals and the appointment of female directors. Therefore, timing not being exogenous is unlikely to be an issue.
} 
the following regression which includes an interaction term between the VIX and CEO / CFO incentives:

$$
\begin{aligned}
D A C C_{i, t} & =\gamma_{0}+\gamma_{1} \text { FDir }_{i, t}+\gamma_{2} D A C C_{i, t-1}+\gamma_{3} V_{I} X_{i, t}+\gamma_{4} \text { Incentive }_{i, t-1} \\
& +\gamma_{5}\left(\text { VIX }_{i, t} \times \text { Incentive }_{i, t-1}\right)+\Lambda_{1} X_{i, t}+\Lambda_{2} G_{i, t}+\eta_{i}+\xi_{i, t}
\end{aligned}
$$

From Equation (1.3.7), the total marginal effect of the VIX is given as:

$$
\frac{\delta D A C C_{i, t}}{\delta V I X_{i, t}}=\gamma_{3}+\gamma_{5} \text { Incentive }_{i, t-1}
$$

Thus, if the estimate of the coefficient of the interaction term $\left(\gamma_{5}\right)$ in Equation (1.3.7) is positive then it can be concluded that, on average, CEO / CFO incentives increase the response of discretionary accruals to changes in the VIX.

I then add an interaction term between CEO / CFO incentives and binary indicator for the presence of at least one female director as well as a triple interaction term between the VIX, CEO / CFO incentives and binary indicator for the presence of at least one female director to form the following regression:

$$
\begin{aligned}
D_{A C C_{i, t}} & =\gamma_{0}+\gamma_{1} \text { F Dir }_{i, t}+\gamma_{2} \text { DACC }_{i, t-1}+\gamma_{3} \text { VIX }_{i, t}+\gamma_{4} \text { Incentive }_{i, t-1} \\
& +\gamma_{5}\left(\text { Incentive }_{i, t-1} \times F \text { Dir }_{i, t}\right)+\gamma_{6}\left(\text { VIX }_{i, t} \times \text { Incentive }_{i, t-1}\right) \\
& +\gamma_{7}\left(\text { VIX }_{i, t} \times \text { Incentive }_{i, t-1} \times F \operatorname{Dir}_{i, t}\right)+\Lambda_{1} X_{i, t}+\Lambda_{2} G_{i, t}+\eta_{i}+\xi_{i, t}
\end{aligned}
$$

Using Equation (1.3.9), the impact of corporate board gender diversity in periods of uncertainty can be assessed by examining $\gamma_{6}$ and $\gamma_{7}$. The coefficient $\gamma_{6}$ represents the impact of investor uncertainty on earnings management controlling for CEO / CFO incentives in firms with male-only boards while the coefficient $\gamma_{7}$ represents the impact for firms with at least one female director. The coefficient $\gamma_{5}$ represents the impact of female $\mathrm{CEO} / \mathrm{CFO}$ incentives on earnings management and helps to ensure that the coefficient $\gamma_{7}$ is solely the 
added influence of females on the coefficient $\gamma_{6}$.

Finally, to assess the impact of adding successive numbers of female directors to the corporate board, I also estimate versions of Equations (1.3.4), (1.3.7) and (1.3.9) in which I replace $F D_{i r} r_{i, t}$ with $\sum_{j=1}^{3} F_{-} j_{i, t}$ where $j$ is equal to 1 for firms with one female director; 2 for firms with two female directors; and 3 for firms with at least three female directors,

respectively. The inclusion of $\sum_{j=1}^{3} F_{-} j_{i, t}$ allows me to easily compare discretionary accruals of firms with no women on their corporate boards to those estimated for the aforementioned scenarios.

For estimations of all the regressions, I report standard errors two-way clustered by firm and time. Clustering standard errors in this way is useful since the error term $\xi_{i, t}$ may vary by firm but not across firm and time.

\subsection{Empirical Results}

\subsubsection{CEO Incentives, Boardroom Gender Diversity, and Reported Earnings}

The results of estimating Equations (1.3.4), (1.3.7) and (1.3.9) using the CEO sample are presented in Table A.5. As expected, the estimate of the coefficient of the Incentive $_{i, t-1}$ term in column (1) of Table A.5 is positive and significant at 10\%. When CEO wealth is tied to the value of a firm's shares, a firm's discretionary accruals will be 0.0042 units higher. The value of the VIX in column (1) is not statistically significant. However, controlling for CEO incentives, the results in column (2) suggest that a unit rise in the VIX leads to a 0.0002 unit fall in the value of discretionary accruals but CEO incentives increases the response of discretionary accruals to the VIX by 0.0006 units. I also find that the estimated coefficient of the triple interaction between the binary variable indicating the presence of at least one female director, the VIX and Incentive $_{i, t-1}$ term in column (3) is negative but not 
statistically significant.

It can be noted from column (4) that firms with two female directors have discretionary accruals which are 0.0042 units lower than firms with no women on the board (significant at 5\%). Additionally, the estimated coefficient of the triple interaction between the VIX, Incentive $_{i, t-1}$ term and $F \_2$ is both negative and statistically significant at $5 \%$ highlighting that, during periods of uncertainty, firms with two female directors will have discretionary accruals that are 0.0010 units lower compared to those of firms with male-only boards (column (6)). ${ }^{12}$

In the baseline model (Equation (1.3.4)) in column (1), I find the estimated coefficients of TotalRisk, FirmSize Fit-1 $_{1}$, Tobins $Q_{i, t-1}$, ROA, BoardSize, SalesGrowth and the lag of the dependent variable $(D A C C)$ to all be significant. FirmSize $e_{i, t-1}$ (significant at 1\%), Tobins $Q_{i, t-1}$, and the lag of the dependent variable $(D A C C)$ are negatively related to discretionary accruals. On the other hand, there is a positive correlation between earnings management and stock price volatility as represented by TotalRisk (significant at 1\%) as well as ROA (significant at 1\%), BoardSize and SalesGrowth. The estimate of the coefficient of $R O A$ is positive and significant confirming that firms with higher returns generally report higher discretionary accruals as was found by Kasznik (1999).

\subsubsection{CFO Incentives, Boardroom Gender Diversity,}

\section{and Reported Earnings}

The results of estimating Equations (1.3.4), (1.3.7) and (1.3.9) using the CFO sample are presented in Table A.6. As for the results of the estimations using the CEO sample, my results in column (1) highlight that there is a positive association between discretionary

\footnotetext{
${ }^{12}$ The triple interaction terms between the VIX, Incentive $_{i, t-1}$ term, and $F \_1, F \_2$ and $F \_3$, respectively, were included to allow for variation in the effect of the number of female directors on discretionary accruals reported during periods of heightened uncertainty. However, I only find the point estimate of the triple interaction term between the VIX, Incentive $e_{i, t-1}$ term and $F_{2} 2$ to be statistically significant. Using an F-test, I find that the estimated coefficients of the interaction terms between the VIX, Incentive $_{i, t-1}$ term, and $F \_1, F \_2$ and $F \_3$, respectively, are not jointly statistically significant.
} 
accruals and both TotalRisk and ROA, respectively. However, in contrast to the results presented in Table A.5, the estimate of the coefficient of the Incentive $_{i, t-1}$ term in column (1) of Table A.6 is positive but not statistically significant. Furthermore, controlling for CFO incentives, the results in column (2) suggest that the estimate of the coefficient on the interaction term between the VIX and Incentive $_{i, t-1}$ term is also not statistically significant. Additionally, note that unlike the results reported in Table A.5, the estimated coefficient of the triple interaction between the binary variable indicating the presence of at least one female director, the VIX and Incentive $_{i, t-1}$ term in column (3) is also not statistically significant. The findings are consistent with those of Stein and Wang (2016) and Francis et al. (2015) since the results suggest that there is weak statistical evidence that CFO incentives may be as much of a cause for concern as CEO incentives.

As shown in column (4), firms with two female directors have discretionary accruals which are 0.0055 units (significant at $5 \%$ ) lower compared to firms with male-only boards. However, the point estimates of the coefficients of the interaction terms between the VIX, Incentive $_{i, t-1}$ term, and $F_{-} 1, F_{-} 2$ and $F_{-} 3$, respectively, are not statistically significant (column (6)). ${ }^{13}$

\subsubsection{Robustness Checks}

\section{Non-Dynamic Estimation}

The extant literature exploring earnings management typically use a regression model controlling for the lag of discretionary accruals because earnings stability is valued by shareholders (see Easton and Zmijewski, 1989; Kormendi and Lipe, 1987; Penman and Zhang, 2002; Richardson et al., 2005). However, dynamic models with firm fixed effects can generate inconsistent estimates if there are large number of firms but a small number of time periods (Nickell (1981)). In order to avoid such biased estimates, the correlation between the lagged

\footnotetext{
${ }^{13}$ Using an F-test, I also find that the estimated coefficients of the interaction terms between the VIX, Incentive $_{i, t-1}$ term, and $F_{-} 1, F_{-2}$ and $F_{\_} 3$, respectively, are not jointly statistically significant.
} 
dependent variable and error term in Equations (1.3.4) to (1.3.9) must tend to zero. To examine the impact of the dynamic effects on the results from the baseline estimations, I estimate the regressions excluding the lagged dependent variable. The results are reported in Tables A.7 and A.8 in the Appendix for Chapter 1.

Using the CEO sample, I find the estimated coefficient of the triple interaction between the VIX, Incentive $_{i, t-1}$ term and $F_{-2} 2$ in column (6) of Table A.7 is both negative and statistically significant at 5\% highlighting that, during periods of uncertainty, firms with two female directors will have discretionary accruals that are 0.0010 units lower compared to those of firms with male-only boards, as suggested by the baseline results. Similar findings to the baseline results are also obtained for the CFO sample, as shown by the results in column (6) of Table A.8.

\section{Unregulated Firms}

Regulatory standards may restrict the ability of upper management to report earnings opportunistically. For example, Cheng et al. (2011) provide evidence that bank managers may report discretionary accruals only when the minimum regulatory capital requirements for the banks in which they work have been met. Therefore, I investigate the results obtained when firms in regulated industries are excluded from the samples. The results are reported in Tables A.9 and A.10 in the Appendix for Chapter $1 .^{14}$

Using the CEO sample, I observe that the estimated coefficient of the triple interaction between the VIX, Incentive $e_{i, t-1}$ term and F_2 in column (6) of Table A.9 is both negative and statistically significant at 5\% highlighting that, during periods of uncertainty, firms with two female directors will have discretionary accruals that are 0.0012 units lower compared to those of firms with male-only boards. Similar findings to the baseline results are also obtained for the CFO sample, as shown by the results in column (6) of Table A.10).

\footnotetext{
${ }^{14}$ Firms in regulated industries are firms in utilities and financial industries with SIC codes between 4400 - 5000 and $6000-6999$.
} 


\section{Winsorization}

Winsorization is a procedure in which the values of observations that lie outside some established range are instead increased or reduced to the endpoints of the range. This practice can induce or exacerbate biases in the estimation due to the exclusion of extreme values (Bollinger and Chandra (2005)). Therefore, my baseline results were not derived from a model using Winsorized variables. To find out whether the inclusion of extreme values impacted my results, I repeat the entire empirical exercise using a regression model in which all continuous variables have been Winsorized. The results are reported in Tables A.11 and A.12 in the Appendix for Chapter 1.

Results from estimations using the CEO sample in column (2) of Table A.11 indicate that, controlling for CEO incentives, a unit rise in the VIX leads to a 0.0002 unit fall in the value of discretionary accruals (significant at 10\%) but CEO incentives increase the response of discretionary accruals to the VIX by 0.0005 units (significant at $5 \%$ ). Therefore, removing the impact of the outliers suggests that the increase in discretionary accruals due to CEO incentives following a unit rise in the VIX is 0.0001 units lower than suggested by the baseline results in the same column of Table A.5. The results in column (3) of Table A.11 indicate as for the baseline results that the estimated coefficient of the interaction term between the VIX and the dummy variable indicating the presence of at least one female director is not statistically significant. In addition, as for the baseline results, the estimated coefficient of the interaction term between the VIX, Incentive $e_{i, t-1}$ term and F_2 in column (6) is both negative and statistically significant at $10 \%$ highlighting that, during periods of uncertainty, firms with two female directors will have discretionary accruals that are 0.0009 units lower compared to those of firms with male-only boards.

The main findings using the CFO sample reported in Table A.12 are also similar to those obtained from the baseline exercise. The signs and significance of the estimates of the main coefficients remain the same but their magnitude is different. 


\section{Alternative Estimation of Discretionary Accruals}

As described in Section (1.3.2), I proxy a firm's earnings management using the value of its discretionary accruals. Numerous studies have investigated different methods to accurately compute discretionary accruals and a comprehensive review is offered by Lee and Vetter (2015). The Jones model (Jones (1991)) computes non-discretionary accruals using the change in revenues and gross value of plant, property and equipment (which gives an indication of capital intensity) for a given year (scaled by total assets in the previous year). In doing so, the Jones model assumes that revenues are non-discretionary thereby leading to an estimate of the discretionary accruals proxy which excludes discretionary revenues and is thereby potentially biased towards zero. The modified-Jones model (Dechow et al. (1995)) is an improvement on the Jones model which assumes credit sales are discretionary because of an assumption that it is easier to exercise discretion over credit rather than cash sales. Yet, despite misspecification problems of both the Jones model and modified-Jones models, they are still considered to be the best models to use by many researchers (Guay et al. (1996)). There have however been some attempts to resolve the misspecification. Both Pae (2005) and McNichols (2002) include the current and lagged values of operating cash flow based on the finding that accruals are negatively related to current operating cash flow but positively related to the lagged value (see Dechow (1994); and Dechow (2002)). Pae (2005) finds that the inclusion of these variables improves the Jones model and there is no qualitative difference between the Jones model and modified Jones model. McNichols (2002) also includes the lead of the operating cash flow. ${ }^{15}$

For my main analysis, I computed Total Current Accruals $\left(T C A C C_{i, t}\right)$, using data from the balance sheet. I then estimated discretionary accruals using the residuals from cross-sectional regressions based on a modified-Jones model augmented with the lagged, current and future operating cash flow. In this section, I make some modifications to the

\footnotetext{
${ }^{15}$ This paragraph benefits substantially from Lee and Vetter (2015).
} 
methodology used to compute discretionary accruals. ${ }^{16}$ Specifically, I compute Total Current Accruals $\left(T C A C C_{i, t}\right)$ using data from a firm's statement of cash flows as the difference between Net Income Before Extraordinary items $\left(N I B E_{i, t}\right)$ and Net Cash Flow from Operating Activities $\left(O A N C F_{i, t}\right)$ minus Extraordinary Items and Discontinued Operations $\left(X I D O C_{i, t}\right)$, scaled by the Total Assets of the firm at time $t-1\left(A T_{i, t-1}\right)$ :

$$
T C A C C_{i, t}=\left(N I B E_{i, t}-\left(O A N C F_{i, t}-X I D O C_{i, t}\right)\right) / A T_{i, t-1}
$$

where the subscripts $i$ and $t$ represent sample firm $i$ in year $t$.

Subsequently, I employ the modified-Jones model augmented with return-on-assets data to compute the estimated total current accruals as:

$$
T C A C C_{i, t}=\beta_{0}+\beta_{1} \frac{1}{A T_{i, t-1}}+\beta_{2} \frac{\Delta R E V_{i, t}-\Delta A R_{i, t}}{A T_{i, t-1}}+\beta_{3} \frac{P P E_{i, t}}{A T_{i, t-1}}+\beta_{4} \frac{O I B D P_{i, t-1}}{A T_{i, t-1}}+\varepsilon_{i, t}
$$

where $\Delta R E V_{i, t}-\Delta A R_{i, t}$ is the difference between the change in revenue from time $t-1$ to $t$ and the change in accounts receivable from time $t-1$ to $t ; P P E_{i, t}$ is the gross value of Plant, Property and Equipment; and $O I B D P_{i, t-1}$ is lagged operating income before depreciation. The discretionary accruals are the estimated residuals of Equation (1.4.2).

As before, I estimate Equation (1.4.2) separately for each period and two-digit SIC code-based industry. I report the results on a consistent sample of firms for which the discretionary accruals can be computed using the methodology outlined. The results are reported in Tables A.13 and A.14 in the Appendix for Chapter 1.

The results of the estimations using the CEO sample are different to the baseline results. In column (2), the estimate of the coefficient on the interaction between the VIX and Incentive $_{i, t-1}$ term suggest that, controlling for CEO incentives, a unit rise in the VIX leads to a 0.0004 unit fall in the value of discretionary accruals but CEO incentives increase

\footnotetext{
${ }^{16}$ For this section, I use the estimation strategy employed by Stein and Wang (2016).
} 
the response of discretionary accruals to the VIX by 0.0013 units. The alternative method of estimating discretionary accruals suggests that the increase in discretionary accruals in response to the VIX due to $\mathrm{CEO}$ incentives is 0.0007 units higher than suggested by the baseline results in column (2) of Table A.5.

The results in column (3) of Table A.13 indicate, unlike the baseline results, that the estimated coefficient of the interaction term between the VIX, CEO incentives and the dummy variable indicating the the presence of at least one female director is negative and statistically significant at $10 \%$. Additionally, in column (6), the estimated coefficients of the interaction terms between the VIX, Incentive ${ }_{i, t-1}$ term, and $F \_2$ and $F \_3$, respectively, suggest that the presence of two female directors in periods of uncertainty leads to discretionary accruals which are 0.0029 units (significant at 10\%) lower relative to those of firms with male-only boards while the presence of at least three reduce discretionary accruals by 0.0046 units (significant at 5\%). Similarly, a major difference to the baseline results using the $\mathrm{CFO}$ sample is that the results in column (6) indicate that the presence of three female directors in periods of uncertainty leads to discretionary accruals which are 0.0102 units lower relative to those of firms with male-only boards (significant at 10\%). The findings suggest that the estimates are quite sensitive to the method used to compute the discretionary accruals proxy.

\subsection{Concluding Remarks}

A strand of the Accounting and Finance literature has found that an increased number of women on the corporate board leads to a higher quality of reported earnings, i.e. lower discretionary accruals. Concurrently, evidence from the experimental economics and psychology literature has provided evidence to support the idea that decision making under uncertainty can differ across genders. Drawing insights from the aforementioned literatures, I investigate, using a firm fixed effects model to deal with endogeneity, whether having female 
directors on the corporate board of a firm leads to a negative association between uncertainty and earnings management even when the wealth of the CEO or CFO is tied to the value of the firm's shares.

The results of my baseline estimations indicate that when CEOs have incentives to manage earnings, discretionary accruals rise during periods of elevated investor uncertainty. However, if firms have 2 female directors on the corporate board then they are likely to have lower discretionary accruals in periods of heightened investor uncertainty compared to firms with male-only boards. On the other hand, the incentives of CFOs to manage earnings have no statistically significant impact on discretionary accruals during periods of elevated investor uncertainty. This conclusion appears to hold in a variety of robustness checks except when considering CEO incentives and estimating the discretionary accruals proxy using data from the cash flow statement rather than the balance sheet. Instead, those estimations highlight that having 2 or more female directors leads to lower discretionary accruals compared to firms with male-only boards in periods of amplified uncertainty.

The fact that results from most estimations, except the robustness check considering CEO incentives and using discretionary accruals calculated using data from the cash flow statement, indicated that discretionary accruals in periods of investor uncertainty were lower (relative to firms with male-only boards) in firms with 2 female directors and not those with at least three female directors may be important. This finding could potentially be due to the number of female directors having a non-linear effect on discretionary accruals during periods of investor uncertainty: 2 female directors may be able to exert more influence than 1 female director. Also, the number of firms in the CEO and CFO samples with 3 or more female directors was smaller than the number with 2 female directors. Therefore, the fixed effects estimations may not have efficiently captured the impact of having 3 or more female directors. Perhaps, a future version of the paper may be able to provide a more definitive conclusion for those firms with 3 or more female directors assuming that corporate boards continue to become more gender diverse. 
Nevertheless, a major implication of my findings from this research is that gender diversity on the corporate board is not always a reliable predictor of how well a firm will be managed. Consequently, arguments for increasing the number of women on corporate boards should be focused on an equity-based rationale. If male and female directors behave in a similar fashion in some aspects of corporate decision making, then men and women must not be treated as monolithic groups but there should be a focus on fairly assessing female directors based on their skills and accomplishments by holding them to the same and not higher expectations as their male counterparts. 


\section{Chapter 2}

\section{The Implications of Sectoral}

\section{Assignment for Wages:}

\section{Longitudinal Evidence for Canada}

\section{$2.1 \quad$ Introduction}

Employers in both the public and private sectors are persistently confronted with the challenge of attracting and retaining employees. Concurrently, several factors have led to difficulty in overcoming the challenge faced. For example, Canada's working age population is forecasted to shrink while there is likely to be a rise in the number of retirees due to the ageing of the baby boom generation and an increase in life expectancy. This may lead to several challenges in planning employment levels. A study by the Federation of Canadian Municipalities (2013) revealed that the population of seniors aged 65 to 85 is projected to rise over the next 20 years with roughly $24 \%$ of the population being in the over 65 age range. ${ }^{1}$

\footnotetext{
${ }^{1}$ From 2013 to 2020 , the share of the Canadian population who were aged 65 and over grew from $15.3 \%$ to $18.0 \%$ (Statistics Canada Table 17-10-0005-01 (formerly CANSIM 051-0001)).
} 
They also reported that the labour force replacement ratio is 0.84 which is well below the rate of replacement of 1.0 which is needed for the number of young people entering the labour market to fill the positions of those expected to retire.

According to Di Matteo (2015), achieving the right "balance between public and private sector employment is of policy importance given the importance of private sector wealth generation as the foundation for resources that are used for public sector service provision and subsequent employment generation". Yet, the nature of the work environments in each of the sectors may influence an individual's choice to work in one sector over the other. The private sector is commonly associated with quicker promotion, better career mobility, and compensation packages linked to an ability to assist firms in reaching their profit maximisation objectives. In contrast, the public sector is often associated with higher pay, better pensions, job security, an ability to retire early, and the possibility to make a difference in society. Furthermore, a key result of Anker et al. (2008) is that an individual's self-perceived competence in a sector has an impact on their desired sector of employment. Although there may be a divergence between self-perceptions and actual competence, there is reason to believe that an individual's observable characteristics, e.g. work and educational experience, may impact their sectoral assignment (Anker et al. (2008)). Consequently, for example, private-sector pay and hiring may vary with changes in the perceived value of a job in the public sector (Postel-Vinay (2015)).

One approach to compare differences in the labour market outcomes of workers in the public and private sectors is to examine wage differentials. One example of why wage disparities might arise is that there are differences between the wage determination processes in the sectors (Gunderson (1979)). Many corporations in the private sector have a profit maximization objective which means they attempt to effectively manage costs by setting wages to match worker productivity. On the other hand, the public sector is not subjected to the same objective given its monopoly power in the provision of essential public services which may result in higher pay especially due to the greater bargaining power of public 
sector workers.

Given the interest in labour market outcomes, use of the Survey of Labour and Income Dynamics (SLID) is ideal because it:

- consists of longitudinal labour market data allowing workers to be tracked across time;

- has coverage of key characteristics including hourly wages and union status; and

- can allow for the public sector to be defined either as reported by the workers surveyed or using North American Industry Classification System (NAICS) codes.

These features of the SLID make it superior to other datasets used in the extant literature on the public-private sector wage differntial in Canada including, for example, the Canadian Census; Labour Force Survey (LFS); Survey of Consumer Finances (SCF); and Labour Market Activity Survey (LMAS). The Census, LFS and SCF are surveys with a cross-sectional design; and the Census does not contain data on hourly wages. While the LMAS was a longitudinal in nature, it only represented samples of the Canadian population from 1986 to 1990. In contrast, using the SLID, I am able to focus on reference years from 1993 to 2010.

I use longitudinal labour market data from the SLID on full-time full-year workers aged between 25 and 60 years who were employed in paid jobs to investigate the evolution in the public-private sector wage differential in Canada from 1993 to 2010. I begin by estimating the public-private sector wage gap for each year using cross-sectional Ordinary Least Squares (OLS) models based on an adapted version of the well-known Mincerian wage equation (Mincer (1974)) which includes a binary indicator of whether or not an individual is employed in the public sector. Subsequently, capitalizing on the longitudinal structure of the data, I shift to estimating fixed effects models which control for the impact of unobservable worker attributes.

Controlling for both observable and unobservable worker characteristics, I estimate the public-private sector wage differential for male and female workers to be $3.3 \%$ and 
$6.5 \%$, respectively. However, after a series of robustness checks, I conclude that there is stronger evidence that there was a public-private sector wage differential for female than male workers over the period from 1993 to 2010. I also contribute to the literature by showing that public-private sector wage differentials observed for male and female workers for reference years between 1999 to 2000 were attributable to time-varying unobservable characteristics. Additionally, I confirm the findings of Robinson and Tomes (1984), Simpson (1985) and Robinson (1995) that not controlling for union coverage can amplify the estimated

public-private sector wage differential; and contribute to the literature by showing that controlling for firm size reduces the public-private sector wage differential. I also show that the public sector pays some workers who are likely to experience discrimination based on their race or sex relatively more than they would have earned if they had worked in the private sector.

In Section 2.2, I provide a comprehensive review of the extant literature on differentials in wages across the private and public sectors. Section 2.3 describes the data and methodology used. This is followed by a review of the results in Section 2.4, and additional robustness checks in Section 2.5. Ultimately, the conclusion (Section 2.6) recapitulates the main results and their implications.

\section{$2.2 \quad$ Literature Review}

The economic literature on public-private sector wage differentials is far from new. Several studies have attempted to provide an estimate of the public-private sector wage differential in various countries including, for example, the United States (e.g. Smith (1976a,b)); Australia (e.g. Cai and Liu (2011)); and the EU-15 countries including Spain, the Netherlands and Germany (e.g. Hartog and Oosterbeek (1993), Disney and Gosling (1998), Dustmann and van Soest (1998), Lucifora and Meurs (2006), Bargain and Melly (2008), Campos and 
Centeno (2012)). My main focus is to investigate the public-private sector wage differential in Canada.

Although estimates vary, the extant literature on the public-private sector wage gap in Canada generally provides a consistent story of a wage premium in the public sector. ${ }^{2}$ The earliest work on the topic using Canadian data was presented in a seminal paper by Gunderson (1979) in which he examined public-private sector wage differentials using data from the Public Use Sample Tapes of the 1971 Canadian Census. According to his Blinder-Oaxaca decomposition analysis of the earnings functions in the public and private sectors, the public sector wage premiums (or economic rents) of male and female workers were $6.2 \%$ and $8.6 \%$, respectively. ${ }^{3}$

There have been several updates to Gunderson's (1979) work using new data which have generated different point estimates. An example is a paper by Shapiro and Stelcner (1989), which used data from the 1981 Canadian Census. Their finding for the public sector wage premium (or economic rent) for male workers was 2 percentage points lower at $4.2 \%$ while for women it was higher at $12.2 \%$. To render their results comparable to that of Gunderson (1979), Shapiro and Stelcner (1989) chose to present results which were unadjusted for sample selection bias despite their recognition that sector choice is endogenous. Prescott and Wandschneider (1999) extended the work of Gunderson (1979) and Shapiro and Stelcner (1989) by attempting to correct for selection bias based on a worker's choice to work full time or part time and their choice to work in the public and private sectors. However, working with data from Canada's 1991 and 1982 SCF, they found that the selection bias related to sector choice did not seem qualitatively important. In addition, their estimates of the public-private sector wage differential were higher than those reported in the earlier

\footnotetext{
${ }^{2}$ A summary of the Canadian literature can also be found in Table B.1.

${ }^{3}$ In labour economics, a common application of the Blinder-Oaxaca decomposition technique of Blinder (1973) and Oaxaca (1973) (as described by Jann (2008)) is to separate the wage differential between two groups into a part that can be explained by differences in observable characteristics (e.g. years of work experience, highest level of education obtained, etc.), and a part that is unexplained by group differences (i.e. an economic rent). Many scholarly journal articles published since 1979 have explored public-private sector wage differentials, often using the aforementioned technique, and have recurrently found that a wage premium exists in the public sector in Canada.
} 
paper by Gunderson (1979). For example, using the 1991 SCF, their estimates for men and women were $14.3 \%$ and $25.0 \%$, respectively. Another shortfall of the papers by Gunderson (1979) and Shapiro and Stelcner (1989) were their failures to control for the union status of the workers which was later shown by, for example, Robinson (1995), Robinson and Tomes (1984) and Simpson (1985) to reduce estimates of the public-private sector wage differential.

Some researchers have attempted to provide estimates of the public-private sector wage differential for the different levels of the Canadian government. For example, Gunderson et al. (2000) found using the 1996 Canadian Census that the municipal, provincial and federal governments had wage premiums of $8.5 \%, 8.7 \%$ and $9.9 \%$, respectively. Their estimates using the 1997 LFS were $10.3 \%, 11.4 \%$ and $7.0 \%$, respectively. This led them to conclude that wage premiums must be close to $9.0 \%$ after finding average public sector wage premiums of $9.0 \%$ and 9.6\% using the 1996 Canadian Census and 1997 Canadian Labour Force Survey (LFS), respectively. Mallett and Wong (2008) provided a different take on the public-private sector wage differential in the three levels of Canadian government by considering both wages and non-wage employee compensation. Analysis based on the 2006 Canadian Census led them to find that non-wage benefits increase the compensation premium for all levels of government. After accounting for non-wage benefits, they calculated the wage premiums of the municipal, provincial and federal governments to be $35.9 \%, 24.9 \%$ and $41.7 \%$, respectively.

The closest Canadian research works to my paper are those by Tiagi (2010) and Mueller (2000). Tiagi's (2010) work is similar in its use of data and attempting to provide an estimate for the entire public sector rather than dissagregating by the level of government. Tiagi (2010) used data from the LFS, of which the SLID is a subset. However, Tiagi (2010) did not use longitudinal data and instead focused on data for September 2008. His Blinder-Oaxaca decomposition analysis indicated that male and female workers had public-sector wage premiums (or economic rents) of $5.4 \%$ and $19.8 \%$, respectively.

Mueller's (2000) work is similar in its methodological approach. Unlike other papers which typically reported analysis using solely OLS models and the Blinder-Oaxaca 
decomposition analysis, Mueller (2000) additionally estimated pooled OLS and fixed effects models. Results obtained from these additional estimations were not decomposed using the Blinder-Oaxaca decomposition technique. Nevertheless, his fixed effects models were cited as being useful to control for unobserved individual heterogeneity to ascertain if the wage differences were due to a public-sector effect or unobserved differences in the characteristics of the workers (e.g. their skill and ambition).

Mueller's (2000) research was conducted using data from the 1988 to 1990 waves of the LMAS. For male workers, his Blinder-Oaxaca decomposition analysis led to an estimate for the total differential of 27.9\%; and economic rents of $3.3 \%$ and $4.5 \%$ when union membership was treated as exogenous or endogenous, respectively. ${ }^{4}$ For women, the total differential was estimated to be $48.2 \%$ while the economic rents in the cases where union membership was treated as exogenous or endogenous were estimated to be $11.3 \%$ and $16.3 \%$, respectively. In contrast, estimates from the pooled OLS (or pooled cross-sectional) and fixed effects models were significantly lower. Estimations of the pooled OLS models suggested that the public-private sector wage differentials were $-4.5 \%$ and $3.9 \%$ for men and women, respectively. Estimations of the fixed effects models suggested that the public-private sector wage differentials were $3.9 \%$ and $5.8 \%$ for men and women, respectively.

In reviewing the above-mentioned literature, it appears to be the case that none of them has a strong time series component. They primarily focus on a period of much less than 10 years. This does not allow for an estimation of the trajectory of the public-private sector wage differential across time. This is important given that research using different periods of data has yielded very different estimates. My paper contributes to the literature by using longitudinal data from all waves of the SLID to explore wage differentials across the public and private sectors in the 18-year period from 1993 to 2010 (inclusive).

\footnotetext{
${ }^{4}$ Mueller (2000) attributes his finding that treating union membership as endogenous leads to a rise in his estimates of the public sector economic rents to the fact that, unlike Robinson and Tomes (1984) and Simpson (1985), he uses the Blinder-Oaxaca decomposition technique and as such assumes that there are differences in the mean characteristics of workers in the public and private sectors. The findings of Robinson and Tomes (1984) and Simpson (1985) were obtained using wage equations including a dummy variable indicating whether individuals in their samples worked in the public sector.
} 


\subsection{Empirical Framework}

\subsubsection{Data}

The primary source of data analysed is the SLID, a subsample of the LFS. The SLID provides annual data on labour market activity and income over time for individuals in Canada. Commencing in 1993, a new panel consisting of approximately 17,000 households (with roughly 34,000 adults) was introduced every three years and remained in the SLID dataset for six consecutive years such that there was always an overlap between two panels. My study focuses on data for the 1993 to 2010 reference years. ${ }^{5}$ In total, this is equivalent to approximately 1.5 million person-years of data.

The SLID only consists of labour market data on individuals aged between 16 and 69 years. However, I focus on individuals aged between 25 and 60 who reported that their main job during the reference year was a full-time full-year paid-worker job in either the public or private sector. The age restriction is made because workers under the age of 25 were more likely to be part-time workers; and public-sector workers were more likely to retire when they were aged 60 years. About half of workers aged 60 received retirement benefits (i.e. payments from the Canada Pension Plan, Old Age Security, Guaranteed Income Supplement, or a private pension). Individuals are identified as being public sector workers using the "PUBPV10" variable in the SLID which flags whether an individual is employed in the public sector. This identification method follows that used by Prescott and Wandschneider (1999) and Tiagi (2010) who used data from the SCF and LFS, respectively. Later in the paper, as a robustness check, I also explore an alternative used by Mueller (2000) where the public sector is identified using the NAICS code for the public administration industry. ${ }^{6}$

\footnotetext{
${ }^{5}$ The longitudinal aspects of the SLID household survey are contained in the data for the 1993 to 2011 reference years. Starting with the 2012 reference year, annual individual and family income data is produced by a new cross-sectional survey called the Canadian Income Survey (CIS). The 2011 reference year is excluded from my analysis because there were insufficient observations across all variables used in the analysis for that year.

${ }^{6}$ Gunderson (1979) and Shapiro and Stelcner (1989) also restricted their sample of public sector workers to those in the public administration industry.
} 
I focus on examining the differences in the monetary compensation workers in the public and private sector receive. Therefore, I analyse strictly positive implicit hourly wages at the end of the reference year (in December). The implicit hourly wage for a paid worker job includes tips, bonuses and commissions. It is a self-reported wage which is converted to an implicit rate based on an individual's reporting of the months, weeks and hours worked. Wages are inflated to 2010 values using the ratio of the value of the consumer price index in December 2010 to that in the reference year. ${ }^{7}$ However, it is important to note that wages are only one component of employee compensation. Other paid benefits include, for example, employer-paid contributions to pensions, health insurance premiums, and tuition. ${ }^{8}$ Table B.4 indicates that the top two benefits offered to workers included contributions to pension plans and medical insurance (/health plan). About $97.2 \%$ of public sector workers received employer contributions to their pension plans relative to $83.3 \%$ of private sector workers. Similarly, $91.1 \%$ of public sector workers were offered medical insurance (/health plan) compared to $76.7 \%$ of private sector workers. Workers in the public sector were also more likely relative to their private sector counterparts to have been offered dental insurance; and life (/disability) insurance. Aside from non-wage benefits, individuals may also have received non-monetary benefits, such as job security in the public sector and career mobility in the private sector, which are not measured in my data. Consequently, the true value of working in each of the sectors may be underestimated by my estimations.

Also, note that my sample does not consist of those who were self-employed or received farm or non-farm self-employment income. Individuals with missing data for any of the variables used in the analysis are also excluded on a person-year basis. The sample, after

\footnotetext{
${ }^{7}$ To inflate the wages to 2010 values, I use values of the seasonally adjusted consumer price index excluding eight of the most volatile components (as defined by the Bank of Canada) obtained from Statistics Canada Table 18-10-0256-01 (formerly CANSIM 326-0023).

${ }^{8}$ Note that although the SLID contains data on employer-sponsored pension plan contributions, it only contains a flag to indicate if the employer offered medical insurance or health (in addition to the regular public health insurance coverage) and not the value of such insurance or any other wage deferred benefits. Therefore, trying to obtain an estimate of the public-private sector wage differential that factors in non-wage benefits using the available data will not offer a direct comparison with the results of Mallett and Wong (2008).
} 
the above-mentioned restrictions have been made, consists of an unblanced panel of about 76,000 individuals with an average of 4 observations per person. There are approximately 231,000 person-year observations of which $31.6 \%$ correspond to periods in which a worker was employed in the public sector.

Examining the SLID data conditioning on the above mentioned restrictions leads to some useful insights regarding differences in the labour market outcomes and characteristics of individuals employed across the private and public sectors. In Table B.2, I provide a summary of all the variables involved in my empirical work. Subsequently, in Table B.3, I report the sample means of the log wages and control variables used in the empirical analysis for all individuals in the sample, and also separately for those employed in the public and private sectors, respectively. The average log wage for workers employed in the public sector is 3.31 while that in the private sector is lower at 3.05. Also, with an average age of 41.4 years, it can be concluded that workers in the sample are on average at their prime working age. Workers in the private sector are about 1.9 years younger than those in the public sector who are on average aged 42.8 years.

In the private sector, the share of workers who are members of unions or covered by collective agreements $(24.6 \%)$ is lower than for the public sector (78.9\%). Lower proportions of workers in the private sector are also employed in all provinces with the exception of Alberta as well as in Montreal, Toronto and Vancouver. In terms of the highest level of education of workers in the sample, the private sector employs more of those with lower levels of education (high school or lower) than does the public sector which employs proportionately more of those with university degrees or certificates. The proportions of workers who were married was also smaller in the private sector. More than half $(58.7 \%)$ of workers employed in the private sector were male while there were more female workers employed in the public sector (54.7\%). A significantly greater share of public sector workers $(36.0 \%)$ than private sector workers $(3.7 \%)$ had a spouse who was employed in the public sector.

As illustrated in Figure B.1, more women than men were employed in the public sector. 
From 1993 to 2010, the share of men working in the public sector fluctuated between $23.4 \%$ and $29.4 \%$ while the share of women employed in the public sector ranged between $34.3 \%$ and 43.1\%. After falling from 28.5\% to $25.3 \%$ between 1994 and 1999, the share of female workers in the public sector rose by 7.1 percentage points to approximately $32.4 \%$ in 2010 . In contrast, the share of male workers in the public sector grew by only 1.8 percentage points from $15.9 \%$ in 1999 to $17.8 \%$ in 2010.

Differences in the characteristics of workers are likely to be associated with differences in labour market outcomes. Figure B.2 shows that while the majority of individuals earned wages well below $\$ 500 /$ hour, some had wages between $\$ 1,000 /$ hour and $\$ 1,500 /$ hour. Without conditioning on the above-mentioned restrictions, it is evident that wages above $\$ 1,000 /$ hour were typically earned by individuals employed in the private sector (Figure B.3). Removing outliers from Figure B.3 suggests that public sector workers earn more than their private sector counterparts (Figure B.4). This finding persists after conditioning on the above-mentioned sample restrictions (Figure B.5).

Figure B.6 shows the variation in the raw public-private sector wage gap by gender over 1993 to 2010. The raw gap displayed a similar trajectory irrespective of gender but the gap was higher for women. The raw public-private sector wage gap for men varied between $17.5 \%$ and $24.8 \%$ while that for women ranged between $32.5 \%$ and $39.9 \%$. It can also be observed that the public-private sector wage gap increased after major economic events. During the aftermath of Canada's recession in the early 1990s, the public-private sector wage gap for men in $1994(24.8 \%)$ was 0.6 percentage points higher than the gap the year before $(24.2 \%)$ while for women it was 0.2 percentage points higher (39.7\% in 1993 and $39.9 \%$ in 1994). After the IT bust of 2001, the public-private sector wage differential for men increased from $17.5 \%$ to $19.7 \%$ in 2002 while the wage differential for women went from $33.4 \%$ to $34.7 \%$. Additionally, at the end of the Great Recession, the public-private sector wage gap for men stood at $24.2 \%$ in 2009 whereas in the preceding 2 years it had been $20.6 \%$. The public-private sector wage gap for women in 2009 was 37.5\%, having increased from 35.4\% in 2007. 


\subsubsection{Model Specification}

To identify the existence of a statistically significant public-private sector wage differential, I use OLS regression methods as well as models to handle the potential endogeneity of sector choice. First, I estimate the public-private sector wage differential using cross-sectional methods to enable comparisons with the majority of the extant literature using Canadian data. The basis of my analysis is an adapted version of the well-known Mincerian wage equation (Mincer (1974)) for worker $i$ which is given as:

$$
\log (w)_{i}=\gamma_{0}+\gamma_{1} \text { Public }_{i}+\Lambda_{1} X_{i}+\epsilon_{i}
$$

where the dependent variable is the worker's log wage which can be explained by a constant $\left(\gamma_{0}\right)$; a set of exogenous explanatory variables in the vector $X_{i}$; a dummy variable Public $_{i}$ which takes the value 1 if the individual works in the public sector and the value 0 if in the private sector; and a random error term $\left(\epsilon_{i}\right) .{ }^{9}$ The model controls for worker characteristics including age (and age squared divided by 100), marital status, highest level of education, province or major city of residence, and union membership (or coverage by a collective agreement). I separately estimate Equation (2.3.1) by the biological sex of the workers for each year from 1993 to 2010.

The coefficient $\gamma_{1}$ in Equation (2.3.1) can be identified if the covariance between Publici and $\epsilon_{i}$ is equal to zero (i.e. $\operatorname{Cov}\left(\operatorname{Public}_{i}, \epsilon_{i}\right)=0$ ). It can be interpreted as the expected payoff from working in the public sector rather than the private sector. A positive value for the estimate of the coefficient $\gamma_{1}$ would indicate that there is, on average, a public sector wage premium.

Next, I take advantage of the longitudinal nature of the SLID data to estimate a version

\footnotetext{
${ }^{9}$ Note that one limitation in estimating the public-private sector wage gap using the approach outlined is that the dummy variable only captures the level effect of the sector of employment on wages; and there is an implicit assumption that workers in both sectors have the same relationship between their wages and attributes controlled for in the vector $X_{i}$ and their wages.
} 
of Equation (2.3.1) where the variables in the regression model are allowed to vary with time $(t)$. This time-varying regression, estimated using pooled cross-sections, is given as:

$$
\log (w)_{i, t}=\gamma_{0}+\gamma_{1} \text { Public }_{i, t}+\Lambda_{1} X_{i, t}+\epsilon_{i, t}
$$

where $\gamma_{1}$ can be identified if $\operatorname{Cov}\left(\right.$ Public $\left._{i, t}, \epsilon_{i, t}\right)=0$ and would be interpreted as the average public-private sector wage differential from 1993 to 2010. Estimation of Equation (2.3.2) is followed by the estimation of Equation (2.3.3):

$$
\log (w)_{i, t}=\gamma_{0}+\gamma_{1} \text { Public }_{i, t}+\sum_{j=1994}^{2010} \gamma_{j}\left(\text { Public }_{i, t} \times \text { Year }_{j}\right)+\Lambda_{1} X_{i, t}+\epsilon_{i, t}
$$

where Year $_{j}$ is a dummy variable for reference year $j=1994, \ldots, 2010$. Therefore, the interaction between Public $_{i, t}$ and Year $_{j}$ indicates whether a worker was employed in the public sector in reference year $j$. This allows the effect of a worker being in the public sector to vary by reference year. From Equation (2.3.3), the effect of being in the public sector is given as:

$$
\mathbb{E}\left[\log (w)_{i, t} \mid \text { Public }_{i, t}=1\right]-\mathbb{E}\left[\log (w)_{i, t} \mid \text { Public }_{i, t}=0\right]=\gamma_{1}+\sum_{j=1994}^{2010} \gamma_{j} \text { Year }_{j}
$$

Thus, the public-private sector wage differential for workers in reference year $j$ is given as the sum of $\gamma_{1}$ and $\gamma_{j}$.

Estimating Equation (2.3.1) by year is more flexible than estimating Equations (2.3.2) and (2.3.3) because it allows the estimated earnings returns (i.e. $\hat{\Lambda}_{1}$ ) to attributes controlled for in the vector $X_{i}$ to vary by year. However, estimating Equations (2.3.2) and (2.3.3) is beneficial because it increases the number of observations used compared to estimating Equation (2.3.1) by year and also provides results which can be used as a basis of comparison for the remainder of my analysis. Moreover, as far as I am aware, existing papers on the 
public-private sector wage gap in Canada have not used more than 10 years of data.

One disadvantage of the OLS approach described above is that it ignores unobserved individual heterogeneity. Wages may be affected by both observable (e.g. age and education) and unobservable characteristics. A worker's innate skills, potential to grow and ambition may affect wages. Additionally, individual preferences may lead to non-random sorting between sectors. For example, individuals may choose to work in the private sector because of the possiblity of quicker promotion and better career mobility. In contrast, some individuals may choose to work in the public sector due to its association with better job security, an ability to retire early, and the possibility to make a difference in society. As a result, individuals may self-select, by way of targeted job hunting, into sectors which may or may not pay them high salaries. Since the aforementioned factors are usually unobserved in the data, they can not be included in the set of explanatory variables but are captured in the error term $\left(\epsilon_{i, t}\right)$. Consequently, the estimator $\hat{\gamma}_{1}$ may be biased because the public sector dummy variable $\left(\right.$ Public $\left._{i, t}\right)$ may be correlated with the error term (i.e. $\operatorname{cov}\left(\right.$ Public $\left.\left._{i, t}, \epsilon_{i, t}\right) \neq 0\right)$.

To control for endogeneity arising due to unobserved individual heterogeneity, I estimate a fixed effects regression model defined as: ${ }^{10}$

$$
\log (w)_{i, t}=\gamma_{0}+\gamma_{1} \text { Public }_{i, t}+\Lambda_{1} X_{i, t}+\tau_{i}+\epsilon_{i, t}
$$

where the error term $\left(\epsilon_{i, t}\right)$ captures random variation in wages that is independent across time; and $\tau_{i}$ captures individual-specific fixed effects. In this specification, the vector $X_{i, t}$ also consists of dummy variables for occupations classified by their National Occupational Classification codes to capture occupation-specific fixed effects and dummy variables for the panel to which the individuals belong to capture SLID panel-specific fixed effects. The identification of the parameter $\gamma_{1}$ is based on individuals who had a job in both the public and private sectors from 1993 to 2010. Additional requirements for the identification of $\gamma_{1}$

\footnotetext{
${ }^{10}$ Note that using the fixed effects model, there is an implicit assumption that workers in both sectors have the same relationship between wages and their observable and unobservable attributes.
} 
include:

- the covariance between the public sector dummy variable $\left(\right.$ Public $\left._{i, t}\right)$ and error term $\left(\epsilon_{i, t}\right)$ should be equal to zero (i.e. $\left.\operatorname{Cov}\left(\operatorname{Public}_{i, t}, \epsilon_{i, t}\right)=0\right)$;

- the error term must be free of unobserved heterogeneity that does not vary through time but is correlated with any of the right-hand-side variables; and

- individuals who switch sectors must not be fundamentally different from the underlying population.

As for my estimations using the pooled cross-sections, I also estimate a version of Equation (2.3.5) consisting of interactions between calendar year dummies and the public sector dummy variable given as:

$$
\log (w)_{i, t}=\gamma_{0}+\gamma_{1} \text { Public }_{i, t}+\sum_{j=1994}^{2010} \gamma_{j}\left(\text { Public }_{i, t} \times \text { Year }_{j}\right)+\Lambda_{1} X_{i, t}+\tau_{i}+\epsilon_{i, t}
$$

Over 1993 to 2010, there were approximately 1,000 occasions when individuals in the sample switched their sector of employment. The majority $(60 \%)$ of the switches were from the private to public sector. The variation in the change in the sector of employment of the individuals in my sample is graphed in Figures B.7 and B.8. Figure B.7 shows the proportion of workers who switched sector of employment by gender between 1993 and 2010 . In 1994, $0.9 \%$ and $1.8 \%$ of men and women switched away from the sector in which they were employed in 1993, respectively. However, the proportions reduced greatly between 1995 and 1996. In 1997, $1.2 \%$ and $1.6 \%$ of men and women were in different sectors to those in which they had been employed the previous year. There was greater turbulence in the proportion switching sector from 1993 to 1999 than in the years that followed. Interestingly, the share of female workers who switched sectors tended to be greater than for men. Figure B. 8 conditions on switching to the public sector. In most years, at least $40 \%$ of individuals who switched sector switched from the private to the public sector. The biggest movement 
to the public sector occured in 2003 and 2004 when $95 \%$ of female workers and $91 \%$ of male workers who changed their sector of employment switched from the private to the public sector, respectively. ${ }^{11}$ The trends in Figures B.7 and B.8 do not appear to be driven by business cycle effects. For example, in 2001, when Canadian gross domestic product (GDP) declined by $0.1 \%$ in the last quarter relative to the third quarter due to the IT bust, the share of both male and female workers who switched sector was lower than recorded for the year 2000 and a greater proportion of switchers moved from the private to the public sector than in the year 2000. Yet, in 2008 when GDP fell in the last quarter by 4.0\%, only the share of female workers who switched sector was lower than recorded in the previous year and there was also a decline in the share of both male and female sector switchers who moved to the public sector relative to the previous year. Nevertheless, these findings suggest that there is some variation on which the fixed effects models expressed in Equations (2.3.5) and (2.3.6) can depend to produce an estimate of the parameter $\gamma_{1}$.

I report robust standard errors for estimation of Equation (2.3.1). However, for estimations of the remaining models, I report standard errors which are clustered at the person level since they are based on multiple observations per person. Clustering standard errors in this way is useful since the error terms in the models may vary by worker but not across worker and time; and I wish to make inferences which are generalizable to the entire population. I also apply longitudinal weights for the individuals in the SLID to all estimations. The weights are based on Canada Revenue Agency T4 files and the 2001 and 2006 Censuses of Population.

\footnotetext{
${ }^{11}$ The 2003 Public Service Modernization Act came into force in 2005 which led to changes in staff recruitment processes. In particular, the Act allows management to hire individuals as long as they are competent and regardless of whether they are the best-qualified as ascertained by the ranking of the applicants. Additionally, a Public Service Staffing Tribunal was established to ensure there is no abuse of authority in internal appointments. This opened the doors to more competition among candidates for jobs in the public sector. Although the Act was not in effect until 2005, it may have induced more individuals to switch to the federal government prior to the effective date.
} 


\subsection{Empirical Results}

\subsubsection{Cross-sectional and Pooled OLS Models}

The results from the estimation of the cross-sectional models (i.e. Equation (2.3.1)) are reported in Table B.6 for male workers and in Table B.7 for female workers. Each point estimate of the public-private sector wage differential for males and females is statistically significant in the results for every reference year suggesting the presence of a statistically significant public-private sector wage gap after adjusting for observable attributes. For ease of exhibition, I plot the aforementioned estimates in Figure B.9 to show the variation in the conditional public-private sector wage gap by gender over 1993 to 2010. The public-private sector wage differential displayed a similar trajectory irrespective of gender. The conditional public-private sector wage gap between the public and the private sectors gradually declined between 1994 and 1999 then subsequently grew until 2009 when the gap reduced again. For the entire study period, the conditional public-private sector wage differential was higher for women than men. The condtional public-private sector wage gap of male workers varied between $5.2 \%$ and $14.8 \%$ while that of women ranged between $16.9 \%$ and $28.6 \%$.

Table B.8 consists of both the raw and conditional public-private sector wage differentials over 1993 to 2010 . While the evolution in both wage gaps was similar, the conditional public-private sector wage gap was considerably smaller. The conditional public-private sector wage differential for men was between 9.4 and 14.4 percentage points lower than the raw wage gap for men. The difference in the raw and conditional wage gaps for women varied between 7.9 and 16.9 percentage points. The aforementioned difference in the magnitude of the estimates implies that the explanatory variables in Equation (2.3.1) only partially contribute to the observed average public-private sector wage gap. Therefore, other unobservable attributes may also contribute to the difference in the wages of public and private sector workers.

Results from estimating Equation (2.3.2) to acquire an estimate of the average 
public-private sector wage gap between 1993 and 2010 for men and women are reported in columns (1) and (2) of Table B.9, respectively. As with the extant literature, I find that women had a greater public-private sector wage gap than men. Wages for men who worked in the public sector exceeded the wages of their counterparts who were employed in the private sector by $8.7 \%$ (significant at 1\%). In contrast, the public-private sector wage differential for women was 13.5 percentage points higher at $22.2 \%$ (significant at $1 \%$ ). The estimated public-private sector wage differentials are closest to the undecomposed estimates obtained by Gunderson (1979) using data from the 1971 Canadian Census which were 9.3\% for men and $22.3 \%$ for women. ${ }^{12}$ Tiagi's (2010) study was closest to mine in its use of data from the LFS, of which the SLID is a subset. However, Tiagi's (2010) estimate of the wage premium for men was 3.3 percentage points lower at $5.4 \%$ while it was 2.4 percentage points lower for women at 19.8\%. Differences between my estimates and those obtained by Tiagi (2010) are most likely due to differences in the data and methodology used. For example, Tiagi (2010) used an endogenous switching regression model with covariates that differ from those in my study. Also, Tiagi's (2010) study was focused on data for September 2008 whereas I use data as at December of each reference year from 1993 to 2010.

It can further be noted that men obtained higher returns from experience proxied by age than did women. This result is fairly common in studies where wage equations are estimated using historical data because men and women tend to have different age-labour force participation profiles. One key difference is that women may take time out of the labour force to raise a family. This causes a downward bias in the estimate of a woman's return to experience when proxied by age. ${ }^{13}$

\footnotetext{
${ }^{12}$ Using the Blinder-Oaxaca decomposition technique, Gunderson's (1979) estimates of the public-private sector wage differential for men and women were $6.2 \%$ and $8.6 \%$, respectively.

${ }^{13} \mathrm{As}$ an attempt to correct for the age-based experience for women, I re-estimate the baseline specification with a control for the worker's number of children to proxy for absence from the labour market (Tables B.10 and B.16). The pooled OLS specifications indicate that the wages of women fall with the number of children they have while the wages of men rise. Similar findings are obtained from the fixed effects estimation for women but, for men, no statistically significant relationship is found. Despite these results, the point estimates of the public-private sector wage differential from both the pooled OLS and fixed effects specifications remain qualitatively unchanged.
} 
I also find that more educated workers had higher earnings. For example, men with a university degree or certificate had wages which were $51.0 \%$ (significant at 1\%) higher than their counterparts who did not graduate from high school. Returns to education were higher for women. Women with a university degree or certificate had wages which were $61.4 \%$ (significant at 1\%) higher relative to women without any formal education. Married women had wages which were only $2.3 \%$ (significant at 1\%) higher than unmarried women while men who were married had wages which were $11.3 \%$ (significant at $1 \%$ ) higher than unmarried men. Being a union member was also positively associated with wages but moreso for female than male workers. ${ }^{14}$ This is likely to be associated with the fact that unions are often actively involved in bargaining for pay equity and equal employment opportunities for women. Male workers who resided in Alberta and other areas of Ontario other than Toronto had wages which were $6.2 \%$ (significant at 1\%) and $1.2 \%$ (significant at 10\%) higher than men in Toronto, respectively. Women who resided in Toronto had higher wages than women in other areas of Canada.

As robustness checks, I re-estimate Equation (2.3.2):

- replacing the public sector dummy variable based on the flag variable in the SLID with an indicator of whether an individual is employed in the public administration sector ${ }^{15}$ (Public_Admin) based on the employer's 4-digit NAICS code (Table B.11);

- controlling for firm size ${ }^{16}$ (Table B.12); and

- excluding observations where individuals have wages above $\$ 1,000$ (Table B.13).

\footnotetext{
${ }^{14}$ Note that when the term 'union member' is used in reference to descriptions of my estimations, it refers to individuals who were covered by a collective agreement regardless of whether they were officially members of a union.

${ }^{15} \mathrm{In}$ some of the earlier work on the public-private sector wage differential in Canada (e.g. Gunderson (1979); Shapiro and Stelcner (1989); and Mueller (2000)), the public sector was proxied by limiting the sample to workers employed in public administration.

${ }^{16}$ The SLID only contains employer attributes including whether or not the employer operates at more than one location, the industry of the employer, the number of employees, and an indicator of whether the employer is in the public or private sector. Of these, the number of employees appears most relevant as it can be used to proxy firm size. Therefore, this robustness check only controls for the number of employees.
} 
Using the indicator for the public administration industry, the share of observations which correspond to periods in which a worker was employed in the public sector is $10.4 \%$. Of these observations, $42.5 \%$ relate to those within the federal government while $27.5 \%$ and $30.0 \%$ are related to those in provincial and municipal governments, respectively. There is also little overlap in the public sectors defined using the flag variable in the SLID and the public administration NAICS code. Specifically, only $32.8 \%$ of those captured by the flag variable in the SLID are also captured by the public administration NAICS code. When using the NAICS codes, it is found that the share of workers in the public administration industry who are male $(58.3 \%)$ is greater than the share of men in other industries $(54.8 \%)$, and also the share in the public sector as defined by the flag variable in the SLID (45.3\%).

Defining the public sector based on NAICS codes causes the estimate of the public-private sector wage differential to rise to $13.3 \%$ (significant at 1\%) for men and the estimate for women to fall to $17.1 \%$ (significant at 1\%) for women. This suggests that estimates of the public-private sector wage differential are sensitive to the definition of the public sector. Additionally, when outliers are excluded, the estimates for the men and women's public-private sector wage gap rise to $8.8 \%$ and $22.6 \%$ (significant at $1 \%$ ), respectively. The outliers put downward pressure on the estimates. ${ }^{17}$

When controlling for firm size, the estimates fall to $7.1 \%$ and $18.5 \%$ for men and women (both estimates significant at 1\%), respectively. I also find that wages for both men and women were positively correlated with the size of the firms for which they work. All estimates of the coefficients of the variables indicating the number of workers employed by the individual's firm are significant at 1\%. The descriptive statistics in Table B.3 indicate that over half (55.9\%) of those employed in the public sector were employed in a firm with at least 100 employees while only $37.0 \%$ of workers in the private sector. These findings suggest that the exercise of estimating Equation (2.3.2) controlling for firm size was important given that it leads to lower estimates of the public-private sector wage differential. This suggests

\footnotetext{
${ }^{17}$ Similar results are obtained from excluding either observations associated with wages in the top $1 \%$ or both the top and bottom $1 \%$ of the wage distribution of the sample (Table B.14).
} 
that the higher public sector wage premium obtained from the baseline estimations could be partly due to individuals in the public sector belonging to a larger organization than those in the private sector. However, to my knowledge, this type of exercise has not been conducted in previous research despite their findings that wages increase with firm size (e.g. Gunderson et al. (2000)).

\subsubsection{Fixed Effects Model}

As explained in Section (2.3), the cross-sectional estimates may be biased due to endogeneity related to non-random selection into the public and private sectors. Results from estimating Equation (2.3.5) which controls for unobserved heterogeneity are reported in Table B.15. The results for men are reported in columns (1) and (2) while those for women are in columns (3) and (4). The estimations reported in columns (1) and (3) control for person and panel fixed effects while those in columns (2) and (4) also control for occupation fixed effects.

The estimates of the public-private sector wage differential which are obtained when controlling for person and panel fixed effects are $3.1 \%$ for men (significant at 10\%) and $6.5 \%$ for women (significant at 1\%). Also controlling for occupation fixed effects causes a slight increase in the estimates suggesting the public-private sector wage gap is not severely influenced by changes in occupation. All of the estimates are lower than those obtained from the cross-sectional and pooled OLS estimations. This indicates that the cross-sectional and pooled OLS estimations were upwardly biased due to omitted time-invariant characteristics. In other words, sectoral assignment may be non-random and workers may be positively selected into the private sector. Individuals employed in the public sector tend to be those who have unobserved skills and attributes which are generally associated with higher wages. The estimates are similar to those obtained by Mueller (2000) who, using a fixed effects approach, obtained estimates of $3.9 \%$ and $5.8 \%$ for men and women, respectively. My results also continue to indicate that wages are positively associated with age, marriage and union membership. However, many of the estimates for the parameters related to a worker's 
province or major city of residence and education become insignificant. This suggests that there may not be much variation in an average worker's education and geographical location of residence across time.

As highlighted earlier by the robustness check performed on the pooled OLS estimation in which the public sector dummy variable was replaced with the public administration industry indicator, the estimates can vary with the definition of the public sector and the accuracy of the flag variable in the SLID on which the public sector dummy variable is based. As with the robustness checks performed for the estimation of Equation (2.3.2), basing the definition of the public sector on the NAICS code of the employer leads to a rise in the estimate of the differential for men and a fall in the estimate for women (Table B.17).

I also find that controlling for firm size reduces the size of the estimate of the public sector wage premium for both men and women (Table B.18). If large firms tend to pay more, then the larger public sector wage premium obtained from the baseline fixed effects estimations could be attributable to private sector workers in small firms moving to larger institutions within the public sector. Additionally, the estimates rise when outliers are omitted (Table B.19). This confirms the finding that the outliers put downward pressure on the estimates obtained. ${ }^{18}$

In another robustness check, I estimate Equation (2.3.5) as a first-differenced OLS model. Note that Equation (2.3.5) can also be expressed as the following first-differenced equation:

$$
\Delta \log (w)_{i, t}=\gamma_{1} \Delta \text { Public }_{i, t}+\Lambda_{1} \Delta X_{i, t}+\xi_{i, t}
$$

In Equation (2.4.1), $\Delta$ Public $_{i, t}\left(=\right.$ Public $_{i, t}-$ Public $\left._{i, t-1}\right)$ represents sector switching and

\footnotetext{
${ }^{18}$ Similar results are obtained for both men and women if observations associated with wages in the top $1 \%$ of the wage distribution of the sample are excluded (Tables B.20 and B.21). However, while similar results are obtained for men when both the top and bottom $1 \%$ of the wage distribution of the sample is excluded, the results for women suggest that the point estimates fall relative to those obtained from the baseline estimations. The results for women suggest that the point estimate obtained from the baseline estimation was biased upwards due to the inclusion of the bottom $1 \%$ of the wage distribution.
} 
$\gamma_{1} \cdot{ }^{19,20}$ When $\Delta$ Public $_{i, t}=-1$ then the worker switched from the public to private sector between time $t$ and $t+1$ while $\Delta$ Public $_{i, t}=1$ implies that the worker switched from the private to public sector and $\Delta$ Public $_{i, t}=0$ indicates that the worker did not switch sectors. The error term of the model is given by $\xi_{i, t}\left(=\epsilon_{i, t}-\epsilon_{i, t-1}\right)$ which does not contain any unobserved factor which is fixed over time.

Table B.22 reports the estimation of Equation (2.4.1). As shown, the results are somewhat higher than those obtained from the baseline fixed effects estimation reported in Table B.15. However, they continue to indicate the presence of a wage premium for both men and women. The public-private sector wage differentials for men (column (1)) and women (column (2)) are estimated to be $4.2 \%$ (significant at 10\%) and $8.5 \%$ (significant at $1 \%$ ), respectively.

One concern in estimating Equations (2.3.5) and (2.4.1) is that the estimate of the coefficient $\gamma_{1}$ might lead to a misleading interpretation. Specifically, assuming there is a public sector wage premium, one might assume that the wage of a worker who switches from the private to public sector would rise while they would fall for a worker switching from the public to the private sector. However, this may not necessarily be true since individuals may be motivated to switch jobs for more money. To explore the impact of sector switching on the estimation, I swap the public sector dummy variable in Equation (2.4.1) for two sector switching dummy variables: a variable which indicates switching from the public to the private sector $\left(\right.$ Public_to_Private $\left.{ }_{i, t}\right)$ and another which indicates switching from the private to the public sector (Private_to_Public $c_{i, t}$ ). The comparison group in the estimation are workers in the private sector who did not transition to the private sector in the current year.

\footnotetext{
${ }^{19}$ Note that expressing the model as a differenced model highlights the fact that the public sector dummy variable $\left(\right.$ Public $\left._{i, t}\right)$ in Equation (2.3.5) can only be identified for workers who had both a public sector and private sector job.

${ }^{20}$ The vector $X_{i, t}$ in Equation (2.4.1) does not include dummy variables for occupations or SLID panels.
} 
Based on this modification, the new regression model can be rewritten as: ${ }^{21}$

$$
\begin{aligned}
\Delta \log (w)_{i, t} & =\gamma_{0}+\gamma_{1} \text { Public_to_Private }_{i, t}+\gamma_{2} \text { Private_to_Public }_{i, t} \\
& +\Lambda_{1} \Delta X_{i, t}+\Delta \epsilon_{i, t}
\end{aligned}
$$

In this specification, the coefficient $\gamma_{1}$ represents the average change in the wage of workers who switched from the public to the private sector from period $t-1$ to $t$ relative to workers who remained in the private sector. Similarly, the coefficient $\gamma_{2}$ represents the average change in the wage of workers who switched from the private to the public sector relative to those who remained in the private sector from period $t-1$ to $t$.

The results from estimating Equation (2.4.2) suggest that females who switch from the public to private sector have wages that are $8.1 \%$ (significant at $1 \%$ ) lower than their counterparts who remain in their sector of employment. The estimate for the differential in wages for men who switch from the public to private sector and men who stay in their sector is not statistically significant. On the other hand, switching from the private to the public sector leads to returns of $7.0 \%$ (significant at 5\%) and $8.8 \%$ (significant at 1\%) for male and female workers, respectively. Yet, although replacing the public sector dummy variable seems to be a plausible idea, the results do not provide information regarding those who stay in the public sector relative to those who stay in the private sector.

In my fixed effects estimations, the identification of the parameters is through the variation in the sectors in which the individuals in my sample are employed over the study period. It is possible that the variation in sector of employment which is depicted in Figures B.7 and B.8, and described in Section 2.3.2, could be insufficient to provide a precise estimate of the public-private sector wage differential. Given the dependence of my fixed effects model estimations on switching between the public and private sectors, I re-estimate Equation (2.3.5) using a sample: (1) excluding switches from the private to public sector; (2) excluding switches from the public to private sector; (3) excluding switches not accompanied by a

\footnotetext{
${ }^{21}$ The vector $X_{i, t}$ in Equation (2.4.2) does not include dummy variables for occupations or SLID panels.
} 
change in job ${ }^{22}$; and (4) including only switches accompanied by an involuntary change ${ }^{23}$ in job. ${ }^{24}$ Conducting these robustness checks allows for an investigation of what types of sector switching are driving the baseline fixed effects results.

As shown in Table B.25, excluding public to private sector switches does not lead to drastic change in the estimates of the public-private sector wage differential for both men and women. However, when private to public sector switches are excluded (Table B.24), only the estimates of the public-private sector wage differential for women $(6.4 \%$ as reported in columns (3) and (4)) are similar to those obtained from the baseline estimations. On the other hand, the estimates of the public-private sector wage differential for male workers were not statistically significant. Similarly, including only switches accompanied by a change in job (Table B.26) or an involuntary change in job (Table B.27) leads to an estimate of the public-private sector wage differential for male workers which is not statistically significant while the estimate for women remains positive and statistically significant. The results of the estimations controlling for person and panel fixed effects suggest that the estimates of the public-private sector wage differential for women are $6.5 \%$ and $5.4 \%$ when including only switches accompanied by a change in job or involuntary changes in jobs, respectively. The estimates change to $6.3 \%$ and $5.3 \%$, respectively, when also controlling for occupation fixed effects.

To confirm the validity of the longitudinal weights, I also perform a robustness check

\footnotetext{
${ }^{22}$ Changes in job are identified by the "CHJOB28" variable in the SLID data which flags whether an individual changed jobs during the reference year.

${ }^{23}$ Involuntary changes in job are identified using the "REAEND9" variable in the SLID data which flags a job change as involuntary if the company moved or went out of business; the job is seasonal; there is a layoff or business slowdown not caused by seasonal conditions; there is a labour dispute; the individual is dismissed by the employer; and/or the job is temporary (or the contract ended). Involuntary changes in job more often occur in the private than public sector. On average, $61.0 \%$ of involuntary changes in job were associated with movements from the private to public sector so this robustness check may be more reflective of those workers. In fact, as with the difference between private and public sector workers, I find that individuals who switched sector and had an involuntary change in job were, on average, younger and earned less compared to individuals in the remainder of the sample. This difference in characteristics may explain the lower point estimate of the public-private sector wage differential for women when including only switches for the case of involuntary changes in jobs (i.e. an estimate of $5.3 \%$ versus $6.6 \%$ when controlling for person, panel and occupation fixed effects).

${ }^{24}$ Similar robustness checks were performed by Campos and Centeno (2012) in their examination of the public-private sector wage gap in the EU-15 countries using a fixed effects model.
} 
by re-estimating Equation (2.3.5) using a sample consisting of individuals who were in the data for a total of 6 years each. The design of the SLID is such that a new panel was introduced every three years and remained in the SLID sample for six consecutive years. As such, the longitudinal weights used in my estimations change with each panel. Restricting the sample to include individuals present for the entire panel therefore leads to a sample in which the population remains constant for each reference year thereby reducing the impact of non-response adjustments from weighting on the estimation results. Additionally, using a balanced panel enables an examination of the impact of attrition as individuals may not be present in the data for six consecutive years. In fact, about $20.8 \%$ of individuals employed in the public sector in the year in which they entered the data were present in the data for an entire panel compared to $13.2 \%$ who were employed in the private sector in year 1 .

The results of estimating Equation (2.3.5) using a balanced panel are reported in Table B.28. I find that the estimate of the public-private sector wage differential for men is not statistically significant. In contrast, the public-private sector wage differential for women is positive and significant at $5 \%(4.2 \%$ in column (3) and $4.4 \%$ in column (4)) suggesting that female civil servants are paid more than their counterparts in the private sector. However, it is worth stating that the estimates obtained for the public-private sector wage differential for female workers are lower than those acquired from the baseline estimations in columns (3) and (4) of Table B.15.

After all the robustness checks, it can be concluded that there is strong evidence that there was a wage premium in the public sector for women during the period between 1993 to 2010. However, given that the results for men were quite sensitive to the robustness checks, the evidence of a wage premium for male workers is weaker. To explore this in further detail, I next discuss the results from estimations of Equations (2.3.3) and (2.3.6) with interactions between the public sector dummy variable and calendar year dummies to examine how unobservable attributes have impacted the public-private sector wage differential between 1993 and 2010 are reported in Table B.29. The estimates of the public-private sector wage 
gap for male workers which were obtained using Equation (2.3.3) ranged between 0.03\% and $16.7 \%$ whereas those obtained using a fixed effects approach were between $-1.1 \%$ and $6.1 \%$ when controlling for only person and panel fixed effects and between $-0.9 \%$ and $6.2 \%$ when additionally controlling for occupation fixed effects. For female workers, the estimates of the public-private sector wage gap that were obtained using Equation (2.3.3) ranged between $15.3 \%$ and $30.9 \%$ whereas those obtained using a fixed effects approach were between $2.3 \%$ and $9.8 \%$ when controlling for only person and panel fixed effects and between $2.3 \%$ and $9.9 \%$ when additionally controlling for occupation fixed effects. Although there are clearly differences in the magnitude of the estimates, the trajectories appear to be the same. Specifically, regardless of the method used to arrive at the estimates, I observe a decline in the public-private sector wage differential between 1994 and 1996, and a rise thereafter.

The public-private sector wage differentials estimated using Equation (2.3.6) are lower than those obtained estimating Equation (2.3.3) irrespective of whether Equation (2.3.6) is estimated controlling for occupation fixed effects. This suggests that individuals with unobservable traits associated with higher earnings tend to be employed in the public sector. That finding is reported for both men and women in most years with the exception of 1996 when the fixed effects estimates suggest that men in the private sector had wages which were $1.1 \%$ higher than their counterparts in the public sector. The fixed effects estimation which controls for occupation fixed effects suggests that the public-private sector wage gap in 1996 was $0.9 \%$ in favour of male workers in the private sector. However, some of the gaps estimated are not significant. The estimates of the public-private sector wage gaps for men and women that were obtained from the estimation of Equation (2.3.3) are only statistically significant for reference years from 1996 to 1999 and 2005 to 2010. Estimates of the public-private sector wage differential for men which are obtained using Equation (2.3.6) are primarily significant for reference years from 1994 to 2002 while the estimates for women are significant for reference years from 1995 to 2000 . This suggests that the public-private sector wage differentials observed from the 1999 to 2000 reference years are 
likely to be attributable to the fact that the public sector generally paid more during that time irrespective of the characteristics of the individuals, i.e. a pure sector effect. Using F-tests, I find that at least one of the estimated coefficients of the interactions between the public sector dummy variable and the calendar year dummies is statistically significant. Therefore, there is some evidence of a public-private sector wage gap after controlling for both observable and time-invariant factors.

To expand on the discussion of how the public sector premium may be changing through time. I estimate the baseline models including a time trend and the detrended unemployment rate separately for men and women. ${ }^{25}$ The results are reported in Tables B.30 and B.31. The results from the pooled OLS estimations indicate that the point estimates of the public sector premium fall from $8.7 \%$ to $8.6 \%$ for men (column (1)) and from $22.2 \%$ to $21.9 \%$ for women (column (3)). This suggests that the estimate was biased upwards in the baseline pooled OLS estimations. Interacting the public sector dummy variable with the time trend, I find that the public sector premium decreases over time. However, the point estimates obtained from the fixed effects specifications controlling for person, panel and occupation fixed effects rise by 5 basis points for men and 1 basis point for women. The findings also show that the public sector premium trends upwards over time for women who switch from the private to the public sector but not for men who make the same switch. Overall, these findings imply that cyclical and secular changes in the economy may impact the point estimate of the public sector premium; and switching from the private to the public sector may, in the long run, only be beneficial for women.

\footnotetext{
${ }^{25}$ The detrended unemployment rate are residuals saved from regressing the unemployment rate of individuals aged 25 years and over (obtained from Statistics Canada Table 14-10-0020-01 (formerly CANSIM 282-0004)) on a constant and time trend by gender.
} 


\subsection{Robustness Checks and Extensions}

\subsubsection{Controlling for Residence in the National Capital Region}

The term 'National Capital Region' refers to the Census Metropolitan Area (CMA) of Ottawa-Gatineau which consists of the Canadian capital of Ottawa, Ontario; the neighbouring city of Gatineau, Quebec; and their neighbouring communities. The share of workers in my sample who resided in Ottawa-Gatineau and worked in the public sector was 5.3 percentage points higher than the share who worked in the private sector (Table B.32). Ottawa-Gatineau had the highest share of workers employed in the public sector. Outside of the National Capital Region, the share of workers who worked in the private sector exceeded the share who worked in the public sector by 2.8 percentage points.

The results reported so far have not controlled for residence in Ottawa-Gatineau. Modifying the specifications of the models set out in Section 2.3.2 to control for the National Capital Region typically leads to lower estimates of the public-private sector wage differential. This suggests that public sector workers in Ottawa - Gatineau are perhaps, on average, paid more than their private sector counterparts.

The estimates of the public-private sector wage differentials obtained from the estimation of Equation (2.3.5) controlling for person and panel fixed effects are found to be $3.1 \%$ (significant at 10\%) and 6.5\% (significant at 1\%) for men and women, respectively (Table B.33). These estimates remain relatively the same after controlling for occupation fixed effects. The results also indicate that when the public-private sector wage differentials are estimated using fixed effects models (i.e. Equation (2.3.5)), the coefficient on the variable indicating whether workers in the sample resided in Ottawa-Gatineau becomes insignificant. This confirms the earlier finding that there is not much variation in the geographic location of residence across time. Consequently, the results of estimating Equations (2.3.3) and (2.3.6) also lead to the same conclusion that there is evidence of public-private sector wage gaps after controlling for both observable and time-invariant factors (Table B.34). 


\subsubsection{The Role of Union Membership}

The baseline regression estimations included a control for union membership. Unionisation can increase labour costs since it provides workers with greater bargaining power. Excluding a control for union membership is useful for examining whether a public sector wage premium exists in the absence of unionisation. Previous research works have indicated that failure to control for the union status of workers can amplify estimates of the public-private sector wage differential since there is likely to be a greater number of unionised workers in the public than private sector. For example, a key finding of research conducted by Robinson and Tomes (1984), using data from the 1979 Social Change in Canada Survey, was that the public sector economic rents found in earlier work by Gunderson (1979) were likely overestimated primarily because of greater levels of unionization in the public sector relative to the private sector. Robinson and Tomes's (1984) finding was also confirmed by similar work by Robinson (1995) which found that the public-private sector wage differential could be negative if union coverage was equivalent across the public and private sectors.

Another example of research indicating the importance of union coverage is the work of Simpson (1985). He was interested in estimating union wage differntials so separately estimated wage equations for a pooled sample of public and private sector workers by whether or not they belonged to a union. The wage equations included a dummy variable indicating employment in the public sector and as such enabled him to examine differences in the wages of public and private sector workers. One conclusion from estimating these equations using microdata from the 1974 Labour Canada Wages Survey was that wages in the public sector were likely higher due to unionization as opposed to higher settlements in the public sector. This conclusion was due to Simpson's (1985) finding that private sector workers who were union members had wages which were actually $4.4 \%$ higher than their counterparts in the public sector who were members of unions. This estimate of the wage differential between private and public sector workers who were union members was revised to $5.3 \%$ after correcting selectivity bias due to choices regarding union membership. 
According to the descriptive statistics of my sample (Table B.3), the share of public sector workers $(78.9 \%)$ who were union members was 54.4 percentage points higher than the share of workers in the private sector $(24.6 \%)$ who were union members. Figure B.10 illustrates the proportion of workers in my sample who were union members by sector and gender between 1993 and 2010. Between 1993 to 2009, the proportion of female public sector workers who were union members remained relatively stable varying between $81.6 \%$ and $83.0 \%$. In contrast, there was a gradual decline in the proportions of male public and private sector workers, and female private sector workers who were union members. By 2009, the share of male public sector workers who were union members had fallen from $80.4 \%$ to $74.7 \%$ while the share of male private sector workers who were union members had declined from $35.9 \%$ to $24.3 \%$ and the share of female private sector workers who were union members had decreased from 19.6\% to 14.9\%. From 2009 to 2010, the shares of male and female civil servants who were union members rose by $1.5 \%$. The share of male and female private sector workers who were union members increased by $2.4 \%$ and $9.7 \%$, respectively.

Doing an analysis by gender, it can be seen that there were more female than male public sector workers who were union members. In contrast, there were more male than female private sector workers who were union members. Additionally, the share of male and female civil servants who were union members was significantly greater than the share of men and women in the private sectors who had such coverage.

Overall, the trends show that there were high levels of union membership among public-sector workers. These trends could have an impact on estimates of the public-private sector wage differential as suggested by the work of Robinson (1995), Robinson and Tomes (1984) and Simpson (1985). To assess the impact of controlling for union membership on my results, I repeat the analysis already conducted without controlling for union membership and compare the results with my baseline estimations. The results are reported in Tables B.35 and B.36. Modifying the specifications of the models set out in Section 2.3.2 to exclude a control for union membership typically leads to higher estimates of the public-private sector 
wage differential but moreso for women than for men. This confirms that not controlling for union status amplifies estimates of the public-private sector wage differential.

The estimation results for the fixed effects model continue to suggest that women had a greater public-private sector wage differential than men (Table B.35). The estimates of the public-private sector wage differentials obtained from the estimation of Equation (2.3.5) controlling for person and panel fixed effects were found to be $3.6 \%$ (significant at $5 \%$ ) and $7.3 \%$ (significant at 1\%) for men and women, respectively. After controlling for occupation fixed effects, the estimate of the public-private sector wage differential for men rose to $3.8 \%$ but the estimate for women remained relatively the same. The results of estimating Equations (2.3.3) and (2.3.6) also lead to the same conclusions as described in Section 2.4.2 (Table B.36). The results confirm that there is evidence of public-private sector wage gaps after controlling for both observable and time-invariant factors.

\subsubsection{Does the Public Sector Pay Visible Minorities More?}

Women and visible minorities tend to be more discriminated against compared to men and non-visible minorities. Yet, the results presented thus far have indicated that the public-private sector wage differential is larger in magnitude for women than men. This suggests that the public sector may provide more favourable labour outcomes for women. McInturff and Tulloch (2014) showed using data from the 2011 National Household Survey that women and visible minority workers may be paid more when employed in the public sector due to a higher level of unionisation and pay equity legislation.

In my sample from the SLID, the majority of workers who were visible minorities worked for the private sector (Table B.37). The shares of workers who were visible minorities that worked in the public and private sector were $9.6 \%$ and $15.3 \%$, respectively. With the exception of workers who were Black or Japanese, a greater share of most visible minority 
groups were employed in the private sector. ${ }^{26}$ The difference in the shares of workers employed in the public and private sectors was statistically significant except for workers who were Black or Japanese. The majority of public sector workers belonging to visible minority groups were Black whereas most of those who worked in the private sector were Chinese.

To my knowledge, there is currently no work estimating the public-private sector wage differential by membership to a visible minority group using data from the SLID. Consequently, in this section I contribute to the literature by estimating a version of Equation (2.3.2) which includes indicators identifying the visible minority group to which the worker belongs, if any. The model can be written as:

$$
\log (w)_{i, t}=\gamma_{0}+\gamma_{1} \text { Public }_{i, t}+\sum_{k=1}^{10} \gamma_{k} \text { VM_Group }_{k, i}+\Lambda_{1} X_{i, t}+\epsilon_{i, t}
$$

where $V M \_G r o u p, i$ where

$$
k=\left\{\begin{array}{c}
1=\text { Black } \\
2=\text { Chinese } \\
3=\text { South East Asian } \\
4=\text { Filipino } \\
5=\text { Arab (West Asian and North African }) \\
6=\text { Asian Other (South Asian, Korean and Japanese }) \\
7=\text { Other Visible Minority Groups (Oceanic and Latin American) }
\end{array}\right\}
$$

is a variable indicating whether the worker belongs to one of the 7 visible minority groups in the set $k^{27}$ In this specification $\gamma_{k}$ can be interpreted as the average difference in wages

\footnotetext{
${ }^{26}$ The first letter of each visible minority group has been capitalized in accordance with the convention use in the SLID codebook.

${ }^{27}$ Visible minority groups were recategorised such that no one group consisted of a total of less than 1,000 observations.
} 
between non-visible minorities and visible minority group $k$ from 1993 to 2010.

Subsequently, I also estimate Equation (2.5.2):

$\log (w)_{i, t}=\gamma_{0}+\gamma_{1}$ Public $_{i, t}+\sum_{k=1}^{10} \gamma_{k}$ VM_Group $_{k, i}+\sum_{k=1}^{10} \delta_{k}\left(\right.$ Public $_{i, t} \times$ VM_Group $\left._{k, i}\right)+\Lambda_{1} X_{i, t}+\epsilon_{i, t}$

where $V M_{-}$Group $_{k, i}$ is a dummy variable for the visible minority group to which the worker belongs. Therefore, the interaction between Public $_{i, t}$ and VM_Group $p_{k, i}$ indicates whether a worker in visible minority group $k$ was employed in the public sector at time $t .^{28}$ This allows the effect of a worker being in the public sector to vary by visible minority group. From Equation (2.5.2), the effect of being in the public sector for visible minority group $k$ is given as:

$$
\mathbb{E}\left[\log (w)_{i, t} \mid \text { Public }_{i, t}=1\right]-\mathbb{E}\left[\log (w)_{i, t} \mid \text { Public }_{i, t}=0\right]=\gamma_{1}+\sum_{k=1}^{10} \delta_{k} V_{\text {V_Group }}, i
$$

Thus, the public-private sector wage differential for workers in visible minority group $k$ is given as the sum of $\gamma_{1}$ and $\gamma_{k}$. The parameter $\gamma_{1}$ represents the public-private sector wage differential of non-visible minorities.

The results from estimating Equations (2.5.1) and (2.5.2) are reported in Table B.38. The estimates of the coefficients of the variables indicating the visible minority status of the workers are all negative and significant, irrespective of the sex of the workers. Filipino men and women had the lowest wages relative to non-visible minorities. The wages of Filipino men and women were $29.8 \%$ and $28.4 \%$ lower than the wages of those of their non-visible minority counterparts, respectively. Controlling for belonging to a visible minority group has the impact of lowering the public-private wage differential relative to those obtained in the baseline pooled OLS estimations reported in Table B.9. Specifically, the public sector premiums for men and women decline from $8.7 \%$ and $22.2 \%$ to $8.0 \%$ (column (1) of Table

\footnotetext{
${ }^{28}$ Note that this interaction is missing for Oceanic male workers since none of them worked for the public sector.
} 
B.38) and 21.1\% (column (3) of Table B.38), respectively. This suggests that the difference in wages in the public and private sectors is in part due to the distribution of workers by visible minority group.

Interacting the visible minority group dummy variables with the public sector dummy variable indicate that male civil servants who were South East Asian, Filipino, or Arab had public-private sector wage differentials that were higher than that of their non-visible minority counterparts. For women, this was true if they were Chinese, South East Asian, or Filipino. South East Asian men and Filipino women had the biggest public-private sector wage differentials at $25.6 \%$ and $36.6 \%$, respectively. In contrast, Filipino men and South East Asian women had the lowest public-private sector wage differentials at $13.5 \%$ and $29.6 \%$, respectively. Using F-tests, I find that at least one of the estimated coefficients of the interactions between the public sector dummy variable and the visible minority group dummies is statistically significant. Therefore, there is some evidence of variation in the public-private sector wage gap by visible minority group. The results suggest that the public sector pays some workers who are likely to experience discrimination based on their race or sex relatively more than they would have earned if they had worked in the private sector.

Some individuals in visible minority groups may have immigrated to Canada. One issue with estimating Equations (2.5.1) and (2.5.2) is that they do not take into account the effects of migration on the relationship between an individual being in a visible minority group and labour market outcomes. The importance of this exclusion in the analysis can be identified from immigration research on, for example, international students. Former international students generally perform better in the labour market than immigrants educated outside of Canada given that their educational qualifications are obtained in Canada and thus are more easily recognized and relevant to Canadian employers (Bisson et al. (2012)). They also typically develop relatively stronger social networks and levels of acculturation during their studies in the country. They arrive younger and spend more years in Canada than foreign-educated immigrants, facilitating greater knowledge about the labour market and 
increased network opportunities and job prospects (e.g. Bonikowska and Hou (2015); Hou and Lu (2017); Skuterud and Chen (2017)).

In order to account for the impact of migration, I estimate Equations (2.5.4):

$$
\begin{aligned}
\log (w)_{i, t} & \left.=\gamma_{0}+\gamma_{1} \text { Public }_{i, t}+\gamma_{2} Y S M_{i, t}+\gamma_{3}\left(Y S M^{2}\right) / 100\right)_{i, t}+\sum_{k=1}^{10} \gamma_{k} V_{M_{-} \text {Group }_{k, i}} \\
& +\Lambda_{1} X_{i, t}+\Lambda_{2} \text { Landing_Year }_{i, t}+\epsilon_{i, t}
\end{aligned}
$$

and Equation (2.5.5):

$$
\begin{aligned}
& \left.\log (w)_{i, t}=\gamma_{0}+\gamma_{1} \text { Public }_{i, t}+\gamma_{2} Y S M_{i, t}+\gamma_{3}\left(Y S M^{2}\right) / 100\right)_{i, t}+\sum_{k=1}^{10} \gamma_{k} \text { VM_Group } k, i \\
& +\sum_{k=1}^{10} \delta_{k}\left(\text { Public }_{i, t} \times \text { VM_Group } k, i\right)+\Lambda_{1} X_{i, t}+\Lambda_{2} \text { Landing_Year }_{i, t}+\epsilon_{i, t}
\end{aligned}
$$

where $Y S M_{i, t}$ and $\left.\left(Y S M^{2}\right) / 100\right)_{i, t}$ represent the number of years since migration (YSM) and its square divided by 100, respectively; and the vector Landing_Year ${ }_{i, t}$ are a set of dummy variables which represent the worker's arrival cohort if they were an immigrant. The landing year variables capture the impact of the worker's characteristics at the time of landing on their wages while the YSM variables capture the effect of economic assimilation (i.e. experience in Canada). Arrival cohorts are grouped into 5-year categories and included for landing years between 1946 to 2010. Equations (2.5.4) and (2.5.5) do not include a dummy variable indicating whether the worker is an immigrant as they are only estimated for workers for whom their immigration status is known and an exhaustive set of arrival cohorts are included in the regressions to ensure that the reference category were workers who were not immigrants. The results are reported in Table B.39.

After controlling for the years since migration and arrival cohort of workers who immigrated to Canada, the public sector premiums for men and women further decline to $7.6 \%$ and $20.3 \%$, respectively (columns (1) and (3) of Table B.39). Additionally, the 
estimates of the coefficients of the variables indicating the visible minority status of the workers remain negative and significant irrespective of the sex of the workers. However, the estimates are larger in magnitude. This implies that the wages of visible minority worker are lower relative to their non-visible minority counterparts in part due to immigration. Wages appear to increase with the number of years since migration. Also, the wages of immigrants relative to non-immigrants improve with each consecutive arrival cohort after the landing year 1950 but more so for men than women.

Estimating Equation (2.5.5), I find that fewer visible minority groups had public-private sector wage differentials that were higher relative to their non-visible minority counterparts (columns (2) and (4)). Specifically, male civil servants who were Filipino or Arab and female civil servants who were South East Asian are no longer found to have public-private sector wage differentials that are statistically significant. The results indicate that South East Asian men and Filipino women had the biggest public-private sector wage differentials at $21.1 \%$ and $31.9 \%$, respectively. Using F-tests, I again find that at least one of the estimated coefficients of the interactions between the public sector dummy variable and the visible minority group dummies is statistically significant. Therefore, there is some evidence of variation in the public-private sector wage gap by visible minority group.

To control for endogeneity arising due to unobserved individual heterogeneity in the estimations described above, I estimate a fixed effects regression model defined as:

$$
\begin{aligned}
& \left.\log (w)_{i, t}=\gamma_{0}+\gamma_{1} \text { Public }_{i, t}+\gamma_{2} Y S M_{i, t}+\gamma_{3}\left(Y S M^{2}\right) / 100\right)_{i, t} \\
& +\sum_{k=1}^{10} \delta_{k}\left(\text { Public }_{i, t} \times V M_{-} \text {Group }_{k, i}\right)+\Lambda_{1} X_{i, t}+\tau_{i}+\epsilon_{i, t}
\end{aligned}
$$

where the error term $\left(\epsilon_{i, t}\right)$ captures random variation in wages that is independent across time; and $\tau_{i}$ captures individual-specific fixed effects. In this specification, the vector $X_{i, t}$ also consists of dummy variables for occupations classified by their National Occupational Classification codes to capture occupation-specific fixed effects and dummy variables for the 
panel to which the individuals belong to capture SLID panel-specific fixed effects. Equation (2.5.6) is estimated with and without the number of years since migration and its square divided by 100 . The visible minority group dummies are only included in the estimation as part of an interaction term with the public sector dummy variables. The results suggest that switching from the private to the public sector reduces the wages of Chinese male workers relative to their non-visible minority counterparts. However, such switches in sector lead to a rise in the wages of South East Asian women relative to their non-visible minority counterparts. Overall, the results from estimating the fixed effects model continues to suggest that the public sector pays some workers who are likely to experience discrimination based on their race or sex relatively more than they would have earned if they had worked in the private sector.

\subsection{Concluding Remarks}

Sectoral assignment matters for labour market outcomes as well as employee recruitment and retention. Yet, despite the changing atmosphere in the Canadian labour market, there is currently little research on the public-private sector wage differential using Canadian data with a strong time series component. My research is important because it provides an understanding of the heterogeneity in estimates of the public sector wage premium obtained from various methodologies. Additionally, it provides labour market information to individuals and to the government. Individuals need information about the labour market which will help them to understand which sector of employment will allow them to earn more based on their characteristics. Meanwhile, the federal, provincial and municipal governments need to understand the magnitude of the public-private sector wage differential for costing purposes and in order to examine who may be most impacted by changes in government spending, due to say sub-contracting work to the private sector, since labour costs are important in the provision of several public services. Therefore, I contribute to the literature 
by investigating the wage gap across the public and private sectors using longitudinal panel data from the 1993 to 2010 waves of the Survey of Labour and Income Dynamics (SLID). My empirical work is based on more than 10 years of data and, consequently, has greater coverage than previous research work on the public-private sector wage differential in Canada.

Moreover, I adopt a varied empirical approach. Specifically, I begin by estimating the public-private sector wage differential using cross-sectional and pooled OLS models and conclude by estimating fixed-effects models to take into account the impact of unobservable characteristics on the estimate of the public-private sector wage gap. My findings using the cross-sectional models suggest that a public sector wage premium existed for both male and female workers for each year from 1993 to 2010. The conditional public-private sector wage gap from the cross-sectional models is estimated to be between $5.2 \%$ and $14.8 \%$ for male workers and between $16.9 \%$ and $28.6 \%$ for female workers depending on the reference year. I find using a pooled OLS model that the average public-private sector wage differential for male and female workers was approximately $8.7 \%$ and $22.2 \%$, respectively. However, controlling for unobservable characteristics, my findings from fixed-effects models highlight that it would be misleading to infer that the public sector had a wage premium that high. The public-private sector wage differential for male workers controlling for person, panel and occupation fixed effects was $3.3 \%$ while for women it was $6.5 \%$. However, the result regarding the presence of a wage premium for men in favour of the public sector was highly sensitive to the robustness checks performed suggesting weak evidence of its existence. In contrast, my finding of a wage premium for women was robust to a variety of econometric specifications. Although, a bias in my results due to the dependence of the fixed effects models on sector switching can not be completely ruled out, the estimates from those models are superior to those acquired from the cross-sectional and pooled OLS models given that the latter do not control for unobserved characteristics.

I also contribute to the literature by showing that while some of the public-private sector wage differentials in certain reference years were due to time invariant unobservable 
characteristics, others were attributable to time-varying unobservable characteristics. In particular, I found that the public-private sector wage differentials for both men and women which were observed from 1999 to 2000 were positive even after controlling for time invariant unobservable characteristics using a fixed effects model. Additionally, I was able to confirm findings of earlier research suggesting that a failure to control for the union status of workers can amplify estimates of the public-private sector wage differential, and also add to the literature by showing that firm size can reduce estimates or the public-private wage premium.

I also showed that nearly all workers in visible minority groups had wages lower relative to non-visible minorities. However, the public sector pays some workers who are likely to experience discrimination based on their race or sex relatively more than they would have earned if they had worked in the private sector. Specifically, male civil servants who were South East Asian, Filipino, or Arab had public-private sector wage differentials that were higher than that of their non-visible minority counterparts. For women, this was true if they were Chinese, South East Asian, or Filipino. The overall finding that the public sector improves the labour market outcomes of some workers remains the same even after conrolling for the number of years since migration and arrival cohort of workers who immigrated to Canada.

To summarize, I have provided strong evidence for the existence of a public sector wage premium. However, my estimates of the public-private sector wage differential have been highly sensitive to the methodology used. Fixed effects models led to smaller estimates of the public-private sector wage differential relative to those acquired from the cross-sectional and pooled OLS models.

This paper presents various opportunities for further research. For example, research should be devoted to investigating the underlying reasons for the heterogeneity in the estimates of the public sector wage premium obtained from various methodologies. In addition, to the extent that the public sector wage premium was higher for women and some visible minority groups, more research is required to determine the factors leading 
to the public sector improving the labour market outcomes of these groups of workers. Analysing whether public-private sector wage differentials vary by the distribution of wages using quantile regression methods would also be a potential avenue for future research. My hope is that this paper has sparked an interest for more research which is informative about the implications of the sectoral assignment of workers in Canada. 


\section{Chapter 3}

\section{Immigrant Earnings Returns to}

\section{Post-Migration Education:}

\section{Evidence for Canada, $1999-2013^{1}$}

\subsection{Introduction}

The demographic challenges being faced by Canada due to the ageing of the population, retiring of the baby boom cohort and declining birth rate have led to growing immigration levels, especially in the economic stream, to sustain the labour force and support economic growth. Evaluating the success of the economic stream of an immigration program involves in part evaluating the success of immigrants both at the time of arrival as well as their ability to adapt to the new labour market over time. A number of studies suggest that the educational

\footnotetext{
${ }^{1}$ This research was conducted under the supervision of Prof. Christopher Worswick. The work is drawn from a joint Canadian Journal of Economics article with Ci et al. (2020). Prof. Christopher Worswick and I feel that my contribution is equivalent to approximately $35 \%$ given the additional analysis I conducted to address comments from anonymous referees in the lead up to the publication of the paper. Thank you to Peter Brown, Jenna Hartman, René Morissette, Anne-Marie Rollin, Grant Schellenberg, Saba Teklehaimanot, Taylor Wright, and two anonymous referees for their feedback and assistance.
} 
credentials and work experience that immigrants gain abroad is often undervalued when they arrive in Canada (e.g. Green and Worswick (2012); Ferrer and Riddell (2008)). A key aspect of the adaption process is the effectiveness of investments in formal education made after arrival to overcome the downgrading of their credentials (e.g. Chiswick (1978); Friedberg (2000)) which often occurs due to the inability of employers to accurately assess their equivalence to Canadian credentials. Over $20 \%$ of new immigrants participate in post-secondary education (PSE) within the first six years of residence in Canada. ${ }^{2}$

Due to a lack of high-quality longitudinal data for major immigrant receiving countries, very little is known about how immigrants' decisions to return to formal education impact their earnings after they return to the labour market. In order to formulate optimal immigration policy, it is essential to understand how effective these kinds of investments after arrival are in terms of facilitating earnings assimilation. If immigrants who come to the new country and struggle in the labour market can make investments in formal education, this may lead to a large increase in their earnings especially if their pre-migration educational credentials were previously undervalued. In this case, it may not be optimal to primarily choose immigrants who will have high earnings at arrival but perhaps poor earnings growth after arrival since immigrants who are expected to face challenges early on in the new country's labour market may be as successful or even more successful in the medium to long term if they are able to make educational investments with an especially high return in terms of earnings shortly after arrival.

The economics literature on the earnings of immigrants in Canada is extensive, and much of it has focused on the earnings of recent immigrants relative to comparable Canadian-born individuals or immigrants arriving in other cohorts (e.g. Baker and Benjamin (1994); McDonald and Worswick (1998); Aydemir and Skuterud (2005); Green and Worswick (2012);

\footnotetext{
${ }^{2}$ Using a sample of immigrants with a university degree obtained in their source country from the Longitudinal Study of Immigrants to Canada (LSIC), Adamuti-Trache (2011) finds that $46 \%$ of immigrants participated in PSE within 4 years of arrival and $11 \%$ of those who participated in PSE did so within 6 months of arrival. However, her research did not attempt to obtain an estimate of the returns to post-migration education.
} 
and Warman and Worswick (2015)). A common finding in this literature is a decline in the success of immigrant landing cohorts in terms of their earnings (holding years-since-migration fixed) across the 1980s and 1990s without clear evidence of a recovery in the early 2000s.

Our objective in this research project is to delve more deeply into a key mechanism through which an immigrant can improve his or her labour market outcomes: formal post-secondary education (PSE). In particular, we estimate the earnings returns to both part-time and full-time PSE participation over the early years after migration. Our econometric approach involves estimating, employing data from the Canadian Employer-Employee Dynamics Database (CEEDD), a parametric difference model in which the change in the log earnings of an immigrant over the six year period after the immigrant lands in Canada as a function of participation in PSE enrollment over the 2nd to 5th year since landing and other characteristics of the immigrant as at the time of landing.

Our results suggest that in PSE enrollment after arriving in Canada increases the annual earnings of both men and women. In particular, we find that the earnings of immigrant men increase by $18.3 \%$ or $7.7 \%$ if they enrol in full-time or part-time PSE, respectively. Immigrant women who enrol in full-time or part-time PSE experience a growth in earnings of $30.6 \%$ or $17.5 \%$, respectively.

To ensure the robustness of the results we also estimate the average treatment effect on the treated (ATT) and average treatment effect (ATE) of PSE on the earnings of immigrants using a propensity score matching approach as well as a fixed effects estimation model incorporating up to the first 14 years of income tax data for new immigrants to Canada. These additional estimations indicate that the results are indeed robust in that they suggest that immigrants gain from enrolling in PSE after arriving in Canada. Furthermore, we show using our fixed effects estimation that the earnings effects of PSE are larger for immigrants admitted in the Skilled Worker category relative to Family Class immigrants and Refugees, and are increasing in the level of education of the immigrants at landing. In addition, immigrants from non-traditional source countries generally have larger returns 
to PSE than immigrants from English language source countries such as the US and the countries of Northwestern Europe. We also show that immigrants experience improvements in their annual earnings when they invest in their human capital through both PSE and work experience; earnings of immigrants rise as time passes after their most recent study period; and our estimates of the returns to post-migration education are not biased by immigrants who leave Canada.

In Section 3.2, we provide a review of the literature on post-migration human capital investments and the wage effects of mid-career training. Section 3.3 describes the data and sample selection as well as the methodology used. This is followed by a review of the results in Section 3.4; some extensions in Section 3.5; and ultimately, the concluding remarks and policy implications of our research (Section 3.6).

\subsection{Literature Review}

Although recognition of and, therefore, the returns to years of schooling and work experience accumulated prior to arrival in Canada varies by immigrant source region (e.g. Ferrer and Riddell (2008)), a common finding in the immigration literature is that the human capital of immigrants is often undervalued relative to their Canadian-born counterparts. Occasionally, immigrants may have unsatisfactory labour market outcomes due to limited transferability of foreign-acquired qualifications and work experience (e.g. Goldmann et al. (2015); Banerjee et al. (2018)). Employers may have difficulty in assessing the Canadian equivalency of foreign credentials (e.g. Chiswick (1978); Friedberg (2000)) leading immigrants to obtain jobs which are not commensurate with their skills. In some cases, immigrants may be overeducated for their roles (e.g. Hou et al. (2019); Li et al. (2006)) in that they may have credentials which exceed what is required for their job. Additionally, immigrants may need to acquire additional certification and/or licensure to work in occupations in, for example, health, engineering, accountancy, and law (Boyd (2013)). Returning to school may be beneficial 
because it might lead to immigrants acquiring Canadian educational qualifications that are more easily recognized and relevant to Canadian employers (Bisson et al. (2012)). Ferrer and Riddell (2008) showed that, compared to their Canadian-born counterparts, immigrants obtain larger earnings returns from completing an educational credential (i.e. sheepskin effects) in addition to the marginal return to each year of schooling prior to completion. Enrollment in post-migration education may also aid immigrants to obtain greater knowledge about the labour market and increase their network opportunities and job prospects (e.g. Bonikowska and Hou (2015); Hou and Lu (2017)). In the subsections that follow, we explore the literature on post-migration human capital investments and the wage effects of mid-career training.

\subsubsection{Post-Migration Human Capital Investments}

A number of studies have been carried out on the post-migration human capital investment of immigrants with the vast majority of these using US data for immigrant men (e.g. Borjas, 1982; Khan (1997); Chiswick and Miller (1994); Duleep and Regets (1997); Friedberg (2000)) and immigrant women (e.g. Chiswick and Miller (1994); Duleep and Regets (1999)). Most of these studies employ cross-sectional data (such as US Census years) that do not allow the researchers to track the same immigrant across time. Typically, these studies either characterize the types of immigrants who return to school after migration or investigate the correlation between current earnings and both pre-and post-migration education. However, they do not provide convincing evidence on the effect of increased education after landing on the actual earnings outcomes in the receiving country because they are not able to exclude the possibility that immigrants who invest in post-migration education may differ in important ways from immigrants who do not make such investments.

Cobb-Clark et al. (2005) used the Longitudinal Study of Immigrants to Australia (collected beginning in 1993) to consider the post-migration investments of immigrants in the first 4.5 years in Australia (the maximum duration of the survey). Higher education levels at 
time of arrival are associated with a greater probability of enrolling in school after migration. In households where the immigrant admission category would suggest that post-migration investments may be important, they find higher rates of school enrolment. ${ }^{3}$ However, they do not report on the earnings impact of these post-migration educational investments because the LSIA has a relatively small number of immigrants. Also, the low employment rates in the first wave of the panel would make it difficult to estimate models of the impact of educational investments on wage or earnings growth.

A US study by Bratsberg and Ragan Jr. (2002) is perhaps the closest in the literature in intent and design to the analysis of our paper. They employ both Census and National Longitudinal Survey of Youth (NLSY) data to look at the issue of the effect of education on the earnings of immigrants. The NLSY data does allow one to track the earnings of individuals through time but the sample of immigrants is very small and by design includes only immigrants who were very young at arrival making the findings less representative of all immigrants. However, the NLSY data does contain the Armed Forces Qualification Test (AFQT) measure of cognitive ability which the authors use as a control for otherwise unobserved ability thereby reducing the likelihood of biased estimates of the effect of education on earnings for immigrants. Whether or not this variable is included in their model, the authors find that the return to foreign education is higher for immigrants with some US education than is the case for immigrants with no US education. While this study does shed light on the effect of post-migration education on earnings of immigrants in the US, the methodology employed is basically cross-sectional due to the approach taken to estimating the model with the longitudinal NLSY data.

\footnotetext{
${ }^{3}$ Cobb-Clark et al. (2005) find that husbands holding Independent, Concessional Family and Humanitarian visas are more likely to be enrolled in school.
} 


\subsubsection{Wage Effects of Adult Mid-Career Training}

Our approach to measuring the effect of education acquired in the receiving country on the earnings of immigrants draws in part on the methods employed in the economics literature on the effect of job training on wages. ${ }^{4}$ In this literature, the same empirical challenge exists in terms of measuring the change in the growth of the hourly wage that would have occurred in the absence of participation in learning (either formal education or workplace training). For Canada, Dostie and Leger (2014) report 3.5\% and 0.6\% gains on weekly wages for classroom employer-supported training when implementing OLS and fixed-effects models. ${ }^{5}$ Women are often found to have higher returns to adult training relative to men (e.g. Parent (2003); Hui and Smith (2003)), although the wage differences by gender are small and vary according to the training measure employed.

Ci et al. (2015) follow an econometric approach to the measurement of job training on wage growth that is similar to the one employed in this paper for the case of post-migration investments in education for immigrants. They employ the confidential versions of the 2002 - 2007 and 2005 - 2009 Survey of Labour and Income Dynamics (SLID) panel datasets of Statistics Canada. Wage returns to mid-career investments in training in the Canadian labour market range in size from $5.5 \%$ to $7.2 \%$ for men and from $7.1 \%$ to $9.0 \%$ for women. Although our estimation strategy bears similarities with those used in other papers, we make a specific contribution to the literature by illustrating that the effect of PSE on earnings for new immigrants in Canada varies not only by their gender but also by their source region, admission category and level of education at arrival.

\footnotetext{
${ }^{4}$ Heckman et al. (1998) estimate that over half of lifetime human capital is obtained through lifelong investments, including training within firms.

${ }^{5}$ Note that fixed effects models remove any biases that would result in a bias in the OLS estimate of the effect of job training on the hourly wage due to unobserved characteristics that affect the wage and are correlated with the decision to participate in job training, so long as the unobserved characteristics do not vary through time.
} 


\subsection{Empirical Framework}

\subsubsection{Data and Sample Selection}

For our analysis, we employ the Canadian Employer-Employee Dynamics Database (CEEDD), a unique panel dataset that combines records from several administrative sources housed at Statistics Canada. ${ }^{6}$ At the time of our analysis, the CEEDD included records from: 1) landing records of all since 1980 (Longitudinal Immigration Database (IMDB)); 2) all tax filers identified from the T1 personal master file $\left.(\mathrm{T} 1) ;^{7} 3\right)$ all employees who received records of remuneration issued by employers (T4); 4) all employees who received a Record of Employment at the end of a period of employment with a firm (ROE); and 5) all private and public firms from the Longitudinal Employment Analysis Program (LEAP). Individual records from the IMDB, T1 and T4 were linked across all three datasets using the unique individual level Social Insurance Number (SIN). Linking the T4 file with the LEAP file by the business registry number, allowed us to retrieve the unique firm-level longitudinal identifier which matches employees with their employers.

The CEEDD has several critical advantages over other datasets for the purposes of our analysis. First, the CEEDD covers the entire Canadian economy with information available for all tax filers who filed at least one tax return between 1999 and 2013 and all businesses that hired and paid employees in Canada in any given year during that period. Second, the panel feature of this dataset has a relatively long time series (up to 14 years of longitudinal tracking) which provides a sufficiently long window of observation so that we can see an individual's earnings both before and after a period of years in post-secondary study. Third, the IMDB data includes landing records for all immigrants who arrived in Canada since 1980. These records offer important information about the immigrant's schooling, linguistic abilities, source region and immigrant category at the time of arrival. Fourth, the variable

\footnotetext{
${ }^{6}$ The analysis presented in this paper was conducted at Statistics Canada in Ottawa.

${ }^{7}$ The information is retrieved from the equivalent of line 323 on the 2018 Canadian income tax return form.
} 
of interest in this analysis - part-time or full-time participation in post-secondary education - can be retrieved from two of the federal tax credits, full-time and part-time education deductions available in the T1 file. ${ }^{8}$ After 1997, we are able to observe the individual who actually incurred the education cost (and received the education) compared to the case in earlier years when the person who claimed the deductions might not necessarily be the person who went to school and paid the tuition. Fifth, employment earnings from the T4 file reported by employers to the Canada Revenue Agency, are in general, more reliable than those self-reported ones available in the survey data. Finally, not only can we control for many individual-level characteristics related to economic outcomes of immigrants in the analysis, we are also able to include firm-level characteristics (e.g. firm size, industry and firm-level fixed effects).

One drawback of the CEEDD data is the lack of information on hours of work per week or weeks of work per year. Consequently, we consider annual earnings rather than an hourly wage rate. When we report results on growth in annual earnings, it will be important to keep in mind that part of this growth will likely be a return to accumulated human capital (either through formal education or through work experience) and part will likely be due to changes in hours of work per year perhaps due to reductions in weeks spent unemployed.

Another drawback of the CEEDD data is the fact that there are no direct variables allowing for an identification of the type of PSE (university/college, level of university, field) that an immigrant may have enrolled in. Yet, while we do not include an analysis of returns to post-migration enrollment by type of PSE program, previous literature have shown that it is possible to use data on educational deductions and tuition fees to infer the type of PSE program an individual may have enrolled in. For example, Morissette et al. (2015) identified university enrollment by checking if a derived full-time equivalent annual tuition amount falls within the range of 0.8 to 2.0 times the annual provincial average undergraduate

\footnotetext{
${ }^{8}$ Frenette et al. (2011) also use these tax credits to define post-secondary education participation. Recent immigrants are more likely to have incomplete information on the Canadian tax system and especially about the education tax deduction rules. This could affect the extent to which our analysis can be generalized to the population of all immigrants to Canada.
} 
tuition amount; and then identified college tuition based on the fact that university tuition is much more costly. Webb (2019) also followed the procedure used by Morissette et al. (2015) but additionally estimated a measure of persistence for whether the individual completed two or more years of university, by calculating whether the total number of months spent in university exceeded 16. He also identified whether an individual completed university by checking whether the total months is greater than or equal to 24 since university programs are typically 32 months in length in most of Canada, but programs in Quebec and non-honours undergraduate programs can be 24 months in length. The methods used by Morissette et al. (2015) and Webb (2019) are worth considering for future research studies on immigrant returns to post-migration enrollment in post-secondary education.

Given the drawbacks of the data, we restrict our attention to immigrants who landed in Canada on or after 1998 since for earlier cohorts we do not know whether or not the person participated in PSE after arrival in Canada for their earlier years after arrival. The study sample is restricted to immigrants who landed from 1998 to 2008, were aged 20 to 49 at landing, and had annual employment (T4) earnings of more than $\$ 1,000$ (in 2013 Canadian dollars) in at least one year from 1999 to 2013.

In Table C.1, sample means of a number of the key variables used in our analysis are presented for all immigrants and then separately for immigrants who spent time in post-secondary education after arrival and those who did not. The mean years-since-migration for observations in our sample is 5.9 years and this is very similar for respondents who participated in PSE in that tax year than for immigrants who did not. The average age is 39.3 and is lower for the sub-group who report PSE participation (38.7) versus those who do not (39.4). ${ }^{9}$ Considerable language variation is present with the largest group being the 'other mother tongue, speaks English' group at 50.1\%. In terms of education at landing, $47.0 \%$ of all observations are from individuals who landed in Canada with a university degree. This share is even higher at $60.0 \%$ once we condition on PSE

\footnotetext{
${ }^{9}$ Rollin (2011) also found that immigrants who attended PSE were younger than those who did not.
} 
suggesting that it is individuals with relatively high levels of education at landing who may be having difficulty finding jobs suited to their skills that return to school. Approximately $32.7 \%$ of observations in our sample are from individuals arriving in Canada as Principal Applicants (PA) under the Skilled Worker (SW) program followed by the Family Class (30.0\%), Spouses of Skilled Workers (17.4\%), and the Refugee category (13.8\%). The group of Principal Applicants (PA) under the Skilled Worker (SW) program has an even a higher share of the observations once we condition on PSE enrollment, while the Family Class and Refugees have lower shares of the observations. The final panel of Table C.1 reveals the wide variation in the source region of the immigrants in our sample. Immigrants from Southern / Eastern Europe, Africa, East Asia, Other Asia, and the Caribbean / South America, are over-represented in the sub-sample of PSE observations suggesting that these groups are more likely to make investments in post-secondary education after arrival in Canada than are immigrants from other source regions.

In Table C.2, we present sample means of the change in each immigrant's log annual earnings between the first and sixth (complete) calendar years since landing in Canada. This variable is especially of interest since it is the dependent variable used in our difference regression and propensity matching specifications. In defining the sample used to calculate this variable, we exclude immigrants who participated in PSE in either their first year in Canada or their sixth year in Canada because we want their annual earnings in each year to not be truncated due to time spent in PSE. ${ }^{10}$ Over this window of the immigrant's early years in Canada, we see strong growth in annual earnings of 0.55 log points for men and $0.57 \log$ points for women. Coinciding with this fast earnings growth is a fairly high rate of participation in PSE at some point over the four-year period. Women are more likely to participate in PSE than are men.

\footnotetext{
${ }^{10} \mathrm{We}$ also restrict the sample to individuals who had positive annual earnings in years one and six since landing so as to be able to calculate the log annual earnings.
} 


\subsubsection{Methodology}

Given that our sample is comprised of relatively recent immigrants to Canada means that even without PSE enrollment, the immigrants are likely experiencing earnings growth as they adjust to the new labour market, develop local language skills and develop professional networks. Consequently, we estimate parametric 'long-difference' models of immigrant earnings growth over the first six (complete calendar) years in Canada to see whether participating in PSE over years two through five is associated with an increase in the growth of earnings. ${ }^{11}$ The model can be defined as:

$$
\text { Growth }_{i}=\beta_{0}+\beta_{1} P S E_{i}+X_{i}^{\prime} \beta+\epsilon_{i}
$$

where dependent variable is the ith immigrant's change in log earnings over the six year period $\left(\right.$ Growth $\left._{i}\right)$ which, as per the model, can be explained by their participation in post-secondary education $\left(P S E_{i}\right)$ and a set of explanatory variables captured in $X_{i} \cdot{ }^{12}$ Specifically, $P S E_{i}$ is equal to 1 if the immigrant enrolled in PSE at some point over the period from the 2nd to 5th year since landing and 0 otherwise. Also, given our rich dataset, $X_{i}$ consists of characteristics which the immigrant possessed at the time of arrival in Canada including: marital status at landing; landing cohort; first language spoken; firm size; occupation; industry of employment; indicator of ever being a TFW; indicator of ever being an international student; province/territory/major city of residence; first language spoken; education at landing; immigration admission category; source region; indicators for whether the individual received an initial salary which was higher or lower than average; age at landing and age at landing squared divided by 100 . The residual term $\left(\epsilon_{i}\right)$ captures

\footnotetext{
${ }^{11}$ Note that this model is not referred to as a difference-in-difference model since we do not separate groups based on fixed characteristics such as age or province/major CMA of residence.

${ }^{12}$ In estimating Equation (3.3.1), enrollment in full-time and part-time is separately considered by adapting the $P S E_{i}$ as well as the immigrants included in the sample. For example, when analyzing the impact of full-time education, $P S E_{i}$ is equal to 1 if the immigrant enrolled in PSE on a full-time basis at some point over the period from the 2 nd to 5 th year since landing and 0 otherwise; and those attending part-time PSE in any year are excluded.
} 
random variation in wages that is independent across time and individuals. Consequently, as per our model specification, the coefficient $\beta_{1}$ quantifies the differential change in the log earnings of PSE participants relative to the group of immigrants who did not participate in PSE such that a positive value of $\beta_{1}$ would indicate a positive return from enrollment in PSE. To identify the coefficient $\beta_{1}$ consistently, the PSE variable $\left(P S E_{i}\right)$ must not be correlated with the time series variation in the residual term $\left(\epsilon_{i}\right)$.

\subsection{Empirical Results}

In Table C.3, we present the results of our estimation of Equation (3.3.1). ${ }^{13}$ The coefficient on the indicator for the immigrant having participated in full-time PSE in at least one of the four years is 0.168 and strongly statistically significant suggesting a growth in annual earnings that is approximately $17 \%$ higher over the four-year window than that which is experienced by immigrants who did not participate in full-time PSE. This indicates a strong return to full-time PSE participation. ${ }^{14}$ The coefficient on the full-time PSE control in column (2) is somewhat lower at 0.146 but qualitatively similar to what was found in column (1) without the control for initial earnings. In columns (3) and (4) we report results from equivalent analyses over the sample of immigrant women. The increase in log earnings is larger for women at 0.272 and $0.289 \log$ points, respectively.

The reported earnings growth from PSE is likely to be partly associated with the human capital that immigrants accumulate through participating in formal education. However, an alternative interpretation is that the returns may be due to employers who were initially uncertain about the foreign credentials of immigrants obtaining a signal from the enrollment of immigrants in PSE that their past education is of a high quality. According to Lange

\footnotetext{
${ }^{13}$ In cases where we analyse the effect of full-time PSE on earnings growth, we exclude individuals who participated in part-time PSE, and in cases where we analyse the incidence of part-time PSE on earnings growth, we exclude individuals who participated in full-time PSE.

${ }^{14}$ This is consistent with the findings of a Statistics Canada study of Rollin (2011) using earlier data taken from the Longitudinal Administrative Database (LAD) tax records.
} 
(2007), as employers learn about the unobserved ability of their workers, they will rely less on schooling and other observed variables to predict productivity. Therefore, the earnings growth of immigrants may depend in part on the speed of employer learning.

While our focus is on the PSE variable, it is worth describing the general patterns of the coefficients on the other control variables. University education is associated with the highest earnings growth among the four educational categories, which suggests that more educated immigrants (at landing) have a larger capacity to adapt to the new labour market over time than do the less educated immigrants. Relative to the Skilled Worker Principal Applicant default group of men, earnings growth was higher for immigrant men who were admitted as spouses of Skilled Workers and immigrant men in the Caregiver program, and earnings growth was lower for immigrant men admitted under the Family Class and as Refugees. The results are similar for women with a significant advantage in terms of earnings growth for women admitted under the Business Class relative to those admitted as Skilled Workers but without a clear advantage (or disadvantage) in earnings growth for women admitted as Refugees. Given that Skilled Workers are admitted through the point system, they would be expected to most easily translate their skills into jobs in Canada it would not be surprising that their earnings growth would be lower than immigrants admitted under the other categories. The fact that their earnings growth is higher than immigrants admitted under the Family Class is somewhat surprising and may reflect the fact that family immigrants do not have a strong labour market attachment and so may not make investments in human capital accumulation after arrival in Canada.

The estimates suggest considerable variation in earnings growth for both men and women by source region with especially high growth for immigrants from Southern/Eastern Europe, Oceania (for men), Caribbean/South America relative to the default group (Northern and Western Europe) and the United States. These findings are not surprising given that the former group of countries are likely to face greater challenges in terms of having their credentials recognized than are the latter group and may on average have weaker fluency in 
either English or French (the two official languages of Canada).

In Table C.4, equivalent results are presented but where the full-time PSE control is replaced by an equivalent part-time PSE control. In order to reduce the number of coefficients reported, only the coefficients on the part-time PSE enrollment variable, the control for initial earnings (when included) and the immigrant admission category variables (and the constant) are reported. Comparing the coefficients on the part-time PSE variable in each column of Table C.4 to the equivalent coefficients on the full-time PSE variable in the equivalent model of Table C.3, we see in each case a lower return to part-time PSE than full-time PSE with the part-time effect being just over half of the full-time effect in the equivalent model. This is not surprising given that fewer hours per week are being devoted to studies for the case of part-time enrollment meaning that the benefits in terms of human capital gained and the resulting rise in productivity and earnings would also be expected to be lower in the part-time case. That said, the other patterns that were observed in Table C.3 are also found in Table C.4. The results are qualitatively similar when controlling for initial earnings. The return to PSE is larger for immigrant women than for immigrant men.

We also estimated an alternative specification employing information on months spent in PSE enrollment in the CEEDD data to see whether earnings growth is increasing in months spent in PSE. Table C.5 has estimates from models equivalent to those of Table C.3 but with the full-time PSE indicator replaced with a control for months spent in PSE over years two through five in Canada. Earnings growth is increasing in months spent in full-time PSE at a rate of roughly $1.5 \%$ to $1.6 \%$ for men and $2.5 \%$ to $2.6 \%$ for women. In Table C.6, this exercise is repeated but with a control for months spent in part-time PSE. As one would expect, the coefficients are smaller than in Table C.5 but are still statistically significant suggesting $0.8 \%$ to $0.9 \%$ increases in earnings growth from a month spent in PSE for immigrant men with larger effects of $1.3 \%$ to $1.4 \%$ for immigrant women. 


\subsection{Extensions}

\subsubsection{Propensity Score Matching}

A natural concern relates to the fact that the immigrants who spend time after arrival in PSE may differ in unobservable and important ways from those who do not. If this is true and these unobserved differences are correlated with the growth in earnings, then this would in general lead to a bias in our estimated coefficients of the PSE variables in our earnings growth models of Tables C.3 to C.6. For example, if the individuals who return to PSE are those who expect to have lower earnings growth in the absence of this investment, then our comparison group will predominantly be made up of individuals expecting higher growth in earnings without PSE. This could lead to a downward bias in our estimate of the earnings effect of PSE due to the comparison group not being a good representation of the counterfactual earnings growth that the individuals who participated in PSE would have experienced in the absence of PSE participation. It may also be that the immigrants who return to the school are the ones who would most benefit from such investments and so their experiences do not necessarily shed light on the effect of more education after immigration for all immigrants.

In Table C.7, we report the estimated coefficients from a linear probability model of the incidence of PSE enrollment for immigrants, separately by gender and full-time/part-time status. In order to be consistent with our log earnings growth models, we consider the incidence of full-time enrolment in PSE at any time over years two through five in Canada after conditioning on immigrants who had employment earnings in year one and in year six in Canada. This model is estimated by least squares regression using the equivalent set of control variables as in Tables C.3 to C.6.

In column (1) of Table C.7, we find that participation in full-time PSE is decreasing in age which is not surprising given that immigrants would expect a larger earnings lifetime earnings return to PSE investments relatively early in their careers, everything else the 
same. The fact that full-time PSE rates are lower for former TFWs may be because these immigrants have either jobs or networks in place allowing them to retain or find suitable jobs without the need for further Canadian education. Participation in full-time PSE is higher for immigrants who arrived in Canada with PSE and this suggests that PSE investments after arrival may serve to improve the transferability of foreign human capital given problems of credential recognition or perhaps gaps in human capital coverage from foreign training. Relative to the Northwest Europe default group, participation in full-time PSE is especially high for immigrants born in Africa, East Asia, Other Asia, and the Caribbean / South America. Given that immigrants from these countries are less likely to be fluent in either English or French, it may be that further PSE is needed in order to gain either the credential or the fluency needed in order to find suitable work in Canada. Immigrants who landed in the Business Class, Family Class and as Refugees are less likely to participate in full-time PSE than are Skilled Worker PAs, while Spouses of Skilled Workers, and Caregivers are more likely to participate in full-time PSE. Finally, initial firm characteristics appear to be important correlates with full-time PSE. Immigrants initially employed in medium to large firms are more likely to enroll in full-time PSE than are other immigrants. This may reflect a dissatisfaction with the remuneration and career opportunities in those firms leading these immigrants to invest more heavily in human capital accumulation.

In the other columns of Table C.7, we present other versions of these models, by gender and for the case of part-time PSE. Considering the part-time PSE results, we see similar coefficient estimates (but typically smaller in absolute value) to those of the full-time PSE models for the same sex. The results of the full-time PSE model for women have generally similar patterns to those described above for men; however, the magnitude of the differences by source region are larger for women than for men.

In order to investigate the importance of this endogeneity of PSE, we employ a propensity score matching approach to estimate the average treatment effect of PSE enrollment (e.g. Rosenbaum and Rubin (1983, 1985), Abadie and Imbens (2006)). Rather than using the 
parametric regression approach of Tables C.3 to (C.6), this matching approach is a more flexible way of generating the counterfactual earnings growth that a person who invests in PSE would have received had they not enrolled in PSE. Comparing difference matching estimates to standard OLS earnings growth models is useful to help identify what is driving any difference between the estimates (Imbens (2014)). ${ }^{15}$

The propensity score matching approach involves matching individuals from a treatment group (immigrants who participated in PSE) to those in a control group (immigrants who did not participate in PSE) based on a propensity score $\left(p_{i}\right)$ computed under the assumption of a logistic distribution as:

$$
p_{i}=\frac{\exp \left(X_{i}^{\prime} \beta\right)}{1+\exp \left(X_{i}^{\prime} \beta\right)}
$$

where $X_{i}$ consists of the same characteristics which the immigrant possessed at the time of arrival in Canada as were employed in the parametric long-difference analysis (Equation (3.3.1)), for example, marital status at landing, landing cohort, and first language spoken. Maximizing the likelihood function derived from Equation (3.5.1) leads to an estimate of the coefficient vector $\hat{\beta}$ which is used to estimate the propensity score $\left(\hat{p}_{i}\right)$ for each immigrant. After randomly ordering the treated and control participants, the nearest neighbour matching involves matching immigrants from the treatment group to those in the control group based on the smallest euclidean distance between the propensity scores.

We estimate the average treatment effect on the treated (ATT) by computing first the counterfactual outcome for each individual in the treatment group (immigrants who participated in PSE) by using a weighted average of the outcomes in the comparison group (immigrants who did not participate in PSE), and then averaging these results over the

\footnotetext{
${ }^{15}$ For a description and recent example of this approach applied to the adult training literature, see Ci et al. (2015) and for more background on the approach see, Heckman et al. (1998) and Imbens (2014). In contrast to regression methods that also rely on the selection on observables assumption, rather than assuming a functional form for the outcome equation, matching computes directly the counterfactual outcome by comparing individuals who did and did not enrol in PSE that are 'similar' in terms of pre-treatment characteristics. When non-linear relationships between the key variables are present, relaxing the functional form assumption of the outcome equation is a clear advantage for matching methods.
} 
treatment group sample. This ATT is then computed as:

$$
A T T=\frac{1}{n^{1}} \Sigma_{i}\left\{\left(Y_{i} \mid D_{i}=1\right)-\Sigma_{j} w_{i, j}\left(Y_{j} \mid D_{j}=0\right)\right\}
$$

where $i$ represents the treatment cases while $j$ indicates the control cases; $n$ refers to the total number of immigrants in both the control and treatment groups; $n^{1}$ is the number of immigrants in the treated group; and $Y_{i}$ is the outcome variable for the immigrant which indicates if there was a change in the earnings of the immigrant over the six year period after landing. Note that $D_{i}=1$ implies that the immigrant is in the treatment group while $D_{i}=0$ implies that the immigrant is in the control group. Also, $w_{i, j}$ is a weight equal to 1 if the treatment case $i$ is matched with the control case $j$ and 0 otherwise. The average treatment effect on the untreated (ATU) is defined as:

$$
A T U=\frac{1}{n^{2}} \Sigma_{j}\left\{\left(Y_{j} \mid D_{j}=0\right)-\Sigma_{i} w_{i, j}\left(Y_{i} \mid D_{i}=1\right)\right\}
$$

where $n^{2}$ is the number of immigrants in the control group; and the average treatment effect (ATE) is defined as:

$$
A T E=\left\{\frac{1}{n} \Sigma_{i} D_{i}\right\} A T T+\left\{1-\left[\frac{1}{n} \Sigma_{i} D_{i}\right]\right\} A T U
$$

In Table C.8, we present the matching estimates for the ATT and ATE (based on nearest neighbour matching) for immigrant men and women, respectively, using the entire sample. In the columns (1) and (3) we present the estimates by gender for the case of no control for initial earnings and in the columns (2) and (4) we present the equivalent estimates when a control for initial earnings is included. In each case, the estimated effect of participation in full-time PSE over years two through five in Canada has a positive effect on the change in log annual earnings between year six and year one in Canada of $17.4 \%$ and $29.5 \%$ for the case 
of full-time enrollment for men and women, respectively, and $16.0 \%$ and $28.6 \%$, respectively, when the initial earnings control is included. Equivalent matching estimates based on the effect of participation in part-time PSE are presented in Table C.9. The matching estimates of the effect of part-time PSE on earnings growth are similar to what was found in the parametric models of Table C.4. We see larger effects for women than for men and larger effects for full-time PSE compared with part-time PSE. Considering the estimated ATE estimates, we see generally very similar estimates as the ATT estimates. The ATE values suggest that the characteristics of immigrants who participate in PSE are very close to the distribution of the characteristics of the overall immigrant population.

\subsubsection{Fixed Effects Estimation}

The analysis to this point has focused on the first six years in Canada and a very specific four-year window during which PSE enrollment would take place. While these results are informative, it may be that some immigrants delay their enrollment in PSE or move back and forth from PSE into the labour market meaning that this tight window may not fully capture the importance of PSE for earnings dynamics of new immigrants. Also, many earnings observations are discarded through this approach. In order to address these concerns, we present a parallel analysis of the possible effects of PSE on immigrant earnings using a fixed effects specification and incorporating up to the first 14 years of income tax data for new immigrants to Canada.

In Table C.11, by PSE we present sample means of log annual employment earnings. ${ }^{16}$ This variable is especially of interest since it is the dependent variable used in our fixed effects regression model. In defining the sample used to calculate this variable, we exclude immigrants who participated in PSE in the current tax year as we want their annual earnings

\footnotetext{
${ }^{16}$ The equivalent versions of Table C.1 for the sample used in the fixed effects estimations can be found in the Appendix for Chapter 3 (i.e. Table C.10).
} 
that year to not be truncated due to time spent in PSE. ${ }^{17}$ We see higher annual earnings of $0.56 \log$ points for men relative to women. Also, women are more likely to participate in post-migration PSE than men.

The objective of our research is to estimate the earnings returns to both part-time and full-time post-secondary education (PSE) participation over the early years after migration. It is important to note that the decision to enroll in PSE is one flexibly made by new immigrants. They may choose whether to enter into PSE as well as the timing of their enrollment. Some may delay their enrollment in PSE or move back and forth from PSE into the labour market and back again. Therefore, our estimation strategy relies on the use of an adapted version of the well-known Mincerian wage equation (Mincer (1974)) for immigrant $i$ at time $t$ which is estimated as a fixed effects regression as follows:

$\log (w)_{i, t}=\beta_{0}+\beta_{1} F T P S E_{i, t}+\beta_{2} P T P S E_{i, t}+\beta_{3} Y S M_{i, t}+\beta_{4}\left(Y S M^{2} / 100\right)_{i, t}+X_{i}^{\prime} \beta+\eta_{i}+\epsilon_{i, t}$

where the dependent variable is the $i$ th immigrant's log earnings ${ }^{18}$ at time $t$ which can be explained by an immigrant's participation in full-time post-secondary education $\left(F T P S E_{i, t}\right)$ and/or part-time post-secondary education $\left(P T P S E_{i, t}\right)$; years-since-migration ${ }^{19}\left(Y S M_{i, t}\right)$ and its square divided by $100\left(\left(Y S M^{2} / 100\right)_{i, t}\right)$; and a set of explanatory variables captured in $X_{i}$. The vector $X_{i}$ consists of the same characteristics which the immigrant possessed at the time of arrival in Canada as were employed in the parametric long-difference analysis (Equation (3.3.1)), for example, marital status at landing, landing cohort, and first language spoken. The residual term $\left(\epsilon_{i, t}\right)$ captures random variation in wages that is independent across time and individuals while $\eta_{i}$ captures unobserved individual heterogeneity, which

\footnotetext{
${ }^{17} \mathrm{We}$ also restrict the sample to individuals who had positive annual earnings in the current tax year so as to be able to calculate the log annual earnings.

${ }^{18}$ The sample used to estimate the fixed effects model is restricted to individuals who had positive annual earnings in the current tax year so as to be able to calculate log annual earnings.

${ }^{19}$ Controlling for YSM, captures the non-linear effects that time spent in Canada post-migration has on wages. It also disentangles the effects of landing cohort and YSM which may otherwise both be absorbed in the coefficients of the landing cohort variable. Additionally, it ensures that the counterfactual for people who don't enroll in PSE is well modelled.
} 
enters the model as a fixed effect. Therefore, as per our model specification, the coefficient $\beta_{1}$ can be interpreted as the immigrant's return from enrolling in full-time PSE. A positive value of $\beta_{1}$ would indicate a positive return from enrollment in full-time PSE. Similarly, $\beta_{2}$ would measure the return of enrollment in part-time PSE. Note that in order to identify the parameters of interest (i.e. $\beta_{1}$ and $\left.\beta_{2}\right)$ consistently, the residual term $\left(\epsilon_{i, t}\right)$ must be free of unobserved heterogeneity that does not vary through time and be uncorrelated with all of the model's right-hand-side variables in all periods.

There are a couple of advantages of using a fixed effects model as our identification strategy. First, the model allows us to include all the years that an immigrant is in Canada (years both before and after investment in PSE). ${ }^{20}$ Second, the model controls for possible unobserved characteristics which may be correlated with enrollment decisions (which are likely to be one-time decisions) over the observed time period. However, given that $X_{i}$ consists of time invariant characteristics, they will inevitably drop out of the fixed effects estimation of Equation (3.5.5). ${ }^{21}$ To retrieve the effects on these variables, we regress the residuals $\left(\epsilon_{i, t}\right)$ of Equation (3.5.5) on the vector $X_{i}$. In other words, we estimate a 'second stage' regression given as:

$$
\epsilon_{i, t}=X_{i}^{\prime} \alpha+v_{i, t}
$$

Estimation of Equation (3.5.6) allows us to recover the estimates of the coefficients in $\beta$ from Equation (3.5.5) since it can be shown that $\beta \equiv \alpha .{ }^{22}$ When estimating Equations (3.5.5) and (3.5.6), we also drop observations from our earnings estimation when the person is enrolled in part-time or full-time PSE to avoid any contemporaneous effects on earnings due to a reduced labour supply during the period of enrollment.

In Table C.12, we present the key coefficient estimates from our fixed-effects estimation. In columns (1) and (3), we do not condition on initial earnings and find that ever having

\footnotetext{
${ }^{20}$ We incorporate up to the first 14 years of income tax data of new immigrants to Canada.

${ }^{21}$ Any variables interacted with the PSE dummy variables can be obtained through the estimation of Equation (3.5.5).

${ }^{22}$ See Cobb-Clark et al. (2005) for an example of this two-step approach.
} 
studied full-time is associated with much higher earnings for men and women at 0.219 and 0.328 log points, respectively. The return for part-time PSE is smaller but still substantive at 0.112 and $0.210 \log$ points, respectively. The equivalent estimates from the models of columns (2) and (4) where we condition on initial log earnings are very similar. The return to year-since-migration is positive and concave in all specifications suggesting substantial earnings growth in the first years in Canada even without PSE investments.

While our focus is on the PSE variable, it is worth describing the general patterns of the coefficient on the other control variables. In Table C.13, we present estimates from a second stage estimation intended to identify relationships between the log earnings and non-time-varying characteristics of our respondents. We take the residuals (including the fixed effects) from the first stage estimation and regress them on a set of controls not included in the first stage estimation due to the fact that they do not vary over time for the same individuals (hence they are absorbed into the individual fixed effects. University education is associated with the highest earnings among the four educational categories, which suggests that more educated immigrants (at landing) have a larger capacity to adapt to the new labour market over time than do the less educated immigrants. Relative to the Skilled Worker Principal Applicant group of men, earnings were higher for immigrant men who were admitted in the Provincial Nominee programs but lower for immigrant men admitted under the Family Class and as Refugees. The results are similar for women. Given that Skilled Workers are admitted through the point system and Provincial Nominees are admitted based on economic criteria, they would be expected to most easily translate their skills into jobs in Canada. Hence, it is not surprising that their earnings would be higher than immigrants admitted under the other categories. The estimates suggest considerable variation in earnings growth for both men and women by source country.

In Table C.14, using an alternative specification, we replace the indicator variables for full-time and part-time enrollment in post-secondary education with the associated duration 
of enrollment in months. ${ }^{23}$ We find that one month of full-time study is associated with earnings returns of 0.032 and $0.041 \mathrm{log}$ points for men and women, respectively. Earnings returns from a month of part-time study are lower at 0.016 and 0.023 log points, respectively.

In Table C.15, we present equivalent estimates but for models where we do not condition on initial earnings (for simplicity) and allow the effect of PSE to vary by immigrant admission category. Returns to full-time or part-time PSE are lower for Family Class immigrants and Refugees relative to the default group of Principal Applicants (PAs) in the Skilled Worker category for men. For women, the Family Class difference is significant but smaller in magnitude than for men. Spouses of Skilled Worker PAs have higher returns to full-time PSE for both men and women, but the same is only true in terms of part-time PSE for the case of a female PA. The results suggest that PSE investments are especially beneficial to immigrants selected under the Skilled Worker program which is typically the most educated group of immigrants arriving in Canada of all the admission categories considered.

In Table C.16, we see that returns from ever having participated in full-time PSE for immigrants from Southern / Eastern Europe, Africa, East Asia, Other Asia, and the Caribbean / South America are higher than for those from Northwest Europe (default group). The coefficients are similar for the part-time PSE interactions with additional positive effects for South Asian and Southeast Asian immigrants. Return differentials between immigrants born in Northwest Europe and immigrants from other countries are greater for female than male immigrants.

In Table C.17, we conduct a similar analysis but with the PSE controls interacted with the level of education at landing. Returns from post-migration PSE participation rise with education level at landing with the magnitude of these effects similar between men and women for full-time PSE and larger for men for part-time PSE. This could reflect the fact that immigrants with more education at landing may benefit greatly from post-secondary

\footnotetext{
${ }^{23}$ Note that the second-stage estimates for the specifications in Tables C.14 to C.17 are not included in this report but are available on request. The estimated coefficients are generally similar to those reported for the baseline model in Table C.13.
} 
education in Canada since it could allow them to more easily have their foreign credentials recognized in the Canadian labour market.

\subsubsection{Robustness Checks and Other Extensions}

\section{Including Immigrants Who Ever Enrolled in Both Full-time and Part-time PSE}

When estimating the models described in Section 3.5.2, we dropped observations from our earnings estimation when the immigrant attended both part-time and full-time PSE at some point since landing (though not necessarily in the same year) to facilitate easier interpretation of the effects of each type of PSE on earnings. As a robustness check, we estimate Equation (3.5.5) including the aforementioned group of immigrants. The results are reported in Table C.18. Including all immigrants leads to lower estimates of the returns from PSE compared to the baseline results in Table C.12. The results suggest that PSE in Canada increases the annual earnings of men and women by $18.0 \%$ and $25.6 \%$, respectively, for those enrolled full time and by $7.5 \%$ and $13.4 \%$ for those enrolled part time, respectively (columns (1) and (3) of Table C.18). The results suggest that participating in both part-time and full-time PSE leads to lower returns than enrolling in one of the two PSE options. If participation in part-time PSE occurs at different times to enrollment in full-time PSE then it may be that the lower returns are related to a greater time away from the labour market.

\section{Changes in Earnings Levels}

The dependent variable of the fixed effects estimations reported in Section 3.5.2 was the log earnings of immigrants (Equation (3.5.5)). This meant that years in which immigrants had zero earnings were excluded. In this section, we report estimations of fixed effects models that replace log earnings with annual earnings. This approach enables an estimation of the changes in the earnings levels of migrants in their first years in Canada. Also, it places no restrictions related to employment choices on who is included in the analysis. The results 
are reported in Table C.19.

In columns (1) and (3), when we do not condition on initial earnings, we continue to find that ever having studied full-time is associated with an increase in the mean annual earnings of both men and women of $\$ 1,461.54$ and $\$ 3,155.87$, respectively. In contrast to the baseline results reported in Table C.12, the returns for part-time PSE are larger relative to the returns from full-time PSE at $\$ 3,936.34$ and $\$ 4,983.66$, respectively. ${ }^{24}$ The equivalent estimates from the models of columns (2) and (4) where we condition on initial earnings are larger in magnitude compared to the absence of this condition irrespective of whether the PSE was part-time or full-time but the interpretations of the estimates is similar. Overall, the results still support our conclusion that PSE improves the earnings of immigrants.

\section{The Timing of the PSE Investment}

There is variation in the timing of immigrant enrollment in PSE. Some immigrants may choose to find a job as soon as they become permanent residents. However, for other immigrants, e.g. spouses, it may be quite normal to not work immediately upon arrival but still work later and also invest in human capital. Given this variation, to explore the impact of the timing of the PSE investment on our estimates of the returns to post-migration education, we estimate Equation (3.5.5) using a sample restricted to immigrants who had positive earnings in each of the first 8 years since migration.

We find that using the new sample leads to a rise in the estimated returns from participation in both full-time and part-time PSE relative to the baseline results reported in

\footnotetext{
${ }^{24}$ We conducted alternative estimations to investigate the differences from the baseline results. We found that the results had a qualitatively similar interpretation when Equation (3.5.5) is estimated with the outcome variable being equal to the earnings levels and each of the following is separately done: (1) exclude years in which immigrants had zero earnings; (2) include immigrants who attended both part-time and full-time PSE at some point since landing; (3) exclude years in which immigrants had zero earnings and include immigrants who attended both part-time and full-time PSE at some point since landing; (4) restrict the sample used for the estimation to immigrants with annual earnings less than $\$ 200,000$; and (5) replace the dependent variable with mean annual earnings Winsorized at the 1st and 99th percentiles of the earnings distribution. Although the finding that returns are higher for part-time compared to full-time PSE enrollment in specifications remains a puzzle, these alternative specifications render support to our general conclusion that PSE improves the earnings of immigrants.
} 
Table C.12. Our findings suggest that the annual earnings of men and women by $22.2 \%$ and $33.0 \%$, respectively, for those enrolled full time and by $11.6 \%$ and $21.4 \%$ for those enrolled part time, respectively (columns (1) and (3) of Table C.20). The rise in the estimated returns suggests that an immigrant who participates in PSE and obtains work experience in Canada during the first 8 years after migration is able to accumulate a higher level of human capital than an immigrant who participates in PSE but does not work.

To extend the analysis, we then estimate the following model:

$$
\begin{aligned}
\log (w)_{i, t} & =\beta_{0}+\beta_{1} F T P S E_{i, t}+\beta_{2} P T P S E_{i, t}+\beta_{3} Y S M_{i, t}+\beta_{4}\left(Y S M^{2} / 100\right)_{i, t}+X_{i}^{\prime} \beta \\
& +\gamma_{j}\left(F T P S E_{i, t} \times S t u d y \_ \text {After_8th_YSM } M_{i, t}\right) \\
& +\gamma_{k}\left(\text { PTPSE } E_{i, t} \times S t u d y \_ \text {After_8th_YSM } M_{i, t}\right)+\eta_{i}+\epsilon_{i, t}
\end{aligned}
$$

where $S t u d y_{-}$After_8th_Y $S M_{i, t}$ is a dummy variable for studying after the first 8 years in which positive earnings were received. Therefore, the estimates of the coefficients $\gamma_{j}$ and $\gamma_{k}$ would indicate the returns obtained from PSE if the immigrant participates in full-time or part-time PSE after the first 8 years in which positive earnings were received, respectively. From Equation (3.5.7), the effect of having studied full-time is given as:

$$
\mathbb{E}\left[\log (w)_{i, t} \mid F T P S E_{i, t}=1\right]-\mathbb{E}\left[\log (w)_{i, t} \mid F T P S E_{i, t}=0\right]=\beta_{1}+\gamma_{j} S t u d y \_ \text {After_8th_YSM} M_{i, t}
$$

Thus, the return obtained by immigrants for studying full-time after the first 8 years in which positive earnings were received is given as the sum of $\beta_{1}$ and $\gamma_{j}$. Similarly, the effect of having studied part-time is given as:

$$
\mathbb{E}\left[\log (w)_{i, t} \mid P T P S E_{i, t}=1\right]-\mathbb{E}\left[\log (w)_{i, t} \mid P T P S E_{i, t}=0\right]=\beta_{2}+\gamma_{k} S t u d y \_ \text {After_8th_YSM } M_{i, t}
$$


Thus, the return obtained by immigrants for studying part-time after the first 8 years in which positive earnings were received is given as the sum of $\beta_{2}$ and $\gamma_{k}$. The results from estimating Equation (3.5.7) are reported in Table C.21.

Studying full-time after the first 8 years in which positive earnings are received reduces the return for women from $33.0 \%$ to $11.9 \%$ (column (3) of Table C.21) and leads to a negative return from full-time PSE for men (column (1) of Table C.21). Additionally, studying part-time after the first 8 years in which positive earnings are received reduces the return for men from $11.6 \%$ to $9.0 \%$ (column (1) of Table C.21). However, the timing of enrollment has no statistically significant impact on the return that women obtain from part-time PSE.

The results indicate that the timing of PSE investments may be important as they suggest that immigrants may differ in unobservable ways. For example, some immigrants who enroll in school after the 8th year of their arrival in Canada may be less ambitious or motivated in

terms of their careers and may consequently not benefit as much from enrollment in PSE. However, some immigrants with higher levels of motivation may experience improvements in their annual earnings if they supplement PSE enrollment with work experience.

\section{Is the Impact of Post-Migration Education Non-Linear?}

Results presented so far have provided a time-invariant estimate of the return to immigrant PSE investments. However, it is possible that the impact of further education may vary non-linearly over time since the most recent study year. We investigate this by using an event study set up of Equation (3.5.5) which includes controls for consecutive periods after the most recent study year (i.e. 2nd to 3rd year since study, 3rd to 4th year since study, and 4 or more years since study) that are allowed to vary with whether the immigrant enrolled 
in full-time or part-time PSE. The model estimated can be written as:

$$
\begin{aligned}
\log (w)_{i, t} & =\beta_{0}+\beta_{1} \text { FTPSE }_{i, t}+\beta_{2} \text { PTPSE }_{i, t}+\beta_{3} Y S M_{i, t}+\beta_{4}\left(Y S M^{2} / 100\right)_{i, t}+X_{i}^{\prime} \beta \\
& +\sum_{j=1}^{3} \gamma_{j}\left(\text { FTPSE }_{i, t} \times \text { Period }_{j}\right)+\sum_{k=1}^{3} \gamma_{k}\left(\text { PTPSE }_{i, t} \times \text { Period }_{k}\right)+\eta_{i}+\epsilon_{i, t}
\end{aligned}
$$

where Period $_{j}$ and Period $_{k}$ are dummy variables for the period after the most recent study year where

$$
\left.j, k=\left\{\begin{array}{l}
1=2 \text { nd to } 3 r d \text { year since study } \\
2=3 r d \text { to } 4 \text { th year since study } \\
3=4 \text { or more years since study }
\end{array}\right\}\right) .
$$

Therefore, the estimates of the coefficients $\gamma_{j}$ and $\gamma_{k}$ would indicate the returns obtained from PSE in period $j=k$. This allows the effect of PSE to vary by period. From Equation (3.5.10), the effect of having studied full-time is given as:

$$
\mathbb{E}\left[\log (w)_{i, t} \mid F_{T P S E_{i, t}}=1\right]-\mathbb{E}\left[\log (w)_{i, t} \mid F T P S E_{i, t}=0\right]=\beta_{1}+\gamma_{j} \sum_{j=1}^{3} \text { Period }_{j}
$$

Thus, the return obtained by immigrants after the $j$ th period since study is given as the sum of $\beta_{1}$ and $\gamma_{j}$. Similarly, the effect of having studied part-time is given as:

$$
\mathbb{E}\left[\log (w)_{i, t} \mid P T P S E_{i, t}=1\right]-\mathbb{E}\left[\log (w)_{i, t} \mid P T P S E_{i, t}=0\right]=\beta_{2}+\gamma_{k} \sum_{k=1}^{3} \text { Period }_{k}
$$

Thus, the return obtained by immigrants after the $k$ th period since study is given as the sum of $\beta_{2}$ and $\gamma_{k}$. The results from estimating Equation (3.5.10) are reported in Table C.22.

Both men and women experience an increase in their returns from both full-time and part-time PSE participation as the number of years since study increases. Specifically, PSE in Canada increased the annual earnings of men and women who enrolled in full-time PSE 
by $23.4 \%$ and $36.4 \%$ in the 2 nd to 3 rd year since study, respectively, and by $12.3 \%$ in the 2nd to 3rd year since study for male immigrants enrolled part-time (columns (1) and (3) of Table C.22). The return in the 2nd to 3rd year since study for women who studied part time is found not to be statistically significant. However, 4 or more years since study, the annual earnings of men and women who enrolled in full-time PSE had risen by $38.0 \%$ and $43.4 \%$, respectively, and by $14.6 \%$ and $24.5 \%$ for those who enrolled in part-time PSE, respectively.

In columns (2) and (4) of Table C.22, we report the results from estimating an alternative specification of Equation (3.5.10) which includes a control for the initial earnings of the immigrant. Comparing the results in columns (1) and (3), we find that the returns for consecutive periods after the most recent study year fall, with the exception of the estimate of the return for 4 or more years since the most recent study year. The results indicate that the earnings of immigrants rise as time passes after their most recent study period and those with high initial earnings are likely to see the greatest improvement in their long run labour market outcomes.

\section{Does Out-migration from Canada Cause a Bias in the Estimated Immigrant Returns to Post-Migration Education?}

Immigrants sometimes return to their source country or migrate to a different country for various reasons including, for example, for a new job or to be with family. Decisions to leave are typically made based on views regarding which location may be best given the current stage of the immigrant's lifecycle (e.g. DeVoretz and Ma (2002); Borjas and Bratsberg (1996)). From calculations of empirical survival and hazard functions using the Kaplan-Meier method, and data from the Landing Records (LIDS) and the IMDB, Aydemir and Robinson (2008) found that about $35 \%$ of male immigrants aged 25 to 45 at arrival who landed between 1980 and 1996 left Canada within 20 years after arrival, and around 60\% of those who left did so in the first year of arrival. Picot and Piraino (2013) showed, using data from the IMDB and the Longitudinal Administrative Databank (LAD), that immigrants from the 1985, 
1990 and 1995 landing cohorts were more likely than their Canadian-born counterparts to out-migrate; and the likelihood of leaving was greatest for immigrants with low earnings. Given these findings, one might expect that the immigrants in our sample who enrolled in PSE and eventually left Canada due to experiencing poorer labour market outcomes may cause a downward bias on the estimated returns to post-migration education.

Table C.23 reports the shares of immigrants in each landing cohort who had out-migrated (i.e. those who had been absent from the tax records for a period of four consecutive years or more) by each year since migration from the 5 th to 14 th year since migration. ${ }^{25}$ None of the immigrants in each of the landing cohorts had relocated until the 6th year since migration. At least $2.52 \%$ of immigrants in cohorts who had been present for 14 years since migration (i.e. those who landed in 1998 or 1999) relocated at least once.

To understand how post-migration education impacts out-migration, we estimate a probit model for the incidence of an immigrant leaving Canada by the 14 th year since migration. ${ }^{26}$ The model estimated can be written as:

$$
\text { Absent }_{i, t}=\beta_{0}+\beta_{1} \text { FTPSE }_{i, t}+\beta_{2} P T P S E_{i, t}+\beta_{3} Y S M_{i, t}+\beta_{4}\left(Y S M^{2} / 100\right)_{i, t}+X_{i}^{\prime} \beta+\epsilon_{i, t}
$$

where the dependent variable $\left(A_{b s e n t}{ }_{i, t}\right)$ is equal to 1 if the immigrant had at least one absence from the tax records of four or more consecutive years by the 14th year since migration and the value 0 otherwise. Using Equation (3.5.14), out-migration is modelled as a function of an immigrant's participation in full-time post-secondary education $\left(F T P S E_{i, t}\right)$ and/or part-time post-secondary education $\left(P T P S E_{i, t}\right)$ at any time prior to out-migrating; years since migration, and its square divided by 100, and a set of explanatory variables

\footnotetext{
${ }^{25}$ The choice of four or more consecutive years is consistent with an analysis conducted by Aydemir and Robinson (2008) using the IMDB. According to their work, immigrants absent from the tax records for a period shorter than 4 years are most likely absent from the workforce as they typically reappear in the data whereas those absent for more than 4 years are often absent from tax files for an additional year or more and are therefore likely to have emigrated.

${ }^{26}$ Out-migration from Canada is inferred from tax-filing behaviour and as such the results of the estimation could be biased if the immigrant did not file taxes for four or more consecutive years but remained in Canada.
} 
captured in $X_{i}$. The vector $X_{i}$ consists of characteristics which the immigrant possessed at the time of arrival in Canada including: marital status at landing; an indicator for whether the individual is divorced; landing cohort; first language spoken; indicator of ever being a TFW; indicator of ever being an international student; province/territory/major city of residence; first language spoken; education at landing; immigration admission category; source region; age at landing and age at landing squared divided by $100 .^{27}$ The results are reported in column (1) of Tables C.24 and C.25.

The findings indicate that immigrants from Africa and Oceania are more likely to leave whereas those from Southern / Eastern Europe or South, East or South Eastern Asia are more likely to stay. Also, immigrants are more likely to out-migrate if they were formerly a TFW rather than an international student. Previous research works have shown that this could be because international students may have superior labour market outcomes relative to immigrants who are born and educated abroad since they have credentials recognized by Canadian employers. Married individuals are also found to be less likely to out-migrate whereas immigrants who were divorced are more likely to out-migrate.

There were also some differences in factors associated with out-migration by gender. For example, relative to the Skilled Worker Principal Applicant group of men, the likelihood of out-migration was higher for those men who are admitted as Refugees. In contrast, relative to the Skilled Worker Principal Applicant group of women, the likelihood of out-migration was lowest for those women who are admitted as Refugees, Caregivers or via the Provincial Nominee Program. Also, the difference in the likelihood of out-migration between female immigrants with a high school certificate or lower relative to those with other levels of education was positive and significant. The difference was greatest for women with a Bachelor's degree or graduate degree. However, for men, the difference was positive and significant only for those with a graduate degree. This suggests that higher levels of education

\footnotetext{
${ }^{27}$ Note that $X_{i}$ consists of the same characteristics which the immigrant possessed at the time of arrival in Canada as were employed in the parametric long-difference analysis (Equation (3.3.1)), for example, marital status at landing, landing cohort, and first language spoken.
} 
at landing may lead to immigrants having greater geographical mobility.

Most importantly, we find that enrollment in PSE leads to immigrants being less likely to out-migrate from the country. Those who enroll in part-time PSE are less likely to out-migrate relative to those who study full-time. This could be because those who study are able to use qualifications recognized in Canada to improve their standards of living. Further, studying part-time may allow immigrants to devote more time to building their human capital through work experience. Similar results are obtained when the probit model defined in Equation (3.5.14) is estimated without cohort dummies and excluding cohorts arriving from 2006 to 2008 (columns (2) and (3) of Tables C.24 and C.25).

In order to investigate the importance of out-migration on our findings on the earnings returns to PSE investments of immigrants, we estimate Equation (3.5.5) excluding those who were ever absent from the tax records for four or more consecutive years (Table C.26). The results continue to suggest, as in the baseline results reported in Table C.12, that PSE in Canada increases the annual earnings of men and women by $21.9 \%$ and $32.8 \%$, respectively, for those enrolled full time and by $11.2 \%$ and $21.0 \%$ for those enrolled part time, respectively (columns (1) and (3) of Table C.26). These results suggest that our estimates of the returns to post-migration education are not likely to be biased by the non-random selection of immigrants who leave Canada.

\subsection{Concluding Remarks}

Our analysis suggests that over $20 \%$ of new immigrants participate in post-secondary education (PSE) within the first six years of residence in Canada. Participation in PSE is highest in the first three years in Canada (after low rates at arrival). Immigrants are more likely to participate in PSE in Canada if they are younger, were not Temporary Foreign Workers or foreign students before landing, and had more education at landing. Immigrants who were Principal Applicants (PA) in the Skilled Worker category and those in the Caregiver 
program are more likely to return to PSE after arrival than immigrants in other categories (such as the Family Class). We see considerable variation in the probability of returning to PSE by source region.

Exploiting the longitudinal nature of the CEEDD data, we analyze the effect of participation in PSE over years two through five in Canada on the earnings growth of immigrants between years one and six. This parametric long-difference approach allows us to remove person specific differences in earnings levels that could lead to biases in the estimated effect of PSE on immigrants' earnings, something that is not possible using traditional cross-sectional data such as Census data. Full-time PSE enrollment for immigrant men is found to increase earnings growth by $18.3 \%$. Part-time participation in PSE increases earnings growth by $7.7 \%$ for immigrant men. Earnings growth effects of PSE enrollment are larger for immigrant women with full-time PSE increasing earnings by $30.6 \%$ and part-time effects being $17.5 \%$.

While our parametric long-difference approach has many advantages over traditional cross-sectional estimates, concern remains that the endogeneity of the decision to return to PSE may lead to bias in our estimates of the effect of PSE on earnings. To address this issue, we employ propensity score matching to investigate whether our results using the parametric long-difference model are robust to this more flexible approach for generating the counterfactual growth in earnings. While matching methods are common in the job training literature, this paper is the first that we know of to use both longitudinal data and propensity score matching on the difference in earnings of immigrants resulting from participation in education after landing in the receiving country. Participation in PSE over years two through five in Canada increases annual earnings growth by $18.3 \%$ and $30.6 \%$ for the case of full-time enrollment for men and women, respectively, and by $7.8 \%$ and $17.5 \%$ for the case of part-time enrollment for men and women. Similar, however lower in magnitude dynamics are found when we compare the PSE participation effects for a recent immigrant who participates in PSE relative to a random recent immigrant. In particular, we found 
increases in annual earnings of $16.6 \%$ and $32.4 \%$ for the case of full-time enrollment in PSE for men and women, respectively, and $10.5 \%$ and $26.9 \%$ for the case of part-time enrollment in PSE for men and women.

The results are also similar utilizing a fixed effects estimation to analyze the effect of participation in PSE in Canada on the log earnings of immigrants. Full-time PSE enrollment for immigrant men is found to increase annual earnings by approximately $21.9 \%$ for men and approximately $32.8 \%$ for women. Part-time participation in PSE increases earnings growth by $11.2 \%$ for immigrant men and $21.0 \%$ for women. Additionally, returns to PSE for immigrants are found to be higher for immigrants in the main economic category (Skilled Workers) relative to Family Class immigrants or Refugees, higher for immigrants with university education at arrival and higher for immigrants from non-traditional source countries. We are interpreting these findings to suggest that immigrants with more human capital at landing and those likely to have difficulty finding jobs that reflect their source country educational credentials are likely to have the largest return to investing in PSE in Canada. These findings indicate that, while PSE can improve the earnings of all immigrants, the importance of PSE to the labour market adjustment process varies with the demographic characteristics of the new immigrants.

We also contribute to the literature with our findings obtained through robustness checks and other extensions of the models summarized above. Specifically, we show that participating in both part-time and full-time PSE reduces the earnings growth effects of PSE enrollment. However, earnings growth due to PSE is likely to be higher if PSE enrollment is supplemented with work experience. Further, the returns from PSE are non-linear. Returns from PSE rise as time passes after the most recent study period indicating that the greatest benefits from PSE are likely to be experienced in the long-run rather than the short-run. Lastly, the estimated returns to post-migration education are not likely to be biased by the non-random selection of immigrants who leave Canada.

The results from the estimations suggest that immigrants have large expected returns to 
post-migration enrollment in PSE. However, some immigrants may have very large returns to PSE while others may have smaller expected returns that might lead them not to invest in PSE and this may lead to higher estimated returns compared to if the sample of immigrants were randomly assigned. Also, some individuals may invest in their human capital in other ways (e.g. building networks or listening to the radio to improve their understanding of the official languages) and others may also not be able to afford the expenses associated with enrolling in PSE. Moreover, enrolling in PSE may not fully eliminate all the barriers faced by immigrants in the Canadian labour market. For example, enrollment in PSE may not necessarily lead to a full improvement of an immigrant's ability in the official languages.

A cost-benefit analysis of post-migration enrollment in PSE, considering the associated tuition and opportunity costs, would have to be conducted in order to formulate clear policy recommendations. However, a possible implication of the findings of our research is that efforts should be made to ensure that PSE is made accessible to immigrants with human capital that is not recognized and consequently face larger barriers in the Canadian labour market upon their arrival. The issue is that a potential general equilibrium effect of an increased propensity of immigrants to enroll in PSE is a reduction in the returns from enrollment in PSE.

A cost-benefit analysis of post-migration enrollment in PSE, considering the associated tuition and opportunity costs, would have to be conducted in order to formulate clear policy recommendations. Within this analysis, one would want to account for any general equilibrium effects of a large increase in enrollment in PSE by immigrants since the method we have used is only useful for analysing small changes in enrollment. Nevertheless, our findings of large earnings return from PSE suggest that maybe efforts should be made to ensure that PSE is made accessible to immigrants with human capital that is not recognized and consequently face larger barriers in the Canadian labour market upon their arrival. Therefore, a possible avenue for further research using suitable longitudinal data would be an investigation of the earnings returns from other forms of training funded by the government 
and/or employers of immigrants, such as language training and workplace training, may also be important. 
Appendix A

Appendix for Chapter 1 
Table A.1: Variable Descriptions

\begin{tabular}{|c|c|c|}
\hline Variable & Description & Calculation \\
\hline \multicolumn{3}{|c|}{ Outcome Variables } \\
\hline$D A C C$ & Discretionary Accruals & $\begin{array}{l}\text { Computed as per the modified-Jones } \\
\text { model of Dechow et al. (1995) augmented } \\
\text { with the lagged, current and future } \\
\text { operating cash flow and estimated, } \\
\text { separately for each period, in the cross } \\
\text { section (following Stein and Wang }(2016) \\
\text { and Kothari et al. (2005)) based on the } \\
\text { two-digit SIC code based industry. } \\
\text { Discretionary accruals are given as the } \\
\text { residuals } \\
\left(D C A C C_{i, t}=T C A C C_{i, t}-T \widehat{C A C C_{i, t}} \text { ) }\right. \\
\text { from the cross-sectional regressions. See } \\
\text { Section }(1.3 .2 \text { ) for more details on the } \\
\text { procedure. }\end{array}$ \\
\hline
\end{tabular}

Main Explanatory Variables

Incentive Incentive Ratio

VIX Chicago Board Options

Exchange Volatility Index (VIX)

FDir Female Board Participation

$F_{-} j_{i, t}$ where $j=1,2,3 \quad$ Female Board Participation

Calculated as per the CEO manipulation incentive measure proposed by Bergstresser and Philippon (2006). The manipulation incentive is given as: Incentive $_{i, t-1}=$ OnePercent $t_{i, t-1}$

$\overline{\text { OnePercent }_{i, t-1}+\text { Salary }_{i, t-1}+{ }_{i, t-1}}$ where the effect of a $1 \%$ increase in the firm's share price on the dollar value of a CEO's wealth in terms of their share and options holdings (the sum of unexercised exercisable options and unexercised unexercisable options) under an assumption that their option holdings have a delta of one is given as:

OnePercent $_{i, t-1}=(0.01 \times$ Price $\left._{i, t-1}\right)\left(\right.$ Shares $_{i, t-1}+$ Options $\left._{i, t-1}\right)$ Value as at the end of the fiscal year. Data on the VIX is obtained from the FRED database.

Dummy variable set to 1 for firms with at least one female director.

Dummy variable set to 1 for firms with (1) one female director; (2) two female directors; and (3) at least three female directors, respectively. 
Table A.1: Variable Descriptions, Cont.

\begin{tabular}{|c|c|c|}
\hline Variable & Description & Calculation \\
\hline \multicolumn{3}{|c|}{ Control Variables } \\
\hline TotalRisk & Total Risk & $\begin{array}{l}\text { Standard deviation of daily stock returns } \\
\text { over the last fiscal year (based on the } \\
\text { number of non-missing observations). }\end{array}$ \\
\hline FirmSize & Firm's Size & $\begin{array}{l}\text { The log of the book value of total assets } \\
\text { as at the associated fiscal vear end. }\end{array}$ \\
\hline TobinsQ & Tobin's Q & $\begin{array}{l}\text { The book value of assets minus the book } \\
\text { value of equity plus the market value of }\end{array}$ \\
\hline$R O A$ & Return on Assets Ratio & $\begin{array}{l}\text { Return on assets is defined as net income } \\
\text { before extraordinary items divided by the }\end{array}$ \\
\hline BoardSize & Board Size & Total number of directors on the board. \\
\hline SalesGrowth & Sales Growth & $\begin{array}{l}\text { The average of the year to year } \\
\text { percentage change in sales over the } \\
\text { preceeding } 3 \text { years. }\end{array}$ \\
\hline
\end{tabular}

Table A.1 describes the variables used in my analysis.

Table A.2: Sample Selection Process

\begin{tabular}{lc}
\hline \hline Filtering Process & $\begin{array}{c}\text { Number of } \\
\text { Observations }\end{array}$ \\
\hline Financial Data from the CRSP/Compustat Merged & \\
- Fundamentals Annual Database (1992 - 2016) & 98,299 \\
Less: Missing Data in Necessary Variables and Duplicates & $(54,405)$ \\
Financial Data & 43,894 \\
CEO Related Data from the ExecuComp Database (1992 - 2016) & 269,651 \\
Merged Data & 20,767 \\
Less: Missing Data in Necessary Variables and Duplicates; and Observations & $(14,743)$ \\
Associated with Negative Discretionary Accruals & 6,024 \\
\hline Final Sample & \\
\hline \hline
\end{tabular}

Table A.2 describes the selection process for the CEO sample. 
Table A.3: Descriptive Statistics for the CEO Sample

\begin{tabular}{|c|c|c|c|c|c|c|c|}
\hline & Mean & $\begin{array}{l}\text { Standard } \\
\text { Deviation }\end{array}$ & $P_{25}$ & Median & $P_{75}$ & Skewness & Count \\
\hline$D A C C$ & 0.02380 & 0.02722 & 0.00688 & 0.01563 & 0.03126 & 3.87720 & 6,024 \\
\hline TotalRisk & 35.13053 & 21.17526 & 21.59402 & 30.37689 & 42.54935 & 3.10764 & 6,024 \\
\hline FirmSize $_{i, t-1}$ & 7.58278 & 1.62987 & 6.38836 & 7.47955 & 8.65718 & 8.65718 & 6,024 \\
\hline Tobins $Q_{i, t-1}$ & 0.99927 & 0.01452 & 0.64447 & 1 & 1.03416 & -28.05964 & 6,024 \\
\hline$R O A$ & 0.06539 & 0.10358 & 0.03273 & 0.06371 & 0.10431 & -6.48521 & 6,024 \\
\hline BoardSize & 5.77208 & 1.20504 & 5 & 6 & 6 & 0.92448 & 6,024 \\
\hline SalesGrowth & 0.06972 & 0.26030 & -0.00308 & 0.07056 & 0.15166 & -3.90828 & 6,024 \\
\hline$V I X$ & 20.64132 & 7.14345 & 16.31 & 19.2 & 23.8 & 1.48472 & 6,024 \\
\hline Incentive $_{i, t-1}$ & 0.26537 & 0.22588 & 0.09082 & 0.20001 & 0.37925 & 1.23087 & 6,024 \\
\hline$F D i r=0$ & & & & & & & 4,194 \\
\hline$F D i r=1$ & & & & & & & 1,830 \\
\hline$F \_1=1$ & & & & & & & 1,408 \\
\hline$F \_2=1$ & & & & & & & 337 \\
\hline$F \_3=1$ & & & & & & & 85 \\
\hline
\end{tabular}

Table A.1 describes the variables used in my analysis (for observations associated with positive discretionary accruals). The time period under analysis for the CEO sample is April 1994 to December 2015 .

Table A.4: Descriptive Statistics for the CFO Sample

\begin{tabular}{lccccccc}
\hline \hline & Mean & $\begin{array}{c}\text { Standard } \\
\text { Deviation }\end{array}$ & $P_{25}$ & Median & $P_{75}$ & Skewness & Count \\
& & & & & & & \\
& & & & & & & \\
DACC & 0.02271 & 0.02623 & 0.00667 & 0.01513 & 0.02931 & 4.02476 & 3,190 \\
TotalRisk $_{\text {FirmSize }}, t-1$ & 34.14448 & 3.71801 & 21.35563 & 29.51938 & 41.44996 & 3.71801 & 3,190 \\
TobinsQ $i, t-1$ & 7.71177 & 1.65506 & 6.49955 & 7.62759 & 8.76826 & 0.24096 & 3,190 \\
ROA & 0.99946 & 0.01196 & 0.82084 & 1 & 1.00941 & -30.14663 & 3,190 \\
BoardSize & 0.06616 & 0.09660 & 0.03083 & 0.06280 & 0.10364 & -2.35601 & 3,190 \\
SalesGrowth & 5.53009 & 1.0813 & 5 & 5 & 6 & 0.85939 & 3,190 \\
VIX & 0.04584 & 0.25157 & -0.02158 & 0.05280 & 0.13013 & -4.64780 & 3,190 \\
Incentive $i, t-1$ & 20.91525 & 7.15956 & 17.75 & 18.21 & 23.4 & 1.78680 & 3,190 \\
FDir $=0$ & 0.13265 & 0.12177 & 0.04453 & 0.09669 & 0.18316 & 1.69068 & 3,190 \\
FDir $=1$ & & & & & & & 2,093 \\
F_1 $=1$ & & & & & & & 84097 \\
F_2 $=1$ & & & & & & & 192 \\
F_3 $=1$ & & & & & & & 57 \\
\hline \hline
\end{tabular}

Table A.1 describes the variables used in my analysis (for observations associated with positive discretionary accruals). The time period under analysis for the CFO sample is January 2008 to December 2015 . 
Table A.5: CEO Incentives, Gender Diversity, and Reported Earnings

\begin{tabular}{|c|c|c|c|c|c|c|}
\hline Variable & $\begin{array}{c}(\mathbf{1}) \\
D A C C\end{array}$ & $\begin{array}{c}\mathbf{( 2 )} \\
D A C C \\
\end{array}$ & $\begin{array}{c}\mathbf{( 3 )} \\
D A C C \\
\end{array}$ & $\begin{array}{c}(4) \\
D A C C\end{array}$ & $\begin{array}{c}(5) \\
D A C C \\
\end{array}$ & $\begin{array}{c}(\mathbf{6}) \\
D A C C \\
\end{array}$ \\
\hline TotalRisk & $\begin{array}{l}0.00012^{* * *} \\
(0.00004)\end{array}$ & $\begin{array}{l}0.00012^{* * *} \\
(0.00004)\end{array}$ & $\begin{array}{l}0.00012^{* * * *} \\
(0.00004)\end{array}$ & $\begin{array}{l}0.00012^{* * *} \\
(0.00004)\end{array}$ & $\begin{array}{l}0.00012^{* * * *} \\
(0.00004)\end{array}$ & $\begin{array}{l}0.00012^{* * *} \\
(0.00004)\end{array}$ \\
\hline FirmSize $_{i, t-1}$ & $\begin{array}{l}-0.00575 * * * \\
(0.00115)\end{array}$ & $\begin{array}{l}-0.00576^{* * *} \\
(0.00115)\end{array}$ & $\begin{array}{l}-0.00572^{* * *} \\
(0.00115)\end{array}$ & $\begin{array}{l}-0.00581 * * * \\
(0.00115)\end{array}$ & $\begin{array}{l}-0.00582^{* * *} \\
(0.00115)\end{array}$ & $\begin{array}{l}-0.00573^{* * *} \\
(0.00115)\end{array}$ \\
\hline Tobins $Q_{i, t-1}$ & $\begin{array}{c}-0.04494^{*} \\
(0.02722)\end{array}$ & $\begin{array}{c}-0.04770^{*} \\
(0.02769)\end{array}$ & $\begin{array}{c}-0.04957^{*} \\
(0.02774)\end{array}$ & $\begin{array}{c}-0.04497^{*} \\
(0.02701)\end{array}$ & $\begin{array}{c}-0.04774^{*} \\
(0.02749)\end{array}$ & $\begin{array}{c}-0.04960^{*} \\
(0.02761)\end{array}$ \\
\hline$R O A$ & $\begin{array}{l}0.03851^{* * *} \\
(0.01125)\end{array}$ & $\begin{array}{l}0.03877^{* * *} \\
(0.01116)\end{array}$ & $\begin{array}{l}0.03881^{* * * *} \\
(0.01108)\end{array}$ & $\begin{array}{l}0.03869^{* * *} \\
(0.01128)\end{array}$ & $\begin{array}{l}0.03896^{* * * *} \\
(0.01119)\end{array}$ & $\begin{array}{l}0.03902^{* * *} \\
(0.01112)\end{array}$ \\
\hline BoardSize & $\begin{array}{l}0.00073^{*} \\
(0.00041)\end{array}$ & $\begin{array}{c}0.00073^{*} \\
(0.00041)\end{array}$ & $\begin{array}{l}0.00072^{*} \\
(0.00041)\end{array}$ & $\begin{array}{c}0.00081^{* *} \\
(0.00041)\end{array}$ & $\begin{array}{c}0.00081^{* *} \\
(0.00041)\end{array}$ & $\begin{array}{l}0.00078^{*} \\
(0.00041)\end{array}$ \\
\hline$D A C C_{i, t-1}$ & $\begin{array}{c}-0.04183^{* *} \\
(0.01706)\end{array}$ & $\begin{array}{c}-0.04181^{* *} \\
(0.01703)\end{array}$ & $\begin{array}{c}-0.04212^{* *} \\
(0.01701)\end{array}$ & $\begin{array}{c}-0.04166^{* *} \\
(0.01706)\end{array}$ & $\begin{array}{c}-0.04164^{* *} \\
(0.01703)\end{array}$ & $\begin{array}{l}-0.04183^{* *} \\
(0.01703)\end{array}$ \\
\hline SalesGrowth & $\begin{array}{l}0.00350^{*} \\
(0.00207)\end{array}$ & $\begin{array}{l}0.00351^{*} \\
(0.00207)\end{array}$ & $\begin{array}{c}0.00353^{*} \\
(0.00207)\end{array}$ & $\begin{array}{c}0.00346^{*} \\
(0.00207)\end{array}$ & $\begin{array}{c}0.00348^{*} \\
(0.00207)\end{array}$ & $\begin{array}{c}0.00348^{*} \\
(0.00207)\end{array}$ \\
\hline FDir & $\begin{array}{l}-0.00152 \\
(0.00108)\end{array}$ & $\begin{array}{l}-0.00153 \\
(0.00107)\end{array}$ & $\begin{array}{l}-0.00036 \\
(0.00144)\end{array}$ & & & \\
\hline$F \_1$ & & & & $\begin{array}{l}-0.00110 \\
(0.00110)\end{array}$ & $\begin{array}{l}-0.00110 \\
(0.00110)\end{array}$ & $\begin{array}{c}0.00033 \\
(0.00150)\end{array}$ \\
\hline$F \_2$ & & & & $\begin{array}{c}-0.00419 * * \\
(0.00170)\end{array}$ & $\begin{array}{c}-0.00422^{* *} \\
(0.00170)\end{array}$ & $\begin{array}{l}-0.00315 \\
(0.00250)\end{array}$ \\
\hline$F \_3$ & & & & $\begin{array}{l}-0.00496 \\
(0.00335)\end{array}$ & $\begin{array}{l}-0.00499 \\
(0.00332)\end{array}$ & $\begin{array}{c}-0.00842^{*} \\
(0.00439)\end{array}$ \\
\hline$V I X$ & $\begin{array}{l}-0.00004 \\
(0.00008)\end{array}$ & $\begin{array}{c}-0.00020^{* *} \\
(0.00010)\end{array}$ & $\begin{array}{c}-0.00020^{* *} \\
(0.00010)\end{array}$ & $\begin{array}{l}-0.00004 \\
(0.00008)\end{array}$ & $\begin{array}{l}-0.00020^{* *} \\
(0.00010)\end{array}$ & $\begin{array}{l}-0.00020^{* *} \\
(0.00010)\end{array}$ \\
\hline Incentive $_{i, t-1}$ & $\begin{array}{l}0.00424^{*} \\
(0.00246)\end{array}$ & $\begin{array}{l}-0.00817 \\
(0.00526)\end{array}$ & $\begin{array}{l}-0.00888 \\
(0.00592)\end{array}$ & $\begin{array}{l}0.00421^{*} \\
(0.00245)\end{array}$ & $\begin{array}{l}-0.00823 \\
(0.00526)\end{array}$ & $\begin{array}{l}-0.00920 \\
(0.00591)\end{array}$ \\
\hline Incentive $_{i, t-1} \times F D i r$ & & & $\begin{array}{c}0.00177 \\
(0.00717)\end{array}$ & & & \\
\hline Incentive $_{i, t-1} \times F_{-} 1$ & & & & & & $\begin{array}{l}-0.00328 \\
(0.00763)\end{array}$ \\
\hline Incentive $_{i, t-1} \times F_{-} 1$ & & & & & & $\begin{array}{c}0.01751 \\
(0.01447)\end{array}$ \\
\hline Incentive $_{i, t-1} \times F_{-} 1$ & & & & & & $\begin{array}{c}0.00014 \\
(0.02563)\end{array}$ \\
\hline$V I X \times$ Incentive $_{i, t-1}$ & & $\begin{array}{l}0.00059^{* * *} \\
(0.00023)\end{array}$ & $\begin{array}{l}0.00069^{* * *} \\
(0.00026)\end{array}$ & & $\begin{array}{l}0.00059^{* * *} \\
(0.00023)\end{array}$ & $\begin{array}{l}0.00069 * * * \\
(0.00026)\end{array}$ \\
\hline$V I X \times$ Incentive $_{i, t-1} \times F$ Dir & & & $\begin{array}{l}-0.00030 \\
(0.00028)\end{array}$ & & & \\
\hline$V I X \times$ Incentive $_{i, t-1} \times F_{-} 1$ & & & & & & $\begin{array}{l}-0.00011 \\
(0.00030)\end{array}$ \\
\hline$V I X \times$ Incentive $_{i, t-1} \times F_{-} 2$ & & & & & & $\begin{array}{l}-0.00100^{* *} \\
(0.00046)\end{array}$ \\
\hline$V I X \times$ Incentive $_{i, t-1} \times F_{-} 3$ & & & & & & $\begin{array}{c}0.00054 \\
(0.00136)\end{array}$ \\
\hline
\end{tabular}


Table A.5: CEO Incentives, Gender Diversity, and Reported Earnings, Cont.

\begin{tabular}{lcccccc}
\hline \hline Constant & $\begin{array}{c}0.09350^{* * *} \\
(0.02894)\end{array}$ & $\begin{array}{c}0.09907^{* * *} \\
(0.02944)\end{array}$ & $\begin{array}{c}0.10059^{* * *} \\
(0.02946)\end{array}$ & $\begin{array}{c}0.09350^{* * *} \\
(0.02875)\end{array}$ & $\begin{array}{l}0.09909^{* * *} \\
(0.02925)\end{array}$ & $\begin{array}{l}0.10033^{* * *} \\
(0.02932)\end{array}$ \\
\hline Observations & 5,833 & 5,833 & 5,833 & 5,833 & 5,833 & 5,833 \\
Adjusted $R^{2}$ & 0.24 & 0.24 & 0.24 & 0.24 & 0.24 & 0.24 \\
$\mathrm{~F}(3,4,933)$ & & & & & & 1.63 \\
Prob $>\mathrm{F}$ & & & & & & 0.18 \\
\hline \hline
\end{tabular}

In columns (1) and (4) of Table A.5, I report the results from estimating Equation (1.3.4); in columns (2) and (5), the results of Equations (1.3.7); and in columns (3) and (6), the results of Equation (1.3.9). All estimations are conducted using the CEO sample. In parentheses, I report standard errors two-way clustered by firm and time. Controls for time effects are included but not reported. Significance levels are indicated by $*, * *, * * *$ for $10 \%, 5 \%$, and $1 \%$ respectively. 
Table A.6: CFO Incentives, Gender Diversity, and Reported Earnings

\begin{tabular}{|c|c|c|c|c|c|c|}
\hline Variable & $\begin{array}{c}(\mathbf{1}) \\
D A C C\end{array}$ & $\begin{array}{c}\mathbf{( 2 )} \\
D A C C\end{array}$ & $\begin{array}{c}(3) \\
D A C C\end{array}$ & $\begin{array}{c}(4) \\
D A C C\end{array}$ & $\begin{array}{c}5) \\
D A C C\end{array}$ & $\begin{array}{c}\mathbf{6}) \\
D A C C\end{array}$ \\
\hline TotalRisk & $\begin{array}{c}0.00007^{*} \\
(0.00004)\end{array}$ & $\begin{array}{c}0.00007^{*} \\
(0.00004)\end{array}$ & $\begin{array}{c}0.00006^{*} \\
(0.00004)\end{array}$ & $\begin{array}{c}0.00007^{*} \\
(0.00004)\end{array}$ & $\begin{array}{c}0.00007^{*} \\
(0.00004)\end{array}$ & $\begin{array}{c}0.00006^{*} \\
(0.00004)\end{array}$ \\
\hline FirmSize $_{i, t-1}$ & $\begin{array}{l}-0.00326 \\
(0.00256)\end{array}$ & $\begin{array}{c}-0.00313 \\
(0.00255)\end{array}$ & $\begin{array}{c}-0.00329 \\
(0.00255)\end{array}$ & $\begin{array}{c}-0.00317 \\
(0.00256)\end{array}$ & $\begin{array}{c}-0.00306 \\
(0.00256)\end{array}$ & $\begin{array}{c}-0.00325 \\
(0.00256)\end{array}$ \\
\hline Tobins $Q_{i, t-1}$ & $\begin{array}{l}-0.00388 \\
(0.03507)\end{array}$ & $\begin{array}{l}-0.00179 \\
(0.03476)\end{array}$ & $\begin{array}{l}-0.00391 \\
(0.03535)\end{array}$ & $\begin{array}{l}-0.00742 \\
(0.03301)\end{array}$ & $\begin{array}{c}-0.00546 \\
(0.03276)\end{array}$ & $\begin{array}{l}-0.00750 \\
(0.03344)\end{array}$ \\
\hline$R O A$ & $\begin{array}{c}0.03885^{* *} \\
(0.01617)\end{array}$ & $\begin{array}{c}0.03892^{* *} \\
(0.01620)\end{array}$ & $\begin{array}{c}0.03898^{* *} \\
(0.01620)\end{array}$ & $\begin{array}{c}0.03890^{* *} \\
(0.01616)\end{array}$ & $\begin{array}{c}0.03895^{* *} \\
(0.01618)\end{array}$ & $\begin{array}{c}0.03921^{* *} \\
(0.01621)\end{array}$ \\
\hline BoardSize & $\begin{array}{c}0.00027 \\
(0.00056)\end{array}$ & $\begin{array}{c}0.00027 \\
(0.00056)\end{array}$ & $\begin{array}{c}0.00026 \\
(0.00056)\end{array}$ & $\begin{array}{c}0.00037 \\
(0.00056)\end{array}$ & $\begin{array}{c}0.00036 \\
(0.00056)\end{array}$ & $\begin{array}{c}0.00038 \\
(0.00056)\end{array}$ \\
\hline$D A C C_{i, t-1}$ & $\begin{array}{c}-0.08699^{* * *} \\
(0.02577)\end{array}$ & $\begin{array}{c}-0.08699^{* * *} \\
(0.02573)\end{array}$ & $\begin{array}{c}-0.08684^{* * *} \\
(0.02578)\end{array}$ & $\begin{array}{c}-0.08653^{* * *} \\
(0.02577)\end{array}$ & $\begin{array}{l}-0.08654^{* * *} \\
(0.02574)\end{array}$ & $\begin{array}{c}-0.08684^{* * *} \\
(0.02590)\end{array}$ \\
\hline SalesGrowth & $\begin{array}{c}0.00457 \\
(0.00290)\end{array}$ & $\begin{array}{c}0.00451 \\
(0.00290)\end{array}$ & $\begin{array}{c}0.00451 \\
(0.00291)\end{array}$ & $\begin{array}{c}0.00466 \\
(0.00289)\end{array}$ & $\begin{array}{c}0.00461 \\
(0.00289)\end{array}$ & $\begin{array}{c}0.00463 \\
(0.00291)\end{array}$ \\
\hline FDir & $\begin{array}{l}-0.00026 \\
(0.00156)\end{array}$ & $\begin{array}{l}-0.00028 \\
(0.00157)\end{array}$ & $\begin{array}{c}0.00027 \\
(0.00209)\end{array}$ & & & \\
\hline$F \_1$ & & & & $\begin{array}{c}0.00024 \\
(0.00158)\end{array}$ & $\begin{array}{c}0.00021 \\
(0.00158)\end{array}$ & $\begin{array}{c}0.00081 \\
(0.00214)\end{array}$ \\
\hline$F \_2$ & & & & $\begin{array}{c}-0.00547^{* *} \\
(0.00264)\end{array}$ & $\begin{array}{l}-0.00543^{* *} \\
(0.00262)\end{array}$ & $\begin{array}{c}-0.00490 \\
(0.00369)\end{array}$ \\
\hline$F \_3$ & & & & $\begin{array}{c}-0.00191 \\
(0.00542)\end{array}$ & $\begin{array}{l}-0.00190 \\
(0.00541)\end{array}$ & $\begin{array}{c}-0.00163 \\
(0.00642)\end{array}$ \\
\hline$V I X$ & $\begin{array}{l}-0.00015 \\
(0.00010)\end{array}$ & $\begin{array}{c}-0.00020^{*} \\
(0.00012)\end{array}$ & $\begin{array}{c}-0.00021^{*} \\
(0.00012)\end{array}$ & $\begin{array}{l}-0.00015 \\
(0.00010)\end{array}$ & $\begin{array}{c}-0.00020^{*} \\
(0.00012)\end{array}$ & $\begin{array}{c}-0.00019 \\
(0.00012)\end{array}$ \\
\hline Incentive $_{i, t-1}$ & $\begin{array}{c}0.00650 \\
(0.00602)\end{array}$ & $\begin{array}{c}-0.00259 \\
(0.01214)\end{array}$ & $\begin{array}{c}0.00336 \\
(0.01433)\end{array}$ & $\begin{array}{c}0.00663 \\
(0.00600)\end{array}$ & $\begin{array}{c}-0.00174 \\
(0.01212)\end{array}$ & $\begin{array}{c}0.00549 \\
(0.01440)\end{array}$ \\
\hline Incentive $_{i, t-1} \times F D i r$ & & & $\begin{array}{l}-0.02041 \\
(0.01662)\end{array}$ & & & \\
\hline Incentive $_{i, t-1} \times F_{-} 1$ & & & & & & $\begin{array}{c}-0.02189 \\
(0.01703)\end{array}$ \\
\hline Incentive $_{i, t-1} \times F_{-} 1$ & & & & & & $\begin{array}{l}-0.02591 \\
(0.03627)\end{array}$ \\
\hline Incentive $_{i, t-1} \times F \_1$ & & & & & & $\begin{array}{c}0.11644 \\
(0.14472)\end{array}$ \\
\hline$V I X \times$ Incentive $_{i, t-1}$ & & $\begin{array}{c}0.00042 \\
(0.00050)\end{array}$ & $\begin{array}{c}0.00022 \\
(0.00055)\end{array}$ & & $\begin{array}{c}0.00038 \\
(0.00050)\end{array}$ & $\begin{array}{c}0.00012 \\
(0.00055)\end{array}$ \\
\hline$V I X \times$ Incentive $_{i, t-1} \times F$ Dir & & & $\begin{array}{c}0.00073 \\
(0.00068)\end{array}$ & & & \\
\hline$V I X \times$ Incentive $_{i, t-1} \times F_{-} 1$ & & & & & & $\begin{array}{c}0.00077 \\
(0.00070)\end{array}$ \\
\hline$V I X \times$ Incentive $_{i, t-1} \times F_{-} 2$ & & & & & & $\begin{array}{c}0.00100 \\
(0.00147)\end{array}$ \\
\hline$V I X \times$ Incentive $_{i, t-1} \times F_{\_} 3$ & & & & & & $\begin{array}{l}-0.00537 \\
(0.00794)\end{array}$ \\
\hline
\end{tabular}


Table A.6: CFO Incentives, Gender Diversity, and Reported Earnings, Cont.

\begin{tabular}{lcccccc}
\hline \hline Constant & 0.05349 & 0.05163 & 0.05488 & 0.05613 & 0.05438 & 0.05735 \\
& $(0.04087)$ & $(0.04059)$ & $(0.04095)$ & $(0.03913)$ & $(0.03889)$ & $(0.03937)$ \\
\hline Observations & 3,046 & 3,046 & 3,046 & 3,046 & 3,046 & 3,046 \\
Adjusted $R^{2}$ & 0.28 & 0.28 & 0.28 & 0.28 & 0.28 & 0.28 \\
$\mathrm{~F}(3,2,225)$ & & & & & & 0.66 \\
Prob $>\mathrm{F}$ & & & & & 0.58 \\
\hline \hline
\end{tabular}

In columns (1) and (4) of Table A.6, I report the results from estimating Equation (1.3.4); in columns (2) and (5), the results of Equations (1.3.7); and in columns (3) and (6), the results of Equation (1.3.9). All estimations are conducted using the CFO sample. In parentheses, I report standard errors two-way clustered by firm and time. Controls for time effects are included but not reported. Significance levels are indicated by $*, * *, * * *$ for $10 \%, 5 \%$, and $1 \%$ respectively. 
Table A.7: Robustness Check Results: CEO Sample - Without Dynamic Effects

\begin{tabular}{|c|c|c|c|c|c|c|}
\hline Variable & $\begin{array}{c}(1) \\
D A C C\end{array}$ & $\begin{array}{c}(2) \\
D A C C\end{array}$ & $\begin{array}{c}(3) \\
D A C C\end{array}$ & $\begin{array}{c}(4) \\
D A C C\end{array}$ & $\begin{array}{c}(5) \\
D A C C\end{array}$ & $\begin{array}{c}(6) \\
D A C C\end{array}$ \\
\hline FDir & $\begin{array}{l}-0.00138 \\
(0.00106)\end{array}$ & $\begin{array}{l}-0.00139 \\
(0.00106)\end{array}$ & $\begin{array}{l}-0.00046 \\
(0.00142)\end{array}$ & & & \\
\hline$F \_1$ & & & & $\begin{array}{l}-0.00096 \\
(0.00109)\end{array}$ & $\begin{array}{l}-0.00097 \\
(0.00109)\end{array}$ & $\begin{array}{c}0.00022 \\
(0.00148)\end{array}$ \\
\hline$F \_2$ & & & & $\begin{array}{l}-0.00404^{* *} \\
(0.00167)\end{array}$ & $\begin{array}{l}-0.00405^{* *} \\
(0.00167)\end{array}$ & $\begin{array}{l}-0.00320 \\
(0.00246)\end{array}$ \\
\hline$F \_3$ & & & & $\begin{array}{l}-0.00464 \\
(0.00328)\end{array}$ & $\begin{array}{l}-0.00467 \\
(0.00326)\end{array}$ & $\begin{array}{l}-0.008314^{*} \\
(0.00432)\end{array}$ \\
\hline$V I X$ & $\begin{array}{l}-0.00002 \\
(0.00008)\end{array}$ & $\begin{array}{l}-0.00016 \\
(0.00010)\end{array}$ & $\begin{array}{l}-0.00016 \\
(0.00010)\end{array}$ & $\begin{array}{l}-0.00002 \\
(0.00008)\end{array}$ & $\begin{array}{l}-0.00016 \\
(0.00010)\end{array}$ & $\begin{array}{l}-0.00015 \\
(0.00010)\end{array}$ \\
\hline Incentive $_{i, t-1}$ & $\begin{array}{c}0.00324 \\
(0.00240)\end{array}$ & $\begin{array}{l}-0.00756 \\
(0.00518)\end{array}$ & $\begin{array}{l}-0.00852 \\
(0.00581)\end{array}$ & $\begin{array}{c}0.00320 \\
(0.00240)\end{array}$ & $\begin{array}{l}-0.00760 \\
(0.00518)\end{array}$ & $\begin{array}{l}-0.00881 \\
(0.00581)\end{array}$ \\
\hline Incentive $_{i, t-1} \times F$ Dir & & & $\begin{array}{c}0.00259 \\
(0.00710)\end{array}$ & & & \\
\hline Incentive $_{i, t-1} \times F_{-} 1$ & & & & & & $\begin{array}{l}-0.00229 \\
(0.00750)\end{array}$ \\
\hline Incentive $_{i, t-1} \times F \_2$ & & & & & & $\begin{array}{c}0.01785 \\
(0.01466)\end{array}$ \\
\hline Incentive $_{i, t-1} \times F \_3$ & & & & & & $\begin{array}{c}0.00256 \\
(0.02669)\end{array}$ \\
\hline$V I X \times$ Incentive $_{i, t-1}$ & & $\begin{array}{c}0.00051^{* *} \\
(0.00022)\end{array}$ & $\begin{array}{l}0.00061^{* *} \\
(0.00025)\end{array}$ & & $\begin{array}{c}0.00051^{* *} \\
(0.00022)\end{array}$ & $\begin{array}{l}0.00061^{* *} \\
(0.00025)\end{array}$ \\
\hline$V I X \times$ Incentive $_{i, t-1} \times F$ Dir & & & $\begin{array}{l}-0.00030 \\
(0.00028)\end{array}$ & & & \\
\hline$V I X \times$ Incentive $_{i, t-1} \times F_{-1}$ & & & & & & $\begin{array}{l}-0.00011 \\
(0.00029)\end{array}$ \\
\hline$V I X \times$ Incentive $_{i, t-1} \times F_{-} 2$ & & & & & & $\begin{array}{l}-0.00098^{* *} \\
(0.00047)\end{array}$ \\
\hline$V I X \times$ Incentive $_{i, t-1} \times F_{\_} 3$ & & & & & & $\begin{array}{c}0.00048 \\
(0.00144)\end{array}$ \\
\hline Constant & $\begin{array}{c}0.07716^{* *} \\
(0.03069)\end{array}$ & $\begin{array}{c}0.08083^{* *} \\
(0.03143)\end{array}$ & $\begin{array}{l}0.08215^{* * *} \\
(0.03143)\end{array}$ & $\begin{array}{c}0.07669^{* *} \\
(0.03071)\end{array}$ & $\begin{array}{c}0.08037^{* *} \\
(0.03147) \\
\end{array}$ & $\begin{array}{c}0.08143^{* *} \\
(0.03160) \\
\end{array}$ \\
\hline Observations & 5,970 & 5,970 & 5,970 & 5,970 & 5,970 & 5,970 \\
\hline Adjusted $R^{2}$ & 0.23 & 0.23 & 0.23 & 0.23 & 0.23 & 0.23 \\
\hline $\mathrm{F}(3,5,058)$ & & & & & & 1.49 \\
\hline Prob $>$ F & & & & & & 0.22 \\
\hline
\end{tabular}

In columns (1) and (4) of Table A.7, I report the results from estimating Equation (1.3.4); in columns (2) and (5), the results of Equations (1.3.7); and in columns (3) and (6), the results of Equation (1.3.9). Each model has a set of controls for total risk (1), firm size (1), Tobin's Q (1), the return on assets ratio (1), board size (1), sales growth (1). The models are estimated without lagged discretionary accruals as an independent variable. All estimations are conducted using the CEO sample. In parentheses, I report standard errors two-way clustered by firm and time. Controls for time effects are included but not reported. Significance levels are indicated by $*, * *, * * *$ for $10 \%, 5 \%$, and $1 \%$ respectively. 
Table A.8: Robustness Check Results: CFO Sample - Without Dynamic Effects

\begin{tabular}{|c|c|c|c|c|c|c|}
\hline Variable & $\begin{array}{c}(1) \\
D A C C\end{array}$ & $\begin{array}{c}(\mathbf{2}) \\
D A C C\end{array}$ & $\begin{array}{c}(3) \\
D A C C\end{array}$ & $\begin{array}{c}(4) \\
D A C C\end{array}$ & $\begin{array}{c}(5) \\
D A C C\end{array}$ & $\begin{array}{c}(\mathbf{6}) \\
D A C C\end{array}$ \\
\hline FDir & $\begin{array}{l}-0.00009 \\
(0.00155)\end{array}$ & $\begin{array}{l}-0.00011 \\
(0.00156)\end{array}$ & $\begin{array}{c}0.00043 \\
(0.00206)\end{array}$ & & & \\
\hline$F \_1$ & & & & $\begin{array}{c}0.00043 \\
(0.00157)\end{array}$ & $\begin{array}{c}0.00041 \\
(0.00157)\end{array}$ & $\begin{array}{c}0.00087 \\
(0.00211)\end{array}$ \\
\hline$F \_2$ & & & & $\begin{array}{l}-0.00552^{* *} \\
(0.00263)\end{array}$ & $\begin{array}{l}-0.00549^{* *} \\
(0.00262)\end{array}$ & $\begin{array}{l}-0.00428 \\
(0.00353)\end{array}$ \\
\hline$F \_3$ & & & & $\begin{array}{l}-0.00108 \\
(0.00551)\end{array}$ & $\begin{array}{l}-0.00108 \\
(0.00551)\end{array}$ & $\begin{array}{c}0.00016 \\
(0.00615)\end{array}$ \\
\hline$V I X$ & $\begin{array}{l}-0.00013 \\
(0.00010)\end{array}$ & $\begin{array}{l}-0.00018 \\
(0.00012)\end{array}$ & $\begin{array}{l}-0.00018 \\
(0.00012)\end{array}$ & $\begin{array}{l}-0.00013 \\
(0.00010)\end{array}$ & $\begin{array}{l}-0.00017 \\
(0.00012)\end{array}$ & $\begin{array}{l}-0.00016 \\
(0.00012)\end{array}$ \\
\hline Incentive $_{i, t-1}$ & $\begin{array}{c}0.00538 \\
(0.00608)\end{array}$ & $\begin{array}{l}-0.00147 \\
(0.01252)\end{array}$ & $\begin{array}{c}0.00483 \\
(0.01469)\end{array}$ & $\begin{array}{c}0.00553 \\
(0.00606)\end{array}$ & $\begin{array}{l}-0.00059 \\
(0.01248)\end{array}$ & $\begin{array}{c}0.00684 \\
(0.01476)\end{array}$ \\
\hline Incentive $_{i, t-1} \times F$ Dir & & & $\begin{array}{l}-0.02187 \\
(0.01725)\end{array}$ & & & \\
\hline Incentive $_{i, t-1} \times F_{-} 1$ & & & & & & $\begin{array}{l}-0.02109 \\
(0.01744)\end{array}$ \\
\hline Incentive $_{i, t-1} \times F \_2$ & & & & & & $\begin{array}{l}-0.03839 \\
(0.03856)\end{array}$ \\
\hline Incentive $_{i, t-1} \times F \_3$ & & & & & & $\begin{array}{c}0.10174 \\
(0.14914)\end{array}$ \\
\hline$V I X \times$ Incentive $_{i, t-1}$ & & $\begin{array}{c}0.00031 \\
(0.00051)\end{array}$ & $\begin{array}{c}0.00010 \\
(0.00055)\end{array}$ & & $\begin{array}{c}0.00028 \\
(0.00051)\end{array}$ & $\begin{array}{c}0.00001 \\
(0.00056)\end{array}$ \\
\hline$V I X \times$ Incentive $_{i, t-1} \times F$ Dir & & & $\begin{array}{c}0.00080 \\
(0.00072)\end{array}$ & & & \\
\hline$V I X \times$ Incentive $_{i, t-1} \times F_{-1}$ & & & & & & $\begin{array}{c}0.00078 \\
(0.00073)\end{array}$ \\
\hline$V I X \times$ Incentive $_{i, t-1} \times F \_2$ & & & & & & $\begin{array}{c}0.00133 \\
(0.00156)\end{array}$ \\
\hline$V I X \times$ Incentive $_{i, t-1} \times F \_3$ & & & & & & $\begin{array}{l}-0.00516 \\
(0.00820)\end{array}$ \\
\hline Constant & $\begin{array}{c}0.04658 \\
(0.04064)\end{array}$ & $\begin{array}{c}0.04516 \\
(0.04039)\end{array}$ & $\begin{array}{c}0.04864 \\
(0.04081)\end{array}$ & $\begin{array}{c}0.04941 \\
(0.03914)\end{array}$ & $\begin{array}{c}0.04812 \\
(0.03893)\end{array}$ & $\begin{array}{c}0.05177 \\
(0.03941)\end{array}$ \\
\hline Observations & 3,090 & 3,090 & 3,090 & 3,090 & 3,090 & 3,090 \\
\hline Adjusted $R^{2}$ & 0.26 & 0.26 & 0.26 & 0.26 & 0.26 & 0.26 \\
\hline $\mathrm{F}(3,2,544)$ & & & & & & 0.99 \\
\hline Prob $>$ F & & & & & & 0.40 \\
\hline
\end{tabular}

In columns (1) and (4) of Table A.8, I report the results from estimating Equation (1.3.4); in columns (2) and (5), the results of Equations (1.3.7); and in columns (3) and (6), the results of Equation (1.3.9). Each model has a set of controls for total risk (1), firm size (1), Tobin's Q (1), the return on assets ratio (1), board size (1), sales growth (1). The models are estimated without lagged discretionary accruals as an independent variable. All estimations are conducted using the CFO sample. In parentheses, I report standard errors two-way clustered by firm and time. Controls for time effects are included but not reported. Significance levels are indicated by $*, * *, * * *$ for $10 \%, 5 \%$, and $1 \%$ respectively. 
Table A.9: Robustness Check Results: CEO Sample - Unregulated Firms

\begin{tabular}{|c|c|c|c|c|c|c|}
\hline Variable & $\begin{array}{c}(1) \\
D A C C\end{array}$ & $\begin{array}{c}(\mathbf{2}) \\
D A C C\end{array}$ & $\begin{array}{c}(3) \\
D A C C\end{array}$ & $\begin{array}{c}(4) \\
D A C C\end{array}$ & $\begin{array}{c}(5) \\
D A C C\end{array}$ & $\begin{array}{c}(6) \\
D A C C\end{array}$ \\
\hline FDir & $\begin{array}{l}-0.00205^{*} \\
(0.00123)\end{array}$ & $\begin{array}{l}-0.00205^{*} \\
(0.00123)\end{array}$ & $\begin{array}{l}-0.00069 \\
(0.00168)\end{array}$ & & & \\
\hline$F \_1$ & & & & $\begin{array}{l}-0.00146 \\
(0.00126)\end{array}$ & $\begin{array}{l}-0.00147 \\
(0.00126)\end{array}$ & $\begin{array}{c}0.00037 \\
(0.00176)\end{array}$ \\
\hline$F \_2$ & & & & $\begin{array}{l}-0.00587^{* * *} \\
(0.00197)\end{array}$ & $\begin{array}{l}-0.00591^{* * *} \\
(0.00198)\end{array}$ & $\begin{array}{l}-0.00541^{*} \\
(0.00299)\end{array}$ \\
\hline$F \_3$ & & & & $\begin{array}{r}-0.00678^{*} \\
(0.00380)\end{array}$ & $\begin{array}{r}-0.00683^{*} \\
(0.00377)\end{array}$ & $\begin{array}{l}-0.01105^{* *} \\
(0.00501)\end{array}$ \\
\hline$V I X$ & $\begin{array}{l}-0.00006 \\
(0.00008)\end{array}$ & $\begin{array}{l}-0.00027^{* *} \\
(0.00011)\end{array}$ & $\begin{array}{l}-0.00026^{* *} \\
(0.00011)\end{array}$ & $\begin{array}{l}-0.00006 \\
(0.00008)\end{array}$ & $\begin{array}{l}-0.00027^{* *} \\
(0.00011)\end{array}$ & $\begin{array}{l}-0.00026^{* *} \\
(0.00011)\end{array}$ \\
\hline Incentive $_{i, t-1}$ & $\begin{array}{l}0.00529 * \\
(0.00277)\end{array}$ & $\begin{array}{r}-0.01029^{*} \\
(0.00589)\end{array}$ & $\begin{array}{r}-0.01099^{*} \\
(0.00650)\end{array}$ & $\begin{array}{l}0.00531^{*} \\
(0.00277)\end{array}$ & $\begin{array}{r}-0.01032^{*} \\
(0.00589)\end{array}$ & $\begin{array}{l}-0.01148^{*} \\
(0.00650)\end{array}$ \\
\hline Incentive $_{i, t-1} \times F$ Dir & & & $\begin{array}{c}0.00198 \\
(0.00807)\end{array}$ & & & \\
\hline Incentive $_{i, t-1} \times F_{-} 1$ & & & & & & $\begin{array}{l}-0.00515 \\
(0.00867)\end{array}$ \\
\hline Incentive $_{i, t-1} \times F \_2$ & & & & & & $\begin{array}{c}0.02368 \\
(0.01552)\end{array}$ \\
\hline Incentive $_{i, t-1} \times F \_3$ & & & & & & $\begin{array}{c}0.00168 \\
(0.02640)\end{array}$ \\
\hline$V I X \times$ Incentive $_{i, t-1}$ & & $\begin{array}{l}0.00074^{* * *} \\
(0.00025)\end{array}$ & $\begin{array}{l}0.00084^{* * *} \\
(0.00028)\end{array}$ & & $\begin{array}{l}0.00074^{* * *} \\
(0.00025)\end{array}$ & $\begin{array}{l}0.00085^{* * *} \\
(0.00028)\end{array}$ \\
\hline$V I X \times$ Incentive $_{i, t-1} \times F D i r$ & & & $\begin{array}{l}-0.00034 \\
(0.00031)\end{array}$ & & & \\
\hline$V I X \times$ Incentive $_{i, t-1} \times F_{\_} 1$ & & & & & & $\begin{array}{l}-0.00008 \\
(0.00034)\end{array}$ \\
\hline$V I X \times$ Incentive $_{i, t-1} \times F \_2$ & & & & & & $\begin{array}{l}-0.00118^{* *} \\
(0.00047)\end{array}$ \\
\hline$V I X \times$ Incentive $_{i, t-1} \times F \_3$ & & & & & & $\begin{array}{c}0.00056 \\
(0.00137)\end{array}$ \\
\hline Constant & $\begin{array}{l}0.10228^{* * *} \\
(0.02994) \\
\end{array}$ & $\begin{array}{l}0.10919^{* * *} \\
(0.03042)\end{array}$ & $\begin{array}{l}0.11094^{* * *} \\
(0.03042)\end{array}$ & $\begin{array}{l}0.10285^{* * *} \\
(0.02961)\end{array}$ & $\begin{array}{l}0.10979^{* * *} \\
(0.03009)\end{array}$ & $\begin{array}{l}0.11127^{* * *} \\
(0.03007) \\
\end{array}$ \\
\hline Observations & 5,074 & 5,074 & 5,074 & 5,074 & 5,074 & 5,074 \\
\hline Adjusted $R^{2}$ & 0.21 & 0.22 & 0.22 & 0.21 & 0.22 & 0.22 \\
\hline $\mathrm{F}(3,4,280)$ & & & & & & 2.25 \\
\hline Prob $>$ F & & & & & & 0.08 \\
\hline
\end{tabular}

In columns (1) and (4) of Table A.9, I report the results from estimating Equation (1.3.4); in columns (2) and (5), the results of Equations (1.3.7); and in columns (3) and (6), the results of Equation (1.3.9). The regressions reported in this table use only the data collected on unregulated firms (i.e. firms in industries with sic codes between 4400 - 5000 and 6000 - 6999). Each model has a set of controls for total risk (1), firm size (1), Tobin's Q (1), the return on assets ratio (1), board size (1), sales growth (1). The models are estimated with lagged discretionary accruals as an independent variable. All estimations are conducted using the CEO sample. In parentheses, I report standard errors two-way clustered by firm and time. Controls for time effects are included but not reported. Significance levels are indicated by $*, * *, * * *$ for $10 \%, 5 \%$, and $1 \%$ respectively. 
Table A.10: Robustness Check Results: CFO Sample - Unregulated Firms

\begin{tabular}{|c|c|c|c|c|c|c|}
\hline Variable & $\begin{array}{c}(1) \\
D A C C\end{array}$ & $\begin{array}{c}(2) \\
D A C C\end{array}$ & $\begin{array}{c}(3) \\
D A C C\end{array}$ & $\begin{array}{c}(4) \\
D A C C\end{array}$ & $\begin{array}{c}(5) \\
D A C C\end{array}$ & $\begin{array}{c}(\mathbf{6}) \\
D A C C\end{array}$ \\
\hline FDir & $\begin{array}{l}-0.00084 \\
(0.00175)\end{array}$ & $\begin{array}{l}-0.00086 \\
(0.00175)\end{array}$ & $\begin{array}{c}0.00009 \\
(0.00236)\end{array}$ & & & \\
\hline$F \_1$ & & & & $\begin{array}{l}-0.00013 \\
(0.00178)\end{array}$ & $\begin{array}{l}-0.00016 \\
(0.00179)\end{array}$ & $\begin{array}{c}0.00063 \\
(0.00241)\end{array}$ \\
\hline$F \_2$ & & & & $\begin{array}{l}-0.00750^{* * *} \\
(0.00290)\end{array}$ & $\begin{array}{l}-0.00740^{* * *} \\
(0.00288)\end{array}$ & $\begin{array}{l}-0.00585 \\
(0.00411)\end{array}$ \\
\hline$F \_3$ & & & & $\begin{array}{l}-0.00395 \\
(0.00602)\end{array}$ & $\begin{array}{l}-0.00390 \\
(0.00600)\end{array}$ & $\begin{array}{l}-0.00365 \\
(0.00708)\end{array}$ \\
\hline$V I X$ & $\begin{array}{c}-0.00017^{*} \\
(0.00010)\end{array}$ & $\begin{array}{l}-0.00025^{*} \\
(0.00013)\end{array}$ & $\begin{array}{l}-0.00024^{*} \\
(0.00013)\end{array}$ & $\begin{array}{l}-0.00017^{*} \\
(0.00010)\end{array}$ & $\begin{array}{c}-0.00024^{*} \\
(0.00013)\end{array}$ & $\begin{array}{r}-0.00022^{*} \\
(0.00013)\end{array}$ \\
\hline Incentive $_{i, t-1}$ & $\begin{array}{c}0.00650 \\
(0.00682)\end{array}$ & $\begin{array}{l}-0.00511 \\
(0.01370)\end{array}$ & $\begin{array}{c}0.00159 \\
(0.01647)\end{array}$ & $\begin{array}{c}0.00675 \\
(0.00679)\end{array}$ & $\begin{array}{l}-0.00344 \\
(0.01364)\end{array}$ & $\begin{array}{c}0.00448 \\
(0.01657)\end{array}$ \\
\hline Incentive $_{i, t-1} \times F$ Dir & & & $\begin{array}{l}-0.02052 \\
(0.01829)\end{array}$ & & & \\
\hline Incentive $_{i, t-1} \times F_{-} 1$ & & & & & & $\begin{array}{l}-0.02484 \\
(0.01891)\end{array}$ \\
\hline Incentive $_{i, t-1} \times F \_2$ & & & & & & $\begin{array}{l}-0.01050 \\
(0.03753)\end{array}$ \\
\hline Incentive $_{i, t-1} \times F \_3$ & & & & & & $\begin{array}{c}0.10852 \\
(0.14870)\end{array}$ \\
\hline$V I X \times$ Incentive $_{i, t-1}$ & & $\begin{array}{c}0.00054 \\
(0.00057)\end{array}$ & $\begin{array}{c}0.00036 \\
(0.00063)\end{array}$ & & $\begin{array}{c}0.00047 \\
(0.00057)\end{array}$ & $\begin{array}{c}0.00023 \\
(0.00064)\end{array}$ \\
\hline$V I X \times$ Incentive $_{i, t-1} \times F$ Dir & & & $\begin{array}{c}0.00059 \\
(0.00075)\end{array}$ & & & \\
\hline$V I X \times$ Incentive $_{i, t-1} \times F_{-} 1$ & & & & & & $\begin{array}{c}0.00085 \\
(0.00079)\end{array}$ \\
\hline$V I X \times$ Incentive $_{i, t-1} \times F_{\_} 2$ & & & & & & $\begin{array}{c}0.00002 \\
(0.00138)\end{array}$ \\
\hline$V I X \times$ Incentive $_{i, t-1} \times F \_3$ & & & & & & $\begin{array}{l}-0.00479 \\
(0.00810)\end{array}$ \\
\hline Constant & $\begin{array}{c}0.06741 \\
(0.04658) \\
\end{array}$ & $\begin{array}{c}0.06466 \\
(0.04600) \\
\end{array}$ & $\begin{array}{c}0.06469 \\
(0.04600) \\
\end{array}$ & $\begin{array}{c}0.07243 \\
(0.04470) \\
\end{array}$ & $\begin{array}{c}0.06993 \\
(0.04422) \\
\end{array}$ & $\begin{array}{c}0.07029 \\
(0.04422) \\
\end{array}$ \\
\hline Observations & 2,649 & 2,649 & 2,649 & 2,649 & 2,649 & 2,649 \\
\hline Adjusted $R^{2}$ & 0.26 & 0.26 & 0.26 & 0.26 & 0.26 & 0.26 \\
\hline $\mathrm{F}(3,1,926)$ & & & & & & 0.51 \\
\hline Prob $>$ F & & & & & & 0.68 \\
\hline
\end{tabular}

In columns (1) and (4) of Table A.10, I report the results from estimating Equation (1.3.4); in columns (2) and (5), the results of Equations (1.3.7); and in columns (3) and (6), the results of Equation (1.3.9). The regressions reported in this table use only the data collected on unregulated firms (i.e. firms in industries with sic codes between 4400 - 5000 and 6000 - 6999). Each model has a set of controls for total risk (1), firm size (1), Tobin's Q (1), the return on assets ratio (1), board size (1), sales growth (1). The models are estimated with lagged discretionary accruals as an independent variable. All estimations are conducted using the CFO sample. In parentheses, I report standard errors two-way clustered by firm and time. Controls for time effects are included but not reported. Significance levels are indicated by $*, * *, * * *$ for $10 \%, 5 \%$, and $1 \%$ respectively. 
Table A.11: Robustness Check Results: CEO Sample - Winsorization

\begin{tabular}{|c|c|c|c|c|c|c|}
\hline Variable & $\begin{array}{c}(1) \\
D A C C\end{array}$ & $\begin{array}{c}(2) \\
D A C C\end{array}$ & $\begin{array}{c}(3) \\
D A C C\end{array}$ & $\begin{array}{c}(4) \\
D A C C\end{array}$ & $\begin{array}{c}(5) \\
D A C C\end{array}$ & $\begin{array}{c}(6) \\
D A C C\end{array}$ \\
\hline FDir & $\begin{array}{l}-0.0008 \\
(0.0009)\end{array}$ & $\begin{array}{l}-0.0008 \\
(0.0009)\end{array}$ & $\begin{array}{l}-0.0004 \\
(0.0013)\end{array}$ & & & \\
\hline$F \_1$ & & & & $\begin{array}{l}-0.0003 \\
(0.0010)\end{array}$ & $\begin{array}{l}-0.0003 \\
(0.0010)\end{array}$ & $\begin{array}{c}0.0002 \\
(0.0014)\end{array}$ \\
\hline$F \_2$ & & & & $\begin{array}{c}-0.0035^{* *} \\
(0.0016)\end{array}$ & $\begin{array}{c}-0.0035^{* *} \\
(0.0016)\end{array}$ & $\begin{array}{l}-0.0027 \\
(0.0024)\end{array}$ \\
\hline$F \_3$ & & & & $\begin{array}{l}-0.0040 \\
(0.0031)\end{array}$ & $\begin{array}{l}-0.0040 \\
(0.0031)\end{array}$ & $\begin{array}{r}-0.0081^{* *} \\
(0.0040)\end{array}$ \\
\hline$V I X$ & $\begin{array}{l}-0.0001 \\
(0.0001)\end{array}$ & $\begin{array}{c}-0.0002^{*} \\
(0.0001)\end{array}$ & $\begin{array}{c}-0.0002^{*} \\
(0.0001)\end{array}$ & $\begin{array}{l}-0.0001 \\
(0.0001)\end{array}$ & $\begin{array}{l}-0.0002^{*} \\
(0.0001)\end{array}$ & $\begin{array}{l}-0.0002^{*} \\
(0.0001)\end{array}$ \\
\hline Incentive $_{i, t-1}$ & $\begin{array}{c}0.0030 \\
(0.0023)\end{array}$ & $\begin{array}{l}-0.0067 \\
(0.0049)\end{array}$ & $\begin{array}{l}-0.0077 \\
(0.0054)\end{array}$ & $\begin{array}{c}0.0029 \\
(0.0023)\end{array}$ & $\begin{array}{l}-0.0067 \\
(0.0054)\end{array}$ & $\begin{array}{l}-0.0100 \\
(0.0049)\end{array}$ \\
\hline Incentive $_{i, t-1} \times F$ Dir & & & $\begin{array}{l}0.0029 \\
(0.0065)\end{array}$ & & & \\
\hline Incentive $_{i, t-1} \times F \_1$ & & & & & & $\begin{array}{l}-0.0018 \\
(0.0068)\end{array}$ \\
\hline Incentive $_{i, t-1} \times F_{-} 2$ & & & & & & $\begin{array}{c}0.0162 \\
(0.0148)\end{array}$ \\
\hline Incentive $_{i, t-1} \times F \_3$ & & & & & & $\begin{array}{c}0.0015 \\
(0.0256)\end{array}$ \\
\hline$V I X \times$ Incentive $_{i, t-1}$ & & $\begin{array}{c}0.0005^{* *} \\
(0.0002)\end{array}$ & $\begin{array}{c}0.0005^{* *} \\
(0.0002)\end{array}$ & & $\begin{array}{c}0.0005^{* *} \\
(0.0002)\end{array}$ & $\begin{array}{r}0.0005^{* *} \\
(0.0002)\end{array}$ \\
\hline$V I X \times$ Incentive $_{i, t-1} \times F D i r$ & & & $\begin{array}{l}-0.0002 \\
(0.0003)\end{array}$ & & & \\
\hline$V I X \times$ Incentive $_{i, t-1} \times F_{-1}$ & & & & & & $\begin{array}{l}-0.0001 \\
(0.0003)\end{array}$ \\
\hline$V I X \times$ Incentive $_{i, t-1} \times F_{-} 2$ & & & & & & $\begin{array}{l}-0.0009^{*} \\
(0.0005)\end{array}$ \\
\hline$V I X \times$ Incentive $_{i, t-1} \times F \_3$ & & & & & & $\begin{array}{c}0.0006 \\
(0.0014)\end{array}$ \\
\hline Constant & $\begin{array}{l}-0.0145 \\
(0.1434)\end{array}$ & $\begin{array}{l}-0.0052 \\
(0.1430)\end{array}$ & $\begin{array}{l}-0.0034 \\
(0.1431)\end{array}$ & $\begin{array}{l}-0.0141 \\
(0.1428)\end{array}$ & $\begin{array}{l}-0.0047 \\
(0.1424)\end{array}$ & $\begin{array}{l}-0.0040 \\
(0.1434)\end{array}$ \\
\hline Observations & 5,832 & 5,832 & 5,832 & 5,832 & 5,832 & 5,832 \\
\hline Adjusted $R^{2}$ & 0.24 & 0.24 & 0.24 & 0.24 & 0.25 & 0.25 \\
\hline $\mathrm{F}(3,4,932)$ & & & & & & 1.29 \\
\hline Prob $>F$ & & & & & & 0.28 \\
\hline
\end{tabular}

In columns (1) and (4) of Table A.11, I report the results from estimating Equation (1.3.4); in columns (2) and (5), the results of Equations (1.3.7); and in columns (3) and (6), the results of Equation (1.3.9). The regressions reported in this table use data which has been Winsorized. Each model has a set of controls for total risk (1), firm size (1), Tobin's Q (1), the return on assets ratio (1), board size (1), sales growth (1). The models are estimated with lagged discretionary accruals as an independent variable. All estimations are conducted using the CEO sample. In parentheses, I report standard errors two-way clustered by firm and time. Controls for time effects are included but not reported. Significance levels are indicated by $*, * *$, $* * *$ for $10 \%, 5 \%$, and $1 \%$ respectively. 
Table A.12: Robustness Check Results: CFO Sample - Winsorization

\begin{tabular}{|c|c|c|c|c|c|c|}
\hline Variable & $\begin{array}{c}(1) \\
D A C C\end{array}$ & $\begin{array}{c}(\mathbf{2}) \\
D A C C\end{array}$ & $\begin{array}{c}(3) \\
D A C C\end{array}$ & $\begin{array}{c}(4) \\
D A C C\end{array}$ & $\begin{array}{c}(5) \\
D A C C\end{array}$ & $\begin{array}{c}(\mathbf{6}) \\
D A C C\end{array}$ \\
\hline FDir & $\begin{array}{l}-0.0001 \\
(0.0015)\end{array}$ & $\begin{array}{l}-0.0001 \\
(0.0015)\end{array}$ & $\begin{array}{c}0.0003 \\
(0.0020)\end{array}$ & & & \\
\hline$F \_1$ & & & & $\begin{array}{c}0.0004 \\
(0.0015)\end{array}$ & $\begin{array}{c}0.0004 \\
(0.0015)\end{array}$ & $\begin{array}{c}0.0008 \\
(0.0020)\end{array}$ \\
\hline$F \_2$ & & & & $\begin{array}{c}-0.0052^{* *} \\
(0.0026)\end{array}$ & $\begin{array}{c}-0.0051^{* *} \\
(0.0026)\end{array}$ & $\begin{array}{l}-0.0043 \\
(0.0036)\end{array}$ \\
\hline$F \_3$ & & & & $\begin{array}{l}-0.0014 \\
(0.0054)\end{array}$ & $\begin{array}{l}-0.0014 \\
(0.0054)\end{array}$ & $\begin{array}{l}-0.0007 \\
(0.0063)\end{array}$ \\
\hline$V I X$ & $\begin{array}{l}-0.0001 \\
(0.0001)\end{array}$ & $\begin{array}{c}-0.0002^{*} \\
(0.0001)\end{array}$ & $\begin{array}{c}-0.0002^{*} \\
(0.0001)\end{array}$ & $\begin{array}{l}-0.0001 \\
(0.0001)\end{array}$ & $\begin{array}{l}-0.0002^{*} \\
(0.0001)\end{array}$ & $\begin{array}{l}-0.0002 \\
(0.0001)\end{array}$ \\
\hline Incentive $_{i, t-1}$ & $\begin{array}{c}0.0042 \\
(0.0060)\end{array}$ & $\begin{array}{l}-0.0057 \\
(0.0117)\end{array}$ & $\begin{array}{l}-0.0006 \\
(0.0128)\end{array}$ & $\begin{array}{c}0.0043 \\
(0.0056)\end{array}$ & $\begin{array}{l}-0.0049 \\
(0.0117)\end{array}$ & $\begin{array}{c}0.0014 \\
(0.0129)\end{array}$ \\
\hline Incentive $_{i, t-1} \times F D i r$ & & & $\begin{array}{l}-0.0201 \\
(0.0164)\end{array}$ & & & \\
\hline Incentive $_{i, t-1} \times F_{-} 1$ & & & & & & $\begin{array}{l}-0.0215 \\
(0.0169)\end{array}$ \\
\hline Incentive $_{i, t-1} \times F \_2$ & & & & & & $\begin{array}{l}-0.0251 \\
(0.0353)\end{array}$ \\
\hline Incentive $_{i, t-1} \times F \_3$ & & & & & & $\begin{array}{c}0.1012 \\
(0.1436)\end{array}$ \\
\hline$V I X \times$ Incentive $_{i, t-1}$ & & $\begin{array}{c}0.0005 \\
(0.0005)\end{array}$ & $\begin{array}{c}0.0003 \\
(0.0005)\end{array}$ & & $\begin{array}{c}0.0004 \\
(0.0005)\end{array}$ & $\begin{array}{c}0.0002 \\
(0.0005)\end{array}$ \\
\hline$V I X \times$ Incentive $_{i, t-1} \times F D i r$ & & & $\begin{array}{l}0.0007 \\
(0.0007)\end{array}$ & & & \\
\hline$V I X \times$ Incentive $_{i, t-1} \times F_{-1} 1$ & & & & & & $\begin{array}{c}0.0008 \\
(0.0007)\end{array}$ \\
\hline$V I X \times$ Incentive $_{i, t-1} \times F_{-2} 2$ & & & & & & $\begin{array}{c}0.0009 \\
(0.0014)\end{array}$ \\
\hline$V I X \times$ Incentive $_{i, t-1} \times F \_3$ & & & & & & $\begin{array}{l}-0.0049 \\
(0.0079)\end{array}$ \\
\hline Constant & $\begin{array}{l}-0.5809 \\
(0.4491)\end{array}$ & $\begin{array}{l}-0.5992 \\
(0.4421)\end{array}$ & $\begin{array}{l}-0.5802 \\
(0.4473)\end{array}$ & $\begin{array}{l}-0.5654 \\
(0.4488)\end{array}$ & $\begin{array}{l}-0.5826 \\
(0.4426)\end{array}$ & $\begin{array}{l}-0.5614 \\
(0.4491)\end{array}$ \\
\hline Observations & 3,046 & 3,046 & 3,046 & 3,046 & 3,046 & 3,046 \\
\hline Adjusted $R^{2}$ & 0.29 & 0.29 & 0.29 & 0.29 & 0.29 & 0.29 \\
\hline $\mathrm{F}(3,2,225)$ & & & & & & 0.65 \\
\hline Prob $>$ F & & & & & & 0.58 \\
\hline
\end{tabular}

In columns (1) and (4) of Table A.12, I report the results from estimating Equation (1.3.4); in columns (2) and (5), the results of Equations (1.3.7); and in columns (3) and (6), the results of Equation (1.3.9). The regressions reported in this table use data which has been Winsorized. Each model has a set of controls for total risk (1), firm size (1), Tobin's Q (1), the return on assets ratio (1), board size (1), sales growth (1). The models are estimated with lagged discretionary accruals as an independent variable. All estimations are conducted using the CFO sample. In parentheses, I report standard errors two-way clustered by firm and time. Controls for time effects are included but not reported. Significance levels are indicated by $*, * *$, $* * *$ for $10 \%, 5 \%$, and $1 \%$ respectively. 
Table A.13: Robustness Check Results:

CEO Sample - Alternative Estimation of Discretionary Accruals

\begin{tabular}{|c|c|c|c|c|c|c|}
\hline Variable & $\begin{array}{c}(1) \\
D A C C\end{array}$ & $\begin{array}{c}(2) \\
D A C C\end{array}$ & $\begin{array}{c}(3) \\
D A C C\end{array}$ & $\begin{array}{c}(4) \\
D A C C\end{array}$ & $\begin{array}{c}(5) \\
D A C C\end{array}$ & $\begin{array}{c}(6) \\
D A C C\end{array}$ \\
\hline FDir & $\begin{array}{l}-0.0014 \\
(0.0019)\end{array}$ & $\begin{array}{l}-0.0014 \\
(0.0019)\end{array}$ & $\begin{array}{l}-0.0014 \\
(0.0027)\end{array}$ & & & \\
\hline$F_{-} 1$ & & & & $\begin{array}{l}-0.0012 \\
(0.0019)\end{array}$ & $\begin{array}{l}-0.0012 \\
(0.0019)\end{array}$ & $\begin{array}{l}-0.0016 \\
(0.0029)\end{array}$ \\
\hline$F \_2$ & & & & $\begin{array}{l}-0.0031 \\
(0.0032)\end{array}$ & $\begin{array}{l}-0.0032 \\
(0.0032)\end{array}$ & $\begin{array}{l}-0.0022 \\
(0.0054)\end{array}$ \\
\hline$F \_3$ & & & & $\begin{array}{l}-0.0001 \\
(0.0091)\end{array}$ & $\begin{array}{l}-0.0004 \\
(0.0091)\end{array}$ & $\begin{array}{l}-0.0020 \\
(0.0157)\end{array}$ \\
\hline$V I X$ & $\begin{array}{l}-0.0001 \\
(0.0001)\end{array}$ & $\begin{array}{c}-0.0004^{* *} \\
(0.0002)\end{array}$ & $\begin{array}{c}-0.0004^{* *} \\
(0.0002)\end{array}$ & $\begin{array}{l}-0.0001 \\
(0.0001)\end{array}$ & $\begin{array}{c}-0.0004^{* *} \\
(0.0049)\end{array}$ & $\begin{array}{c}-0.0004^{* *} \\
(0.0002)\end{array}$ \\
\hline Incentive $_{i, t-1}$ & $\begin{array}{l}-0.0060 \\
(0.0050)\end{array}$ & $\begin{array}{c}-0.0330 * * * \\
(0.0107)\end{array}$ & $\begin{array}{c}-0.0388^{* * *} \\
(0.0112)\end{array}$ & $\begin{array}{l}-0.0060 \\
(0.0050)\end{array}$ & $\begin{array}{c}-0.0330^{* * *} \\
(0.0107)\end{array}$ & $\begin{array}{c}-0.0389 * * * \\
(0.0112)\end{array}$ \\
\hline Incentive $_{i, t-1} \times F D i r$ & & & $\begin{array}{c}0.0214 \\
(0.0158)\end{array}$ & & & \\
\hline Incentive $_{i, t-1} \times F_{-} 1$ & & & & & & $\begin{array}{c}0.0085 \\
(0.0173)\end{array}$ \\
\hline Incentive $_{i, t-1} \times F_{\_} 2$ & & & & & & $\begin{array}{c}0.0584 \\
(0.0580)\end{array}$ \\
\hline Incentive $_{i, t-1} \times F_{\_} 3$ & & & & & & $\begin{array}{c}0.1055^{* *} \\
(0.0528)\end{array}$ \\
\hline$V I X \times$ Incentive $_{i, t-1}$ & & $\begin{array}{c}0.0013^{* * *} \\
(0.0005)\end{array}$ & $\begin{array}{c}0.0015^{* * *} \\
(0.0005)\end{array}$ & & $\begin{array}{c}0.0013^{* * *} \\
(0.0005)\end{array}$ & $\begin{array}{c}0.0015^{* * *} \\
(0.0005)\end{array}$ \\
\hline$V I X \times$ Incentive $_{i, t-1} \times F D i r$ & & & $\begin{array}{r}-0.0010^{*} \\
(0.0004)\end{array}$ & & & \\
\hline$V I X \times$ Incentive $_{i, t-1} \times F_{\_} 1$ & & & & & & $\begin{array}{l}-0.0003 \\
(0.0006)\end{array}$ \\
\hline$V I X \times$ Incentive $_{i, t-1} \times F \_2$ & & & & & & $\begin{array}{r}-0.0029^{*} \\
(0.0006)\end{array}$ \\
\hline$V I X \times$ Incentive $_{i, t-1} \times F \_3$ & & & & & & $\begin{array}{c}-0.0046^{* * *} \\
(0.0015)\end{array}$ \\
\hline Constant & $\begin{array}{c}0.0751 \\
(0.0580)\end{array}$ & $\begin{array}{c}0.0866 \\
(0.0588)\end{array}$ & $\begin{array}{c}0.0891 \\
(0.0591)\end{array}$ & $\begin{array}{c}0.0751 \\
(0.0581)\end{array}$ & $\begin{array}{c}0.0866 \\
(0.0589)\end{array}$ & $\begin{array}{c}0.0909 \\
(0.0593)\end{array}$ \\
\hline Observations & 6,293 & 6,293 & 6,293 & 6,293 & 6,293 & 6,293 \\
\hline Adjusted $R^{2}$ & 0.30 & 0.30 & 0.30 & 0.30 & 0.30 & 0.30 \\
\hline $\mathrm{F}(3,5,406)$ & & & & & & 3.52 \\
\hline Prob $>$ F & & & & & & 0.01 \\
\hline
\end{tabular}

In columns (1) and (4) of Table A.13, I report the results from estimating Equation (1.3.4); in columns (2) and (5), the results of Equations (1.3.7); and in columns (3) and (6), the results of Equation (1.3.9). The regressions reported in this table use discretionary accruals which have been calculated using data from a firm's statement of cash flows as opposed to data from a firm's balance sheet. Each model has a set of controls for total risk (1), firm size (1), Tobin's Q (1), the return on assets ratio (1), board size (1), sales growth (1). The models are estimated with lagged discretionary accruals as an independent variable. All estimations are conducted using the CEO sample. In parentheses, I report standard errors two-way clustered by firm and time. Controls for time effects are included but not reported. Significance levels are indicated by $*, * *, * * *$ for $10 \%, 5 \%$, and $1 \%$ respectively. 
Table A.14: Robustness Check Results:

CFO Sample - Alternative Estimation of Discretionary Accruals

\begin{tabular}{|c|c|c|c|c|c|c|}
\hline Variable & $\begin{array}{c}(1) \\
D A C C\end{array}$ & $\begin{array}{c}(2) \\
D A C C\end{array}$ & $\begin{array}{c}(3) \\
D A C C\end{array}$ & $\begin{array}{c}(4) \\
D A C C\end{array}$ & $\begin{array}{c}(5) \\
D A C C\end{array}$ & $\begin{array}{c}(6) \\
D A C C\end{array}$ \\
\hline FDir & $\begin{array}{l}-0.00018 \\
(0.00323)\end{array}$ & $\begin{array}{l}-0.00018 \\
(0.00323)\end{array}$ & $\begin{array}{c}0.00294 \\
(0.00423)\end{array}$ & & & \\
\hline$F \_1$ & & & & $\begin{array}{c}0.00041 \\
(0.00328)\end{array}$ & $\begin{array}{c}0.00041 \\
(0.00328)\end{array}$ & $\begin{array}{c}0.00196 \\
(0.00441)\end{array}$ \\
\hline$F \_2$ & & & & $\begin{array}{l}-0.00431 \\
(0.00438)\end{array}$ & $\begin{array}{l}-0.00431 \\
(0.00439)\end{array}$ & $\begin{array}{c}0.00643 \\
(0.00553)\end{array}$ \\
\hline$F \_3$ & & & & $\begin{array}{l}-0.00985 \\
(0.00941)\end{array}$ & $\begin{array}{l}-0.00985 \\
(0.00942)\end{array}$ & $\begin{array}{l}-0.00472 \\
(0.01397)\end{array}$ \\
\hline$V I X$ & $\begin{array}{c}0.00002 \\
(0.00016)\end{array}$ & $\begin{array}{c}0.00001 \\
(0.00021)\end{array}$ & $\begin{array}{c}0.00001 \\
(0.00022)\end{array}$ & $\begin{array}{c}0.00002 \\
(0.00016)\end{array}$ & $\begin{array}{c}0.00001 \\
(0.00021)\end{array}$ & $\begin{array}{c}0.00002 \\
(0.00022)\end{array}$ \\
\hline Incentive $_{i, t-1}$ & $\begin{array}{c}0.00374 \\
(0.01339)\end{array}$ & $\begin{array}{c}0.00244 \\
(0.02361)\end{array}$ & $\begin{array}{c}0.01297 \\
(0.02655)\end{array}$ & $\begin{array}{c}0.00370 \\
(0.01338)\end{array}$ & $\begin{array}{c}0.00303 \\
(0.02364)\end{array}$ & $\begin{array}{c}0.01548 \\
(0.02657)\end{array}$ \\
\hline Incentive $_{i, t-1} \times F$ Dir & & & $\begin{array}{l}-0.02433 \\
(0.03534)\end{array}$ & & & \\
\hline Incentive $_{i, t-1} \times F_{-} 1$ & & & & & & $\begin{array}{l}-0.02397 \\
(0.03914)\end{array}$ \\
\hline Incentive $_{i, t-1} \times F \_2$ & & & & & & $\begin{array}{l}-0.07782 \\
(0.05603)\end{array}$ \\
\hline Incentive $_{i, t-1} \times F \_3$ & & & & & & $\begin{array}{c}0.20735 \\
(0.14426)\end{array}$ \\
\hline$V I X \times$ Incentive $_{i, t-1}$ & & $\begin{array}{c}0.00006 \\
(0.00102)\end{array}$ & $\begin{array}{l}-0.00017 \\
(0.00103)\end{array}$ & & $\begin{array}{c}0.00003 \\
(0.00102)\end{array}$ & $\begin{array}{l}-0.00009 \\
(0.00103)\end{array}$ \\
\hline$V I X \times$ Incentive $_{i, t-1} \times F$ Dir & & & $\begin{array}{l}-0.00006 \\
(0.00157)\end{array}$ & & & \\
\hline$V I X \times$ Incentive $_{i, t-1} \times F_{-1}$ & & & & & & $\begin{array}{c}0.00046 \\
(0.00183)\end{array}$ \\
\hline$V I X \times$ Incentive $_{i, t-1} \times F \_2$ & & & & & & $\begin{array}{l}-0.00067 \\
(0.00203)\end{array}$ \\
\hline$V I X \times$ Incentive $_{i, t-1} \times F \_3$ & & & & & & $\begin{array}{r}-0.01016^{*} \\
(0.00611)\end{array}$ \\
\hline Constant & $\begin{array}{l}-0.24664 \\
(0.30952)\end{array}$ & $\begin{array}{l}-0.24675 \\
(0.30962)\end{array}$ & $\begin{array}{l}-0.24784 \\
(0.30886)\end{array}$ & $\begin{array}{l}-0.24241 \\
(0.31265) \\
\end{array}$ & $\begin{array}{l}-0.24248 \\
(0.31274) \\
\end{array}$ & $\begin{array}{l}-0.23919 \\
(0.31331) \\
\end{array}$ \\
\hline Observations & 3,344 & 3,344 & 3,344 & 3,344 & 3,344 & 3,344 \\
\hline Adjusted $R^{2}$ & 0.36 & 0.36 & 0.36 & 0.36 & 0.36 & 0.36 \\
\hline $\mathrm{F}(3,2,547)$ & & & & & & 0.99 \\
\hline Prob $>$ F & & & & & & 0.40 \\
\hline
\end{tabular}

In columns (1) and (4) of Table A.14, I report the results from estimating Equation (1.3.4); in columns (2) and (5), the results of Equations (1.3.7); and in columns (3) and (6), the results of Equation (1.3.9). The regressions reported in this table use discretionary accruals which have been calculated using data from a firm's statement of cash flows as opposed to data from a firm's balance sheet. Each model has a set of controls for total risk (1), firm size (1), Tobin's Q (1), the return on assets ratio (1), board size (1), sales growth (1). The models are estimated with lagged discretionary accruals as an independent variable. All estimations are conducted using the CFO sample. In parentheses, I report standard errors two-way clustered by firm and time. Controls for time effects are included but not reported. Significance levels are indicated by $*, * *, * * *$ for $10 \%, 5 \%$, and $1 \%$ respectively. 
Table A.15: Robustness Check Results:

CEO Sample - Positive and Negative Discretionary Accruals

\begin{tabular}{|c|c|c|c|c|c|c|}
\hline Variable & $\begin{array}{c}(\mathbf{1}) \\
D A C C\end{array}$ & $\begin{array}{c}(2) \\
D A C C\end{array}$ & $\begin{array}{c}(3) \\
D A C C\end{array}$ & $\begin{array}{c}(4) \\
D A C C\end{array}$ & $\begin{array}{c}(5) \\
D A C C\end{array}$ & $\begin{array}{c}(6) \\
D A C C\end{array}$ \\
\hline FDir & $\begin{array}{l}-0.00101 \\
(0.00104)\end{array}$ & $\begin{array}{l}-0.00100 \\
(0.00104)\end{array}$ & $\begin{array}{l}-0.00069 \\
(0.00149)\end{array}$ & & & \\
\hline$F_{-1}$ & & & & $\begin{array}{l}-0.00086 \\
(0.00105)\end{array}$ & $\begin{array}{l}-0.00085 \\
(0.00105)\end{array}$ & $\begin{array}{c}0.00004 \\
(0.00155)\end{array}$ \\
\hline$F \_2$ & & & & $\begin{array}{l}-0.00201 \\
(0.00178)\end{array}$ & $\begin{array}{l}-0.00200 \\
(0.00178)\end{array}$ & $\begin{array}{l}-0.00346 \\
(0.00254)\end{array}$ \\
\hline$F \_3$ & & & & $\begin{array}{l}-0.00215 \\
(0.00374)\end{array}$ & $\begin{array}{l}-0.00215 \\
(0.00374)\end{array}$ & $\begin{array}{l}-0.00653 \\
(0.00499)\end{array}$ \\
\hline$V I X$ & $\begin{array}{l}-0.00006 \\
(0.00008)\end{array}$ & $\begin{array}{l}-0.00019^{*} \\
(0.00010)\end{array}$ & $\begin{array}{l}-0.00019^{*} \\
(0.00010)\end{array}$ & $\begin{array}{l}-0.00006 \\
(0.00008)\end{array}$ & $\begin{array}{l}-0.00019^{*} \\
(0.00010)\end{array}$ & $\begin{array}{r}-0.00019^{*} \\
(0.00010)\end{array}$ \\
\hline Incentive $_{i, t-1}$ & $\begin{array}{c}0.00208 \\
(0.00255)\end{array}$ & $\begin{array}{l}-0.00740 \\
(0.00529)\end{array}$ & $\begin{array}{l}-0.00523 \\
(0.00593)\end{array}$ & $\begin{array}{c}0.00207 \\
(0.00255)\end{array}$ & $\begin{array}{l}-0.00740 \\
(0.00529)\end{array}$ & $\begin{array}{l}-0.00564 \\
(0.00593)\end{array}$ \\
\hline Incentive $_{i, t-1} \times F$ Dir & & & $\begin{array}{l}-0.00656 \\
(0.00737)\end{array}$ & & & \\
\hline Incentive $_{i, t-1} \times F_{-} 1$ & & & & & & $\begin{array}{l}-0.01001 \\
(0.00806)\end{array}$ \\
\hline Incentive $_{i, t-1} \times F \_2$ & & & & & & $\begin{array}{c}0.01208 \\
(0.01273)\end{array}$ \\
\hline Incentive $_{i, t-1} \times F \_3$ & & & & & & $\begin{array}{l}-0.03714 \\
(0.02929)\end{array}$ \\
\hline$V I X \times$ Incentive $_{i, t-1}$ & & $\begin{array}{l}0.00045^{*} \\
(0.00023)\end{array}$ & $\begin{array}{c}0.00036 \\
(0.00025)\end{array}$ & & $\begin{array}{l}0.00045^{*} \\
(0.00023)\end{array}$ & $\begin{array}{c}0.00037 \\
(0.00025)\end{array}$ \\
\hline$V I X \times$ Incentive $_{i, t-1} \times F D i r$ & & & $\begin{array}{c}0.00026 \\
(0.00018)\end{array}$ & & & \\
\hline$V I X \times$ Incentive $_{i, t-1} \times F_{-1}$ & & & & & & $\begin{array}{c}0.00032 \\
(0.00031)\end{array}$ \\
\hline$V I X \times$ Incentive $_{i, t-1} \times F_{-} 2$ & & & & & & $\begin{array}{l}-0.00029 \\
(0.00043)\end{array}$ \\
\hline$V I X \times$ Incentive $_{i, t-1} \times F \_3$ & & & & & & $\begin{array}{l}0.00265^{*} \\
(0.00145)\end{array}$ \\
\hline Constant & $\begin{array}{c}0.05675 \\
(0.04423)\end{array}$ & $\begin{array}{c}0.06024 \\
(0.04441)\end{array}$ & $\begin{array}{c}0.05978 \\
(0.04441)\end{array}$ & $\begin{array}{c}0.05668 \\
(0.04424)\end{array}$ & $\begin{array}{c}0.06017 \\
(0.04442)\end{array}$ & $\begin{array}{c}0.06077 \\
(0.04446)\end{array}$ \\
\hline Observations & 11,614 & 11,614 & 11,614 & 11,614 & 11,614 & 11,614 \\
\hline Adjusted $R^{2}$ & 0.11 & 0.11 & 0.11 & 0.11 & 0.11 & 0.11 \\
\hline $\mathrm{F}(3,10,650)$ & & & & & & 1.70 \\
\hline Prob $>$ F & & & & & & 0.16 \\
\hline
\end{tabular}

In columns (1) and (4) of Table A.15, I report the results from estimating Equation (1.3.4); in columns (2) and (5), the results of Equations (1.3.7); and in columns (3) and (6), the results of Equation (1.3.9). The dependent variable in the regressions reported in this table consists of both positive and negative discretionary accruals. Each model has a set of controls for total risk (1), firm size (1), Tobin's Q (1), the return on assets ratio (1), board size (1), sales growth (1). The models are estimated with lagged discretionary accruals as an independent variable. All estimations are conducted using the CEO sample. In parentheses, I report standard errors two-way clustered by firm and time. Controls for time effects are included but not reported. Significance levels are indicated by $*, * *, * * *$ for $10 \%, 5 \%$, and $1 \%$ respectively. 
Table A.16: Robustness Check Results:

CFO Sample - Positive and Negative Discretionary Accruals

\begin{tabular}{|c|c|c|c|c|c|c|}
\hline Variable & $\begin{array}{c}(1) \\
D A C C\end{array}$ & $\begin{array}{c}(2) \\
D A C C\end{array}$ & $\begin{array}{c}(3) \\
D A C C\end{array}$ & $\begin{array}{c}(4) \\
D A C C\end{array}$ & $\begin{array}{c}(5) \\
D A C C\end{array}$ & $\begin{array}{c}(6) \\
D A C C\end{array}$ \\
\hline FDir & $\begin{array}{c}0.0006 \\
(0.0017)\end{array}$ & $\begin{array}{c}0.0006 \\
(0.0017)\end{array}$ & $\begin{array}{l}-0.0009 \\
(0.0021)\end{array}$ & & & \\
\hline$F \_1$ & & & & $\begin{array}{c}0.0008 \\
(0.0017)\end{array}$ & $\begin{array}{l}0.0008 \\
(0.0017)\end{array}$ & $\begin{array}{l}-0.0005 \\
(0.0022)\end{array}$ \\
\hline$F \_2$ & & & & $\begin{array}{l}-0.0022 \\
(0.0028)\end{array}$ & $\begin{array}{l}-0.0023 \\
(0.0029)\end{array}$ & $\begin{array}{l}-0.0038 \\
(0.0041)\end{array}$ \\
\hline$F \_3$ & & & & $\begin{array}{c}0.0019 \\
(0.0052)\end{array}$ & $\begin{array}{c}0.0019 \\
(0.0052)\end{array}$ & $\begin{array}{l}-0.0012 \\
(0.0069)\end{array}$ \\
\hline$V I X$ & $\begin{array}{l}-0.0001 \\
(0.0001)\end{array}$ & $\begin{array}{l}-0.0001 \\
(0.0001)\end{array}$ & $\begin{array}{l}-0.0001 \\
(0.0001)\end{array}$ & $\begin{array}{l}-0.0001 \\
(0.0001)\end{array}$ & $\begin{array}{l}-0.0001 \\
(0.0001)\end{array}$ & $\begin{array}{l}-0.0001 \\
(0.0001)\end{array}$ \\
\hline Incentive $_{i, t-1}$ & $\begin{array}{l}-0.0025 \\
(0.0059)\end{array}$ & $\begin{array}{l}-0.0005 \\
(0.0121)\end{array}$ & $\begin{array}{l}-0.0005 \\
(0.0134)\end{array}$ & $\begin{array}{l}-0.0026 \\
(0.0059)\end{array}$ & $\begin{array}{l}-0.0002 \\
(0.0121)\end{array}$ & $\begin{array}{l}-0.0004 \\
(0.0134)\end{array}$ \\
\hline Incentive $_{i, t-1} \times F$ Dir & & & $\begin{array}{l}-0.0070 \\
(0.0165)\end{array}$ & & & \\
\hline Incentive $_{i, t-1} \times F_{-} 1$ & & & & & & $\begin{array}{l}-0.0026 \\
(0.0175)\end{array}$ \\
\hline Incentive $_{i, t-1} \times F_{-} 2$ & & & & & & $\begin{array}{l}-0.0268 \\
(0.0346)\end{array}$ \\
\hline Incentive $_{i, t-1} \times F_{\_} 3$ & & & & & & $\begin{array}{l}-0.0039 \\
(0.0807)\end{array}$ \\
\hline$V I X \times$ Incentive $_{i, t-1}$ & & $\begin{array}{l}-0.0001 \\
(0.0005)\end{array}$ & $\begin{array}{l}-0.0003 \\
(0.0005)\end{array}$ & & $\begin{array}{l}-0.0001 \\
(0.0005)\end{array}$ & $\begin{array}{l}-0.0003 \\
(0.0005)\end{array}$ \\
\hline$V I X \times$ Incentive $_{i, t-1} \times F$ Dir & & & $\begin{array}{c}0.0009 \\
(0.0007)\end{array}$ & & & \\
\hline$V I X \times$ Incentive $_{i, t-1} \times F_{-1}$ & & & & & & $\begin{array}{c}0.0006 \\
(0.0007)\end{array}$ \\
\hline$V I X \times$ Incentive $_{i, t-1} \times F \_2$ & & & & & & $\begin{array}{c}0.0017 \\
(0.0013)\end{array}$ \\
\hline$V I X \times$ Incentive $_{i, t-1} \times F \_3$ & & & & & & $\begin{array}{c}0.0015 \\
(0.0028)\end{array}$ \\
\hline Constant & $\begin{array}{c}0.0533 \\
(0.0662) \\
\end{array}$ & $\begin{array}{c}0.0535 \\
(0.0663) \\
\end{array}$ & $\begin{array}{c}0.0573 \\
(0.0665) \\
\end{array}$ & $\begin{array}{c}0.0533 \\
(0.0662) \\
\end{array}$ & $\begin{array}{c}0.0537 \\
(0.0663) \\
\end{array}$ & $\begin{array}{c}0.0574 \\
(0.0666) \\
\end{array}$ \\
\hline Observations & 6,203 & 6,203 & 6,203 & 6,203 & 6,203 & 6,203 \\
\hline Adjusted $R^{2}$ & 0.16 & 0.16 & 0.16 & 0.16 & 0.16 & 0.16 \\
\hline $\mathrm{F}(3,5,266)$ & & & & & & 0.83 \\
\hline Prob $>$ F & & & & & & 0.48 \\
\hline
\end{tabular}

In columns (1) and (4) of Table A.16, I report the results from estimating Equation (1.3.4); in columns (2) and (5), the results of Equations (1.3.7); and in columns (3) and (6), the results of Equation (1.3.9). The dependent variable in the regressions reported in this table consists of both positive and negative discretionary accruals. Each model has a set of controls for total risk (1), firm size (1), Tobin's Q (1), the return on assets ratio (1), board size (1), sales growth (1). The models are estimated with lagged discretionary accruals as an independent variable. All estimations are conducted using the CFO sample. In parentheses, I report standard errors two-way clustered by firm and time. Controls for time effects are included but not reported. Significance levels are indicated by $*, * *, * * *$ for $10 \%, 5 \%$, and $1 \%$ respectively. 
Appendix B

Appendix for Chapter 2 
Table B.1: Summary of Key Findings of Existing Literature

\begin{tabular}{|c|c|c|c|}
\hline Author (Date) & Methodology & $\overline{\text { Data }}$ & Conclusion \\
\hline Gunderson (1979) & $\begin{array}{l}\text { OLS estimations of } \\
\text { earnings equations for } \\
\text { public and private } \\
\text { sectors; and } \\
\text { Blinder-Oaxaca } \\
\text { decomposition analysis. } \\
\text { Public and private sectors } \\
\text { are proxied by limiting } \\
\text { the sample to workers in } \\
\text { public administration and } \\
\text { manufacturing, } \\
\text { respectively. }\end{array}$ & $\begin{array}{l}1971 \text { Canadian Census } \\
\text { (Public Use Sample Tape) }\end{array}$ & $\begin{array}{l}\text { Total differential of } 9.3 \% \\
\text { and } 22.3 \% \text { for men and } \\
\text { women, respectively. } \\
\text { Economic rents of } 6.2 \% \\
\text { and } 8.6 \% \text { for men and } \\
\text { women, respectively. }\end{array}$ \\
\hline $\begin{array}{l}\text { Shapiro and } \\
\text { Stelcner (1989) }\end{array}$ & $\begin{array}{l}\text { OLS estimations of } \\
\text { earnings equations for } \\
\text { public and private } \\
\text { sectors; and } \\
\text { Blinder-Oaxaca } \\
\text { decomposition analysis. } \\
\text { Public and private sectors } \\
\text { are proxied by limiting } \\
\text { the sample to workers in } \\
\text { public administration and } \\
\text { manufacturing, } \\
\text { respectively. }\end{array}$ & $\begin{array}{l}1981 \text { Canadian Census } \\
\text { (Public Use Sample Tape) }\end{array}$ & $\begin{array}{l}\text { Total differential of } 19.1 \% \\
\text { and } 27.2 \% \text { for men and } \\
\text { women, respectively. } \\
\text { Economic rents of } 4.2 \% \\
\text { and } 12.2 \% \text { for men and } \\
\text { women, respectively. }\end{array}$ \\
\hline \multirow[t]{2}{*}{$\begin{array}{l}\text { Prescott and } \\
\text { Wandschneider } \\
(1999)\end{array}$} & \multirow[t]{2}{*}{$\begin{array}{l}\text { First stage involves } \\
\text { estimation of a bivariate } \\
\text { probit model to capture } \\
\text { the choice of sector of } \\
\text { employment and choice } \\
\text { between full time and } \\
\text { part time work. Wage } \\
\text { equations are estimated } \\
\text { in the second stage to } \\
\text { obtain selectivity } \\
\text { adjusted estimates using } \\
\text { Blinder-Oaxaca } \\
\text { decomposition analysis. }\end{array}$} & $\begin{array}{l}1982 \text { Survey of Consumer } \\
\text { Finances }\end{array}$ & $\begin{array}{l}\text { Total differential of } 19.8 \% \\
\text { and } 27.3 \% \text { for men and } \\
\text { women, respectively. } \\
\text { Economic rents of } 15.1 \% \\
\text { and } 15.7 \% \text { for men and } \\
\text { women, respectively. }\end{array}$ \\
\hline & & $\begin{array}{l}1991 \text { Survey of Consumer } \\
\text { Finances }\end{array}$ & $\begin{array}{l}\text { Total differential of } 25.0 \% \\
\text { and } 42.9 \% \text { for men and } \\
\text { women, respectively. } \\
\text { Economic rents of } 14.3 \% \\
\text { and } 25.0 \% \text { for men and } \\
\text { women, respectively. }\end{array}$ \\
\hline
\end{tabular}


Table B.1: Summary of Key Findings of Existing Literature, Cont.

\begin{tabular}{|c|c|c|c|}
\hline Author (Date) & Methodology & Data & Conclusion \\
\hline Mueller (2000) & $\begin{array}{l}\text { OLS estimations of } \\
\text { earnings equations for } \\
\text { public and private } \\
\text { sectors; and } \\
\text { Blinder-Oaxaca } \\
\text { decomposition analysis. } \\
\text { In these first estimations, } \\
\text { union status is treated as } \\
\text { endogenous and } \\
\text { exogenous to assess the } \\
\text { role of union status. } \\
\text { Pooled OLS and fixed } \\
\text { effects models are also } \\
\text { estimated and these } \\
\text { results are not } \\
\text { decomposed using the } \\
\text { Blinder-Oaxaca } \\
\text { decomposition technique. } \\
\text { The public sector is } \\
\text { proxied by limiting the } \\
\text { sample to workers in } \\
\text { public administration. }\end{array}$ & $\begin{array}{l}1988 \text { to } 1990 \text { Waves of } \\
\text { the Labour Market } \\
\text { Activity Survey }\end{array}$ & $\begin{array}{l}\text { The Blinder-Oaxaca } \\
\text { decomposition analysis } \\
\text { led to estimates of the } \\
\text { total differential of } 27.9 \% \\
\text { and } 48.2 \% \text { for men and } \\
\text { women, respectively. } \\
\text { When union status was } \\
\text { treated as exogenous, the } \\
\text { economic rents were } \\
\text { estimated to be } 3.3 \% \text { and } \\
11.3 \% \text { for men and } \\
\text { women, respectively. The } \\
\text { estimates when union } \\
\text { status was treated as } \\
\text { endogenous were } 4.5 \% \\
\text { and } 16.3 \% \text {, respectively. } \\
\text { Estimations of pooled } \\
\text { OLS models suggested } \\
\text { that the public-private } \\
\text { sector wage differentials } \\
\text { were }-4.5 \% \text { and } 3.9 \% \text { for } \\
\text { men and women, } \\
\text { respectively. Estimations } \\
\text { of fixed effects models } \\
\text { suggested that the } \\
\text { differentials were } 3.9 \% \\
\text { and } 5.8 \% \text {, respectively. }\end{array}$ \\
\hline $\begin{array}{l}\text { Gunderson et al. } \\
(2000)\end{array}$ & $\begin{array}{l}\text { OLS estimations of wage } \\
\text { equations with dummy } \\
\text { variables for each public } \\
\text { sector industry } \\
\text { designation (federal, } \\
\text { provincial and } \\
\text { municipal). The analysis } \\
\text { is not done by gender. }\end{array}$ & $\begin{array}{l}\text { 1996 Canadian Census } \\
\text { and } 1997 \text { Labour Force } \\
\text { Survey }\end{array}$ & $\begin{array}{l}\text { Using the Census, the } \\
\text { public-private sector wage } \\
\text { gaps are estimated to be } \\
9.9 \%, 8.7 \% \text { and } 8.5 \% \text { at } \\
\text { the federal, provincial and } \\
\text { local levels, respectively. } \\
\text { Using the LFS, the } \\
\text { estimates are } 7.0 \%, 11.4 \% \\
\text { and } 10.3 \% \text {, respectively. } \\
\text { The average public sector } \\
\text { wage premium is } \\
\text { estimated to be } 9.0 \% \text { and } \\
9.6 \% \text { using the Census } \\
\text { and LFS, respectively. }\end{array}$ \\
\hline $\begin{array}{l}\text { Mallett and Wong } \\
(2008)\end{array}$ & $\begin{array}{l}\text { An index of aggregate } \\
\text { earnings in } 48 \\
\text { geographical areas is } \\
\text { weighted by the number } \\
\text { of civil servants in each } \\
\text { area. Wage premium is } \\
\text { estimated by comparing } \\
\text { average wage settlements } \\
\text { in the private and public } \\
\text { sectors. }\end{array}$ & 2006 Canadian Census & $\begin{array}{l}\text { Estimates of } \\
\text { public-private sector wage } \\
\text { differential are } 17.3 \% \text {, } \\
11.2 \% \text { and } 7.9 \% \text { for the } \\
\text { federal, municipal and } \\
\text { provincial governments, } \\
\text { respectively. Accounting } \\
\text { for non-wage benefits led } \\
\text { to estimates of } 41.7 \% \text {, } \\
35.9 \% \text { and } 24.9 \%, \\
\text { respectively. }\end{array}$ \\
\hline Tiagi (2010) & $\begin{array}{l}\text { Endogenous switching } \\
\text { regression model and } \\
\text { Blinder-Oaxaca } \\
\text { decomposition analysis. } \\
\text { Instruments used are an } \\
\text { indicator of whether the } \\
\text { worker has a spouse } \\
\text { employed in the public } \\
\text { sector and family size. }\end{array}$ & $\begin{array}{l}\text { September } 2008 \text { Labour } \\
\text { Force Survey }\end{array}$ & $\begin{array}{l}\text { Total differential of } 31.1 \% \\
\text { and } 51.8 \% \text { for men and } \\
\text { women, respectively. } \\
\text { Economic rents of } 5.4 \% \\
\text { and } 19.8 \% \text { for men and } \\
\text { women, respectively. }\end{array}$ \\
\hline
\end{tabular}

Table B.1 provides a summary of the literature on the public-private sector wage differential in Canada. 
Table B.2: Variable Descriptions

\begin{tabular}{|c|c|c|}
\hline Variable & Label & Description \\
\hline \multicolumn{3}{|l|}{ Outcome Variables } \\
\hline $\log (w)$ & Log Wage & $\begin{array}{l}\text { Logarithm of the implicit hourly wage for a paid } \\
\text { worker job includes tips, bonuses and commissions. } \\
\text { It is a self-reported wage which is converted to an } \\
\text { implicit rate based on an individual's reporting of } \\
\text { the months, weeks and hours worked. Wages are } \\
\text { inflated to } 2010 \text { values using the ratio of the value } \\
\text { of the consumer price index in December } 2010 \text { to } \\
\text { that in the reference year. }\end{array}$ \\
\hline \multicolumn{3}{|c|}{ Main Explanatory Variables } \\
\hline Public & Public & $\begin{array}{l}\text { Binary variable equal to } 1 \text { if individual is employed } \\
\text { in the public sector based on "PUBPV10" flag } \\
\text { variable in the SLID. }\end{array}$ \\
\hline Public_Admin & Public Administration & $\begin{array}{l}\text { Binary variable equal to } 1 \text { if individual is employed } \\
\text { in the public sector based on the employer's 4-digit } \\
\text { North American Industry Classification System } \\
\text { (NAICS) code being equal to values from } 9110 \text { to } \\
\text { 9191. }\end{array}$ \\
\hline$\left(\right.$ Public $_{i, t} \times$ Year $\left._{j}\right)$ & Public $(j)$ & $\begin{array}{l}\text { An interaction term between a dummy variable for } \\
\text { reference year } j=1994, \ldots, 2010\left(\text { Year }_{j}\right) \text { and the } \\
\text { public sector dummy variable }\left(\text { Public }_{i, t}\right) \text {. It } \\
\text { indicates whether a worker was employed in the } \\
\text { public sector in reference year } j \text {. }\end{array}$ \\
\hline $\begin{array}{l}\left(\text { Public }_{i, t} \times\right. \\
\text { VM_Group } \\
\left.M_{-, i}\right)\end{array}$ & Public $(k)$ & $\begin{array}{l}\text { An interaction term between a dummy variable for } \\
\text { the individual's visible minority group } \\
\left(V M_{-} G \text { roup } p_{k, i}\right) \text { and the public sector dummy } \\
\text { variable }\left(\text { Public }_{i, t}\right) \text {. }\end{array}$ \\
\hline \multicolumn{3}{|l|}{ Control Variables } \\
\hline Age & Age & Age of individual measured in years. \\
\hline$\left(A g e^{2}\right) / 100$ & $\left(\mathrm{Age}^{2}\right) / 100$ & Age squared divided by 100 . \\
\hline Marsg_Married & Married & $\begin{array}{l}\text { Binary variable equal to } 1 \text { if the individual is } \\
\text { married. }\end{array}$ \\
\hline Educ_less_hs & Less than High School & $\begin{array}{l}\text { Binary variable equal to } 1 \text { if individual's highest } \\
\text { level of education is less than a high school } \\
\text { graduation. (default) }\end{array}$ \\
\hline Educ_hs & High School & $\begin{array}{l}\text { Binary variable equal to } 1 \text { if individual's highest } \\
\text { level of education is a high school graduation. }\end{array}$ \\
\hline Educ_nonunivps & $\begin{array}{l}\text { Non-University } \\
\text { Post-Secondary }\end{array}$ & $\begin{array}{l}\text { Binary variable equal to } 1 \text { if individual's highest } \\
\text { level of education is a non-university } \\
\text { post-secondary certificate. }\end{array}$ \\
\hline Educ_univ & University & $\begin{array}{l}\text { Binary variable equal to } 1 \text { if individual's highest } \\
\text { level of education is a university degree or } \\
\text { certificate. }\end{array}$ \\
\hline Uncoll_member & Union Member & $\begin{array}{l}\text { Binary variable equal to } 1 \text { if the individual was a } \\
\text { member of a union or covered by a collective } \\
\text { agreement during the reference year. }\end{array}$ \\
\hline Employees_less_than_20 & Less than 20 Employees & $\begin{array}{l}\text { Binary variable equal to } 1 \text { if the number of } \\
\text { employees at the individual's place of work was less } \\
\text { than 20. (default) }\end{array}$ \\
\hline Employees_20_to_99 & 20 to 99 Employees & $\begin{array}{l}\text { Binary variable equal to } 1 \text { if the number of } \\
\text { employees at the individual's place of work was } \\
\text { between } 20 \text { and } 99 .\end{array}$ \\
\hline Employees_100_to_499 & 100 to 499 Employees & $\begin{array}{l}\text { Binary variable equal to } 1 \text { if the number of } \\
\text { employees at the individual's place of work was } \\
\text { between } 100 \text { and } 499 .\end{array}$ \\
\hline Employees_500_to_999 & 500 to 999 Employees & $\begin{array}{l}\text { Binary variable equal to } 1 \text { if the number of } \\
\text { employees at the individual's place of work was } \\
\text { between } 500 \text { and } 999 \text {. }\end{array}$ \\
\hline
\end{tabular}


Table B.2: Variable Descriptions, Cont.

\begin{tabular}{|c|c|c|}
\hline Variable & Label & Description \\
\hline \multicolumn{3}{|l|}{ Control Variables } \\
\hline Employees_1000plus & 1000+ Employees & $\begin{array}{l}\text { Binary variable equal to } 1 \text { if the number of } \\
\text { employees at the individual's place of work was } \\
1000 \text { or more. }\end{array}$ \\
\hline Toronto & Toronto & $\begin{array}{l}\text { Binary variable equal to } 1 \text { if the individual resided } \\
\text { in Toronto as of December } 31 \text { of the reference } \\
\text { year. (default) }\end{array}$ \\
\hline Ontario_other & Ontario (other) & $\begin{array}{l}\text { Binary variable equal to } 1 \text { if the individual resided } \\
\text { in areas of Ontario other than Toronto as of } \\
\text { December } 31 \text { of the reference year. }\end{array}$ \\
\hline Montreal & Montreal & $\begin{array}{l}\text { Binary variable equal to } 1 \text { if the individual resided } \\
\text { in Montreal as of December } 31 \text { of the reference } \\
\text { year. }\end{array}$ \\
\hline Quebec_other & Quebec (other) & $\begin{array}{l}\text { Binary variable equal to } 1 \text { if the individual resided } \\
\text { in areas of Quebec other than Montreal as of } \\
\text { December } 31 \text { of the reference year. }\end{array}$ \\
\hline Vancouver & Vancouver & $\begin{array}{l}\text { Binary variable equal to } 1 \text { if the individual resided } \\
\text { in Vancouver as of December } 31 \text { of the reference } \\
\text { year. }\end{array}$ \\
\hline British_Columbia_other & $\begin{array}{l}\text { British Columbia } \\
\text { (other) }\end{array}$ & $\begin{array}{l}\text { Binary variable equal to } 1 \text { if the individual resided } \\
\text { in areas of British Columbia other than Vancouver } \\
\text { as of December } 31 \text { of the reference year. }\end{array}$ \\
\hline Alberta & Alberta & $\begin{array}{l}\text { Binary variable equal to } 1 \text { if the individual resided } \\
\text { in Alberta as of December } 31 \text { of the reference year. }\end{array}$ \\
\hline Manitoba & Manitoba & $\begin{array}{l}\text { Binary variable equal to } 1 \text { if the individual resided } \\
\text { in Manitoba as of December } 31 \text { of the reference } \\
\text { year. }\end{array}$ \\
\hline New_Brunswick & New Brunswick & $\begin{array}{l}\text { Binary variable equal to } 1 \text { if the individual resided } \\
\text { in New Brunswick as of December } 31 \text { of the } \\
\text { reference year. }\end{array}$ \\
\hline Newfoundland_and_Labrador & $\begin{array}{l}\text { Newfoundland and } \\
\text { Labrador }\end{array}$ & $\begin{array}{l}\text { Binary variable equal to } 1 \text { if the individual resided } \\
\text { in Newfoundland and Labrador as of December } 31 \\
\text { of the reference year. }\end{array}$ \\
\hline Nova_Scotia & Nova Scotia & $\begin{array}{l}\text { Binary variable equal to } 1 \text { if the individual resided } \\
\text { in Nova Scotia as of December } 31 \text { of the reference } \\
\text { year. }\end{array}$ \\
\hline Prince_Edward_Island & Prince Edward Island & $\begin{array}{l}\text { Binary variable equal to } 1 \text { if the individual resided } \\
\text { in Prince Edward Island as of December } 31 \text { of the } \\
\text { reference year. }\end{array}$ \\
\hline Saskatchewan & Saskatchewan & $\begin{array}{l}\text { Binary variable equal to } 1 \text { if the individual resided } \\
\text { in Saskatchewan as of December } 31 \text { of the } \\
\text { reference year. }\end{array}$ \\
\hline \multicolumn{3}{|l|}{ Instrumental Variables } \\
\hline \multirow[t]{2}{*}{ Public_Share_W $A v g_{p, t-5}$} & Shift-Share Instrument & $\begin{array}{l}\text { The weighted average of the change in the share of } \\
\text { workers in the public sector computed as: } \\
\text { Public_Share_W } W v g_{p, t-5}=\end{array}$ \\
\hline & & $\begin{array}{l}\sum_{g=1}^{G} \text { Public_Share }{ }_{p, g, t-6} \text { Change_Public }_{g, t-5} \\
\text { where Public_Share }{ }_{p, g, t-6} \text { is the share of } \\
\text { individuals in with the individual's highest level of } \\
\text { education }(g) \text { residing in Census Metropolitan } \\
\text { Area of residence }(p) \text { who work in the public } \\
\text { sector } 2 \text { years prior to the reference year; and } \\
\text { Change_Public } c_{g, t-5} \text { is the normalized change in } \\
\text { the share of workers with the individual's highest } \\
\text { level of education }(g) \text { who work in the public } \\
\text { sector in Canada as a whole. }\end{array}$ \\
\hline Spouse_Public & Spouse in Public & $\begin{array}{l}\text { Binary variable equal to } 1 \text { if the individual if the } \\
\text { individual's spouse works in the public sector as } \\
\text { determined by "PUBPV10" flag variable in the } \\
\text { SLID. }\end{array}$ \\
\hline Family_Size & Family Size & $\begin{array}{l}\text { The count of the number of individuals in a } \\
\text { worker's family. Calculated as the number of } \\
\text { children the worker has plus } 2 \text { if they have a } \\
\text { spouse or plus } 1 \text { if they do not. }\end{array}$ \\
\hline
\end{tabular}

Table B.2 describes the variables used in my analysis. 
Table B.3: Descriptive Statistics by Sector of Employment

\begin{tabular}{|c|c|c|c|c|}
\hline & $A l l$ & Public & Private & Difference \\
\hline Log Wage & 3.1236 & 3.3095 & 3.0541 & $0.2554^{* * *}$ \\
\hline Highest Level of Education & All & Public & Private & Difference \\
\hline $\begin{array}{l}\text { Less than High School (default) } \\
\text { High School } \\
\text { Non-University Post-Secondary Certificate } \\
\text { University }\end{array}$ & $\begin{array}{l}0.1054 \\
0.2612 \\
0.3464 \\
0.2450\end{array}$ & $\begin{array}{l}0.0436 \\
0.1808 \\
0.3438 \\
0.3988\end{array}$ & $\begin{array}{l}0.1285 \\
0.2913 \\
0.3474 \\
0.1876\end{array}$ & $\begin{array}{l}-0.0849^{* * *} \\
-0.1105^{* * *} \\
-0.0036 \\
0.2112^{* * *}\end{array}$ \\
\hline Firm Size & All & Public & Private & Difference \\
\hline $\begin{array}{l}\text { Less than } 20 \text { Employees (default) } \\
20 \text { to } 99 \text { Employees } \\
100 \text { to } 499 \text { Employees } \\
500 \text { to } 999 \text { Employees } \\
1000+\text { Employees }\end{array}$ & $\begin{array}{l}0.2592 \\
0.3093 \\
0.2452 \\
0.0705 \\
0.1053\end{array}$ & $\begin{array}{l}0.1251 \\
0.3041 \\
0.2540 \\
0.1050 \\
0.1997\end{array}$ & $\begin{array}{l}0.3093 \\
0.3112 \\
0.2419 \\
0.0576 \\
0.0701\end{array}$ & $\begin{array}{l}-0.1842^{* * *} \\
-0.0071 \\
0.0121^{* * *} \\
0.0474^{* * *} \\
0.1296^{* * *}\end{array}$ \\
\hline Province or Major City of Residence & All & Public & Private & Difference \\
\hline $\begin{array}{l}\text { Toronto (default) } \\
\text { Ontario (other) } \\
\text { Montreal } \\
\text { Quebec (other) } \\
\text { Vancouver } \\
\text { British Columbia (other) } \\
\text { Alberta } \\
\text { Manitoba } \\
\text { New Brunswick } \\
\text { Newfoundland and Labrador } \\
\text { Nova Scotia } \\
\text { Prince Edward Island } \\
\text { Saskatchewan } \\
\end{array}$ & $\begin{array}{l}0.1485 \\
0.2394 \\
0.1181 \\
0.1369 \\
0.0632 \\
0.0537 \\
0.1002 \\
0.0363 \\
0.0251 \\
0.0156 \\
0.0316 \\
0.0041 \\
0.0273 \\
\end{array}$ & $\begin{array}{l}0.0976 \\
0.2605 \\
0.1073 \\
0.1484 \\
0.0578 \\
0.0591 \\
0.0906 \\
0.0448 \\
0.0313 \\
0.0210 \\
0.0391 \\
0.0058 \\
0.0367 \\
\end{array}$ & $\begin{array}{l}0.1675 \\
0.2315 \\
0.1222 \\
0.1326 \\
0.0652 \\
0.0517 \\
0.1037 \\
0.0331 \\
0.0227 \\
0.0136 \\
0.0288 \\
0.0035 \\
0.0237 \\
\end{array}$ & $\begin{array}{l}-0.0699^{* * *} \\
0.0290^{* * *} \\
-0.0149^{* * *} \\
0.0158^{* * *} \\
-0.0074^{* *} \\
0.0074^{* * *} \\
-0.0131^{* * *} \\
0.0117^{* * *} \\
0.0086^{* * *} \\
0.0074^{* * *} \\
0.0103^{* * *} \\
0.0023^{* * *} \\
0.0130^{* * *} \\
\end{array}$ \\
\hline Other Characteristics & $A l l$ & Public & Private & Difference \\
\hline $\begin{array}{l}\text { Married } \\
\text { Age } \\
\text { Female } \\
\text { Union Member } \\
\text { Spouse in Public Sector }\end{array}$ & $\begin{array}{c}0.7081 \\
41.3991 \\
0.4491 \\
0.3936 \\
0.1251\end{array}$ & $\begin{array}{c}0.7225 \\
42.7860 \\
0.5468 \\
0.7893 \\
0.3597\end{array}$ & $\begin{array}{c}0.7027 \\
40.8805 \\
0.4126 \\
0.2457 \\
0.0374 \\
\end{array}$ & $\begin{array}{l}0.0198^{* * *} \\
1.9055^{* * *} \\
0.1342^{* * *} \\
0.5436^{* * *} \\
0.3223^{* * *}\end{array}$ \\
\hline Observations & 231,000 & 73,000 & 158,000 & \\
\hline Share of Observations & $100.0 \%$ & $31.6 \%$ & $68.4 \%$ & \\
\hline
\end{tabular}

Table B.3 reports descriptive statistics by sector of employment based on my calculations using the SLID. Observation numbers are rounded as per Statistcs Canada confidentiality rules. Significance levels are indicated by $*, * *, * * *$ for $10 \%, 5 \%$, and $1 \%$ respectively. 
Table B.4: Non-wage Benefits by Sector of Employment

\begin{tabular}{|c|c|c|c|c|}
\hline & All & Public & Private & Difference \\
\hline Commission / Tips & 0.10660 & 0.04616 & 0.12973 & $-0.08358^{* * *}$ \\
\hline Contributions to Pension Plan & 0.88984 & 0.97161 & 0.83298 & $0.13862^{* * *}$ \\
\hline Dental Insurance & 0.75301 & 0.84020 & 0.72049 & $0.11971^{* * *}$ \\
\hline Contributions to Group RRSP & 0.77797 & 0.68570 & 0.80045 & $-0.11475^{* * *}$ \\
\hline Life / Disability Insurance & 0.75545 & 0.87786 & 0.70979 & $0.16807^{* * *}$ \\
\hline The Option of a Low Interest Loan & 0.05724 & 0.04480 & 0.06189 & $-0.01709 * * *$ \\
\hline Medical Insurance / Health Plan & 0.80574 & 0.91081 & 0.76655 & $0.14425^{* * *}$ \\
\hline Profit Sharing Plan & 0.09591 & 0.01976 & 0.12431 & $-0.10455^{* * *}$ \\
\hline Stock Purchase or Stock Option Plan & 0.12976 & 0.01719 & 0.17174 & $-0.15454^{* * *}$ \\
\hline Benefits Listed Above Not Offered & 0.00007 & 0.00012 & 0.00005 & 0.00007 \\
\hline Observations & 231,000 & 73,000 & 158,000 & \\
\hline Share of Observations & $100.0 \%$ & $31.6 \%$ & $68.4 \%$ & \\
\hline
\end{tabular}

Table B.4 reports descriptive statistics on non-wage benefits by sector of employment based on my calculations using the SLID. Observation numbers are rounded as per Statistcs Canada confidentiality rules. Significance levels are indicated by $*, * *, * * *$ for $10 \%, 5 \%$, and $1 \%$ respectively. 
Figure B.1: Proportion of Workers in the Public Sector by Gender Canada, 1993 to 2010

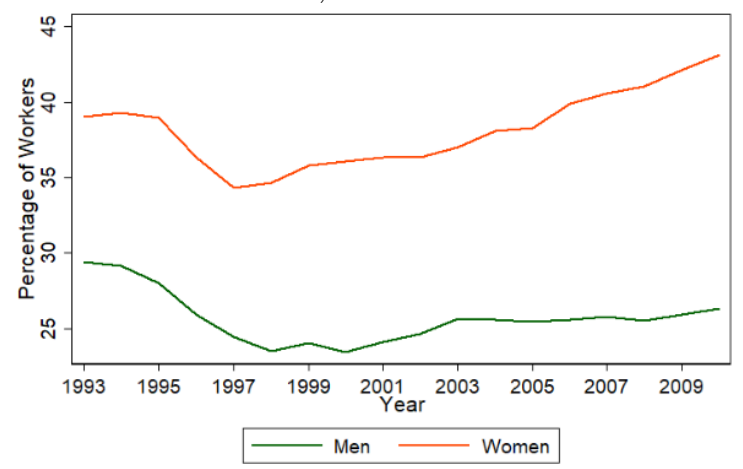

Source: Based on my calculations using data from the Survey of Labour and Income Dynamics (1993 to 2010).

Figure B.2: Wages of Workers in the Public and Private Sectors (Conditional on Sample Restrictions)

Canada, 1993 to 2010

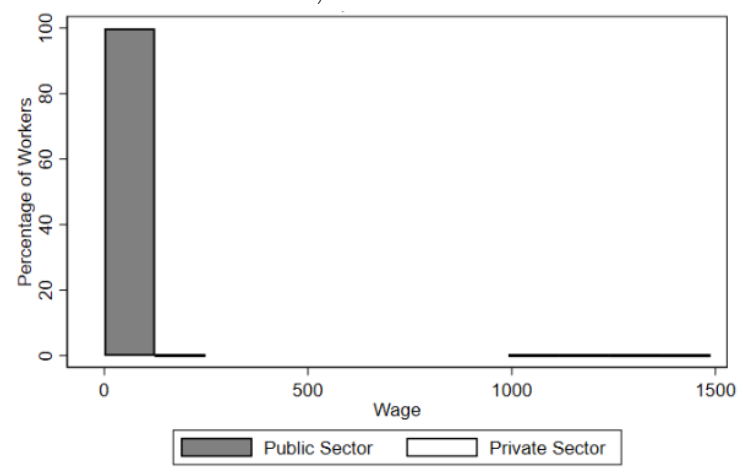

Source: Based on my calculations using data from the Survey of Labour and Income Dynamics (1993 to 2010). This histogram does not contain smaller bins due to Statistics Canada RDC disclosure rules.

Figure B.3: Wages of Workers in the Public and Private Sectors

Canada, 1993 to 2010

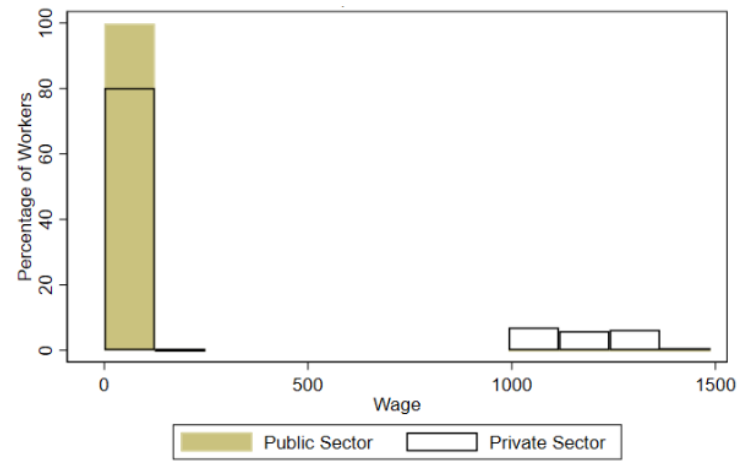

Source: Based on my calculations using data from the Survey of Labour and Income Dynamics (1993 to 2010). This histogram does not contain smaller bins due to Statistics Canada RDC disclosure rules. 
Figure B.4: Wages of Workers in the Public and Private Sectors (Without Outliers) Canada, 1993 to 2010

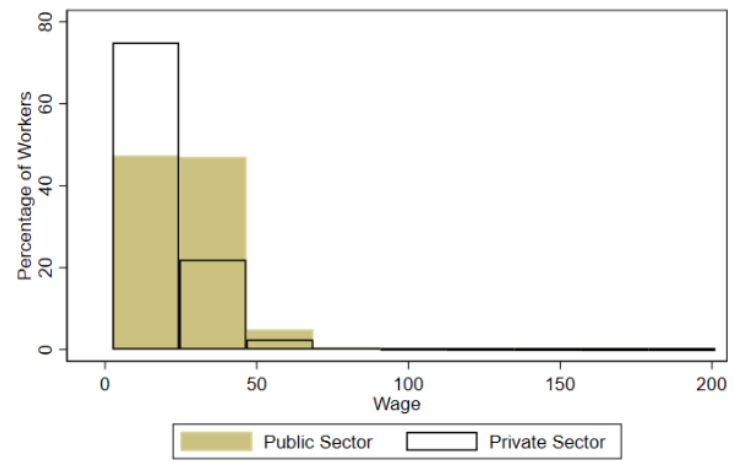

Source: Based on my calculations using data from the Survey of Labour and Income Dynamics (1993 to 2010). This histogram does not contain smaller bins due to Statistics Canada RDC disclosure rules.

Figure B.5: Wages of Workers in the Public and Private Sectors (Conditional on Sample Restrictions and Without Outliers)

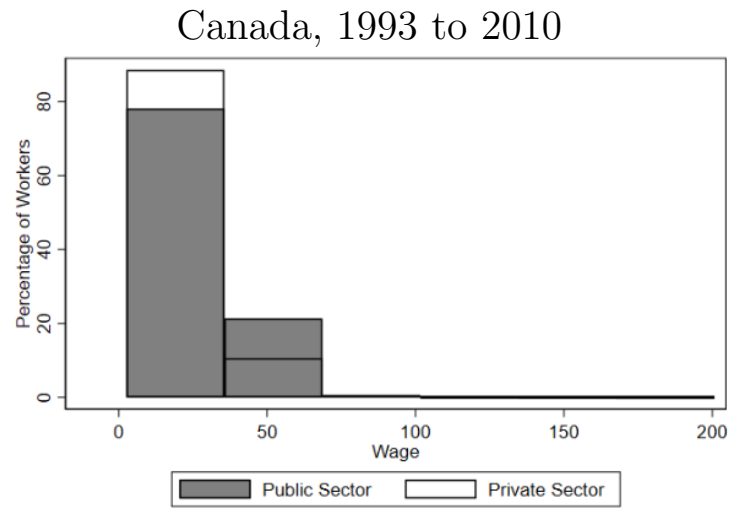

Source: Based on my calculations using data from the Survey of Labour and Income Dynamics (1993 to 2010). Note that this histogram could not be drawn with smaller bins due to Statistics Canada RDC disclosure rules. 
Figure B.6: Raw Public-Private Sector Wage Differential by Gender Canada, 1993 to 2010

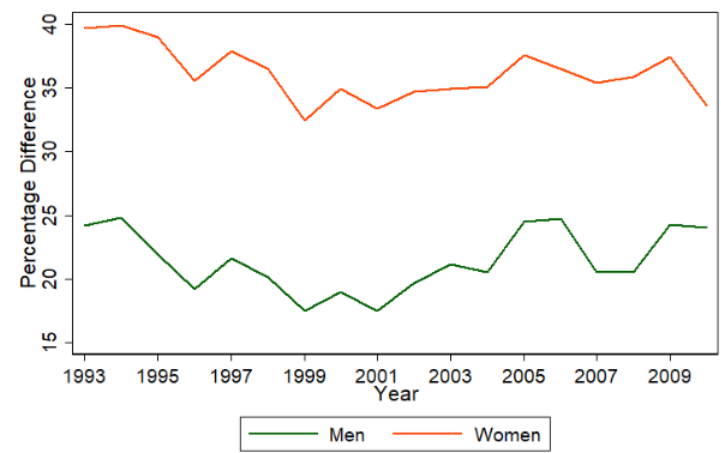

Source: Based on my calculations using data from the Survey of Labour and Income Dynamics (1993 to 2010).

Figure B.7: Proportion of Workers Who Switched Sectors by Gender Canada, 1993 to 2010

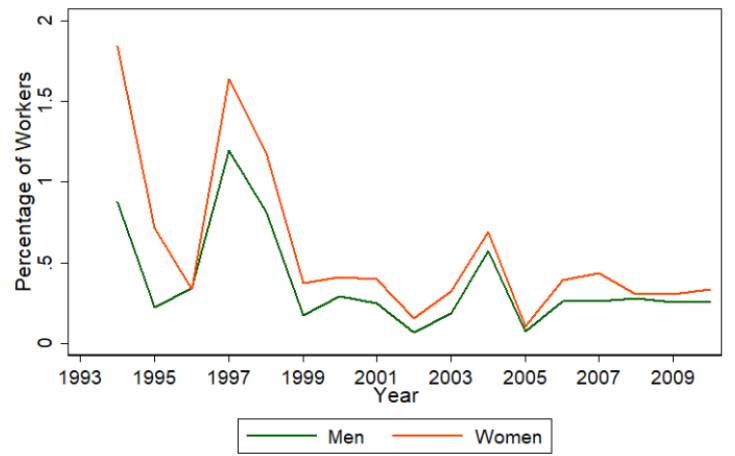

Source: Based on my calculations using data from the Survey of Labour and Income Dynamics (1993 to 2010).

Figure B.8: Proportion of Switchers Who Switched to the Public Sector by Gender Canada, 1993 to 2010

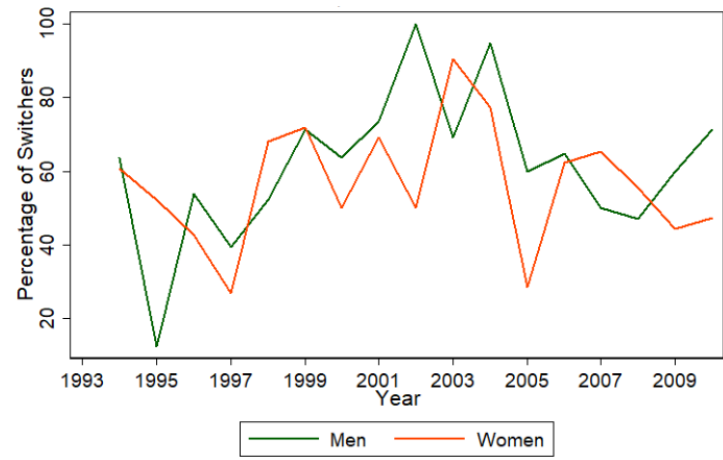

Source: Based on my calculations using data from the Survey of Labour and Income Dynamics (1993 to 2010). 
Table B.5: Raw Wage Public-Private Sector Wage Differentials

\begin{tabular}{|c|c|c|c|c|c|c|c|c|}
\hline \multirow{2}{*}{ Year } & \multicolumn{4}{|c|}{ Males } & \multicolumn{4}{|c|}{ Females } \\
\hline & Public & Private & Difference & Observations & Public & Private & Difference & Observations \\
\hline 1993 & 3.3502 & 3.1084 & $0.2418^{* * *}$ & 4,000 & 3.1817 & 2.7850 & $0.3967^{* * *}$ & 3,000 \\
\hline 1994 & 3.3440 & 3.0956 & $0.2484^{* * *}$ & 4,000 & 3.1975 & 2.7982 & $0.3993^{* * *}$ & 3,000 \\
\hline 1995 & 3.3303 & 3.1112 & $0.2191^{* * *}$ & 4,000 & 3.1848 & 2.7945 & $0.3903^{* * *}$ & 3,000 \\
\hline 1996 & 3.2771 & 3.0851 & $0.1920^{* * *}$ & 8,000 & 3.1618 & 2.8058 & $0.3560^{* * *}$ & 6,000 \\
\hline 1997 & 3.3126 & 3.0966 & $0.2160^{* * *}$ & 8,000 & 3.1781 & 2.7994 & $0.3787^{* * *}$ & 6,000 \\
\hline 1998 & 3.3099 & 3.1083 & $0.2016^{* * *}$ & 8,000 & 3.1891 & 2.8242 & $0.3649 * * *$ & 6,000 \\
\hline 1999 & 3.3203 & 3.1457 & $0.1746^{* * *}$ & 8,000 & 3.1751 & 2.8504 & $0.3247^{* * *}$ & 7,000 \\
\hline 2000 & 3.3470 & 3.1576 & $0.1894^{* * *}$ & 8,000 & 3.2000 & 2.8504 & $0.3496^{* * *}$ & 6,000 \\
\hline 2001 & 3.3444 & 3.1696 & $0.1748^{* * *}$ & 8,000 & 3.2097 & 2.8757 & $0.3340^{* * *}$ & 7,000 \\
\hline 2002 & 3.3727 & 3.1757 & $0.1970 * * *$ & 7,000 & 3.2299 & 2.8830 & $0.3469^{* * *}$ & 7,000 \\
\hline 2003 & 3.3953 & 3.1838 & $0.2115^{* * *}$ & 7,000 & 3.2355 & 2.8864 & $0.3491^{* * *}$ & 7,000 \\
\hline 2004 & 3.3972 & 3.1923 & $0.2049 * * *$ & 7,000 & 3.2544 & 2.9035 & $0.3509^{* * *}$ & 6,000 \\
\hline 2005 & 3.4282 & 3.1830 & $0.2452^{* * *}$ & 7,000 & 3.2688 & 2.8927 & $0.3761^{* * *}$ & 6,000 \\
\hline 2006 & 3.4633 & 3.2162 & $0.2471^{* * *}$ & 6,000 & 3.2848 & 2.9197 & $0.3651^{* * *}$ & 6,000 \\
\hline 2007 & 3.4499 & 3.2444 & $0.2055 * * *$ & 6,000 & 3.2911 & 2.9369 & $0.3542^{* * *}$ & 6,000 \\
\hline 2008 & 3.4443 & 3.2388 & $0.2055^{* * *}$ & 6,000 & 3.3118 & 2.9532 & $0.3586^{* * *}$ & 6,000 \\
\hline 2009 & 3.4809 & 3.2384 & $0.2425^{* * *}$ & 6,000 & 3.3530 & 2.9785 & $0.3745^{* * *}$ & 6,000 \\
\hline 2010 & 3.4902 & 3.2499 & $0.2403^{* * *}$ & 6,000 & 3.3439 & 3.0076 & $0.3363^{* * *}$ & 6,000 \\
\hline 1993 to 2010 & 3.3854 & 3.1727 & $0.2127^{* * *}$ & 122,000 & 3.2466 & 2.8853 & $0.3613^{* * *}$ & 109,000 \\
\hline Observations & 31,000 & 91,000 & & & 42,000 & 67,000 & & \\
\hline
\end{tabular}

Table B.5 reports the average log wage in the private and public sectors as well as the difference in these averages. Estimates are based on my calculations using the SLID. Observation numbers are rounded as per Statistcs Canada confidentiality rules. Significance levels are indicated by * $* *$, *** for $10 \%, 5 \%$, and $1 \%$ respectively. 
Table B.6: Cross-sectional Wage Regressions - Males

\begin{tabular}{lcccccc}
\hline \hline & 1993 & 1994 & 1995 & 1996 & 1997 & 1998 \\
\hline Variable & $\mathbf{( 1 )}$ & $\mathbf{( 2 )}$ & $\mathbf{( 3 )}$ & $\mathbf{( 4 )}$ & $\mathbf{( 5 )}$ & $\mathbf{( 6 )}$ \\
\hline Public & $\begin{array}{c}0.0996^{* * *} \\
(0.0202)\end{array}$ & $\begin{array}{c}0.1331^{* * *} \\
(0.0207)\end{array}$ & $\begin{array}{c}0.1107^{* * *} \\
(0.0208)\end{array}$ & $\begin{array}{c}0.0690^{* * *} \\
(0.0149)\end{array}$ & $\begin{array}{c}0.0812^{* * *} \\
(0.0149)\end{array}$ & $\begin{array}{c}0.0580^{* * *}(0.0145) \\
\text { Constant }\end{array}$ \\
$\begin{array}{c}1.1996^{* * *} \\
(0.1992)\end{array}$ & $\begin{array}{c}1.1653^{* * *} \\
(0.2037)\end{array}$ & $\begin{array}{c}1.30766^{* * *} \\
(0.1860)\end{array}$ & $\begin{array}{c}1.6779^{* * *} \\
(0.1391)\end{array}$ & $\begin{array}{c}1.4289^{* * *} \\
(0.1302)\end{array}$ & $\begin{array}{c}1.5773^{* * *} \\
(0.1275)\end{array}$ \\
\hline Observations & 4,000 & 4,000 & 4,000 & 8,000 & 8,000 & 8,000 \\
$R^{2}$ & 0.2805 & 0.2577 & 0.2925 & 0.2097 & 0.2383 & 0.2417 \\
\hline \hline
\end{tabular}

Table B.6: Cross-sectional Wage Regressions - Males, Cont.

\begin{tabular}{|c|c|c|c|c|c|c|}
\hline & 1999 & 2000 & 2001 & 2002 & 2003 & 2004 \\
\hline Variable & $(7)$ & $(8)$ & $(9)$ & (10) & (11) & $(12)$ \\
\hline Public & $\begin{array}{c}0.0521^{* * *} * \\
(0.0126)\end{array}$ & $\begin{array}{c}0.0601^{* * *} \\
(0.0156)\end{array}$ & $\begin{array}{c}0.0527^{* * *} * \\
(0.0152)\end{array}$ & $\begin{array}{c}0.0869^{* * *} \\
(0.0153)\end{array}$ & $\begin{array}{c}0.0894^{* * *} \\
(0.0147)\end{array}$ & $\begin{array}{c}0.0867^{* * *} \\
(0.0171)\end{array}$ \\
\hline Constant & $\begin{array}{c}1.6484^{* * *} \\
(0.1237)\end{array}$ & $\begin{array}{c}1.7340^{* * * *} \\
(0.1302)\end{array}$ & $\begin{array}{c}1.6508^{* * *} \\
(0.1319)\end{array}$ & $\begin{array}{c}1.7282^{* * * *} \\
(0.1370)\end{array}$ & $\begin{array}{c}1.8446^{* * *} \\
(0.1253)\end{array}$ & $\begin{array}{c}1.6904^{* * *} \\
(0.1331)\end{array}$ \\
\hline Observations & 8,000 & 8,000 & 8,000 & 8,000 & 7,000 & 7,000 \\
\hline$R^{2}$ & 0.2293 & 0.2171 & 0.2253 & 0.2242 & 0.2321 & 0.2323 \\
\hline
\end{tabular}

Table B.6: Cross-sectional Wage Regressions - Males, Cont.

\begin{tabular}{|c|c|c|c|c|c|c|}
\hline & 2005 & 2006 & 2007 & 2008 & 2009 & 2010 \\
\hline Variable & (13) & $(14)$ & $(15)$ & (16) & $(17)$ & $(18)$ \\
\hline Public & $\begin{array}{c}0.1070^{* * *} \\
(0.0162)\end{array}$ & $\begin{array}{c}0.1048^{* * *} \\
(0.0173)\end{array}$ & $\begin{array}{c}0.0874^{* * *} \\
(0.0186)\end{array}$ & $\begin{array}{c}0.0985^{* * *} \\
(0.0184)\end{array}$ & $\begin{array}{c}0.1480^{* * *} \\
(0.0187)\end{array}$ & $\begin{array}{c}0.1194^{* * *} \\
(0.0190)\end{array}$ \\
\hline Constant & $\begin{array}{c}1.5606^{* * * *} \\
(0.1325)\end{array}$ & $\begin{array}{c}1.7871^{* * *} * \\
(0.1450)\end{array}$ & $\begin{array}{c}1.8306^{* * *} \\
(0.1357)\end{array}$ & $\begin{array}{c}1.8799^{* * *} * \\
(0.1409)\end{array}$ & $\begin{array}{c}1.6050^{* * *} \\
(0.1509)\end{array}$ & $\begin{array}{c}1.7658^{* * *} * \\
(0.1598)\end{array}$ \\
\hline Observations & 7,000 & 6,000 & 6,000 & 6,000 & 6,000 & 6,000 \\
\hline$R^{2}$ & 0.2593 & 0.2621 & 0.2334 & 0.2374 & 0.2489 & 0.2645 \\
\hline
\end{tabular}

Table B.6 reports the estimated coefficients from the cross-sectional wage regressions given in Equation (2.3.1). The dependent variable is the log wage of the worker at time $t$. Each model has a set of controls for education (3), union membership (1), province/major city of residence (12), marital status (1), age (1), age squared divided by 100 (1). Longitudinal weights for each person, provided in the SLID, are applied. In parentheses, I report robust standard errors. Observation numbers are rounded as per Statistcs Canada confidentiality rules. Significance levels are indicated by *,**, *** for $10 \%, 5 \%$, and $1 \%$ respectively. 
Table B.7: Cross-sectional Wage Regressions - Females

\begin{tabular}{lcccccc}
\hline \hline & 1993 & 1994 & 1995 & 1996 & 1997 & 1998 \\
\hline Variable & $\mathbf{( 1 )}$ & $\mathbf{( 2 )}$ & $\mathbf{( 3 )}$ & $\mathbf{( 4 )}$ & $\mathbf{( 5 )}$ & $\mathbf{( 6 )}$ \\
\hline Public & $\begin{array}{c}0.2320^{* * *} \\
(0.0275)\end{array}$ & $\begin{array}{c}0.2401^{* * *} \\
(0.0267)\end{array}$ & $\begin{array}{c}0.2442^{* * *} \\
(0.0288)\end{array}$ & $\begin{array}{c}0.1933^{* * *} \\
(0.0181)\end{array}$ & $\begin{array}{c}0.2097^{* * *} \\
(0.0167)\end{array}$ & $\begin{array}{c}0.2015^{* * *} \\
(0.0155) \\
\text { Constant }\end{array}$ \\
$\begin{array}{c}2.1420^{* * *} \\
(0.2033)\end{array}$ & $\begin{array}{c}1.4392^{* * *} \\
(0.2109)\end{array}$ & $\begin{array}{c}1.3238^{* * *} \\
(0.2043)\end{array}$ & $\begin{array}{c}1.3862^{* * *} \\
(0.1374)\end{array}$ & $\begin{array}{c}1.6102^{* * *} \\
(0.1381)\end{array}$ & $\begin{array}{c}1.5445^{* * *} \\
(0.1346)\end{array}$ \\
\hline Observations & 3,000 & 3,000 & 3,000 & 6,000 & 6,000 & 6,000 \\
$R^{2}$ & 0.3187 & 0.3478 & 0.3219 & 0.3319 & 0.3308 & 0.3191 \\
\hline \hline
\end{tabular}

Table B.7: Cross-sectional Wage Regressions - Females, Cont.

\begin{tabular}{|c|c|c|c|c|c|c|}
\hline & 1999 & 2000 & 2001 & 2002 & 2003 & 2004 \\
\hline Variable & $(7)$ & $(8)$ & $(9)$ & (10) & (11) & (12) \\
\hline Public & $\begin{array}{c}0.1694^{* * *} \\
(0.0166)\end{array}$ & $\begin{array}{c}0.2048^{* * *} \\
(0.0167)\end{array}$ & $\begin{array}{c}0.1958^{* * *} \\
(0.0161)\end{array}$ & $\begin{array}{c}0.2129^{* * *} \\
(0.0159)\end{array}$ & $\begin{array}{c}0.2150^{* * *} \\
(0.0167)\end{array}$ & $\begin{array}{c}0.2230^{* * * *} \\
(0.0184)\end{array}$ \\
\hline Constant & $\begin{array}{c}1.6492^{* * *} \\
(0.1262)\end{array}$ & $\begin{array}{c}1.4765^{* * *} \\
(0.1392)\end{array}$ & $\begin{array}{c}1.8726^{* * *} \\
(0.1277)\end{array}$ & $\begin{array}{c}1.7040^{* * *} * \\
(0.1371)\end{array}$ & $\begin{array}{c}1.8861^{* * *} \\
(0.1504)\end{array}$ & $\begin{array}{c}2.0356^{* * *} \\
(0.1704)\end{array}$ \\
\hline Observations & 7,000 & 6,000 & 7,000 & 7,000 & 7,000 & 6,000 \\
\hline$R^{2}$ & 0.3038 & 0.3018 & 0.2805 & 0.2837 & 0.2860 & 0.2751 \\
\hline
\end{tabular}

Table B.7: Cross-sectional Wage Regressions - Females, Cont.

\begin{tabular}{lcccccc}
\hline \hline & 2005 & 2006 & 2007 & 2008 & 2009 & 2010 \\
\hline Variable & $\mathbf{( 1 3 )}$ & $\mathbf{( 1 4 )}$ & $\mathbf{( 1 5 )}$ & $\mathbf{( 1 6 )}$ & $\mathbf{( 1 7 )}$ & $(\mathbf{1 8 )}$ \\
\hline Public & $\begin{array}{c}0.2279^{* * *} \\
(0.0203)\end{array}$ & $\begin{array}{c}0.2242^{* * *} \\
(0.0184)\end{array}$ & $\begin{array}{c}0.2295^{* * *} \\
(0.0188)\end{array}$ & $\begin{array}{c}0.2560^{* * *} \\
(0.0190)\end{array}$ & $\begin{array}{c}0.2857^{* * *} \\
(0.0207)\end{array}$ & $\begin{array}{c}0.2567^{* * *} \\
(0.0214) \\
\text { Constant }\end{array}$ \\
$\begin{array}{c}1.5870^{* * *} \\
(0.1321)\end{array}$ & $\begin{array}{c}1.3567^{* * *} \\
(0.1325)\end{array}$ & $\begin{array}{c}1.7196^{* * *} \\
(0.1392)\end{array}$ & $\begin{array}{c}1.5262^{* * *} \\
(0.1338)\end{array}$ & $\begin{array}{c}1.7586^{* * *} \\
(0.1575)\end{array}$ & $\begin{array}{c}1.5910^{* * *} \\
(0.1456)\end{array}$ \\
\hline Observations & 7,000 & 6,000 & 6,000 & 6,000 & 6,000 & 6,000 \\
$R^{2}$ & 0.3036 & 0.3188 & 0.3044 & 0.3027 & 0.2927 & 0.2899 \\
\hline \hline
\end{tabular}

Table B.7 reports the estimated coefficients from the cross-sectional wage regressions given in Equation (2.3.1). The dependent variable is the log wage of the worker at time $t$. Each model has a set of controls for education (3), union membership (1), province/major city of residence (12), marital status (1), age (1), age squared divided by 100 (1). Longitudinal weights for each person, provided in the SLID, are applied. In parentheses, I report robust standard errors. Observation numbers are rounded as per Statistcs Canada confidentiality rules. Significance levels are indicated by $*, * *, * * *$ for $10 \%, 5 \%$, and $1 \%$ respectively. 
Figure B.9: Estimates of the Public-Private Sector Wage Differential

from Cross-Sectional Models by Gender Canada, 1993 to 2010

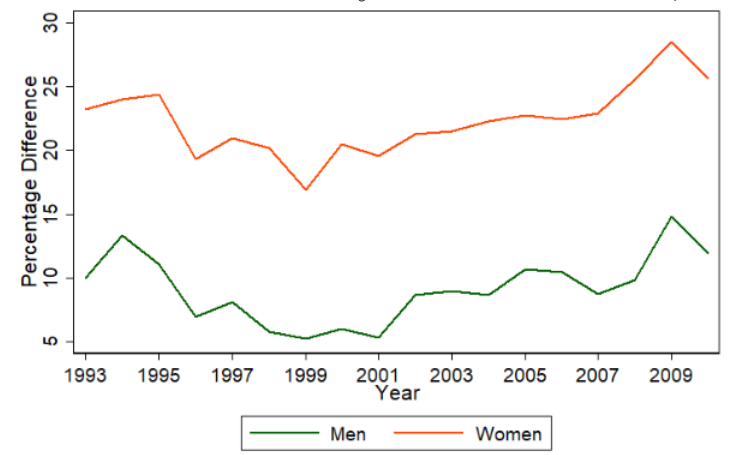

Source: Based on my calculations using data from the Survey of Labour and Income Dynamics (1993 to 2010).

Estimates of the public-private sector wage differential plotted in Figure B.9 are all significant at 1\% as indicated in Tables B.6 and B.7. The confidence bounds have been excluded because they lie on top of and do not cross the plotted lines.

Table B.8: A Comparison of Raw Public-Private Sector Wage Differentials and Estimates from Cross-sectional Regressions

\begin{tabular}{|c|c|c|c|c|c|c|}
\hline Year & $\begin{array}{l}\text { Raw Wage } \\
\text { Males }\end{array}$ & $\begin{array}{r}\text { Differential (A) } \\
\text { Females }\end{array}$ & $\begin{array}{c}\text { Estimates from } \\
\text { Males }\end{array}$ & $\begin{array}{l}\text { Cross-Sectional Models (B) } \\
\text { Females }\end{array}$ & $\begin{array}{l}\text { Difference }(= \\
\text { Males }\end{array}$ & $\begin{array}{l}\text { A - B) } \\
\text { Females }\end{array}$ \\
\hline 1993 & 24.2 & 39.7 & 10.0 & 23.2 & 14.2 & 16.5 \\
\hline 1994 & 24.8 & 39.9 & 13.3 & 24.0 & 11.5 & 15.9 \\
\hline 1995 & 21.9 & 39.0 & 11.1 & 24.4 & 10.8 & 14.6 \\
\hline 1996 & 19.2 & 35.6 & 6.9 & 19.3 & 12.3 & 16.3 \\
\hline 1997 & 21.6 & 37.9 & 8.1 & 21.0 & 13.5 & 16.9 \\
\hline 1998 & 20.2 & 36.5 & 5.8 & 20.1 & 14.4 & 16.4 \\
\hline 1999 & 17.5 & 32.5 & 5.2 & 16.9 & 12.3 & 15.6 \\
\hline 2000 & 18.9 & 35.0 & 6.0 & 20.5 & 12.9 & 14.5 \\
\hline 2001 & 17.5 & 33.4 & 5.3 & 19.6 & 12.2 & 13.8 \\
\hline 2002 & 19.7 & 34.7 & 8.7 & 21.3 & 11.0 & 13.4 \\
\hline 2003 & 21.2 & 34.9 & 8.9 & 21.5 & 12.3 & 13.4 \\
\hline 2004 & 20.5 & 35.1 & 8.7 & 22.3 & 11.8 & 12.8 \\
\hline 2005 & 24.5 & 37.6 & 10.7 & 22.8 & 13.8 & 14.8 \\
\hline 2006 & 24.7 & 36.5 & 10.5 & 22.4 & 14.2 & 14.1 \\
\hline 2007 & 20.6 & 35.4 & 8.7 & 23.0 & 11.9 & 12.4 \\
\hline 2008 & 20.6 & 35.9 & 9.9 & 25.6 & 10.7 & 10.3 \\
\hline 2009 & 24.2 & 37.5 & 14.8 & 28.6 & 9.4 & 8.9 \\
\hline 2010 & 24.0 & 33.6 & 11.9 & 25.7 & 12.1 & 7.9 \\
\hline
\end{tabular}

Table B.8 reports (as percentages) the difference in the average log wage in the private and public sectors; and the public-private sector wage differential estimated using cross-sectional models which were reported in Tables B.6 and B.7. Estimates are based on my calculations using the SLID. Significance levels are indicated by $*, * *, * * *$ for $10 \%, 5 \%$, and $1 \%$ respectively. 
Table B.9: Pooled OLS Wage Regressions - Baseline

\begin{tabular}{|c|c|c|}
\hline & Men & Women \\
\hline Variable & (1) & $(2)$ \\
\hline Public & $\begin{array}{c}0.0870^{* * *} \\
(0.0040)\end{array}$ & $\begin{array}{c}0.2218^{* * *} \\
(0.0045)\end{array}$ \\
\hline Age & $\begin{array}{c}0.0521^{* * *} \\
(0.0017)\end{array}$ & $\begin{array}{c}0.0426^{* * *} \\
(0.0017)\end{array}$ \\
\hline$\left(\mathrm{Age}^{2}\right) / 100$ & $\begin{array}{c}-0.0523^{* * *} \\
(0.0020)\end{array}$ & $\begin{array}{c}-0.0449^{* * *} \\
(0.0020)\end{array}$ \\
\hline Married & $\begin{array}{c}0.1126^{* * *} \\
(0.0042)\end{array}$ & $\begin{array}{c}0.0228^{* * *} \\
(0.0040)\end{array}$ \\
\hline High School & $\begin{array}{c}0.1547^{* * * *} \\
(0.0054)\end{array}$ & $\begin{array}{c}0.2452^{* * *} \\
(0.0065)\end{array}$ \\
\hline Non-University Post-Secondary & $\begin{array}{c}0.2489^{* * *} \\
(0.0051)\end{array}$ & $\begin{array}{c}0.3334^{* * *} \\
(0.0063)\end{array}$ \\
\hline University & $\begin{array}{c}0.5103^{* * *} * \\
(0.0063)\end{array}$ & $\begin{array}{c}0.6142^{* * *} * \\
(0.0072)\end{array}$ \\
\hline Union Member & $\begin{array}{c}0.0519^{* * *} * \\
(0.0036)\end{array}$ & $\begin{array}{c}0.0685^{* * *} \\
(0.0043)\end{array}$ \\
\hline Ontario (other) & $\begin{array}{c}0.0125^{*} \\
(0.0067)\end{array}$ & $\begin{array}{c}-0.0651^{* * *} \\
(0.0073)\end{array}$ \\
\hline Montreal & $\begin{array}{c}-0.0460^{* * *} \\
(0.0092)\end{array}$ & $\begin{array}{c}-0.0740^{* * *} \\
(0.0094)\end{array}$ \\
\hline Quebec (other) & $\begin{array}{c}-0.1159^{* * *} \\
(0.0070)\end{array}$ & $\begin{array}{c}-0.1711^{* * *} \\
(0.0076)\end{array}$ \\
\hline Vancouver & $\begin{array}{c}0.0066 \\
(0.0103)\end{array}$ & $\begin{array}{c}-0.0337^{* * *} \\
(0.0104)\end{array}$ \\
\hline British Columbia (other) & $\begin{array}{c}0.0115 \\
(0.0084)\end{array}$ & $\begin{array}{c}-0.0918^{* * *} \\
(0.0091)\end{array}$ \\
\hline Alberta & $\begin{array}{c}0.0616^{* * *} \\
(0.0080)\end{array}$ & $\begin{array}{c}-0.0760^{* * *} \\
(0.0087)\end{array}$ \\
\hline Manitoba & $\begin{array}{c}-0.1293^{* * *} \\
(0.0081)\end{array}$ & $\begin{array}{c}-0.1811^{* * *} \\
(0.0085)\end{array}$ \\
\hline New Brunswick & $\begin{array}{c}-0.0842^{* * *} \\
(0.0082)\end{array}$ & $\begin{array}{c}-0.2039^{* * *} * \\
(0.0086)\end{array}$ \\
\hline Newfoundland and Labrador & $\begin{array}{c}-0.2045^{* * *} \\
(0.0081)\end{array}$ & $\begin{array}{c}-0.2766^{* * *} \\
(0.0085)\end{array}$ \\
\hline Nova Scotia & $\begin{array}{c}-0.1908^{* * *} \\
(0.0100)\end{array}$ & $\begin{array}{c}-0.3181^{* * *} \\
(0.0094)\end{array}$ \\
\hline Prince Edward Island & $\begin{array}{c}-0.1832^{* * *} \\
(0.0084)\end{array}$ & $\begin{array}{c}-0.2545^{* * *} \\
(0.0086)\end{array}$ \\
\hline Saskatchewan & $\begin{array}{c}-0.3049^{* * *} \\
(0.0117)\end{array}$ & $\begin{array}{c}-0.2771^{* * *} * \\
(0.0097)\end{array}$ \\
\hline
\end{tabular}


Table B.9: Pooled OLS Wage Regressions - Baseline, Cont.

\begin{tabular}{lcc}
\hline \hline Variable & Men & Women \\
\hline Constant & $(\mathbf{1})$ & $\mathbf{( 2 )}$ \\
\hline Observations & $1.6611^{* * *}$ & $1.6779^{* * *}$ \\
Individuals & $(0.0342)$ & $(0.0352)$ \\
$R^{2}$ & 115,000 & 103,000 \\
\hline \hline
\end{tabular}

Table B.9 reports the estimated coefficients from the pooled OLS wage regressions given in Equation (2.3.2). The dependent variable is the log wage of the worker at time $t$. Longitudinal weights for each person, provided in the SLID, are applied. In parentheses, I report standard errors clustered at the person level. Observation numbers are rounded as per Statistcs Canada confidentiality rules. Significance levels are indicated by $*, * *, * * *$ for $10 \%, 5 \%$, and $1 \%$ respectively.

Table B.10: Pooled OLS Wage Regressions - Controlling for the Number of Children

\begin{tabular}{lcc}
\hline \hline & Men & Women \\
\hline Variable & $(\mathbf{1})$ & $(\mathbf{2})$ \\
Public & $0.0863^{* * *}$ & $0.2219^{* * *}$ \\
& $(0.0040)$ & $(0.0045)$ \\
Number of Children & $0.0201^{* * *}$ & $-0.0043^{* *}$ \\
& $(0.0018)$ & $(0.0021)$ \\
Constant & $1.7741^{* * *}$ & $1.6583^{* * *}$ \\
& $(0.0355)$ & $(0.0365)$ \\
\hline Observations & 116,000 & 103,000 \\
Individuals & 36,000 & 34,000 \\
$R^{2}$ & 0.2337 & 0.2968 \\
\hline \hline
\end{tabular}

Table B.10 reports the estimated coefficients from the pooled OLS wage regressions given in Equation (2.3.2). The dependent variable is the log wage of the worker at time $t$. Each model has a set of controls for education (3), union membership (1), province/major city of residence (12), marital status (1), age (1), age squared divided by 100 (1). The regressions also control for the number of children as a proxy for the number of absences from the job market so as to correct for the age-based experience of the workers.

Longitudinal weights for each person, provided in the SLID, are applied. In parentheses, I report standard errors clustered at the person level. Observation numbers are rounded as per Statistcs Canada confidentiality rules. Significance levels are indicated by *,**, *** for $10 \%, 5 \%$, and $1 \%$ respectively. 
Table B.11: Pooled OLS Wage Regressions - Public Administration

\begin{tabular}{|c|c|c|}
\hline & Men & Women \\
\hline Variable & $(1)$ & $(2)$ \\
\hline Public Administration & $\begin{array}{c}0.1328^{* * *} \\
(0.0044)\end{array}$ & $\begin{array}{c}0.1708^{* * *} \\
(0.0055)\end{array}$ \\
\hline Constant & $\begin{array}{c}1.6558^{* * *} \\
(0.0341)\end{array}$ & $\begin{array}{c}1.6394^{* * * *} \\
(0.0357)\end{array}$ \\
\hline Observations & 115,000 & 103,000 \\
\hline Individuals & 36,000 & 33,000 \\
\hline$R^{2}$ & 0.2340 & 0.2779 \\
\hline
\end{tabular}

Table B.11 reports the estimated coefficients from the pooled OLS wage regressions given in Equation (2.3.2). The dependent variable is the log wage of the worker at time $t$. Each model has a set of controls for education (3), union membership (1), province/major city of residence (12), marital status (1), age (1), age squared divided by 100 (1). The Public indicator variable is replaced with a dummy variable (Public_Admin) categorizing the public and private sectors using the NAICS codes of the employers. Longitudinal weights for each person, provided in the SLID, are applied. In parentheses, I report standard errors clustered at the person level. Observation numbers are rounded as per Statistcs Canada confidentiality rules. Significance levels are indicated by *,**, *** for $10 \%, 5 \%$, and $1 \%$ respectively.

Table B.12: Pooled OLS Wage Regressions - Controlling for Firm Size

\begin{tabular}{lcc}
\hline \hline & Men & Women \\
\hline Variable & $(\mathbf{1})$ & $(\mathbf{2})$ \\
\hline Public & $0.0708^{* * *}$ & $0.1848^{* * *}$ \\
& $(0.0040)$ & $(0.0045)$ \\
20 to 99 Employees & $0.1027^{* * *}$ & $0.0998^{* * *}$ \\
& $(0.0048)$ & $(0.0047)$ \\
100 to 499 Employees & $0.1844^{* * *}$ & $0.1935^{* * *}$ \\
500 to 999 Employees & $(0.0050)$ & $(0.0054)$ \\
& $0.2371^{* * *}$ & $0.2613^{* * *}$ \\
$1000+$ Employees & $(0.0072)$ & $(0.0073)$ \\
& $0.2912^{* * *}$ & $0.2807^{* * *}$ \\
Constant & $(0.0063)$ & $(0.0068)$ \\
& $1.6203^{* * *}$ & $1.6076^{* * *}$ \\
& $(0.0336)$ & $(0.0343)$ \\
\hline Observations & 115,000 & 103,000 \\
Individuals & 36,000 & 33,000 \\
$R^{2}$ & 0.2690 & 0.3327 \\
\hline \hline
\end{tabular}

Table B.12 reports the estimated coefficients from the pooled OLS wage regressions given in Equation (2.3.2). The dependent variable is the log wage of the worker at time $t$. Each model has a set of controls for education (3), union membership (1), province/major city of residence (12), marital status (1), age (1), age squared divided by 100 (1). Controls are included for the size of the employer as proxied by the number of employees. Longitudinal weights for each person, provided in the SLID, are applied. In parentheses, I report standard errors clustered at the person level. Observation numbers are rounded as per Statistcs Canada confidentiality rules. Significance levels are indicated by $* * *, * * *$ for $10 \%, 5 \%$, and $1 \%$ respectively. 
Table B.13: Pooled OLS Wage Regressions

- Excluding Observations Associated With Wages Above $\$ 1,000$

\begin{tabular}{lcc}
\hline \hline Variable & Men & Women \\
\hline Public & $\mathbf{( 1 )}$ & $\mathbf{( 2 )}$ \\
Constant & $0.0884^{* * *}$ & $\begin{array}{c}(0.0040) \\
(0.0043)\end{array}$ \\
\hline Observations & $\begin{array}{c}1.6596^{* * *} \\
(0.0339)\end{array}$ & $\begin{array}{c}1.6661^{* * *} \\
(0.0330)\end{array}$ \\
Individuals & 115,000 & 103,000 \\
$R^{2}$ & 36,000 & 33,000 \\
\hline \hline
\end{tabular}

Table B.13 reports the estimated coefficients from the pooled OLS wage regressions given in Equation (2.3.2). The dependent variable is the log wage of the worker at time $t$. Each model has a set of controls for education (3), union membership (1), province/major city of residence (12), marital status (1), age (1), age squared divided by 100 (1). Observations where real wages greater than $\$ 1,000$ are excluded.

Longitudinal weights for each person, provided in the SLID, are applied. In parentheses, I report standard errors clustered at the person level. Observation numbers are rounded as per Statistcs Canada confidentiality rules. Significance levels are indicated by *,**, *** for $10 \%, 5 \%$, and $1 \%$ respectively.

Table B.14: Pooled OLS Wage Regressions - Winsorization

\begin{tabular}{|c|c|c|c|c|}
\hline \multirow[b]{2}{*}{ Variable } & \multicolumn{2}{|c|}{ Men } & \multicolumn{2}{|c|}{ Women } \\
\hline & (1) & $(2)$ & (3) & $(4)$ \\
\hline Public & $\begin{array}{c}0.0975^{* * *} \\
(0.0037)\end{array}$ & $\begin{array}{c}0.0962^{* * *} \\
(0.0037)\end{array}$ & $\begin{array}{c}0.2278^{* * *} * \\
(0.0042)\end{array}$ & $\begin{array}{c}0.2226^{* * *} \\
(0.0041)\end{array}$ \\
\hline Constant & $\begin{array}{c}1.7304^{* * *} \\
(0.0324)\end{array}$ & $\begin{array}{c}1.7486^{* * *} \\
(0.0316)\end{array}$ & $\begin{array}{c}1.7195^{* * *} \\
(0.0324)\end{array}$ & $\begin{array}{c}1.7458^{* * *} \\
(0.0317)\end{array}$ \\
\hline Excluding Top $1 \%$ & $\checkmark$ & $\checkmark$ & $\checkmark$ & $\checkmark$ \\
\hline Excluding Bottom $1 \%$ & & $\checkmark$ & & $\checkmark$ \\
\hline Observations & 114,000 & 113,000 & 103,000 & 101,000 \\
\hline Individuals & 35,000 & 35,000 & 33,000 & 33,000 \\
\hline$R^{2}$ & 0.2320 & 0.2384 & 0.3271 & 0.3271 \\
\hline
\end{tabular}

Table B.14 reports the estimated coefficients from the pooled OLS wage regressions given in Equation (2.3.2). The dependent variable is the log wage of the worker at time $t$. Each model has a set of controls for education (3), union membership (1), province/major city of residence (12), marital status (1), age (1), age squared divided by 100 (1). In columns (1) and (3), observations associated with real wages in the top $1 \%$ of the wage distribution of the sample are excluded. Similarly, in columns (2) and (4), observations associated with real wages in the top and bottom $1 \%$ of the wage distribution of the sample are excluded. Longitudinal weights for each person, provided in the SLID, are applied. In parentheses, I report standard errors clustered at the person level. Observation numbers are rounded as per Statistcs Canada confidentiality rules. Significance levels are indicated by *,**, *** for $10 \%, 5 \%$, and $1 \%$ respectively. 
Table B.15: Fixed Effects Wage Regressions - Baseline

\begin{tabular}{|c|c|c|c|c|}
\hline \multirow[b]{2}{*}{ Variable } & \multicolumn{2}{|c|}{ Men } & \multicolumn{2}{|c|}{ Women } \\
\hline & (1) & $(2)$ & $(3)$ & $(4)$ \\
\hline Public & $\begin{array}{c}0.0315^{*} \\
(0.0162)\end{array}$ & $\begin{array}{c}0.0334^{* *} \\
(0.0160)\end{array}$ & $\begin{array}{c}0.0650^{* * *} \\
(0.0137)\end{array}$ & $\begin{array}{c}0.0655^{* * *} \\
(0.0134)\end{array}$ \\
\hline Age & $\begin{array}{c}0.0762^{* * *} \\
(0.0038)\end{array}$ & $\begin{array}{c}0.0756^{* * *} \\
(0.0038)\end{array}$ & $\begin{array}{c}0.0693^{* * *} \\
(0.0041)\end{array}$ & $\begin{array}{c}0.0676^{* * *} \\
(0.0041)\end{array}$ \\
\hline$\left(\mathrm{Age}^{2}\right) / 100$ & $\begin{array}{c}-0.0626^{* * *} \\
(0.0044)\end{array}$ & $\begin{array}{c}-0.0620^{* * *} \\
(0.0044)\end{array}$ & $\begin{array}{c}-0.0544^{* * *} \\
(0.0047)\end{array}$ & $\begin{array}{c}-0.0526^{* * *} \\
(0.0047)\end{array}$ \\
\hline Married & $\begin{array}{c}0.0173^{* *} \\
(0.0070)\end{array}$ & $\begin{array}{c}0.0179^{* * *} * \\
(0.0069)\end{array}$ & $\begin{array}{c}0.0220^{* * *} \\
(0.0084)\end{array}$ & $\begin{array}{c}0.0218^{* * * *} \\
(0.0083)\end{array}$ \\
\hline High School & $\begin{array}{l}-0.0256 \\
(0.0237)\end{array}$ & $\begin{array}{l}-0.0248 \\
(0.0236)\end{array}$ & $\begin{array}{c}-0.0540^{*} \\
(0.0297)\end{array}$ & $\begin{array}{c}-0.0606^{* *} \\
(0.0291)\end{array}$ \\
\hline Non-University Post-Secondary & $\begin{array}{c}0.0141 \\
(0.0225)\end{array}$ & $\begin{array}{c}0.0142 \\
(0.0224)\end{array}$ & $\begin{array}{c}-0.0298 \\
(0.0258)\end{array}$ & $\begin{array}{l}-0.0402 \\
(0.0253)\end{array}$ \\
\hline University & $\begin{array}{c}0.0596 \\
(0.0446)\end{array}$ & $\begin{array}{c}0.0606 \\
(0.0446)\end{array}$ & $\begin{array}{c}0.0454 \\
(0.0283)\end{array}$ & $\begin{array}{c}0.0354 \\
(0.0277)\end{array}$ \\
\hline Union Member & $\begin{array}{c}0.0222^{* * *} \\
(0.0064)\end{array}$ & $\begin{array}{c}0.0220^{* * *} * \\
(0.0063)\end{array}$ & $\begin{array}{c}0.0342^{* * *} \\
(0.0071)\end{array}$ & $\begin{array}{c}0.0332^{* * * *} \\
(0.0070)\end{array}$ \\
\hline Ontario (other) & $\begin{array}{c}-0.0002 \\
(0.0223)\end{array}$ & $\begin{array}{c}-0.0005 \\
(0.0217)\end{array}$ & $\begin{array}{c}-0.0106 \\
(0.0366)\end{array}$ & $\begin{array}{c}-0.0049 \\
(0.0366)\end{array}$ \\
\hline Montreal & $\begin{array}{c}0.0099 \\
(0.0398)\end{array}$ & $\begin{array}{c}0.0090 \\
(0.0400)\end{array}$ & $\begin{array}{l}-0.0540 \\
(0.0467)\end{array}$ & $\begin{array}{c}-0.0554 \\
(0.0471)\end{array}$ \\
\hline Quebec (other) & $\begin{array}{l}-0.0321 \\
(0.0405)\end{array}$ & $\begin{array}{l}-0.0314 \\
(0.0408)\end{array}$ & $\begin{array}{c}-0.0920^{*} \\
(0.0499)\end{array}$ & $\begin{array}{c}-0.0899^{*} \\
(0.0501)\end{array}$ \\
\hline Vancouver & $\begin{array}{l}-0.0275 \\
(0.0406)\end{array}$ & $\begin{array}{c}-0.0293 \\
(0.0397)\end{array}$ & $\begin{array}{c}0.0473 \\
(0.0607)\end{array}$ & $\begin{array}{c}0.0491 \\
(0.0591)\end{array}$ \\
\hline British Columbia (other) & $\begin{array}{c}-0.0392 \\
(0.0463)\end{array}$ & $\begin{array}{c}-0.0425 \\
(0.0453)\end{array}$ & $\begin{array}{l}-0.0060 \\
(0.0829)\end{array}$ & $\begin{array}{c}0.0026 \\
(0.0799)\end{array}$ \\
\hline Alberta & $\begin{array}{c}-0.0330 \\
(0.0440)\end{array}$ & $\begin{array}{c}-0.0363 \\
(0.0432)\end{array}$ & $\begin{array}{l}-0.0674 \\
(0.0545)\end{array}$ & $\begin{array}{c}-0.0604 \\
(0.0533)\end{array}$ \\
\hline Manitoba & $\begin{array}{c}-0.0574 \\
(0.0578)\end{array}$ & $\begin{array}{c}-0.0613 \\
(0.0579)\end{array}$ & $\begin{array}{l}-0.0239 \\
(0.0565)\end{array}$ & $\begin{array}{l}-0.0167 \\
(0.0554)\end{array}$ \\
\hline New Brunswick & $\begin{array}{c}-0.1247^{* *} \\
(0.0501)\end{array}$ & $\begin{array}{c}-0.1250^{* *} \\
(0.0486)\end{array}$ & $\begin{array}{l}-0.1149 \\
(0.0845)\end{array}$ & $\begin{array}{c}-0.1098 \\
(0.0842)\end{array}$ \\
\hline Newfoundland and Labrador & $\begin{array}{c}-0.1549^{* *} \\
(0.0697)\end{array}$ & $\begin{array}{c}-0.1443^{* *} \\
(0.0686)\end{array}$ & $\begin{array}{c}-0.2202^{* * *} \\
(0.0601)\end{array}$ & $\begin{array}{c}-0.2150^{* * *} \\
(0.0604)\end{array}$ \\
\hline Nova Scotia & $\begin{array}{c}-0.1431^{*} \\
(0.0738)\end{array}$ & $\begin{array}{c}-0.1320^{* *} \\
(0.0665)\end{array}$ & $\begin{array}{c}-0.1738^{* *} \\
(0.0876)\end{array}$ & $\begin{array}{c}-0.1668^{*} \\
(0.0897)\end{array}$ \\
\hline Prince Edward Island & $\begin{array}{c}-0.1146^{*} \\
(0.0626)\end{array}$ & $\begin{array}{c}-0.1100^{*} \\
(0.0603)\end{array}$ & $\begin{array}{c}-0.1767^{* *} \\
(0.0693)\end{array}$ & $\begin{array}{c}-0.1760^{* *} \\
(0.0719)\end{array}$ \\
\hline Saskatchewan & $\begin{array}{l}-0.1001 \\
(0.0703)\end{array}$ & $\begin{array}{l}-0.1087 \\
(0.0703)\end{array}$ & $\begin{array}{l}-0.0327 \\
(0.0698)\end{array}$ & $\begin{array}{c}-0.0241 \\
(0.0690)\end{array}$ \\
\hline
\end{tabular}


Table B.15: Fixed Effects Wage Regressions - Baseline, Cont.

\begin{tabular}{lcccc}
\hline \hline & \multicolumn{2}{c}{ Men } & \multicolumn{2}{c}{ Women } \\
\hline Variable & $\mathbf{( 1 )}$ & $\mathbf{( 2 )}$ & $\mathbf{( 3 )}$ & $\mathbf{( 4 )}$ \\
\hline Constant & $\begin{array}{c}1.1824^{* * *} \\
(0.0884)\end{array}$ & $\begin{array}{c}1.1940^{* * *}(0.0874) \\
\text { Person and Panel FE }\end{array}$ & $\begin{array}{c}1.1278^{* * *} \\
(0.0968)\end{array}$ & $\begin{array}{c}1.1718^{* * *} \\
(0.0959)\end{array}$ \\
\hline $\begin{array}{l}\text { Occupation FE } \\
\text { Observations }\end{array}$ & & $\checkmark$ & $\checkmark$ & $\checkmark$ \\
Individuals & 107,000 & 107,000 & 94,000 & 94,000 \\
$R^{2}$ & 27,000 & 27,000 & 25,000 & 25,000 \\
\hline \hline
\end{tabular}

Table B.15 reports the estimated coefficients from the fixed effects wage regression given in Equation (2.3.5). The dependent variable is the log wage of the worker at time $t$. Longitudinal weights for each person, provided in the SLID, are applied. In parentheses, I report standard errors clustered at the person level. Observation numbers are rounded as per Statistcs Canada confidentiality rules. Significance levels are indicated by $*, * *, * * *$ for $10 \%, 5 \%$, and $1 \%$ respectively.

Table B.16: Fixed Effects Wage Regressions - Controlling for the Number of Children

\begin{tabular}{lcccc}
\hline \multicolumn{2}{c}{ Men } & \multicolumn{2}{c}{ Women } \\
\hline Variable & $\mathbf{( 1 )}$ & $\mathbf{( 2 )}$ & $\mathbf{3})$ & $(\mathbf{4})$ \\
\hline \multirow{2}{*}{ Public } & $0.0314^{*}$ & $0.0333^{* *}$ & $0.0647^{* * *}$ & $0.0652^{* * *}$ \\
& $(0.0162)$ & $(0.0160)$ & $(0.0137)$ & $(0.0134)$ \\
Number of Children & 0.0031 & 0.0032 & $-0.0069^{*}$ & $-0.0065^{*}$ \\
& $(0.0031)$ & $(0.0030)$ & $(0.0037)$ & $(0.0036)$ \\
Constant & $1.1994^{* * *}$ & $1.2116^{* * *}$ & $1.1017^{* * *}$ & $1.1467^{* * *}$ \\
& $(0.0894)$ & $(0.0885)$ & $(0.0981)$ & $(0.0970)$ \\
\hline \multirow{2}{*}{ Person and Panel FE } & $\checkmark$ & $\checkmark$ & $\checkmark$ & $\checkmark$ \\
Occupation FE & $\checkmark$ & $\checkmark$ & & $\checkmark$ \\
Observations & 107,000 & 107,000 & 94,000 & 94,000 \\
$R^{2}$ & 27,000 & 27,000 & 25,000 & 25,000 \\
\hline \hline
\end{tabular}

Table B.16 reports the estimated coefficients from the fixed effects wage regression given in Equation (2.3.5). The dependent variable is the log wage of the worker at time $t$. Each model has a set of controls for education (3), union membership (1), province/major city of residence (12), marital status (1), age (1), age squared divided by 100 (1). The regressions also control for the number of children as a proxy for the number of absences from the job market so as to correct for the age-based experience of the workers. Longitudinal weights for each person, provided in the SLID, are applied. In parentheses, I report standard errors clustered at the person level. Observation numbers are rounded as per Statistcs Canada confidentiality rules. Significance levels are indicated by $*, * *, * * *$ for $10 \%, 5 \%$, and $1 \%$ respectively. 
Table B.17: Fixed Effects Wage Regressions - Public Administration

\begin{tabular}{|c|c|c|c|c|}
\hline \multirow[b]{2}{*}{ Variable } & \multicolumn{2}{|c|}{ Men } & \multicolumn{2}{|c|}{ Women } \\
\hline & (1) & $(2)$ & $(3)$ & $(4)$ \\
\hline Public Administration & $\begin{array}{c}0.0397^{* *} \\
(0.0163)\end{array}$ & $0.0421^{* * *}$ & $0.0488^{* * *}$ & $0.0513 * * *$ \\
\hline Constant & $\begin{array}{c}1.1835^{* * * *} \\
(0.0884)\end{array}$ & $\begin{array}{c}1.1954^{* * *} * \\
(0.0874)\end{array}$ & $\begin{array}{c}1.1355^{* * *} \\
(0.0971)\end{array}$ & $\begin{array}{c}1.1808^{* * * *} \\
(0.0961)\end{array}$ \\
\hline $\begin{array}{l}\text { Person and Panel FE } \\
\text { Occupation FE }\end{array}$ & $\checkmark$ & $\checkmark$ & $\checkmark$ & $\checkmark$ \\
\hline Observations & 107,000 & 107,000 & 94,000 & 94,000 \\
\hline Individuals & 27,000 & 27,000 & 25,000 & 25,000 \\
\hline$R^{2}$ & 0.8602 & 0.8607 & 0.8665 & 0.8670 \\
\hline
\end{tabular}

Table B.17 reports the estimated coefficients from the fixed effects wage regression given in Equation (2.3.5). The dependent variable is the log wage of the worker at time $t$. Each model has a set of controls for education (3), union membership (1), province/major city of residence (12), marital status (1), age (1), age squared divided by 100 (1). The Public indicator variable is replaced with a dummy variable (Public_Admin) categorizing the public and private sectors using the NAICS codes of the employers. Longitudinal weights for each person, provided in the SLID, are applied. In parentheses, I report standard errors clustered at the person level. Observation numbers are rounded as per Statistcs Canada confidentiality rules. Significance levels are indicated by *,**, *** for $10 \%, 5 \%$, and $1 \%$ respectively.

Table B.18: Fixed Effects Wage Regressions - Controlling for Firm Size

\begin{tabular}{lcccc}
\hline \hline & \multicolumn{2}{c}{ Men } & \multicolumn{2}{c}{ Women } \\
\hline Variable & $(\mathbf{1})$ & $\mathbf{( 2 )}$ & $\mathbf{( 3 )}$ & $\mathbf{( 4 )}$ \\
\hline \multirow{2}{*}{ Public } & $0.0272^{*}$ & $0.0293^{*}$ & $0.0606^{* * *}$ & $0.0610^{* * *}$ \\
& $(0.0162)$ & $(0.0160)$ & $(0.0136)$ & $(0.0134)$ \\
20 to 99 Employees & $0.0102^{* *}$ & $0.0096^{*}$ & $0.0211^{* * *}$ & $0.0211^{* * *}$ \\
& $(0.0050)$ & $(0.0050)$ & $(0.0056)$ & $(0.0056)$ \\
100 to 499 Employees & $0.0167^{* * *}$ & $0.0162^{* * *}$ & $0.0358^{* * *}$ & $0.0358^{* * *}$ \\
& $(0.0061)$ & $(0.0061)$ & $(0.0064)$ & $(0.0064)$ \\
500 to 999 Employees & $0.0273^{* * *}$ & $0.0263^{* * *}$ & $0.0359^{* * *}$ & $0.0353^{* * *}$ \\
& $(0.0078)$ & $(0.0077)$ & $(0.0085)$ & $(0.0084)$ \\
$1000+$ Employees & $0.0353^{* * *}$ & $0.0340^{* * *}$ & $0.0379^{* * *}$ & $0.0374^{* * *}$ \\
& $(0.0082)$ & $(0.0081)$ & $(0.0079)$ & $(0.0078)$ \\
Constant & $1.1804^{* * *}$ & $1.1924^{* * *}$ & $1.1175^{* * *}$ & $1.1614^{* * *}$ \\
& $(0.0882)$ & $(0.0873)$ & $(0.0966)$ & $(0.0956)$ \\
\hline \multirow{2}{*}{ Person and Panel FE } & & & & $\checkmark$ \\
Occupation FE & $\checkmark$ & $\checkmark$ & $\checkmark$ & $\checkmark$ \\
Observations & & $\checkmark$ & & $\checkmark$ \\
Individuals & 107,000 & 107,000 & 94,000 & 94,000 \\
$R^{2}$ & 27,000 & 27,000 & 25,000 & 25,000 \\
\hline \hline
\end{tabular}

Table B.18 reports the estimated coefficients from the fixed effects wage regression given in Equation (2.3.5). The dependent variable is the log wage of the worker at time $t$. Each model has a set of controls for education (3), union membership (1), province/major city of residence (12), marital status (1), age (1), age squared divided by 100 (1). Controls are included for the size of the employer as proxied by the number of employees. Longitudinal weights for each person, provided in the SLID, are applied. In parentheses, I report standard errors clustered at the person level. Observation numbers are rounded as per Statistcs Canada confidentiality rules. Significance levels are indicated by $* * * * * * *$ for $10 \%, 5 \%$, and $1 \%$ respectively. 
Table B.19: Fixed Effects Wage Regressions

- Excluding Observations Associated With Wages Above $\$ 1,000$

\begin{tabular}{lcccc}
\hline \hline \multicolumn{2}{c}{ Men } & \multicolumn{2}{c}{ Women } \\
\hline Variable & $\mathbf{( 1 )}$ & $\mathbf{( 2 )}$ & $\mathbf{( 3 )}$ & $\mathbf{( 4 )}$ \\
\hline Public & $\begin{array}{c}0.0444^{* * *} \\
(0.0147)\end{array}$ & $\begin{array}{c}0.0461^{* * *} \\
(0.0146)\end{array}$ & $\begin{array}{c}0.0714^{* * *} \\
(0.0128)\end{array}$ & $\begin{array}{c}0.0698^{* * *} \\
(0.0124)\end{array}$ \\
Constant & $\begin{array}{c}1.1904^{* * *} \\
(0.0867)\end{array}$ & $\begin{array}{c}1.2037^{* * *} \\
(0.0858)\end{array}$ & $\begin{array}{c}1.0951^{* * *} \\
(0.0872)\end{array}$ & $\begin{array}{c}1.1410^{* * *} \\
(0.0859)\end{array}$ \\
\hline Person and Panel FE & \multicolumn{2}{c}{} & $\checkmark$ & $\checkmark$ \\
Occupation FE & $\checkmark$ & $\checkmark$ & $\checkmark$ & $\checkmark$ \\
Observations & 107,000 & 107,000 & 94,000 & 94,000 \\
Individuals & 27,000 & 27,000 & 25,000 & 25,000 \\
$R^{2}$ & 0.8729 & 0.8734 & 0.9098 & 0.9102 \\
\hline \hline
\end{tabular}

Table B.19 reports the estimated coefficients from the fixed effects wage regression given in Equation (2.3.5). The dependent variable is the log wage of the worker at time $t$. Each model has a set of controls for education (3), union membership (1), province/major city of residence (12), marital status (1), age (1), age squared divided by 100 (1). Observations where real wages greater than $\$ 900$ are excluded.

Longitudinal weights for each person, provided in the SLID, are applied. In parentheses, I report standard errors clustered at the person level. Observation numbers are rounded as per Statistcs Canada confidentiality rules. Significance levels are indicated by *,**, *** for $10 \%, 5 \%$, and $1 \%$ respectively.

Table B.20: Fixed Effects Wage Regressions - Winsorization (Top 1\%)

\begin{tabular}{|c|c|c|c|c|}
\hline \multirow[b]{2}{*}{ Variable } & \multicolumn{2}{|c|}{ Men } & \multicolumn{2}{|c|}{ Women } \\
\hline & (1) & $(2)$ & (3) & $(4)$ \\
\hline Public & $\begin{array}{c}0.0455^{* * *} \\
(0.0149)\end{array}$ & $\begin{array}{c}0.0466^{* * *} \\
(0.0147)\end{array}$ & $\begin{array}{c}0.0707 * * * \\
(0.0126)\end{array}$ & $\begin{array}{c}0.0691^{* * *} \\
(0.0122)\end{array}$ \\
\hline Constant & $\begin{array}{c}1.1917^{* * * *} \\
(0.0836)\end{array}$ & $\begin{array}{c}1.2081^{* * *} \\
(0.0827)\end{array}$ & $\begin{array}{c}1.1280^{* * *} \\
(0.0850)\end{array}$ & $\begin{array}{c}1.1753^{* * *} \\
(0.0837)\end{array}$ \\
\hline $\begin{array}{l}\text { Person and Panel FE } \\
\text { Occupation FE }\end{array}$ & $\checkmark$ & $\begin{array}{l}\checkmark \\
\checkmark\end{array}$ & $\checkmark$ & $\begin{array}{l}\checkmark \\
\checkmark\end{array}$ \\
\hline Observations & 105,000 & 105,000 & 94,000 & 94,000 \\
\hline Individuals & 27,000 & 27,000 & 25,000 & 25,000 \\
\hline$R^{2}$ & 0.8715 & 0.8720 & 0.9121 & 0.9125 \\
\hline
\end{tabular}

Table B.20 reports the estimated coefficients from the fixed effects wage regression given in Equation (2.3.5). The dependent variable is the log wage of the worker at time $t$. Each model has a set of controls for education (3), union membership (1), province/major city of residence (12), marital status (1), age (1), age squared divided by 100 (1). Estimations reported in this table exclude observations associated with real wages in the top $1 \%$ of the wage distribution of the sample. Longitudinal weights for each person, provided in the SLID, are applied. In parentheses, I report standard errors clustered at the person level. Observation numbers are rounded as per Statistcs Canada confidentiality rules. Significance levels are indicated by $* * *, * * *$ for $10 \%, 5 \%$, and $1 \%$ respectively. 
Table B.21: Fixed Effects Wage Regressions - Winsorization (Top and Bottom 1\%)

\begin{tabular}{|c|c|c|c|c|}
\hline \multirow[b]{2}{*}{ Variable } & \multicolumn{2}{|c|}{ Men } & \multicolumn{2}{|c|}{ Women } \\
\hline & $(1)$ & $(2)$ & $(3)$ & $(4)$ \\
\hline Public & $\begin{array}{c}0.0444^{* * *} \\
(0.0146)\end{array}$ & $\begin{array}{c}0.0454^{* * *} \\
(0.0144)\end{array}$ & $\begin{array}{c}0.0624^{* * *} \\
(0.0123)\end{array}$ & $\begin{array}{c}0.0615^{* * *} \\
(0.0119)\end{array}$ \\
\hline Constant & $\begin{array}{c}1.1989^{* * *} \\
(0.0813)\end{array}$ & $\begin{array}{c}1.2154^{* * *} \\
(0.0804)\end{array}$ & $\begin{array}{c}1.1628^{* * *} \\
(0.0836)\end{array}$ & $\begin{array}{c}1.2089^{* * *} \\
(0.0822)\end{array}$ \\
\hline Person and Panel FE & $\checkmark$ & $\checkmark$ & $\checkmark$ & $\checkmark$ \\
\hline Occupation FE & & $\checkmark$ & & $\checkmark$ \\
\hline Observations & 105,000 & 105,000 & 92,000 & 92,000 \\
\hline Individuals & 27,000 & 27,000 & 24,000 & 24,000 \\
\hline$R^{2}$ & 0.8775 & 0.8781 & 0.9157 & 0.9162 \\
\hline
\end{tabular}

Table B.21 reports the estimated coefficients from the fixed effects wage regression given in Equation (2.3.5). The dependent variable is the log wage of the worker at time $t$. Each model has a set of controls for education (3), union membership (1), province/major city of residence (12), marital status (1), age (1), age squared divided by 100 (1). Estimations reported in this table exclude observations associated with real wages in the top and bottom $1 \%$ of the wage distribution of the sample. Longitudinal weights for each person, provided in the SLID, are applied. In parentheses, I report standard errors clustered at the person level. Observation numbers are rounded as per Statistcs Canada confidentiality rules. Significance levels are indicated by $*, * *, * * *$ for $10 \%, 5 \%$, and $1 \%$ respectively. 
Table B.22: First Difference OLS Wage Regressions

\begin{tabular}{|c|c|c|}
\hline Variable & $\begin{array}{c}\text { Men } \\
(1)\end{array}$ & $\begin{array}{c}\text { Women } \\
(2)\end{array}$ \\
\hline Public & $\begin{array}{c}0.0422^{*} \\
(0.0243)\end{array}$ & $\begin{array}{c}0.0851^{* * * *} \\
(0.0193)\end{array}$ \\
\hline Age & $\begin{array}{c}-0.0053^{* * *} \\
(0.0011)\end{array}$ & $\begin{array}{c}-0.0037 * * * \\
(0.0011)\end{array}$ \\
\hline$\left(\mathrm{Age}^{2}\right) / 100$ & $\begin{array}{c}0.0049 * * * \\
(0.0013)\end{array}$ & $\begin{array}{c}0.0032^{* *} \\
(0.0013)\end{array}$ \\
\hline Married & $\begin{array}{c}0.0126 \\
(0.0080)\end{array}$ & $\begin{array}{c}0.0163^{* *} \\
(0.0074)\end{array}$ \\
\hline High School & $\begin{array}{l}-0.0122 \\
(0.0234)\end{array}$ & $\begin{array}{l}-0.0633 \\
(0.0397)\end{array}$ \\
\hline Non-University Post-Secondary & $\begin{array}{c}0.0279 \\
(0.0201)\end{array}$ & $\begin{array}{l}-0.0268 \\
(0.0326)\end{array}$ \\
\hline University & $\begin{array}{c}0.0520 \\
(0.0621)\end{array}$ & $\begin{array}{c}0.0248 \\
(0.0343)\end{array}$ \\
\hline Union Member & $\begin{array}{c}0.0055 \\
(0.0063)\end{array}$ & $\begin{array}{c}0.0167^{* *} \\
(0.0065)\end{array}$ \\
\hline Ontario (other) & $\begin{array}{l}-0.0041 \\
(0.0218)\end{array}$ & $\begin{array}{l}-0.0037 \\
(0.0763)\end{array}$ \\
\hline Montreal & $\begin{array}{c}0.0141 \\
(0.0258)\end{array}$ & $\begin{array}{l}-0.0343 \\
(0.0556)\end{array}$ \\
\hline Quebec (other) & $\begin{array}{c}0.0003 \\
(0.0291)\end{array}$ & $\begin{array}{l}-0.0149 \\
(0.0603)\end{array}$ \\
\hline Vancouver & $\begin{array}{c}-0.0536 \\
(0.0398)\end{array}$ & $\begin{array}{c}-0.0698 \\
(0.0614)\end{array}$ \\
\hline British Columbia (other) & $\begin{array}{l}-0.0596 \\
(0.0564)\end{array}$ & $\begin{array}{l}-0.0664 \\
(0.0695)\end{array}$ \\
\hline Alberta & $\begin{array}{c}-0.0766^{*} \\
(0.0445)\end{array}$ & $\begin{array}{l}-0.0501 \\
(0.0622)\end{array}$ \\
\hline Manitoba & $\begin{array}{c}-0.0528 \\
(0.0573)\end{array}$ & $\begin{array}{l}-0.0502 \\
(0.0676)\end{array}$ \\
\hline New Brunswick & $\begin{array}{l}-0.0422 \\
(0.0547)\end{array}$ & $\begin{array}{l}-0.1124 \\
(0.0805)\end{array}$ \\
\hline Newfoundland and Labrador & $\begin{array}{c}-0.0410 \\
(0.0561)\end{array}$ & $\begin{array}{c}-0.1406^{* *} \\
(0.0622)\end{array}$ \\
\hline Nova Scotia & $\begin{array}{l}-0.0402 \\
(0.0449)\end{array}$ & $\begin{array}{l}-0.1011 \\
(0.0799)\end{array}$ \\
\hline Prince Edward Island & $\begin{array}{c}-0.1118^{* *} \\
(0.0533)\end{array}$ & $\begin{array}{c}-0.0121 \\
(0.0680)\end{array}$ \\
\hline Saskatchewan & $\begin{array}{c}-0.1671^{*} \\
(0.0917)\end{array}$ & $\begin{array}{c}0.1126 \\
(0.1466)\end{array}$ \\
\hline
\end{tabular}


Table B.22: First Difference OLS Wage Regressions, Cont.

\begin{tabular}{lcc}
\hline \hline Variable & Men & Women \\
\hline Constant & $(\mathbf{1})$ & $(\mathbf{2})$ \\
\hline Observations & $\begin{array}{c}0.1595^{* * *} \\
(0.0242)\end{array}$ & $\begin{array}{c}0.1219^{* * *} \\
(0.0229)\end{array}$ \\
Individuals & 72,000 & 62,000 \\
$R^{2}$ & 25,000 & 23,000 \\
\hline \hline
\end{tabular}

Table B.22 reports the estimated coefficients from the first differenced OLS wage regression given in Equation (2.4.1). The dependent variable is the log wage of the worker at time $t$. All variables are first differenced. Longitudinal weights for each person, provided in the SLID, are applied. In parentheses, I report standard errors clustered at the person level. Observation numbers are rounded as per Statistcs Canada confidentiality rules. Significance levels are indicated by *,**, *** for $10 \%, 5 \%$, and $1 \%$ respectively.

Table B.23: First Difference OLS Wage Regressions with Indicators for the Direction of Sector Switching

\begin{tabular}{lcc}
\hline \hline Variable & Men & Women \\
\hline Public_to_Private & $(\mathbf{1})$ & $(\mathbf{2})$ \\
Private_to_Public & 0.0030 & $-0.0812^{* * *}$ \\
Constant & $(0.0384)$ & $(0.0259)$ \\
& $\begin{array}{c}0.0701^{* *} \\
(0.0305)\end{array}$ & $\begin{array}{c}0.0880^{* * *} \\
(0.0264)\end{array}$ \\
\hline Observations & $0.1587^{* * *}$ & $0.1218^{* * *}$ \\
$(0.0242)$ & $(0.0229)$ \\
Individuals & 72,000 & 62,000 \\
$R^{2}$ & 25,000 & 23,000 \\
\hline
\end{tabular}

Table B.23 reports the estimated coefficients from the first differenced OLS wage regression given in Equation (2.4.2). The dependent variable is the log wage of the worker at time $t$. Each model has a set of controls for education (3), union membership (1), province/major city of residence (12), marital status (1), age (1), age squared divided by 100 (1). The public sector dummy variable is replaced with indicators for the direction of switching (Public_to_Private and Private_to_Public); these are the only variables that are not first differenced. Longitudinal weights for each person, provided in the SLID, are applied. In parentheses, I report standard errors clustered at the person level. Observation numbers are rounded as per Statistcs Canada confidentiality rules. Significance levels are indicated by *, **, *** for $10 \%, 5 \%$, and $1 \%$ respectively. 
Table B.24: Fixed Effects Wage Regressions - Without Private to Public Sector Switches

\begin{tabular}{|c|c|c|c|c|}
\hline \multirow[b]{2}{*}{ Variable } & \multicolumn{2}{|c|}{ Men } & \multicolumn{2}{|c|}{ Women } \\
\hline & (1) & $(2)$ & $(3)$ & $(4)$ \\
\hline Public & $\begin{array}{c}0.0258 \\
(0.0175)\end{array}$ & $\begin{array}{c}0.0269 \\
(0.0173)\end{array}$ & $\begin{array}{c}0.0640^{* * *} \\
(0.0148)\end{array}$ & $\begin{array}{c}0.0645^{* * *} \\
(0.0146)\end{array}$ \\
\hline Constant & $\begin{array}{c}1.1867^{* * * *} \\
(0.0885)\end{array}$ & $\begin{array}{c}1.1976 * * * \\
(0.0875)\end{array}$ & $\begin{array}{c}1.1284^{* * *} \\
(0.0974)\end{array}$ & $\begin{array}{c}1.1720^{* * * *} \\
(0.0964)\end{array}$ \\
\hline Person and Panel FE & $\checkmark$ & $\checkmark$ & $\checkmark$ & $\checkmark$ \\
\hline Occupation FE & & $\checkmark$ & & $\checkmark$ \\
\hline Observations & 107,000 & 107,000 & 94,000 & 94,000 \\
\hline Individuals & 27,000 & 27,000 & 25,000 & 25,000 \\
\hline$R^{2}$ & 0.8605 & 0.8610 & 0.8668 & 0.8673 \\
\hline
\end{tabular}

Table B.24 reports the estimated coefficients from the fixed effects wage regression given in Equation (2.3.5). The dependent variable is the log wage of the worker at time $t$. Each model has a set of controls for education (3), union membership (1), province/major city of residence (12), marital status (1), age (1), age squared divided by 100 (1). Switches from the private to the public sector are excluded. Longitudinal weights for each person, provided in the SLID, are applied. In parentheses, I report standard errors clustered at the person level. Observation numbers are rounded as per Statistcs Canada confidentiality rules. Significance levels are indicated by $*,{ }^{* *},{ }^{* *}$ for $10 \%, 5 \%$, and $1 \%$ respectively.

Table B.25: Fixed Effects Wage Regressions - Without Public to Private Sector Switches

\begin{tabular}{|c|c|c|c|c|}
\hline \multirow[b]{2}{*}{ Variable } & \multicolumn{2}{|c|}{ Men } & \multicolumn{2}{|c|}{ Women } \\
\hline & (1) & $(2)$ & (3) & $(4)$ \\
\hline Public & $\begin{array}{c}0.0314^{*} \\
(0.0173)\end{array}$ & $\begin{array}{c}0.0335^{* *} \\
(0.0171)\end{array}$ & $\begin{array}{c}0.0630^{* * *} \\
(0.0142)\end{array}$ & $\begin{array}{c}0.0632^{* * *} \\
(0.0139)\end{array}$ \\
\hline Constant & $\begin{array}{c}1.1790^{* * *} \\
(0.0885)\end{array}$ & $\begin{array}{c}1.1911^{* * *} \\
(0.0875)\end{array}$ & $\begin{array}{c}1.1210^{* * *} \\
(0.0967)\end{array}$ & $\begin{array}{c}1.1646^{* * *} \\
(0.0958)\end{array}$ \\
\hline $\begin{array}{l}\text { Person and Panel FE } \\
\text { Occupation FE }\end{array}$ & $\checkmark$ & $\begin{array}{l}\checkmark \\
\checkmark\end{array}$ & $\checkmark$ & $\begin{array}{l}\checkmark \\
\checkmark\end{array}$ \\
\hline Observations & 107,000 & 107,000 & 94,000 & 94,000 \\
\hline Individuals & 27,000 & 27,000 & 25,000 & 25,000 \\
\hline$R^{2}$ & 0.8603 & 0.8608 & 0.8667 & 0.8673 \\
\hline
\end{tabular}

Table B.25 reports the estimated coefficients from the fixed effects wage regression given in Equation (2.3.5). The dependent variable is the log wage of the worker at time $t$. Each model has a set of controls for education (3), union membership (1), province/major city of residence (12), marital status (1), age (1), age squared divided by 100 (1). Switches from the public to private sector are excluded. Longitudinal weights for each person, provided in the SLID, are applied. In parentheses, I report standard errors clustered at the person level. Observation numbers are rounded as per Statistcs Canada confidentiality rules. Significance levels are indicated by $*, * *, * * *$ for $10 \%, 5 \%$, and $1 \%$ respectively. 
Table B.26: Fixed Effects Wage Regressions

- Sector Switches Accompanied by Job Switches

\begin{tabular}{|c|c|c|c|c|}
\hline \multirow[b]{2}{*}{ Variable } & \multicolumn{2}{|c|}{ Men } & \multicolumn{2}{|c|}{ Women } \\
\hline & (1) & $(2)$ & $(3)$ & (4) \\
\hline Public & $\begin{array}{l}-0.0108 \\
(0.0318)\end{array}$ & $\begin{array}{l}-0.0109 \\
(0.0321)\end{array}$ & $\begin{array}{c}0.0650^{* * *} \\
(0.0236)\end{array}$ & $\begin{array}{c}0.0632^{* * *} \\
(0.0234)\end{array}$ \\
\hline Constant & $\begin{array}{c}1.5205^{* * *} \\
(0.1193)\end{array}$ & $\begin{array}{c}1.5207^{* * *} \\
(0.1198)\end{array}$ & $\begin{array}{c}1.7695^{* * *} \\
(0.1818)\end{array}$ & $\begin{array}{c}1.7758^{* * *} \\
(0.1825)\end{array}$ \\
\hline Person and Panel FE & $\checkmark$ & $\checkmark$ & $\checkmark$ & $\checkmark$ \\
\hline Occupation FE & & $\checkmark$ & & $\checkmark$ \\
\hline Observations & 65,000 & 65,000 & 55,000 & 55,000 \\
\hline Individuals & 19,000 & 19,000 & 16,000 & 16,000 \\
\hline$R^{2}$ & 0.8942 & 0.8942 & 0.8944 & 0.8945 \\
\hline
\end{tabular}

Table B.26 reports the estimated coefficients from the fixed effects wage regression given in Equation (2.3.5). The dependent variable is the log wage of the worker at time $t$. Each model has a set of controls for education (3), union membership (1), province/major city of residence (12), marital status (1), age (1), age squared divided by 100 (1). Switches not accompanied by a change in job are excluded. Longitudinal weights for each person, provided in the SLID, are applied. In parentheses, I report standard errors clustered at the person level. Observation numbers are rounded as per Statistcs Canada confidentiality rules. Significance levels are indicated by $*, * *, * * *$ for $10 \%, 5 \%$, and $1 \%$ respectively.

Table B.27: Fixed Effects Wage Regressions

- Sector Switches Accompanied by Involuntary Job Switches

\begin{tabular}{lcccc}
\hline & \multicolumn{2}{c}{ Men } & \multicolumn{2}{c}{ Women } \\
\hline Variable & $\mathbf{( 1 )}$ & $\mathbf{( 2 )}$ & $\mathbf{( 3 )}$ & $\mathbf{( 4 )}$ \\
\hline \multirow{2}{*}{ Public } & -0.0161 & -0.0162 & $0.0541^{* *}$ & $0.0525^{* *}$ \\
& $(0.0324)$ & $(0.0328)$ & $(0.0235)$ & $(0.0234)$ \\
Constant & $1.5206^{* * *}$ & $1.5210^{* * *}$ & $1.7753^{* * *}$ & $1.7801^{* * *}$ \\
& $(0.1194)$ & $(0.1199)$ & $(0.1840)$ & $(0.1846)$ \\
\hline Person and Panel FE & $\checkmark$ & & & $\checkmark$ \\
Occupation FE & $\checkmark$ & $\checkmark$ & $\checkmark$ & $\checkmark$ \\
Observations & 65,000 & 65,000 & 55,000 & 55,000 \\
Individuals & 19,000 & 19,000 & 16,000 & 16,000 \\
$R^{2}$ & 0.8942 & 0.8942 & 0.8945 & 0.8946 \\
\hline \hline
\end{tabular}

Table B.27 reports the estimated coefficients from the fixed effects wage regression given in Equation (2.3.5). The dependent variable is the log wage of the worker at time $t$. Each model has a set of controls for education (3), union membership (1), province/major city of residence (12), marital status (1), age (1), age squared divided by 100 (1). Switches accompanied by a voluntary change in job are excluded.

Longitudinal weights for each person, provided in the SLID, are applied. In parentheses, I report standard errors clustered at the person level. Observation numbers are rounded as per Statistcs Canada confidentiality rules. Significance levels are indicated by $*, * *, * * *$ for $10 \%, 5 \%$, and $1 \%$ respectively. 
Table B.28: Fixed Effects Wage Regressions - Balanced Panel

\begin{tabular}{|c|c|c|c|c|}
\hline \multirow[b]{2}{*}{ Variable } & \multicolumn{2}{|c|}{ Men } & \multicolumn{2}{|c|}{ Women } \\
\hline & (1) & $(2)$ & $(3)$ & $(4)$ \\
\hline Public & $\begin{array}{l}-0.0078 \\
(0.0214)\end{array}$ & $\begin{array}{l}-0.0040 \\
(0.0219)\end{array}$ & $\begin{array}{c}0.0420^{* *} \\
(0.0207)\end{array}$ & $\begin{array}{c}0.0445^{* *} \\
(0.0206)\end{array}$ \\
\hline Constant & $\begin{array}{c}1.5993^{* * *} \\
(0.1313)\end{array}$ & $\begin{array}{c}1.6123^{* * *} \\
(0.1319)\end{array}$ & $\begin{array}{c}1.8574^{* * * *} \\
(0.1572)\end{array}$ & $\begin{array}{c}1.8636^{* * *} \\
(0.1571)\end{array}$ \\
\hline Person and Panel FE & $\checkmark$ & $\checkmark$ & $\checkmark$ & $\checkmark$ \\
\hline Occupation FE & & $\checkmark$ & & $\checkmark$ \\
\hline Observations & 39,000 & 39,000 & 31,000 & 31,000 \\
\hline Individuals & 7,000 & 7,000 & 5,000 & 5,000 \\
\hline$R^{2}$ & 0.8620 & 0.8622 & 0.8751 & 0.8753 \\
\hline
\end{tabular}

Table B.28 reports the estimated coefficients from the fixed effects wage regression given in Equation (2.3.5). The dependent variable is the log wage of the worker at time $t$. Each model has a set of controls for education (3), union membership (1), province/major city of residence (12), marital status (1), age (1), age squared divided by 100 (1). The sample for the estimation is restricted to include only individuals with a total of 6 observations. Longitudinal weights for each person, provided in the SLID, are applied. In parentheses, I report standard errors clustered at the person level. Observation numbers are rounded as per Statistcs Canada confidentiality rules. Significance levels are indicated by *, **, *** for $10 \%, 5 \%$, and $1 \%$ respectively. 
Table B.29: Pooled OLS and Fixed Effects Wage Regressions - Trend Across Time

\begin{tabular}{|c|c|c|c|c|c|c|}
\hline \multirow[b]{2}{*}{ Variable } & \multicolumn{3}{|c|}{ Men } & \multicolumn{3}{|c|}{ Women } \\
\hline & (1) & $(2)$ & $(3)$ & $(4)$ & (5) & (6) \\
\hline Public & $\begin{array}{c}0.0839 * * * \\
(0.0131)\end{array}$ & $\begin{array}{c}0.0655^{* * *} \\
(0.0198)\end{array}$ & $\begin{array}{c}0.0685^{* * *} \\
(0.0196)\end{array}$ & $\begin{array}{c}0.2021^{* * *} \\
(0.0136)\end{array}$ & $\begin{array}{c}0.0806^{* * *} \\
(0.0185)\end{array}$ & $\begin{array}{c}0.0821^{* * *} \\
(0.0184)\end{array}$ \\
\hline Age & $\begin{array}{c}0.0528^{* * *} \\
(0.0017)\end{array}$ & $\begin{array}{c}0.0766^{* * *} \\
(0.0038)\end{array}$ & $\begin{array}{c}0.0761^{* * *} \\
(0.0038)\end{array}$ & $\begin{array}{c}0.0442^{* * *} \\
(0.0017)\end{array}$ & $\begin{array}{c}0.0696^{* * *} \\
(0.0041)\end{array}$ & $\begin{array}{c}0.0679 * * * \\
(0.0041)\end{array}$ \\
\hline$\left(\mathrm{Age}^{2}\right) / 100$ & $\begin{array}{c}-0.0533^{* * *} \\
(0.0020)\end{array}$ & $\begin{array}{c}-0.0632^{* * *} \\
(0.0045)\end{array}$ & $\begin{array}{c}-0.0626^{* * *} \\
(0.0044)\end{array}$ & $\begin{array}{c}-0.0470 * * * \\
(0.0020)\end{array}$ & $\begin{array}{c}-0.0556^{* * *} \\
(0.0047)\end{array}$ & $\begin{array}{c}-0.0538^{* * *} \\
(0.0047)\end{array}$ \\
\hline Married & $\begin{array}{c}0.1138^{* * *} \\
(0.0042)\end{array}$ & $\begin{array}{c}0.0173^{* *} \\
(0.0070)\end{array}$ & $\begin{array}{c}0.0179 * * * \\
(0.0069)\end{array}$ & $\begin{array}{c}0.0226^{* * *} \\
(0.0040)\end{array}$ & $\begin{array}{c}0.0217^{* *} \\
(0.0085)\end{array}$ & $\begin{array}{c}0.0215^{* * *} \\
(0.0083)\end{array}$ \\
\hline High School & $\begin{array}{c}0.1534^{* * *} \\
(0.0054)\end{array}$ & $\begin{array}{l}-0.0263 \\
(0.0237)\end{array}$ & $\begin{array}{l}-0.0256 \\
(0.0237)\end{array}$ & $\begin{array}{c}0.2437^{* * *} \\
(0.0065)\end{array}$ & $\begin{array}{l}-0.0533^{*} \\
(0.0298)\end{array}$ & $\begin{array}{c}-0.0599 * * \\
(0.0293)\end{array}$ \\
\hline \multirow{2}{*}{$\begin{array}{l}\text { Non-University } \\
\text { Post-Secondary }\end{array}$} & $0.2466^{* * *}$ & 0.0129 & 0.0130 & $0.3308^{* * *}$ & -0.0293 & -0.0397 \\
\hline & $(0.0051)$ & $(0.0224)$ & $(0.0224)$ & $(0.0063)$ & $(0.0261)$ & $(0.0255)$ \\
\hline University & $\begin{array}{c}0.5064^{* * *} \\
(0.0063)\end{array}$ & $\begin{array}{c}0.0582 \\
(0.0446)\end{array}$ & $\begin{array}{c}0.0591 \\
(0.0445)\end{array}$ & $\begin{array}{c}0.6086^{* * *} \\
(0.0072)\end{array}$ & $\begin{array}{c}0.0465 \\
(0.0283)\end{array}$ & $\begin{array}{c}0.0365 \\
(0.0277)\end{array}$ \\
\hline Union Member & $\begin{array}{c}0.0514^{* * *} \\
(0.0036)\end{array}$ & $\begin{array}{c}0.0221^{* * *} \\
(0.0064)\end{array}$ & $\begin{array}{c}0.0219^{* * *} \\
(0.0062)\end{array}$ & $\begin{array}{c}0.0683^{* * *} \\
(0.0043)\end{array}$ & $\begin{array}{c}0.0338 * * * \\
(0.0071)\end{array}$ & $\begin{array}{c}0.0329 * * * \\
(0.0070)\end{array}$ \\
\hline Ontario (other) & $\begin{array}{l}0.0118^{*} \\
(0.0067)\end{array}$ & $\begin{array}{l}-0.0022 \\
(0.0225)\end{array}$ & $\begin{array}{l}-0.0025 \\
(0.0219)\end{array}$ & $\begin{array}{c}-0.0667^{* * *} \\
(0.0073)\end{array}$ & $\begin{array}{l}-0.0102 \\
(0.0366)\end{array}$ & $\begin{array}{l}-0.0044 \\
(0.0366)\end{array}$ \\
\hline Montreal & $\begin{array}{c}-0.0457^{* * *} \\
(0.0092)\end{array}$ & $\begin{array}{c}0.0085 \\
(0.0399)\end{array}$ & $\begin{array}{c}0.0077 \\
(0.0401)\end{array}$ & $\begin{array}{c}-0.0756^{* * *} \\
(0.0094)\end{array}$ & $\begin{array}{l}-0.0563 \\
(0.0477)\end{array}$ & $\begin{array}{l}-0.0576 \\
(0.0482)\end{array}$ \\
\hline Quebec (other) & $\begin{array}{c}-0.1162^{* * *} \\
(0.0070)\end{array}$ & $\begin{array}{l}-0.0344 \\
(0.0406)\end{array}$ & $\begin{array}{l}-0.0336 \\
(0.0408)\end{array}$ & $\begin{array}{c}-0.1729 * * * \\
(0.0076)\end{array}$ & $\begin{array}{c}-0.0928^{*} \\
(0.0504)\end{array}$ & $\begin{array}{c}-0.0907^{*} \\
(0.0507)\end{array}$ \\
\hline Vancouver & $\begin{array}{c}0.0071 \\
(0.0103)\end{array}$ & $\begin{array}{l}-0.0278 \\
(0.0407)\end{array}$ & $\begin{array}{c}-0.0296 \\
(0.0398)\end{array}$ & $\begin{array}{c}-0.0348^{* * *} \\
(0.0104)\end{array}$ & $\begin{array}{c}0.0509 \\
(0.0602)\end{array}$ & $\begin{array}{c}0.0528 \\
(0.0585)\end{array}$ \\
\hline British Columbia (other) & $\begin{array}{c}0.0135 \\
(0.0084)\end{array}$ & $\begin{array}{l}-0.0379 \\
(0.0465)\end{array}$ & $\begin{array}{l}-0.0411 \\
(0.0455)\end{array}$ & $\begin{array}{c}-0.0936 * * * \\
(0.0091)\end{array}$ & $\begin{array}{l}-0.0011 \\
(0.0826)\end{array}$ & $\begin{array}{c}0.0077 \\
(0.0794)\end{array}$ \\
\hline Alberta & $\begin{array}{c}0.0614^{* * *} \\
(0.0080)\end{array}$ & $\begin{array}{l}-0.0336 \\
(0.0442)\end{array}$ & $\begin{array}{l}-0.0368 \\
(0.0433)\end{array}$ & $\begin{array}{c}-0.0781^{* * *} \\
(0.0087)\end{array}$ & $\begin{array}{l}-0.0665 \\
(0.0545)\end{array}$ & $\begin{array}{l}-0.0594 \\
(0.0533)\end{array}$ \\
\hline Manitoba & $\begin{array}{c}-0.1280^{* * *} \\
(0.0081)\end{array}$ & $\begin{array}{l}-0.0574 \\
(0.0579)\end{array}$ & $\begin{array}{l}-0.0612 \\
(0.0580)\end{array}$ & $\begin{array}{c}-0.1828 * * * \\
(0.0085)\end{array}$ & $\begin{array}{l}-0.0249 \\
(0.0564)\end{array}$ & $\begin{array}{l}-0.0176 \\
(0.0552)\end{array}$ \\
\hline New Brunswick & $\begin{array}{c}-0.0843^{* * *} \\
(0.0082)\end{array}$ & $\begin{array}{l}-0.0991 \\
(0.0703)\end{array}$ & $\begin{array}{l}-0.1075 \\
(0.0703)\end{array}$ & $\begin{array}{c}-0.2051^{* * *} \\
(0.0085)\end{array}$ & $\begin{array}{c}-0.0274 \\
(0.0692)\end{array}$ & $\begin{array}{l}-0.0187 \\
(0.0684)\end{array}$ \\
\hline \multirow{2}{*}{$\begin{array}{l}\text { Newfoundland and } \\
\text { Labrador }\end{array}$} & $-0.2041^{* * *}$ & $-0.1253^{* *}$ & $-0.1255^{* *}$ & $-0.2783^{* * *}$ & -0.1148 & -0.1096 \\
\hline & $(0.0080)$ & $(0.0503)$ & $(0.0488)$ & $(0.0085)$ & $(0.0842)$ & $(0.0840)$ \\
\hline Nova Scotia & $\begin{array}{c}-0.1892^{* * *} \\
(0.0100)\end{array}$ & $\begin{array}{c}-0.1564^{* *} \\
(0.0702)\end{array}$ & $\begin{array}{c}-0.1458^{* *} \\
(0.0692)\end{array}$ & $\begin{array}{c}-0.3187^{* * *} \\
(0.0094)\end{array}$ & $\begin{array}{c}-0.2170^{* * *} \\
(0.0604)\end{array}$ & $\begin{array}{c}-0.2117^{* * *} \\
(0.0607)\end{array}$ \\
\hline Prince Edward Island & $\begin{array}{c}-0.1826^{* * *} \\
(0.0084)\end{array}$ & $\begin{array}{r}-0.1402^{*} \\
(0.0743)\end{array}$ & $\begin{array}{r}-0.1291^{*} \\
(0.0670)\end{array}$ & $\begin{array}{c}-0.2559 * * * \\
(0.0086)\end{array}$ & $\begin{array}{r}-0.1689^{*} \\
(0.0880)\end{array}$ & $\begin{array}{c}-0.1618^{*} \\
(0.0900)\end{array}$ \\
\hline Saskatchewan & $\begin{array}{c}-0.3031^{* * *} \\
(0.0117)\end{array}$ & $\begin{array}{r}-0.1137^{*} \\
(0.0627)\end{array}$ & $\begin{array}{r}-0.1091^{*} \\
(0.0604)\end{array}$ & $\begin{array}{c}-0.2783^{* * *} \\
(0.0096)\end{array}$ & $\begin{array}{c}-0.1736^{* * *} \\
(0.0660)\end{array}$ & $\begin{array}{c}-0.1726^{* *} \\
(0.0681)\end{array}$ \\
\hline
\end{tabular}


Table B.29: Pooled OLS and Fixed Effects Wage Regressions - Trend Across Time, Cont.

\begin{tabular}{|c|c|c|c|c|c|c|}
\hline \multirow[b]{2}{*}{ Variable } & \multicolumn{3}{|c|}{ Men } & \multicolumn{3}{|c|}{ Women } \\
\hline & (1) & $(2)$ & $(3)$ & $(4)$ & (5) & (6) \\
\hline \multirow[t]{2}{*}{ Public (1994) } & -0.0178 & $-0.0173^{*}$ & $-0.0172^{*}$ & -0.0050 & -0.0126 & -0.0133 \\
\hline & $(0.0185)$ & $(0.0097)$ & $(0.0097)$ & $(0.0187)$ & $(0.0111)$ & $(0.0111)$ \\
\hline \multirow[t]{2}{*}{ Public (1995) } & -0.0235 & $-0.0378 * * *$ & $-0.0389 * * *$ & -0.0238 & $-0.0294^{* *}$ & $-0.0298^{* *}$ \\
\hline & $(0.0188)$ & $(0.0103)$ & $(0.0101)$ & $(0.0198)$ & $(0.0118)$ & $(0.0118)$ \\
\hline \multirow[t]{2}{*}{ Public (1996) } & $-0.0836^{* * *}$ & $-0.0767 * * *$ & $-0.0774^{* * *}$ & $-0.0491^{* * *}$ & $-0.0577^{* * *}$ & $-0.0587^{* * *}$ \\
\hline & $(0.0167)$ & $(0.0107)$ & $(0.0107)$ & $(0.0160)$ & $(0.0116)$ & $(0.0116)$ \\
\hline \multirow[t]{2}{*}{ Public (1997) } & $-0.0516^{* * *}$ & $-0.0561^{* * *}$ & $-0.0567^{* * *}$ & $-0.0322^{* *}$ & $-0.0536 * * *$ & $-0.0543^{* * *}$ \\
\hline & $(0.0163)$ & $(0.0111)$ & $(0.0110)$ & $(0.0160)$ & $(0.0123)$ & $(0.0122)$ \\
\hline \multirow{2}{*}{ Public (1998) } & $-0.0598 * * *$ & $-0.0625^{* * *}$ & $-0.0631^{* * *}$ & $-0.0286^{*}$ & $-0.0492^{* * *}$ & $-0.0501^{* * *}$ \\
\hline & $(0.0163)$ & $(0.0113)$ & $(0.0113)$ & $(0.0157)$ & $(0.0128)$ & $(0.0130)$ \\
\hline \multirow[t]{2}{*}{ Public (1999) } & $-0.0413^{* * *}$ & $-0.0334^{* *}$ & $-0.0339 * *$ & $-0.0353^{* *}$ & $-0.0441^{* * *}$ & $-0.0447^{* * *}$ \\
\hline & $(0.0156)$ & $(0.0141)$ & $(0.0139)$ & $(0.0151)$ & $(0.0144)$ & $(0.0144)$ \\
\hline \multirow[t]{2}{*}{ Public (2000) } & -0.0171 & $-0.0308^{* *}$ & $-0.0314^{* *}$ & -0.0150 & $-0.0314^{* *}$ & $-0.0320 * *$ \\
\hline & $(0.0168)$ & $(0.0156)$ & $(0.0155)$ & $(0.0163)$ & $(0.0153)$ & $(0.0154)$ \\
\hline \multirow[t]{2}{*}{ Public (2001) } & -0.0226 & $-0.0390^{* *}$ & $-0.0400^{* *}$ & -0.0076 & -0.0189 & -0.0196 \\
\hline & $(0.0171)$ & $(0.0160)$ & $(0.0159)$ & $(0.0161)$ & $(0.0165)$ & $(0.0165)$ \\
\hline \multirow[t]{2}{*}{ Public (2002) } & -0.0002 & $-0.0322^{*}$ & $-0.0332^{*}$ & 0.0128 & -0.0002 & -0.0011 \\
\hline & $(0.0167)$ & $(0.0181)$ & $(0.0180)$ & $(0.0162)$ & $(0.0185)$ & $(0.0185)$ \\
\hline \multirow[t]{2}{*}{ Public (2003) } & 0.0189 & -0.0209 & -0.0219 & 0.0113 & -0.0012 & -0.0022 \\
\hline & $(0.0162)$ & $(0.0178)$ & $(0.0177)$ & $(0.0161)$ & $(0.0181)$ & $(0.0181)$ \\
\hline \multirow[t]{2}{*}{ Public (2004) } & 0.0172 & -0.0291 & $-0.0302^{*}$ & 0.0259 & -0.0021 & -0.0033 \\
\hline & $(0.0175)$ & $(0.0184)$ & $(0.0183)$ & $(0.0166)$ & $(0.0189)$ & $(0.0189)$ \\
\hline \multirow[t]{2}{*}{ Public (2005) } & $0.0303^{*}$ & -0.0275 & -0.0300 & $0.0379 * *$ & -0.0063 & -0.0078 \\
\hline & $(0.0168)$ & $(0.0214)$ & $(0.0213)$ & $(0.0157)$ & $(0.0207)$ & $(0.0206)$ \\
\hline \multirow[t]{2}{*}{ Public (2006) } & $0.0495^{* * *}$ & -0.0136 & -0.0154 & $0.0460^{* * *}$ & 0.0065 & 0.0050 \\
\hline & $(0.0171)$ & $(0.0217)$ & $(0.0216)$ & $(0.0170)$ & $(0.0218)$ & $(0.0217)$ \\
\hline \multirow[t]{2}{*}{ Public (2007) } & $0.0430 * *$ & -0.0221 & -0.0239 & $0.0514^{* * *}$ & 0.0122 & 0.0107 \\
\hline & $(0.0181)$ & $(0.0228)$ & $(0.0226)$ & $(0.0160)$ & $(0.0218)$ & $(0.0218)$ \\
\hline \multirow[t]{2}{*}{ Public (2008) } & $0.0463^{* * *}$ & -0.0155 & -0.0173 & $0.0732^{* * *}$ & 0.0020 & 0.0006 \\
\hline & $(0.0170)$ & $(0.0251)$ & $(0.0249)$ & $(0.0159)$ & $(0.0226)$ & $(0.0226)$ \\
\hline \multirow[t]{2}{*}{ Public (2009) } & $0.0656^{* * *}$ & -0.0119 & -0.0137 & $0.1072^{* * *}$ & 0.0178 & 0.0165 \\
\hline & $(0.0183)$ & $(0.0253)$ & $(0.0251)$ & $(0.0158)$ & $(0.0236)$ & $(0.0235)$ \\
\hline \multirow[t]{2}{*}{ Public (2010) } & $0.0833^{* * *}$ & -0.0045 & -0.0067 & $0.0916^{* * *}$ & 0.0074 & 0.0058 \\
\hline & $(0.0176)$ & $(0.0278)$ & $(0.0275)$ & $(0.0158)$ & $(0.0246)$ & $(0.0245)$ \\
\hline \multirow[t]{2}{*}{ Constant } & $1.6506^{* * *}$ & $1.1763^{* * *}$ & $1.1874^{* * *}$ & $1.6528 * * *$ & $1.1344^{* * *}$ & $1.1777^{* * *}$ \\
\hline & $(0.0341)$ & $(0.0894)$ & $(0.0884)$ & $(0.0352)$ & $(0.0979)$ & $(0.0969)$ \\
\hline Person and Panel FE & & $\checkmark$ & $\checkmark$ & & $\checkmark$ & $\checkmark$ \\
\hline Occupation FE & & & $\checkmark$ & & & $\checkmark$ \\
\hline Observations & 115,000 & 107,000 & 107,000 & 103,000 & 94,000 & 94,000 \\
\hline Individuals & 36,000 & 27,000 & 27,000 & 33,000 & 25000 & 25000 \\
\hline$R^{2}$ & 0.2343 & 0.8604 & 0.8609 & 0.2998 & 0.8669 & 0.8674 \\
\hline $\mathrm{F}$ & 16.81 & 4.87 & 5.01 & 24.62 & 4.14 & 4.19 \\
\hline Prob $>$ F & 0.0000 & 0.0000 & 0.0000 & 0.0000 & 0.0000 & 0.0000 \\
\hline
\end{tabular}

Table B.29 reports the estimated coefficients from the pooled OLS wage regressions given in Equation (2.3.3) and the fixed effects wage regression given in Equation (2.3.6). The dependent variable is the log wage of the worker at time $t$. Interaction terms between calendar year dummies and the public sector indicator variable are included (i.e. $\left(\right.$ Public $_{i, t} \times$ Year $\left._{j}\right)$ ). Details of the F-test on the interactions between calendar year dummies and the public sector dummy variable are provided in the last 2 rows of the table. Longitudinal weights for each person, provided in the SLID, are applied. In parentheses, I report standard errors clustered at the person level. Observation numbers are rounded as per Statistcs Canada confidentiality rules. Significance levels are indicated by $*, * *, * * *$ for $10 \%, 5 \%$, and $1 \%$ respectively. 
Table B.30: Pooled OLS Wage Regressions

- With Time Trend and Detrended Unemployment Rate

\begin{tabular}{lcccc}
\hline \hline & \multicolumn{2}{c}{ Men } & \multicolumn{2}{c}{ Women } \\
\hline Variable & $(\mathbf{1})$ & $(\mathbf{2})$ & $\mathbf{( 3 )}$ & $(\mathbf{4})$ \\
\hline \multirow{2}{*}{ Public } & $0.0857^{* * *}$ & $0.1043^{* * *}$ & $0.2191^{* * *}$ & $0.2501^{* * *}$ \\
& $(0.0040)$ & $(0.0073)$ & $(0.0045)$ & $(0.0073)$ \\
Time Trend & $0.0219^{* * *}$ & $0.0234^{* * *}$ & $0.0292^{* * *}$ & $0.0330^{* * *}$ \\
& $(0.0011)$ & $(0.0013)$ & $(0.0011)$ & $(0.0015)$ \\
Detrended Unemployment Rate & $0.0056^{* * *}$ & $0.0056^{* * *}$ & $0.0168^{* * *}$ & $0.0168^{* * *}$ \\
& $(0.0017)$ & $(0.0017)$ & $(0.0026)$ & $(0.0026)$ \\
Public $\times$ Time Trend & & $-0.0063^{* * *}$ & & $-0.0111^{* * *}$ \\
& & $(0.0021)$ & & $(0.0020)$ \\
Constant & $1.7209^{* * *}$ & $1.7201^{* * *}$ & $1.7401^{* * *}$ & $1.7333^{* * *}$ \\
& $(0.0342)$ & $(0.0342)$ & $(0.0351)$ & $(0.0351)$ \\
\hline \multirow{2}{*}{ Observations } & & & & \\
Individuals & 116,000 & 116,000 & 103,000 & 103,000 \\
$R^{2}$ & 36,000 & 36,000 & 34,000 & 34,000 \\
\hline \hline
\end{tabular}

Table B.30 reports the estimated coefficients from the pooled OLS wage regressions given in Equation (2.3.2). The dependent variable is the log wage of the worker at time $t$. Each model has a set of controls for education (3), union membership (1), province/major city of residence (12), marital status (1), age (1), age squared divided by 100 (1). Controls are also included for the time trend and detrended unemployment rate. The detrended unemployment rate are residuals saved from regressing the unemployment rate of individuals aged 25 years and over (obtained from Statistics Canada Table 14-10-0020-01 (formerly CANSIM 282-0004)) on a constant and time trend by gender. Longitudinal weights for each person, provided in the SLID, are applied. In parentheses, I report standard errors clustered at the person level. Observation numbers are rounded as per Statistcs Canada confidentiality rules. Significance levels are indicated by $*, * *, * * *$ for $10 \%, 5 \%$, and $1 \%$ respectively. 
Table B.31: Fixed Effects Wage Regressions

- With Time Trend and Detrended Unemployment Rate

\begin{tabular}{|c|c|c|c|c|}
\hline \multirow[b]{2}{*}{ Variable } & \multicolumn{2}{|c|}{ Men } & \multicolumn{2}{|c|}{ Women } \\
\hline & (1) & $(2)$ & $(3)$ & $(4)$ \\
\hline Public & $\begin{array}{c}0.0339^{* *} \\
(0.0161)\end{array}$ & $\begin{array}{c}0.0280 \\
(0.0171)\end{array}$ & $\begin{array}{c}0.0656^{* * *} \\
(0.0134)\end{array}$ & $\begin{array}{c}0.0558^{* * *} \\
(0.0143)\end{array}$ \\
\hline Time Trend & $\begin{array}{c}0.0751^{* * *} \\
(0.0038)\end{array}$ & $\begin{array}{c}0.0751^{* * *} \\
(0.0038)\end{array}$ & $\begin{array}{c}0.0680^{* * *} \\
(0.0041)\end{array}$ & $\begin{array}{c}0.0674^{* * *} \\
(0.0041)\end{array}$ \\
\hline Detrended Unemployment Rate & $\begin{array}{c}-0.0032^{* *} \\
(0.0013)\end{array}$ & $\begin{array}{c}-0.0032^{* *} \\
(0.0013)\end{array}$ & $\begin{array}{c}0.0042^{* *} \\
(0.0019)\end{array}$ & $\begin{array}{c}0.0042^{* *} \\
(0.0019)\end{array}$ \\
\hline Public $\times$ Time Trend & & $\begin{array}{c}0.0018 \\
(0.0015)\end{array}$ & & $\begin{array}{c}0.0032^{* *} \\
(0.0015)\end{array}$ \\
\hline Constant & $\begin{array}{c}4.1052^{* * *} \\
(0.0750)\end{array}$ & $\begin{array}{c}4.1137^{* * *} \\
(0.0756)\end{array}$ & $\begin{array}{c}3.7970^{* * *} \\
(0.0832)\end{array}$ & $\begin{array}{c}3.8085^{* * *} \\
(0.0840)\end{array}$ \\
\hline Person and Panel FE & $\checkmark$ & $\checkmark$ & $\checkmark$ & $\checkmark$ \\
\hline Occupation FE & $\checkmark$ & $\checkmark$ & $\checkmark$ & $\checkmark$ \\
\hline Observations & 107,000 & 107,000 & 94,000 & 94,000 \\
\hline Individuals & 27,000 & 27,000 & 25,000 & 25,000 \\
\hline$R^{2}$ & 0.8608 & 0.8608 & 0.8672 & 0.8672 \\
\hline
\end{tabular}

Table B.31 reports the estimated coefficients from the fixed effects wage regression given in Equation (2.3.5). The dependent variable is the log wage of the worker at time $t$. Each model has a set of controls for education (3), union membership (1), province/major city of residence (12), marital status (1), age (1), age squared divided by 100 (1). Controls are also included for the time trend and detrended unemployment rate. The detrended unemployment rate are residuals saved from regressing the unemployment rate of individuals aged 25 years and over (obtained from Statistics Canada Table 14-10-0020-01 (formerly CANSIM 282-0004)) on a constant and time trend by gender. Longitudinal weights for each person, provided in the SLID, are applied. In parentheses, I report standard errors clustered at the person level. Observation numbers are rounded as per Statistcs Canada confidentiality rules. Significance levels are indicated by $*, * *, * * *$ for $10 \%, 5 \%$, and $1 \%$ respectively. 
Table B.32: Distribution of Workers

by Census Metropolitan Area (CMA) and Sector of Employment

\begin{tabular}{lcccc}
\hline \hline & & & & \\
& All & Public & Private & Difference \\
\hline Halifax & & & 0.0124 & $0.0077^{* * *}$ \\
Quebec City & 0.0145 & 0.0201 & $0.0160^{* * *}$ \\
Montreal & 0.0289 & 0.0405 & 0.0245 & $-0.0149^{* * *}$ \\
Ottawa-Gatineau & 0.1181 & 0.1073 & 0.1222 & $0.0526^{* * *}$ \\
Toronto & 0.0431 & 0.0814 & 0.0288 & $-0.0699^{* * *}$ \\
Hamilton & 0.1485 & 0.0976 & 0.1675 & $-0.0039^{* *}$ \\
St. Catharines - Niagara & 0.0243 & 0.0215 & 0.0254 & $-0.0017^{*}$ \\
Kitchener - Cambridge - Waterloo & 0.0129 & 0.0116 & 0.0133 & $-0.0097^{* * *}$ \\
London & 0.0165 & 0.0095 & 0.0192 & -0.0016 \\
Windsor & 0.0163 & 0.0151 & 0.0167 & -0.0002 \\
Winnipeg & 0.0107 & 0.0106 & 0.0108 & $0.0076^{* * *}$ \\
Calgary & 0.0259 & 0.0314 & 0.0238 & $-0.0148^{* * *}$ \\
Edmonton & 0.0332 & 0.0224 & 0.0372 & 0.0025 \\
Vancouver & 0.0345 & 0.0363 & 0.0338 & $-0.0074^{* *}$ \\
Victoria & 0.0632 & 0.0578 & 0.0652 & $0.0089^{* * *}$ \\
Other CMA & 0.0091 & 0.0156 & 0.0067 & $0.0288^{* * *}$ \\
\hline Observations & 0.4004 & 0.4214 & 0.3926 & \\
Share of Observations & & & & \\
\hline \hline
\end{tabular}

Table B.32 reports descriptive statistics on the distribution of workers by CMA and sector of employment based on my calculations using the SLID. Significance levels are indicated by *, **, *** for $10 \%, 5 \%$, and $1 \%$ respectively.

Table B.33: Fixed Effects Wage Regressions

Controlling for Residence in the National Capital Region

\begin{tabular}{lcccc}
\hline \hline & \multicolumn{3}{c}{ Men } & \multicolumn{2}{c}{ Women } \\
\hline Variable & $\mathbf{( 1 )}$ & $\mathbf{( 2 )}$ & $\mathbf{( 3 )}$ & $(\mathbf{4})$ \\
\hline \multirow{2}{*}{ Public } & $0.0312^{*}$ & $0.0331^{* *}$ & $0.0650^{* * *}$ & $0.0655^{* * *}$ \\
& $(0.0161)$ & $(0.0159)$ & $(0.0137)$ & $(0.0134)$ \\
Ottawa - Gatineau & -0.0578 & -0.0588 & -0.0380 & -0.0298 \\
& $(0.0404)$ & $(0.0384)$ & $(0.0420)$ & $(0.0419)$ \\
Constant & $1.1914^{* * *}$ & $1.2022^{* * *}$ & $1.1307^{* * *}$ & $1.1750^{* * *}$ \\
& $(0.0880)$ & $(0.0871)$ & $(0.0961)$ & $(0.0953)$ \\
\hline \multirow{2}{*}{ Person and Panel FE } & & & & $\checkmark$ \\
Occupation FE & $\checkmark$ & $\checkmark$ & $\checkmark$ & $\checkmark$ \\
Observations & 107,000 & 107,000 & 94,000 & 94,000 \\
Individuals & 27,000 & 27,000 & 25,000 & 25,000 \\
$R^{2}$ & 0.8603 & 0.8608 & 0.8666 & 0.8671 \\
\hline \hline
\end{tabular}

Table B.33 reports the estimated coefficients from the fixed effects wage regression given in Equation (2.3.5). The dependent variable is the log wage of the worker at time $t$. Each model has a set of controls for education (3), union membership (1), province/major city of residence (12), marital status (1), age (1), age squared divided by 100 (1). Longitudinal weights for each person, provided in the SLID, are applied. In parentheses, I report standard errors clustered at the person level. Observation numbers are rounded as per Statistcs Canada confidentiality rules. Significance levels are indicated by *, $* *, * * *$ for $10 \%, 5 \%$, and $1 \%$ respectively. 
Table B.34: Pooled OLS and Fixed Effects Wage Regressions Controlling for Residence in the National Capital Region - Trend Across Time

\begin{tabular}{|c|c|c|c|c|c|c|}
\hline \multirow[b]{2}{*}{ Variable } & \multicolumn{3}{|c|}{ Men } & \multicolumn{3}{|c|}{ Women } \\
\hline & $(1)$ & $(2)$ & $(3)$ & $(4)$ & $(5)$ & $(6)$ \\
\hline Public & $0.0803 * * *$ & $0.0646 * * *$ & $0.0677^{* * *} *$ & $0.1958^{* * *}$ & $0.0806^{* * *}$ & $0.0820 * * *$ \\
\hline Ottawa - Gatineau & $0.0774^{* * *}$ & -0.0613 & -0.0622 & $0.0702^{* * *}$ & -0.0383 & -0.0301 \\
\hline & $(0.0090)$ & $(0.0408)$ & $(0.0388)$ & $(0.0083)$ & $(0.0427)$ & $(0.0427)$ \\
\hline Public (1994) & $\begin{array}{c}-0.0173 \\
(0.0185)\end{array}$ & $\begin{array}{c}-0.0172^{*} \\
(0.0097)\end{array}$ & $\begin{array}{c}-0.0171^{*} \\
(0.0097)\end{array}$ & $\begin{array}{c}-0.0036 \\
(0.0184)\end{array}$ & $\begin{array}{c}-0.0125 \\
(0.0111)\end{array}$ & $\begin{array}{c}-0.0133 \\
(0.0112)\end{array}$ \\
\hline Public (1995) & $\begin{array}{c}-0.0232 \\
(0.0188)\end{array}$ & $\begin{array}{c}-0.0378^{* * *} \\
(0.0103)\end{array}$ & $\begin{array}{c}-0.0389^{* * * *} \\
(0.0101)\end{array}$ & $\begin{array}{c}-0.0222 \\
(0.0197)\end{array}$ & $\begin{array}{c}-0.0295^{* *} \\
(0.0118)\end{array}$ & $\begin{array}{c}-0.0298^{* *} \\
(0.0119)\end{array}$ \\
\hline Public (1996) & $\begin{array}{c}-0.0834^{* * * *} \\
(0.0167)\end{array}$ & $\begin{array}{c}-0.0766^{* * * *} \\
(0.0107)\end{array}$ & $\begin{array}{c}-0.0773^{* * * *} \\
(0.0107)\end{array}$ & $\begin{array}{c}-0.0463^{* * * *} \\
(0.0158)\end{array}$ & $\begin{array}{c}-0.0576^{* * *} \\
(0.0116)\end{array}$ & $\begin{array}{c}-0.0586^{* * *} \\
(0.0116)\end{array}$ \\
\hline Public (1997) & $\begin{array}{c}-0.0511^{* * *} \\
(0.0163)\end{array}$ & $\begin{array}{c}-0.0565^{* * *} \\
(0.0110)\end{array}$ & $\begin{array}{c}-0.0570 * * * \\
(0.0110)\end{array}$ & $\begin{array}{c}-0.0295^{*} \\
(0.0158)\end{array}$ & $\begin{array}{c}-0.0535^{* * *} \\
(0.0123)\end{array}$ & $\begin{array}{c}-0.0543^{* * *} \\
(0.0123)\end{array}$ \\
\hline Public (1998) & $\begin{array}{c}-0.0593^{* * *} \\
(0.0162)\end{array}$ & $\begin{array}{c}-0.0624^{* * *} \\
(0.0113)\end{array}$ & $\begin{array}{c}-0.0630^{* * *} \\
(0.0113)\end{array}$ & $\begin{array}{c}-0.0264^{*} \\
(0.0156)\end{array}$ & $\begin{array}{c}-0.0492^{* * *} \\
(0.0129)\end{array}$ & $\begin{array}{c}-0.0501^{* * *} \\
(0.0130)\end{array}$ \\
\hline Public (1999) & $\begin{array}{c}-0.0413^{* * *} \\
(0.0156)\end{array}$ & $\begin{array}{c}-0.0326^{* *} \\
(0.0141)\end{array}$ & $\begin{array}{c}-0.0331^{* *} \\
(0.0139)\end{array}$ & $\begin{array}{c}-0.0323^{* *} \\
(0.0149)\end{array}$ & $\begin{array}{c}-0.0441^{* * *} \\
(0.0144)\end{array}$ & $\begin{array}{c}-0.0447^{* * *} \\
(0.0144)\end{array}$ \\
\hline Public (2000) & $\begin{array}{l}-0.0169 \\
(0.0168)\end{array}$ & $\begin{array}{c}-0.0302^{*} \\
(0.0156)\end{array}$ & $\begin{array}{c}-0.0308^{* *} \\
(0.0155)\end{array}$ & $\begin{array}{l}-0.0110 \\
(0.0162)\end{array}$ & $\begin{array}{c}-0.0313^{* *} \\
(0.0154)\end{array}$ & $\begin{array}{c}-0.0320^{* *} \\
(0.0154)\end{array}$ \\
\hline Public (2001) & $\begin{array}{c}-0.0226 \\
(0.0171)\end{array}$ & $\begin{array}{c}-0.0385^{* *} \\
(0.0160)\end{array}$ & $\begin{array}{c}-0.0395 * * \\
(0.0158)\end{array}$ & $\begin{array}{c}-0.0030 \\
(0.0160)\end{array}$ & $\begin{array}{l}-0.0188 \\
(0.0165)\end{array}$ & $\begin{array}{c}-0.0196 \\
(0.0166)\end{array}$ \\
\hline Public (2002) & $\begin{array}{c}-0.0009 \\
(0.0167)\end{array}$ & $\begin{array}{c}-0.0317^{*} \\
(0.0181)\end{array}$ & $\begin{array}{c}-0.0327^{*} \\
(0.0179)\end{array}$ & $\begin{array}{c}0.0152 \\
(0.0161)\end{array}$ & $\begin{array}{c}-0.0001 \\
(0.0185)\end{array}$ & $\begin{array}{c}-0.0011 \\
(0.0185)\end{array}$ \\
\hline Public (2003) & $\begin{array}{c}0.0185 \\
(0.0162)\end{array}$ & $\begin{array}{c}-0.0204 \\
(0.0177)\end{array}$ & $\begin{array}{l}-0.0213 \\
(0.0176)\end{array}$ & $\begin{array}{c}0.0138 \\
(0.0160)\end{array}$ & $\begin{array}{l}-0.0012 \\
(0.0181)\end{array}$ & $\begin{array}{c}-0.0021 \\
(0.0181)\end{array}$ \\
\hline Public (2004) & $\begin{array}{c}0.0162 \\
(0.0175)\end{array}$ & $\begin{array}{c}-0.0285 \\
(0.0184)\end{array}$ & $\begin{array}{c}-0.0294 \\
(0.0182)\end{array}$ & $\begin{array}{l}0.0282^{*} \\
(0.0165)\end{array}$ & $\begin{array}{c}-0.0022 \\
(0.0190)\end{array}$ & $\begin{array}{c}-0.0034 \\
(0.0190)\end{array}$ \\
\hline Public (2005) & $\begin{array}{c}0.0285^{*} \\
(0.0167)\end{array}$ & $\begin{array}{c}-0.0264 \\
(0.0214)\end{array}$ & $\begin{array}{c}-0.0288 \\
(0.0212)\end{array}$ & $\begin{array}{c}0.0377^{* *} \\
(0.0155)\end{array}$ & $\begin{array}{c}-0.0064 \\
(0.0207)\end{array}$ & $\begin{array}{c}-0.0079 \\
(0.0207)\end{array}$ \\
\hline Public (2006) & $\begin{array}{c}0.0477^{* * *} \\
(0.0170)\end{array}$ & $\begin{array}{c}-0.0126 \\
(0.0217)\end{array}$ & $\begin{array}{c}-0.0144 \\
(0.0215)\end{array}$ & $\begin{array}{c}0.0460^{* * * *} \\
(0.0169)\end{array}$ & $\begin{array}{c}0.0065 \\
(0.0218)\end{array}$ & $\begin{array}{c}0.0050 \\
(0.0217)\end{array}$ \\
\hline Public (2007) & $\begin{array}{c}0.0413^{* *} \\
(0.0181)\end{array}$ & $\begin{array}{c}-0.0211 \\
(0.0227)\end{array}$ & $\begin{array}{c}-0.0229 \\
(0.0225)\end{array}$ & $\begin{array}{c}0.0503^{* * * *} \\
(0.0158)\end{array}$ & $\begin{array}{c}0.0122 \\
(0.0218)\end{array}$ & $\begin{array}{c}0.0108 \\
(0.0218)\end{array}$ \\
\hline Public (2008) & $\begin{array}{c}0.0448^{* * *} \\
(0.0169)\end{array}$ & $\begin{array}{c}-0.0145 \\
(0.0251)\end{array}$ & $\begin{array}{c}-0.0161 \\
(0.0248)\end{array}$ & $\begin{array}{c}0.0728^{* * *} * \\
(0.0157)\end{array}$ & $\begin{array}{c}0.0020 \\
(0.0227)\end{array}$ & $\begin{array}{c}0.0006 \\
(0.0226)\end{array}$ \\
\hline Public (2009) & $\begin{array}{c}0.0641^{* * *} \\
(0.0182)\end{array}$ & $\begin{array}{c}-0.0110 \\
(0.0253)\end{array}$ & $\begin{array}{c}-0.0128 \\
(0.0250)\end{array}$ & $\begin{array}{c}0.1073^{* * * *} \\
(0.0157)\end{array}$ & $\begin{array}{c}0.0177 \\
(0.0236)\end{array}$ & $\begin{array}{c}0.0164 \\
(0.0235)\end{array}$ \\
\hline Public (2010) & $\begin{array}{c}0.0809^{* * * *} \\
(0.0175)\end{array}$ & $\begin{array}{c}-0.0038 \\
(0.0277)\end{array}$ & $\begin{array}{c}-0.0057 \\
(0.0275)\end{array}$ & $\begin{array}{c}0.0918^{* * *} \\
(0.0156)\end{array}$ & $\begin{array}{c}0.0074 \\
(0.0246)\end{array}$ & $\begin{array}{c}0.0059 \\
(0.0245)\end{array}$ \\
\hline Constant & $\begin{array}{c}1.6484^{* * *} \\
(0.0341)\end{array}$ & $\begin{array}{c}1.1854^{* * *} \\
(0.0890)\end{array}$ & $\begin{array}{c}1.1957^{* * *} \\
(0.0881)\end{array}$ & $\begin{array}{c}1.6535^{* * *} * \\
(0.0351)\end{array}$ & $\begin{array}{c}1.1374^{* * *} \\
(0.0972)\end{array}$ & $\begin{array}{c}1.1810^{* * *} \\
(0.0962)\end{array}$ \\
\hline Observations & 115,000 & 107,000 & 107,000 & 103,000 & 94,000 & 94,000 \\
\hline Individuals & 36,000 & 27,000 & 27,000 & 33,000 & 25,000 & 25,000 \\
\hline$R^{2}$ & 0.2352 & 0.8605 & 0.8610 & 0.3021 & 0.8669 & 0.8674 \\
\hline $\mathrm{F}$ & 16.24 & 4.88 & 5.02 & 23.77 & 4.12 & 4.17 \\
\hline Prob $>$ F & 0.0000 & 0.0000 & 0.0000 & 0.0000 & 0.0000 & 0.0000 \\
\hline
\end{tabular}

Table B.34 reports the estimated coefficients from the pooled OLS wage regressions given in Equation (2.3.2) and the fixed effects wage regression given in Equation (2.3.5). The dependent variable is the log wage of the worker at time $t$. Each model has a set of controls for education (3), union membership (1), province/major city of residence (12), marital status (1), age (1), age squared divided by 100 (1). Interaction terms between calendar year dummies and the public sector indicator variable are included (i.e. $\left(\right.$ Public $\left.\left._{i, t} \times Y_{\text {Year }}\right)\right)$. Details of the F-test on the interaction terms between calendar year dummies and the public sector indicator variable are provided in the last 2 rows of the table. Longitudinal weights for each person, provided in the SLID, are applied. In parentheses, I report standard errors clustered at the person level. Observation numbers are rounded as per Statistcs Canada confidentiality rules. Significance levels are indicated by $*, * *, * * *$ for $10 \%, 5 \%$, and $1 \%$ respectively. 
Figure B.10: Proportion of Workers who were Union Members by Sector and Gender Canada, 1993 to 2010

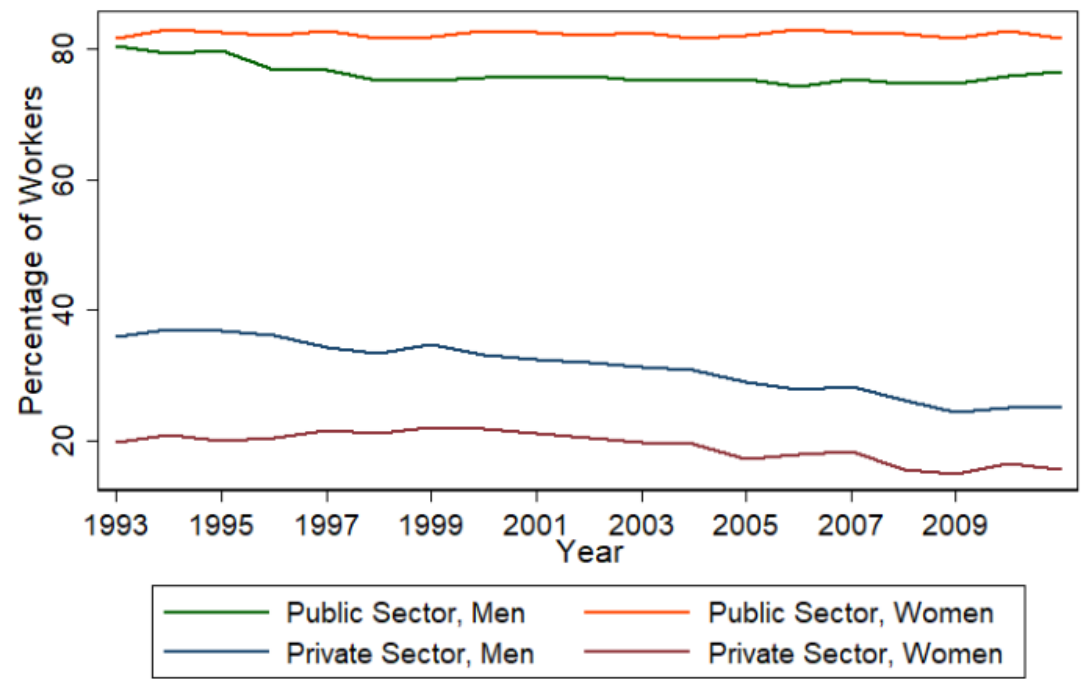

Source: Based on my calculations using data from the Survey of Labour and Income Dynamics (1993 to 2010).

Table B.35: Fixed Effects Wage Regressions Not Controlling for Union Coverage

\begin{tabular}{|c|c|c|c|c|}
\hline \multirow[b]{2}{*}{ Variable } & \multicolumn{2}{|c|}{ Men } & \multicolumn{2}{|c|}{ Women } \\
\hline & (1) & $(2)$ & $(3)$ & $(4)$ \\
\hline Public & $\begin{array}{c}0.0363^{* *} \\
(0.0162)\end{array}$ & $\begin{array}{c}0.0382^{* *} \\
(0.0160)\end{array}$ & $\begin{array}{c}0.0731^{* * *} * \\
(0.0138)\end{array}$ & $\begin{array}{c}0.0732^{* * *} \\
(0.0135)\end{array}$ \\
\hline Constant & $\begin{array}{c}1.1881^{* * * *} \\
(0.0883)\end{array}$ & $\begin{array}{c}1.1993^{* * *} * \\
(0.0874)\end{array}$ & $\begin{array}{c}1.1359 * * * \\
(0.0969) \\
\end{array}$ & $\begin{array}{c}1.1798^{* * *} \\
(0.0959) \\
\end{array}$ \\
\hline $\begin{array}{l}\text { Person and Panel FE } \\
\text { Occupation FE }\end{array}$ & $\checkmark$ & $\begin{array}{l}\checkmark \\
\checkmark\end{array}$ & $\checkmark$ & $\begin{array}{l}\checkmark \\
\checkmark\end{array}$ \\
\hline Observations & 107,000 & 107,000 & 94,000 & 94,000 \\
\hline Individuals & 27,000 & 27,000 & 25,000 & 25,000 \\
\hline$R^{2}$ & 0.8602 & 0.8607 & 0.8665 & 0.8670 \\
\hline
\end{tabular}

Table B.35 reports the estimated coefficients for the fixed effects wage regression given in Equation (2.3.5). The dependent variable is the log wage of the worker at time $t$. Each model has a set of controls for education (3), union membership (1), province/major city of residence (12), marital status (1), age (1), age squared divided by 100 (1). Longitudinal weights for each person, provided in the SLID, are applied. In parentheses, I report standard errors clustered at the person level. Observation numbers are rounded as per Statistcs Canada confidentiality rules. Significance levels are indicated by *, **, $* * *$ for $10 \%, 5 \%$, and $1 \%$ respectively. 
Table B.36: Pooled OLS and Fixed Effects Wage Regressions Not Controlling for Union Coverage - Trend Across Time

\begin{tabular}{|c|c|c|c|c|c|c|}
\hline \multirow[b]{2}{*}{ Variable } & \multicolumn{3}{|c|}{ Men } & \multicolumn{3}{|c|}{ Women } \\
\hline & (1) & $(2)$ & (3) & (4) & (5) & $(6)$ \\
\hline Public & $\begin{array}{c}0.1093^{* * *} \\
(0.0129)\end{array}$ & $\begin{array}{c}0.0698^{* * *} \\
(0.0197)\end{array}$ & $\begin{array}{c}0.0728^{* * *} \\
(0.0195)\end{array}$ & $\begin{array}{l}0.24302^{* * *} \\
(0.0132)\end{array}$ & $\begin{array}{c}0.0866^{* * *} \\
(0.0185)\end{array}$ & $\begin{array}{c}0.0878^{* * *} \\
(0.0185)\end{array}$ \\
\hline Public (1994) & $\begin{array}{l}-0.0179 \\
(0.0184)\end{array}$ & $\begin{array}{r}-0.0171^{*} \\
(0.0098)\end{array}$ & $\begin{array}{l}-0.0170^{*} \\
(0.0098)\end{array}$ & $\begin{array}{l}-0.0033 \\
(0.0186)\end{array}$ & $\begin{array}{l}-0.0119 \\
(0.0111)\end{array}$ & -0.0126 \\
\hline Public (1995) & $\begin{array}{l}-0.0231 \\
(0.0186)\end{array}$ & $\begin{array}{c}-0.0376^{* * *} * \\
(0.0103)\end{array}$ & $\begin{array}{c}-0.0387^{* * *} \\
(0.0102)\end{array}$ & $\begin{array}{c}-0.0227 \\
(0.0198)\end{array}$ & $\begin{array}{c}-0.0285^{* *} \\
(0.0119)\end{array}$ & $\begin{array}{c}-0.0289^{* *} \\
(0.0119)\end{array}$ \\
\hline Public (1996) & $\begin{array}{c}-0.0839^{* * *} \\
(0.0166)\end{array}$ & $\begin{array}{c}-0.0764^{* * *} \\
(0.0107)\end{array}$ & $\begin{array}{c}-0.0771^{* * *} \\
(0.0107)\end{array}$ & $\begin{array}{c}-0.0479 * * * \\
(0.0159)\end{array}$ & $\begin{array}{c}-0.0570 * * * \\
(0.0117)\end{array}$ & $\begin{array}{c}-0.0579 * * * \\
(0.0117)\end{array}$ \\
\hline Public (1997) & $\begin{array}{c}-0.05191^{* * *} \\
(0.0161)\end{array}$ & $\begin{array}{c}-0.0559^{* * *} \\
(0.0110)\end{array}$ & $\begin{array}{c}-0.0564^{* * *} \\
(0.0110)\end{array}$ & $\begin{array}{l}-0.0308^{*} \\
(0.0159)\end{array}$ & $\begin{array}{l}-0.0524^{* * *} \\
(0.0124)\end{array}$ & $\begin{array}{c}-0.0532^{* * *} \\
(0.0124)\end{array}$ \\
\hline Public (1998) & $\begin{array}{c}-0.0609^{* * *} \\
(0.0161)\end{array}$ & $\begin{array}{c}-0.0626^{* * *} \\
(0.0113)\end{array}$ & $\begin{array}{c}-0.0632^{* * *} \\
(0.0112)\end{array}$ & $\begin{array}{c}-0.0275^{*} \\
(0.0157)\end{array}$ & $\begin{array}{c}-0.0481^{* * *} \\
(0.0130)\end{array}$ & $\begin{array}{c}-0.0490^{* * *} \\
(0.0131)\end{array}$ \\
\hline Public (1999) & $\begin{array}{c}-0.0423^{* * *} \\
(0.0155)\end{array}$ & $\begin{array}{c}-0.0334^{* *} \\
(0.0140)\end{array}$ & $\begin{array}{c}-0.0340^{* *} \\
(0.0139)\end{array}$ & $\begin{array}{c}-0.0337^{* *} \\
(0.0150)\end{array}$ & $\begin{array}{c}-0.0424^{* * *} \\
(0.0145)\end{array}$ & $\begin{array}{c}-0.0430^{* * *} \\
(0.0145)\end{array}$ \\
\hline Public (2000) & $\begin{array}{l}-0.0178 \\
(0.0166)\end{array}$ & $\begin{array}{c}-0.0306^{* *} \\
(0.0156)\end{array}$ & $\begin{array}{c}-0.0312^{* *} \\
(0.0155)\end{array}$ & $\begin{array}{l}-0.0123 \\
(0.0162)\end{array}$ & $\begin{array}{l}-0.0293^{*} \\
(0.0155)\end{array}$ & $\begin{array}{l}-0.0300^{*} \\
(0.0155)\end{array}$ \\
\hline Public (2001) & $\begin{array}{c}-0.0232 \\
(0.0170)\end{array}$ & $\begin{array}{c}-0.0389^{* *} \\
(0.0159)\end{array}$ & $\begin{array}{c}-0.0399 * * \\
(0.0158)\end{array}$ & $\begin{array}{l}-0.0041 \\
(0.0160)\end{array}$ & $\begin{array}{c}-0.0164 \\
(0.0166)\end{array}$ & $\begin{array}{c}-0.0172 \\
(0.0166)\end{array}$ \\
\hline Public (2002) & $\begin{array}{l}-0.0008 \\
(0.0165)\end{array}$ & $\begin{array}{c}-0.0313^{*} \\
(0.0181)\end{array}$ & $\begin{array}{c}-0.0324^{*} \\
(0.0179)\end{array}$ & $\begin{array}{c}0.0151 \\
(0.0161)\end{array}$ & $\begin{array}{c}0.0026 \\
(0.0187)\end{array}$ & $\begin{array}{c}0.0015 \\
(0.0187)\end{array}$ \\
\hline Public (2003) & $\begin{array}{c}0.0186 \\
(0.0161)\end{array}$ & $\begin{array}{l}-0.0204 \\
(0.0178)\end{array}$ & $\begin{array}{l}-0.0215 \\
(0.0177)\end{array}$ & $\begin{array}{c}0.0139 \\
(0.0161)\end{array}$ & $\begin{array}{c}0.0013 \\
(0.0182)\end{array}$ & $\begin{array}{c}0.0003 \\
(0.0182)\end{array}$ \\
\hline Public (2004) & $\begin{array}{c}0.0170 \\
(0.0174)\end{array}$ & $\begin{array}{l}-0.0287 \\
(0.0184)\end{array}$ & $\begin{array}{l}-0.0297 \\
(0.0183)\end{array}$ & $\begin{array}{c}0.02794^{*} \\
(0.0165)\end{array}$ & $\begin{array}{c}0.0004 \\
(0.0191)\end{array}$ & $\begin{array}{l}-0.0008 \\
(0.0191)\end{array}$ \\
\hline Public (2005) & $\begin{array}{c}0.0302^{*} \\
(0.0166)\end{array}$ & $\begin{array}{c}-0.0268 \\
(0.0214)\end{array}$ & $\begin{array}{c}-0.0292 \\
(0.0213)\end{array}$ & $\begin{array}{c}0.0397^{* *} \\
(0.0156)\end{array}$ & $\begin{array}{c}-0.0039 \\
(0.0209)\end{array}$ & $\begin{array}{c}-0.0054 \\
(0.0208)\end{array}$ \\
\hline Public (2006) & $\begin{array}{c}0.0491^{* * * *} \\
(0.0169)\end{array}$ & $\begin{array}{l}-0.0128 \\
(0.0218)\end{array}$ & $\begin{array}{l}-0.0146 \\
(0.0216)\end{array}$ & $\begin{array}{c}0.0479^{* * *} \\
(0.0170)\end{array}$ & $\begin{array}{c}0.0089 \\
(0.0220)\end{array}$ & $\begin{array}{c}0.0074 \\
(0.0219)\end{array}$ \\
\hline Public (2007) & $\begin{array}{c}0.0444^{* *} \\
(0.0180)\end{array}$ & $\begin{array}{c}-0.0210 \\
(0.0228)\end{array}$ & $\begin{array}{c}-0.0228 \\
(0.0226)\end{array}$ & $\begin{array}{c}0.0527^{* * * *} \\
(0.0159)\end{array}$ & $\begin{array}{c}0.0144 \\
(0.0220)\end{array}$ & $\begin{array}{c}0.0130 \\
(0.0219)\end{array}$ \\
\hline Public (2008) & $\begin{array}{c}0.0468^{* * *} \\
(0.0168)\end{array}$ & $\begin{array}{l}-0.0144 \\
(0.0252)\end{array}$ & $\begin{array}{l}-0.0162 \\
(0.0250)\end{array}$ & $\begin{array}{c}0.0758^{* * *} * \\
(0.0158)\end{array}$ & $\begin{array}{c}0.0047 \\
(0.0228)\end{array}$ & $\begin{array}{c}0.0034 \\
(0.0227)\end{array}$ \\
\hline Public (2009) & $\begin{array}{c}0.0657^{* * *} \\
(0.0180)\end{array}$ & $\begin{array}{l}-0.0105 \\
(0.0254)\end{array}$ & $\begin{array}{l}-0.0123 \\
(0.0252)\end{array}$ & $\begin{array}{c}0.1088^{* * * *} \\
(0.0157)\end{array}$ & $\begin{array}{c}0.0201 \\
(0.0238)\end{array}$ & $\begin{array}{c}0.0189 \\
(0.0237)\end{array}$ \\
\hline Public (2010) & $\begin{array}{c}0.0850^{* * *} \\
(0.0173)\end{array}$ & $\begin{array}{c}-0.0033 \\
(0.0279)\end{array}$ & $\begin{array}{l}-0.0053 \\
(0.0276)\end{array}$ & $\begin{array}{c}0.0941^{* * *} \\
(0.0157)\end{array}$ & $\begin{array}{c}0.0104 \\
(0.0248)\end{array}$ & $\begin{array}{c}0.0089 \\
(0.0247)\end{array}$ \\
\hline Constant & $\begin{array}{c}1.6450^{* * *} \\
(0.0341) \\
\end{array}$ & $\begin{array}{c}1.1821^{* * *} * \\
(0.0893) \\
\end{array}$ & $\begin{array}{c}1.1928^{* * *} \\
(0.0884) \\
\end{array}$ & $\begin{array}{c}1.6581 * * * \\
(0.0351) \\
\end{array}$ & $\begin{array}{c}1.1441^{* * * *} \\
(0.0979)\end{array}$ & $\begin{array}{c}1.1873^{* * *} \\
(0.0968)\end{array}$ \\
\hline $\begin{array}{l}\text { Person and Panel FE } \\
\text { Occupation FE }\end{array}$ & & $\checkmark$ & $\begin{array}{l}\checkmark \\
\checkmark\end{array}$ & & $\checkmark$ & $\begin{array}{l}\checkmark \\
\checkmark\end{array}$ \\
\hline Observations & 115,000 & 107,000 & 107,000 & 103,000 & 94,000 & 94.000 \\
\hline Individuals & 36,000 & 27,000 & 27,000 & 33,000 & 25,000 & 25,000 \\
\hline$R^{2}$ & 0.2319 & 0.8604 & 0.8609 & 0.2966 & 0.8667 & 0.8672 \\
\hline & 17.56 & 4.88 & 5.02 & 25.08 & 4.12 & 4.17 \\
\hline Prob $>F$ & 0.0000 & 0.0000 & 0.0000 & 0.0000 & 0.0000 & 0.0000 \\
\hline
\end{tabular}

Table B.36 reports the estimated coefficients for the pooled OLS wage regressions given in Equation (2.3.2) and the fixed effects wage regression given in Equation (2.3.5). The dependent variable is the log wage of the worker at time $t$. Each model has a set of controls for education (3), union membership (1), province/major city of residence (12), marital status (1), age (1), age squared divided by 100 (1). Interaction terms between calendar year dummies and the public sector indicator variable are included (i.e. $\left(\right.$ Public $_{i, t} \times$ Year $\left.\left._{j}\right)\right)$. Details of the F-test on the interaction terms between calendar year dummies and the public sector indicator variable are provided in the last 2 rows of the table. Longitudinal weights for each person, provided in the SLID, are applied. In parentheses, I report standard errors clustered at the person level. Observation numbers are rounded as per Statistcs Canada confidentiality rules. Significance levels are indicated by *, **, *** for $10 \%, 5 \%$, and $1 \%$ respectively. 
Table B.37: Distribution of Workers

by Visible Minority Group and Sector of Employment

\begin{tabular}{|c|c|c|c|c|}
\hline & All & Public & Private & Difference \\
\hline Black & 0.0173 & 0.0186 & 0.0168 & 0.0018 \\
\hline South Asian & 0.0081 & 0.0034 & 0.0099 & $-0.0065 * * *$ \\
\hline Chinese & 0.0269 & 0.0125 & 0.0322 & $-0.0197^{* * *}$ \\
\hline Korean & 0.0011 & 0.0005 & 0.0013 & $-0.0008^{* * *}$ \\
\hline Japanese & 0.0022 & 0.0028 & 0.0020 & 0.0008 \\
\hline South East Asian & 0.0210 & 0.0125 & 0.0242 & $-0.0117^{* * *}$ \\
\hline Filipino & 0.0160 & 0.0122 & 0.0174 & $-0.0052^{* * *}$ \\
\hline Oceanic & 0.0003 & 0.0001 & 0.0004 & $-0.0003^{* * *}$ \\
\hline Arab & 0.0101 & 0.0073 & 0.0112 & $-0.0039 * * *$ \\
\hline Latin American & 0.0064 & 0.0035 & 0.0075 & $-0.0040 * * *$ \\
\hline Not a Visible Minority & 0.8626 & 0.9036 & 0.8473 & $0.0563^{* * *}$ \\
\hline Observations & 231,000 & 73,000 & 158,000 & \\
\hline Share of Observations & $100.0 \%$ & $31.6 \%$ & $68.4 \%$ & \\
\hline
\end{tabular}

Table B.37 reports descriptive statistics on the distribution of workers by visible minority group and sector of employment based on my calculations using the SLID. Observation numbers are rounded as per Statistcs Canada confidentiality rules. Significance levels are indicated by *, **, *** for $10 \%, 5 \%$, and $1 \%$ respectively.

Table B.38: Pooled OLS Wage Regressions Controlling for Belonging to a Visible Minority Group

\begin{tabular}{lcccc}
\hline \hline & \multicolumn{2}{c}{ Men } & \multicolumn{2}{c}{ Women } \\
\hline Variable & $(\mathbf{1})$ & $(\mathbf{2})$ & $\mathbf{( 3 )}$ & $(\mathbf{4})$ \\
\hline \multirow{2}{*}{ Public } & $0.0799^{* * *}$ & $0.0739^{* * *}$ & $0.2110^{* * *}$ & $0.2001^{* * * *}$ \\
& $(0.0040)$ & $(0.0040)$ & $(0.0044)$ & $(0.0045)$ \\
Black & $-0.2101^{* * *}$ & $-0.2008^{* * *}$ & $-0.1582^{* * *}$ & $-0.1593^{* * *}$ \\
& $(0.0158)$ & $(0.0192)$ & $(0.0143)$ & $(0.0184)$ \\
Chinese & $-0.1895^{* * *}$ & $-0.1970^{* * *}$ & $-0.1801^{* * *}$ & $-0.1965^{* * *}$ \\
& $(0.0141)$ & $(0.0153)$ & $(0.0126)$ & $(0.0142)$ \\
South East Asian & $-0.2258^{* * *}$ & $-0.2501^{* * *}$ & $-0.1771^{* * *}$ & $-0.1984^{* * *}$ \\
Filipino & $(0.0151)$ & $(0.0167)$ & $(0.0142)$ & $(0.0166)$ \\
& $-0.2977^{* * *}$ & $-0.3094^{* * *}$ & $-0.2836^{* * *}$ & $-0.3235^{* * *}$ \\
Arab & $(0.0168)$ & $(0.0195)$ & $(0.0157)$ & $(0.0184)$ \\
& $-0.1910^{* * *}$ & $-0.2048^{* * *}$ & $-0.2109^{* * *}$ & $-0.2210^{* * *}$ \\
Asian Other & $(0.0230)$ & $(0.0260)$ & $(0.0241)$ & $(0.0288)$ \\
Other Visible Minority Groups & $-0.2220^{* * *}$ & $-0.2558^{* * *}$ & $-0.1925^{* * *}$ & $-0.2522^{* * *}$ \\
& $(0.0229)$ & $(0.0254)$ & $(0.0326)$ & $(0.0390)$ \\
& $-0.2067^{* * *}$ & $-0.2110^{* * *}$ & $-0.2061^{* * *}$ & $-0.2309^{* * *}$ \\
& $(0.0260)$ & $(0.0293)$ & $(0.0234)$ & $(0.0262)$ \\
\hline
\end{tabular}


Table B.38: Pooled OLS Wage Regressions

Controlling for Belonging to a Visible Minority Group, Cont.

\begin{tabular}{|c|c|c|c|c|}
\hline \multirow[b]{2}{*}{ Variable } & \multicolumn{2}{|c|}{ Men } & \multicolumn{2}{|c|}{ Women } \\
\hline & (1) & $(2)$ & $(3)$ & $(4)$ \\
\hline Public $\times$ Black & & $\begin{array}{l}-0.0380 \\
(0.0315)\end{array}$ & & $\begin{array}{c}0.0010 \\
(0.0274)\end{array}$ \\
\hline Public $\times$ Chinese & & $\begin{array}{c}0.0570 \\
(0.0358)\end{array}$ & & $\begin{array}{c}0.1002^{* * * *} \\
(0.0255)\end{array}$ \\
\hline Public $\times$ South East Asian & & $\begin{array}{c}0.1823^{* * *} \\
(0.0319)\end{array}$ & & $\begin{array}{c}0.0957^{* * *} \\
(0.0286)\end{array}$ \\
\hline Public $\times$ Filipino & & $\begin{array}{l}0.0614^{*} \\
(0.0331)\end{array}$ & & $\begin{array}{c}0.1664^{* * * *} \\
(0.0296)\end{array}$ \\
\hline Public $\times$ Arab & & $\begin{array}{l}0.0913^{*} \\
(0.0485)\end{array}$ & & $\begin{array}{c}0.0304 \\
(0.0523)\end{array}$ \\
\hline Public $\times$ Asian Other & & $\begin{array}{c}0.2403^{* * *} \\
(0.0435)\end{array}$ & & $\begin{array}{c}0.2944^{* * * *} \\
(0.0512)\end{array}$ \\
\hline Public $\times$ Other Visible Minority Groups & & $\begin{array}{c}0.0264 \\
(0.0512)\end{array}$ & & $\begin{array}{c}0.1437^{* * *} \\
(0.0523)\end{array}$ \\
\hline Constant & $\begin{array}{c}1.7307^{* * *} \\
(0.0338)\end{array}$ & $\begin{array}{c}1.7296^{* * *} \\
(0.0338)\end{array}$ & $\begin{array}{c}1.7382^{* * *} \\
(0.0348)\end{array}$ & $\begin{array}{c}1.7417^{* * *} \\
(0.0348)\end{array}$ \\
\hline Observations & 116,000 & 116,000 & 103,000 & 103,000 \\
\hline Individuals & 36,000 & 36,000 & 34,000 & 34,000 \\
\hline$R^{2}$ & 0.2511 & 0.2520 & 0.3127 & 0.3142 \\
\hline $\mathrm{F}$ & & 9.16 & & 13.10 \\
\hline Prob $>F$ & & 0.0000 & & 0.0000 \\
\hline
\end{tabular}

Table B.38 reports the estimated coefficients for the pooled OLS wage regressions given in Equation (2.5.1) and (2.5.2). The dependent variable is the log wage of the worker at time $t$. Each model has a set of controls for education (3), union membership (1), province/major city of residence (12), marital status (1), age (1), age squared divided by 100 (1). Interaction terms between visible minority group dummies and the public sector indicator variable are included (i.e. $\left(\right.$ Public $_{i, t} \times V M_{-}$Group $\left._{k, i}\right)$ ). Details of the F-test on the interaction terms between visible minority group dummies and the public sector indicator variable are provided in the last 2 rows of the table. Longitudinal weights for each person, provided in the SLID, are applied. In parentheses, I report standard errors clustered at the person level. Observation numbers are rounded as per Statistcs Canada confidentiality rules. Significance levels are indicated by $*, * *, * * *$ for $10 \%, 5 \%$, and $1 \%$ respectively. 
Table B.39: Pooled OLS Wage Regressions

Controlling for Belonging to a Visible Minority Group and Time Since Migration

\begin{tabular}{|c|c|c|c|c|}
\hline \multirow[b]{2}{*}{ Variable } & \multicolumn{2}{|c|}{ Men } & \multicolumn{2}{|c|}{ Women } \\
\hline & (1) & $(2)$ & $(3)$ & $(4)$ \\
\hline Public & $\begin{array}{c}0.0757^{* * *} \\
(0.0040)\end{array}$ & $\begin{array}{c}0.0723^{* * *} \\
(0.0040)\end{array}$ & $\begin{array}{c}0.2027^{* * *} \\
(0.0044)\end{array}$ & $\begin{array}{c}0.1978^{* * *} \\
(0.0045)\end{array}$ \\
\hline Black & $\begin{array}{c}-0.1760^{* * *} \\
(0.0159)\end{array}$ & $\begin{array}{c}-0.1585^{* * *} \\
(0.0191)\end{array}$ & $\begin{array}{c}-0.1016^{* * *} \\
(0.0148)\end{array}$ & $\begin{array}{c}-0.0998^{* * *} \\
(0.0184)\end{array}$ \\
\hline Chinese & $\begin{array}{c}-0.1343^{* * *} \\
(0.0147)\end{array}$ & $\begin{array}{c}-0.1400^{* * *} \\
(0.0158)\end{array}$ & $\begin{array}{c}-0.0920^{* * *} \\
(0.0128)\end{array}$ & $\begin{array}{c}-0.1030^{* * *} \\
(0.0143)\end{array}$ \\
\hline South East Asian & $\begin{array}{c}-0.1599^{* * *} \\
(0.0156)\end{array}$ & $\begin{array}{c}-0.1799^{* * *} \\
(0.0172)\end{array}$ & $\begin{array}{c}-0.0927^{* * *} \\
(0.0148)\end{array}$ & $\begin{array}{c}-0.1000^{* * *} \\
(0.0172)\end{array}$ \\
\hline Filipino & $\begin{array}{c}-0.2032^{* * *} \\
(0.0174)\end{array}$ & $\begin{array}{c}-0.2074^{* * *} \\
(0.0197)\end{array}$ & $\begin{array}{c}-0.1544^{* * *} \\
(0.0167)\end{array}$ & $\begin{array}{c}-0.1858^{* * *} \\
(0.0190)\end{array}$ \\
\hline Arab & $\begin{array}{c}-0.1101^{* * *} \\
(0.0231)\end{array}$ & $\begin{array}{c}-0.1216^{* * *} \\
(0.0260)\end{array}$ & $\begin{array}{c}-0.0985^{* * *} \\
(0.0227)\end{array}$ & $\begin{array}{c}-0.1047^{* * *} \\
(0.0279)\end{array}$ \\
\hline Asian Other & $\begin{array}{c}-0.1649^{* * *} \\
(0.0226)\end{array}$ & $\begin{array}{c}-0.1968^{* * *} \\
(0.0251)\end{array}$ & $\begin{array}{c}-0.1016^{* * *} \\
(0.0316)\end{array}$ & $\begin{array}{l}-0.1470^{* * *} \\
(0.0382)\end{array}$ \\
\hline Other Visible Minority Groups & $\begin{array}{c}-0.1257^{* * *} \\
(0.0265)\end{array}$ & $\begin{array}{c}-0.1224^{* * *} \\
(0.0296)\end{array}$ & $\begin{array}{c}-0.0969^{* * *} \\
(0.0234)\end{array}$ & $\begin{array}{c}-0.1139^{* * *} \\
(0.0264)\end{array}$ \\
\hline Public $\times$ Black & & $\begin{array}{c}-0.0748^{* *} \\
(0.0310)\end{array}$ & & $\begin{array}{l}-0.0095 \\
(0.0278)\end{array}$ \\
\hline Public $\times$ Chinese & & $\begin{array}{c}0.0317 \\
(0.0359)\end{array}$ & & $\begin{array}{c}0.0581^{* *} \\
(0.0245)\end{array}$ \\
\hline Public $\times$ South East Asian & & $\begin{array}{c}0.1391^{* * *} \\
(0.0316)\end{array}$ & & $\begin{array}{c}0.0246 \\
(0.0276)\end{array}$ \\
\hline Public $\times$ Filipino & & $\begin{array}{c}0.0100 \\
(0.0359)\end{array}$ & & $\begin{array}{c}0.1208^{* * *} \\
(0.0306)\end{array}$ \\
\hline Public $\times$ Arab & & $\begin{array}{c}0.0646 \\
(0.0459)\end{array}$ & & $\begin{array}{c}0.0119 \\
(0.0455)\end{array}$ \\
\hline Public $\times$ Asian Other & & $\begin{array}{c}0.2183^{* * *} \\
(0.0428)\end{array}$ & & $\begin{array}{c}0.2142^{* * *} \\
(0.0511)\end{array}$ \\
\hline Public $\times$ Other Visible Minority Groups & & $\begin{array}{c}-0.0458 \\
(0.0514)\end{array}$ & & $\begin{array}{c}0.0858^{*} \\
(0.0491)\end{array}$ \\
\hline YSM & $\begin{array}{c}0.0243^{* * *} \\
(0.0026)\end{array}$ & $\begin{array}{c}0.0243^{* * *} \\
(0.0026)\end{array}$ & $\begin{array}{c}0.0219^{* * *} \\
(0.0027)\end{array}$ & $\begin{array}{c}0.0213^{* * *} \\
(0.0027)\end{array}$ \\
\hline$\left(\mathrm{YSM}^{2}\right) / 100$ & $\begin{array}{c}-0.0223^{* * *} \\
(0.0045)\end{array}$ & $\begin{array}{c}-0.0221^{* * *} \\
(0.0045)\end{array}$ & $\begin{array}{c}-0.0134^{* * *} \\
(0.0051)\end{array}$ & $\begin{array}{c}-0.0125^{* *} \\
(0.0051)\end{array}$ \\
\hline Landing Years (1946 to 1950 ) & $\begin{array}{c}-0.5778^{* * *} \\
(0.0605)\end{array}$ & $\begin{array}{c}-0.5808^{* * *} \\
(0.0606)\end{array}$ & $\begin{array}{c}-0.7158^{* * *} \\
(0.0863)\end{array}$ & $\begin{array}{c}-0.7066^{* * *} \\
(0.0863)\end{array}$ \\
\hline Landing Years (1951 to 1955$)$ & $\begin{array}{c}-0.6860 * * * \\
(0.0551)\end{array}$ & $\begin{array}{c}-0.6899^{* * *} \\
(0.0552)\end{array}$ & $\begin{array}{c}-0.7813^{* * *} \\
(0.0568)\end{array}$ & $\begin{array}{c}-0.7711^{* * *} \\
(0.0567)\end{array}$ \\
\hline Landing Years (1956 to 1960) & $\begin{array}{c}-0.6315^{* * *} \\
(0.0505)\end{array}$ & $\begin{array}{c}-0.6342^{* * *} \\
(0.0507)\end{array}$ & $\begin{array}{c}-0.6950^{* * *} \\
(0.0542)\end{array}$ & $\begin{array}{c}-0.6845^{* * *} \\
(0.0541)\end{array}$ \\
\hline Landing Years (1961 to 1965$)$ & $\begin{array}{c}-0.6223^{* * *} \\
(0.0493)\end{array}$ & $\begin{array}{c}-0.6236^{* * *} \\
(0.0495)\end{array}$ & $\begin{array}{c}-0.6515^{* * *} \\
(0.0500)\end{array}$ & $\begin{array}{c}-0.6418^{* * *} \\
(0.0499)\end{array}$ \\
\hline Landing Years (1966 to 1970 ) & $\begin{array}{c}-0.5678^{* * *} \\
(0.0453)\end{array}$ & $\begin{array}{c}-0.5696^{* * *} \\
(0.0454)\end{array}$ & $\begin{array}{c}-0.5874^{* * *} \\
(0.0465)\end{array}$ & $\begin{array}{c}-0.5791^{* * *} \\
(0.0464)\end{array}$ \\
\hline Landing Years (1971 to 1975 ) & $\begin{array}{c}-0.4854^{* * *} \\
(0.0432)\end{array}$ & $\begin{array}{c}-0.4860^{* * *} \\
(0.0433)\end{array}$ & $\begin{array}{c}-0.5341^{* * *} \\
(0.0438)\end{array}$ & $\begin{array}{c}-0.5238^{* * *} \\
(0.0437)\end{array}$ \\
\hline Landing Years (1976 to 1980 ) & $\begin{array}{c}-0.4447^{* * *} \\
(0.0414)\end{array}$ & $\begin{array}{c}-0.4450^{* * *} \\
(0.0416)\end{array}$ & $\begin{array}{c}-0.5137^{* * *} \\
(0.0411)\end{array}$ & $\begin{array}{c}-0.5073^{* * *} \\
(0.0409)\end{array}$ \\
\hline
\end{tabular}


Table B.39: Pooled OLS Wage Regressions

Controlling for Belonging to a Visible Minority Group and Time Since Migration, Cont.

\begin{tabular}{|c|c|c|c|c|}
\hline \multirow[b]{2}{*}{ Variable } & \multicolumn{2}{|c|}{ Men } & \multicolumn{2}{|c|}{ Women } \\
\hline & (1) & $(2)$ & $(3)$ & $(4)$ \\
\hline Landing Years (1981 to 1985 ) & $\begin{array}{c}-0.4434^{* * *} \\
(0.0379)\end{array}$ & $\begin{array}{c}-0.4428^{* * *} \\
(0.0381)\end{array}$ & $\begin{array}{c}-0.4684^{* * *} \\
(0.0393)\end{array}$ & $\begin{array}{c}-0.4596^{* * *} \\
(0.0392)\end{array}$ \\
\hline Landing Years (1986 to 1990) & $\begin{array}{c}-0.4119^{* * *} \\
(0.0290)\end{array}$ & $\begin{array}{c}-0.4078^{* * *} \\
(0.0290)\end{array}$ & $\begin{array}{c}-0.4321^{* * *} \\
(0.0302)\end{array}$ & $\begin{array}{c}-0.4220^{* * *} \\
(0.0300)\end{array}$ \\
\hline Landing Years (1991 to 1995) & $\begin{array}{c}-0.3951^{* * *} \\
(0.0264)\end{array}$ & $\begin{array}{c}-0.3923^{* * *} \\
(0.0265)\end{array}$ & $\begin{array}{c}-0.4668^{* * *} \\
(0.0274)\end{array}$ & $\begin{array}{c}-0.4521^{* * *} \\
(0.0274)\end{array}$ \\
\hline Landing Years (1996 to 2000) & $\begin{array}{c}-0.3312^{* * *} \\
(0.0254)\end{array}$ & $\begin{array}{c}-0.3286^{* * *} \\
(0.0255)\end{array}$ & $\begin{array}{c}-0.3376^{* * *} \\
(0.0248)\end{array}$ & $\begin{array}{c}-0.3313^{* * *} \\
(0.0248)\end{array}$ \\
\hline Landing Years (2001 to 2005) & $\begin{array}{c}-0.2629 * * * \\
(0.0305)\end{array}$ & $\begin{array}{c}-0.2626^{* * *} \\
(0.0304)\end{array}$ & $\begin{array}{c}-0.3527^{* * *} \\
(0.0398)\end{array}$ & $\begin{array}{c}-0.3444^{* * *} \\
(0.0395)\end{array}$ \\
\hline Landing Years (2006 to 2010) & $\begin{array}{c}-0.2056^{* * *} \\
(0.0650)\end{array}$ & $\begin{array}{c}-0.2025^{* * *} \\
(0.0646)\end{array}$ & $\begin{array}{c}-0.3667^{* * *} \\
(0.0646)\end{array}$ & $\begin{array}{c}-0.3499^{* * *} \\
(0.0636)\end{array}$ \\
\hline Constant & $\begin{array}{c}1.7338^{* * * *} \\
(0.0340)\end{array}$ & $\begin{array}{c}1.7328^{* * *} \\
(0.0340)\end{array}$ & $\begin{array}{c}1.6842^{* * *} \\
(0.0352)\end{array}$ & $\begin{array}{c}1.6880 * * * \\
(0.0352)\end{array}$ \\
\hline Observations & 112,000 & 112,000 & 100,000 & 100,000 \\
\hline Individuals & 34,000 & 34,000 & 33,000 & 33,000 \\
\hline$R^{2}$ & 0.2639 & 0.2646 & 0.3297 & 0.3303 \\
\hline $\mathrm{F}$ & & 7.72 & & 5.86 \\
\hline Prob $>F$ & & 0.0000 & & 0.0000 \\
\hline
\end{tabular}

Table B.39 reports the estimated coefficients for the pooled OLS wage regressions given in Equation (2.5.1) and (2.5.2). The dependent variable is the log wage of the worker at time $t$. Each model has a set of controls for education (3), union membership (1), province/major city of residence (12), marital status (1), age (1), age squared divided by 100 (1). Interaction terms between visible minority group dummies and the public sector indicator variable are included (i.e. $\left(\right.$ Public $_{i, t} \times V M_{-}$Group $\left.\left._{k, i}\right)\right)$. Details of the F-test on the interaction terms between visible minority group dummies and the public sector indicator variable are provided in the last 2 rows of the table. Longitudinal weights for each person, provided in the SLID, are applied. In parentheses, I report standard errors clustered at the person level. Observation numbers are rounded as per Statistcs Canada confidentiality rules. Significance levels are indicated by *, **, *** for $10 \%, 5 \%$, and $1 \%$ respectively. 
Table B.40: Fixed Effects Wage Regressions

Controlling for Belonging to a Visible Minority Group

\begin{tabular}{|c|c|c|c|c|}
\hline \multirow[b]{2}{*}{ Variable } & \multicolumn{2}{|c|}{ Men } & \multicolumn{2}{|c|}{ Women } \\
\hline & (1) & $(2)$ & $(3)$ & $(4)$ \\
\hline Public & $\begin{array}{c}0.0404^{* *} \\
(0.0171)\end{array}$ & $\begin{array}{c}0.0410^{* *} \\
(0.0171)\end{array}$ & $\begin{array}{c}0.0616^{* * *} \\
(0.0138)\end{array}$ & $\begin{array}{c}0.0609 * * * \\
(0.0138)\end{array}$ \\
\hline Public $\times$ Black & $\begin{array}{c}0.2089 \\
(0.1347)\end{array}$ & $\begin{array}{c}0.2052 \\
(0.1359)\end{array}$ & $\begin{array}{l}-0.0950 \\
(0.0585)\end{array}$ & $\begin{array}{l}-0.0886 \\
(0.0562)\end{array}$ \\
\hline Public $\times$ Chinese & $\begin{array}{c}-0.1828^{*} \\
(0.1054)\end{array}$ & $\begin{array}{r}-0.1809^{*} \\
(0.1054)\end{array}$ & $\begin{array}{l}-0.0686 \\
(0.3329)\end{array}$ & $\begin{array}{l}-0.0672 \\
(0.3346)\end{array}$ \\
\hline Public $\times$ South East Asian & $\begin{array}{c}0.0326 \\
(0.0673)\end{array}$ & $\begin{array}{c}0.0242 \\
(0.0681)\end{array}$ & $\begin{array}{c}0.3420^{* * *} \\
(0.0789)\end{array}$ & $\begin{array}{c}0.3447^{* * *} \\
(0.0780)\end{array}$ \\
\hline Public $\times$ Filipino & $\begin{array}{l}-0.0219 \\
(0.0463)\end{array}$ & $\begin{array}{l}-0.0259 \\
(0.0456)\end{array}$ & $\begin{array}{c}0.0107 \\
(0.0886)\end{array}$ & $\begin{array}{c}0.0145 \\
(0.0889)\end{array}$ \\
\hline Public $\times$ Arab & $\begin{array}{l}-0.1413 \\
(0.1661)\end{array}$ & $\begin{array}{l}-0.1372 \\
(0.1606)\end{array}$ & $\begin{array}{c}0.1327 \\
(0.0954)\end{array}$ & $\begin{array}{c}0.1300 \\
(0.0954)\end{array}$ \\
\hline Public $\times$ Asian Other & $\begin{array}{l}-0.0044 \\
(0.1056)\end{array}$ & $\begin{array}{l}-0.0075 \\
(0.1035)\end{array}$ & $\begin{array}{l}-0.0284 \\
(0.1562)\end{array}$ & $\begin{array}{l}-0.0302 \\
(0.1550)\end{array}$ \\
\hline Public $\times$ Other Visible Minority Groups & $\begin{array}{c}0.0840 \\
(0.0862)\end{array}$ & $\begin{array}{c}0.0802 \\
(0.0832)\end{array}$ & $\begin{array}{c}0.1605 \\
(0.1023)\end{array}$ & $\begin{array}{c}0.1545 \\
(0.1000)\end{array}$ \\
\hline YSM & & $\begin{array}{l}0.0073^{*} \\
(0.0041)\end{array}$ & & $\begin{array}{l}-0.0030 \\
(0.0049)\end{array}$ \\
\hline$\left(\mathrm{YSM}^{2}\right) / 100$ & & $\begin{array}{l}-0.0100 \\
(0.0080)\end{array}$ & & $\begin{array}{l}-0.0010 \\
(0.0087)\end{array}$ \\
\hline Constant & $\begin{array}{c}1.1933^{* * *} \\
(0.0873)\end{array}$ & $\begin{array}{c}1.1909^{* * *} \\
(0.0891)\end{array}$ & $\begin{array}{c}1.1778^{* * *} \\
(0.0956)\end{array}$ & $\begin{array}{c}1.1543^{* * *} \\
(0.0966)\end{array}$ \\
\hline Observations & 107,000 & 104,000 & 94,000 & 92,000 \\
\hline Individuals & 27,000 & 26,000 & 25,000 & 24,000 \\
\hline$R^{2}$ & 0.8608 & 0.8614 & 0.8672 & 0.8667 \\
\hline $\begin{array}{l}\text { Person and Panel FE } \\
\text { Occupation FE } \\
\text { F }\end{array}$ & $\begin{array}{c}\checkmark \\
\checkmark \\
3.64\end{array}$ & $\begin{array}{l}\checkmark \\
\checkmark \\
1.07\end{array}$ & $\begin{array}{c}\checkmark \\
\checkmark \\
3.45\end{array}$ & $\begin{array}{c}\checkmark \\
\checkmark \\
3.83\end{array}$ \\
\hline Prob $>F$ & 0.0003 & 0.3780 & 0.0006 & 0.0004 \\
\hline
\end{tabular}

Table B.40 reports the estimated coefficients for the fixed effects wage regressions given in Equation (2.5.1) and (2.5.2). The dependent variable is the log wage of the worker at time $t$. Each model has a set of controls for education (3), union membership (1), province/major city of residence (12), marital status (1), age (1), age squared divided by 100 (1). Interaction terms between visible minority group dummies and the public sector indicator variable are included (i.e. $\left(\right.$ Public $_{i, t} \times V M_{-}$Group $\left._{k, i}\right)$ ). Details of the F-test on the interaction terms between visible minority group dummies and the public sector indicator variable are provided in the last 2 rows of the table. Longitudinal weights for each person, provided in the SLID, are applied. In parentheses, I report standard errors clustered at the person level. Observation numbers are rounded as per Statistcs Canada confidentiality rules. Significance levels are indicated by $*, * *, * * *$ for $10 \%, 5 \%$, and $1 \%$ respectively. 


\section{Appendix $\mathrm{C}$}

Appendix for Chapter 3 
Table C.1: Descriptive Statistics of Immigrant Characteristics by Enrollment in Post-Secondary Education

\begin{tabular}{|c|c|c|c|c|}
\hline & All & No PSE & PSE & Difference \\
\hline Years-Since-Migration & 5.893 & 5.881 & 5.943 & $-0.062 * * *$ \\
\hline Age in the Current Year & 39.293 & 39.429 & 38.732 & $0.697^{* * *}$ \\
\hline Age at Landing & 32.678 & 32.810 & 32.132 & $0.677^{* * *}$ \\
\hline Married at Landing & 0.728 & 0.736 & 0.695 & $0.041^{* * *}$ \\
\hline Indicator of Ever Being a Temporary Foreign Worker & 0.098 & 0.105 & 0.071 & $0.035^{* * *}$ \\
\hline Indicator of Ever Being a Foreign Student & 0.038 & 0.037 & 0.041 & $-0.005 * * *$ \\
\hline Province / Major CMA of Residence & All & No PSE & PSE & Difference \\
\hline Toronto (default) & 0.426 & 0.425 & 0.430 & $-0.005^{* * *}$ \\
\hline Newfoundland & 0.001 & 0.001 & 0.001 & $0.000^{* * *}$ \\
\hline PEI & 0.025 & 0.001 & 0.000 & $0.000^{* * *}$ \\
\hline Nova Scotia & 0.005 & 0.005 & 0.003 & $0.002^{* * *}$ \\
\hline New Brunswick & 0.003 & 0.003 & 0.002 & $0.001^{* * *}$ \\
\hline Quebec (Other) & 0.019 & 0.018 & 0.020 & $-0.002^{* * *}$ \\
\hline Montreal & 0.119 & 0.114 & 0.136 & $-0.021^{* * *}$ \\
\hline Ontario (Other) & 0.097 & 0.097 & 0.096 & $0.001^{* * *}$ \\
\hline Vancouver & 0.133 & 0.133 & 0.132 & $0.001^{* * *}$ \\
\hline Manitoba & 0.029 & 0.029 & 0.027 & $0.003^{* * *}$ \\
\hline Saskatchewan & 0.010 & 0.010 & 0.006 & $0.004^{* * *}$ \\
\hline Alberta & 0.124 & 0.125 & 0.118 & $0.007^{* * *}$ \\
\hline Other British Columbia & 0.026 & 0.028 & 0.017 & $0.010^{* * *}$ \\
\hline Territory & 0.001 & 0.001 & 0.001 & $0.000^{* * *}$ \\
\hline Mother Tongue and Official Language & All & No PSE & PSE & Difference \\
\hline English Mother Tongue (default) & 0.100 & 0.108 & 0.068 & $0.041^{* * *}$ \\
\hline French Mother Tongue & 0.012 & 0.012 & 0.011 & $0.001^{* * *}$ \\
\hline English and French Mother Tongue & 0.023 & 0.024 & 0.019 & $0.005^{* * *}$ \\
\hline Other Mother Tongue, Speaks English & 0.501 & 0.493 & 0.532 & $-0.039 * * *$ \\
\hline Other Mother Tongue, Speaks French & 0.036 & 0.032 & 0.052 & $-0.020^{* * *}$ \\
\hline Other Mother Tongue, Speaks both English and French & 0.061 & 0.054 & 0.092 & $-0.038^{* * *}$ \\
\hline $\begin{array}{l}\text { Other Mother Tongue, Speaks neither English nor } \\
\text { French }\end{array}$ & 0.267 & 0.277 & 0.227 & $0.050^{* * *}$ \\
\hline Educational Attainment at Landing & All & No PSE & PSE & Difference \\
\hline High School or Lower (default) & 0.291 & 0.324 & 0.154 & $0.170^{* * *}$ \\
\hline College Diploma & 0.240 & 0.238 & 0.246 & $-0.008^{* * *}$ \\
\hline Bachelor's Degree & 0.338 & 0.312 & 0.446 & $-0.134 * * *$ \\
\hline Graduate Degree & 0.132 & 0.126 & 0.154 & $-0.028^{* * *}$ \\
\hline
\end{tabular}


Table C.1: Descriptive Statistics of Immigrant Characteristics by Enrollment in Post-Secondary Education, Cont.

\begin{tabular}{lcccc}
\hline \hline Immigration Class & All & No PSE & PSE & Difference \\
\hline Principal Skilled Worker (default) & 0.327 & 0.305 & 0.415 & $-0.109^{* * *}$ \\
Spouse of Skilled Worker & 0.174 & 0.163 & 0.219 & $-0.057^{* * *}$ \\
Provincial Nominee & 0.016 & 0.017 & 0.011 & $0.007^{* * *}$ \\
Caregiver & 0.030 & 0.029 & 0.034 & $-0.005^{* * *}$ \\
Business Class & 0.012 & 0.013 & 0.008 & $0.005^{* * *}$ \\
Family Class & 0.300 & 0.322 & 0.205 & $0.118^{* * *}$ \\
Refugee & 0.138 & 0.145 & 0.107 & $0.038^{* * *}$ \\
Other & 0.050 & 0.051 & 0.046 & $0.005^{* * *}$ \\
\hline Source Region & All & No PSE & PSE & Difference \\
\hline Northwest Europe (default) & & & & \\
Southern / Eastern Europe & 0.061 & 0.068 & 0.034 & $0.035^{* * *}$ \\
Africa & 0.127 & 0.122 & 0.150 & $-0.028^{* * *}$ \\
East Asia & 0.095 & 0.088 & 0.124 & $-0.036^{* * *}$ \\
South Asia & 0.164 & 0.157 & 0.196 & $-0.039^{* * *}$ \\
Southeast Asia & 0.242 & 0.250 & 0.206 & $0.045^{* * *}$ \\
Other Asia & 0.136 & 0.140 & 0.123 & $0.016^{* * *}$ \\
Oceania & 0.046 & 0.045 & 0.051 & $-0.005^{* * *}$ \\
Caribbean / South America & 0.005 & 0.005 & 0.002 & $0.003^{* * *}$ \\
Other & 0.100 & 0.100 & 0.102 & $-0.002^{* * *}$ \\
United States & 0.006 & 0.006 & 0.005 & $0.0011^{* * *}$ \\
\hline Observations & 0.017 & 0.019 & 0.008 & $0.011^{* * * *}$ \\
\hline \hline
\end{tabular}

Table C.1 reports descriptive statistics of the characteristics of immigrants by enrollment in post-secondary education based on calculations using CEEDD as described in Section 3.3. Significance levels are indicated by $* *$ and $* * *$ for $5 \%$ and $1 \%$, respectively.

Table C.2: Descriptive Statistics (Variables Used in the Parametric Long-Difference Model)

\begin{tabular}{lccc}
\hline \hline & Men & Women & Difference \\
\hline $\begin{array}{l}\text { Change of log earnings from the first year since landing to the } \\
\text { sixth year since landing }\end{array}$ & 0.549 & 0.574 & $-0.025^{* * *}$ \\
$\begin{array}{l}\text { Indicator of full-time post-secondary participation within the } \\
\text { window from the second year to the fifth year since landing }\end{array}$ & 0.136 & 0.180 & $-0.043^{* * *}$ \\
$\begin{array}{l}\text { Indicator of part-time post-secondary participation within the } \\
\text { window from the second year to the fifth year since landing }\end{array}$ & 0.147 & 0.174 & $-0.026^{* * *}$ \\
\hline Observations & $2,553,035$ & $2,125,440$ & \\
\hline \hline
\end{tabular}

Table C.2 reports descriptive statistics of the key variables used in the parametric long-difference analysis. Significance levels are indicated by $* *$ and $* * *$ for $5 \%$ and $1 \%$, respectively. 
Table C.3: Earnings Return to Full-Time PSE Investment of Immigrants Within the 6-Year Window Since Their Arrival

\begin{tabular}{|c|c|c|c|c|c|c|c|c|}
\hline \multirow{3}{*}{$\begin{array}{l}\text { Variable } \\
\text { FT PSE Enrollment }\end{array}$} & \multicolumn{4}{|c|}{ Men } & \multicolumn{4}{|c|}{ Women } \\
\hline & \multicolumn{2}{|c|}{ (1) } & \multicolumn{2}{|c|}{$(2)$} & \multicolumn{2}{|c|}{ (3) } & \multicolumn{2}{|c|}{$(4)$} \\
\hline & $0.168^{* * *}$ & $(0.011)$ & $0.146^{* * *}$ & $(0.012)$ & $0.289^{* * *}$ & $(0.012)$ & $0.272^{* * *}$ & $(0.017)$ \\
\hline Initial Earnings & & & $-0.000 * * *$ & $(0.000)$ & & & -0.000 & $(0.000)$ \\
\hline Ever a TFW & $-0.231^{* * *}$ & $(0.008)$ & $-0.123^{* * *}$ & $(0.024)$ & $-0.213^{* * *}$ & $(0.013)$ & $-0.145^{* * *}$ & $(0.046)$ \\
\hline Ever a Foreign Student & 0.001 & $(0.012)$ & 0.009 & $(0.012)$ & $-0.038^{* *}$ & $(0.017)$ & -0.020 & $(0.022)$ \\
\hline $\begin{array}{l}\text { Education } \\
\text { College Diploma }\end{array}$ & $0.082^{* * *}$ & $(0.007)$ & $0.080^{* * *}$ & $(0.007)$ & $0.057^{* * *}$ & $(0.009)$ & $0.057^{* * *}$ & $(0.009)$ \\
\hline Bachelor's Degree & $.196^{* * *}$ & $(0.008)$ & $0.203^{* * *}$ & $(0.008)$ & $0.134^{* * *}$ & $(0.010)$ & $0.139^{* * *}$ & $(0.011)$ \\
\hline Graduate Degree & $0.212^{* * *}$ & $(0.010)$ & $0.235^{* * *}$ & $(0.011)$ & $0.123^{* * *}$ & $(0.013)$ & $0.143^{* * *}$ & $(0.022)$ \\
\hline Admission Category & $0.050 * * *$ & $(0.011)$ & $0.025 * *$ & $(0.012)$ & $0.066 * * *$ & $(0.014)$ & $0.050 * * *$ & $(0.0$ \\
\hline Business Class & 0.040 & $(0.030)$ & -0.015 & $(0.031)$ & $0.111^{* * *}$ & $(0.030)$ & $0.088^{* * *}$ & $(0.034)$ \\
\hline Family Class & $-0.108^{* * *}$ & $(0.010)$ & $-0.140^{* * *}$ & $(0.012)$ & $-0.109 * * *$ & $(0.015)$ & $-0.128 * * *$ & $(0.019)$ \\
\hline Provincial Nominee & 0.008 & $(0.046)$ & 0.050 & $(0.047)$ & 0.013 & $(0.057)$ & 0.042 & $(0.061)$ \\
\hline Caregiver & $0.396^{* * *}$ & $(0.059)$ & $0.307^{* * *}$ & $(0.061)$ & $0.185^{* * *}$ & $(0.055)$ & 0.126 & $(0.067)$ \\
\hline Refugee & $-0.066^{* * *}$ & $(0.012)$ & $-0.088^{* * *}$ & $(0.012)$ & -0.016 & $(0.017)$ & -0.033 & $(0.020)$ \\
\hline Other & $-0.172^{* * *}$ & $(0.045)$ & $-0.188^{* * *}$ & $(0.044)$ & $-0.185^{* * *}$ & $(0.053)$ & $-0.186 * * *$ & $(0.052)$ \\
\hline Source Region & & & & & & & & \\
\hline Unit & $.045^{* *}$ & $(0.019)$ & 0.012 & $(0.021)$ & -0.06 & $(0.026)$ & -0.035 & $(0.034)$ \\
\hline $\begin{array}{l}\text { Southern / Eastern } \\
\text { Europe }\end{array}$ & $0.119^{* * *}$ & $(0.013)$ & $0.072^{* * *}$ & $(0.017)$ & $0.243^{* * *}$ & $(0.020)$ & $0.229^{* * *}$ & $(0.024)$ \\
\hline Africa & $0.065^{* * *}$ & $(0.013)$ & 0.023 & $(0.017)$ & $0.089^{* * *}$ & $(0.020)$ & $0.073^{* * *}$ & $(0.024)$ \\
\hline East Asia & $0.033^{* *}$ & $(0.014)$ & -0.033 & $(0.020)$ & 0.033 & $(0.020)$ & 0.015 & $(0.024)$ \\
\hline South Asia & $-0.032^{* *}$ & $(0.013)$ & $-0.086^{* * *}$ & $(0.018)$ & 0.002 & $(0.019)$ & -0.019 & $(0.026)$ \\
\hline Southeast Asia & $0.045^{* * *}$ & $(0.013)$ & -0.010 & $(0.018)$ & $0.123^{* * *}$ & $(0.019)$ & $0.107^{* * *}$ & $(0.023)$ \\
\hline Other Asia & $053^{* * *}$ & $(0.017)$ & 0.003 & $(0.020)$ & $0.184^{* * *}$ & $(0.026)$ & $0.162^{* * *}$ & $(0.031)$ \\
\hline Oceania & $0.110^{* * *}$ & $(0.027)$ & $0.098^{* * *}$ & $(0.034)$ & -0.097 & $(0.051)$ & -0.093 & $(0.050)$ \\
\hline $\begin{array}{l}\text { Caribbean / South } \\
\text { America }\end{array}$ & $0.092^{* * *}$ & $(0.012)$ & $0.041^{* *}$ & $(0.017)$ & $0.150^{* * *}$ & $(0.019)$ & $0.131^{* * *}$ & $(0.024)$ \\
\hline Other & $0.115^{* * *}$ & $(0.029)$ & $0.065^{* *}$ & $(0.031)$ & 0.067 & $(0.037)$ & 0.060 & $(0.037)$ \\
\hline Initial Firı & & & & & & & & \\
\hline $20-9$ & 0.009 & $(0.008)$ & -0.001 & $(0.008)$ & 0.011 & $(0.010)$ & 0.016 & $(0.010)$ \\
\hline 100 - 500 Employees & $-0.021^{* * *}$ & $(0.008)$ & -0.006 & $(0.009)$ & 0.004 & $(0.010)$ & 0.015 & $(0.012)$ \\
\hline More than 500 & -0.010 & $(0.008)$ & 0.011 & $(0.009)$ & $0.053^{* * *}$ & $(0.009)$ & $0.065^{* * *}$ & $(0.013)$ \\
\hline Constant & $0.402^{* * *}$ & $(0.063)$ & $0.580^{* * *}$ & $(0.071)$ & $-1.021^{* * *}$ & $(0.076)$ & $-0.906^{* * *}$ & $(0.115)$ \\
\hline $\mathrm{Ob}$ & \multicolumn{2}{|c|}{226,770} & \multicolumn{2}{|c|}{226,770} & \multicolumn{2}{|c|}{185,195} & \multicolumn{2}{|c|}{185,195} \\
\hline$R^{2}$ & \multicolumn{2}{|c|}{0.07} & \multicolumn{2}{|c|}{0.09} & \multicolumn{2}{|c|}{0.07} & \multicolumn{2}{|c|}{0.08} \\
\hline
\end{tabular}

Table C.3 reports the estimated coefficients from the parametric long-difference estimation in which the dependent variable is the difference between the log earnings in the sixth year and those in the first year since arrival; and the full-time PSE enrollment dummy is equal to 1 if the immigrant enrolls in PSE on a full-time basis at some point over the period from the 2 nd to the 5 th year since landing. Each model has a set of controls for occupation (9), industry (21), province/territory/major city of residence (13), first language spoken (6), marital status (2), year of landing (9), age at landing (1), age at landing squared divided by 100 (1). The sample includes those who had employment earnings and did not attend PSE on a full-time basis in 1st and 6th year since arrival. Those attending part-time PSE in any year are excluded. Robust standard errors are reported in parentheses. Significance levels are indicated by $* *$ and $* * *$ for $5 \%$ and $1 \%$, respectively. 
Table C.4: Earnings Return to Part-Time PSE Investment of Immigrants Within the 6-Year Window Since Their Arrival

\begin{tabular}{|c|c|c|c|c|c|c|c|c|}
\hline \multirow{3}{*}{$\begin{array}{l}\text { Variable } \\
\text { PT PSE Enrollment }\end{array}$} & \multicolumn{4}{|c|}{ Men } & \multicolumn{4}{|c|}{ Women } \\
\hline & \multicolumn{2}{|c|}{ (1) } & \multicolumn{2}{|c|}{$(2)$} & \multicolumn{2}{|c|}{$(3)$} & \multicolumn{2}{|c|}{$(4)$} \\
\hline & $0.089^{* * *}$ & $(0.009)$ & $0.075^{* * *}$ & $(0.009)$ & $0.166^{* * *}$ & $(0.011)$ & $0.156^{* * *}$ & $(0.013)$ \\
\hline Initial Earnings & & & $-0.000 * * *$ & $(0.000)$ & & & -0.000 & $(0.000)$ \\
\hline Ever a TFW & $-0.230 * * *$ & $(0.008)$ & $-0.123^{* * *}$ & $(0.023)$ & $-0.223^{* * *}$ & $(0.013)$ & $-0.155^{* * *}$ & $(0.046)$ \\
\hline Ever a Foreign Student & -0.008 & $(0.012)$ & 0.000 & $(0.012)$ & $-0.049^{* *}$ & $(0.016)$ & -0.029 & $(0.021)$ \\
\hline $\begin{array}{l}\text { Education } \\
\text { College Diploma }\end{array}$ & $0.081^{* * *}$ & $(0.007)$ & $0.078^{* * *}$ & $(0.007)$ & $0.056^{* * *}$ & $(0.009)$ & $0.056^{* * *}$ & $(0.009)$ \\
\hline Bachelor's Degree & $0.195^{* * *}$ & $(0.008)$ & $0.201^{* * *}$ & $(0.008)$ & $0.132^{* * *}$ & $(0.010)$ & $0.136^{* * *}$ & $(0.011)$ \\
\hline Graduate Degree & $0.214^{* * *}$ & $(0.010)$ & $0.237^{* * *}$ & $(0.011)$ & $0.126^{* * *}$ & $(0.013)$ & $0.146^{* * *}$ & $(0.022)$ \\
\hline Admission Category & $0.050 * * *$ & $(0.011)$ & $0.025 *$ & $(0.012)$ & $0.074 * * *$ & $(0.014)$ & $0.057 * *$ & (0.018) \\
\hline Business Class & 0.035 & $(0.030)$ & -0.020 & $(0.031)$ & $0.102^{* * *}$ & $(0.030)$ & $0.079 *$ & $(0.034)$ \\
\hline Family Class & $-0.098^{* * *}$ & $(0.010)$ & $-0.130^{* * *}$ & $(0.011)$ & $-0.108^{* * *}$ & $(0.014)$ & $-0.128^{* * *}$ & $(0.019)$ \\
\hline Provincial Nominee & 0.041 & $(0.046)$ & 0.084 & $(0.046)$ & 0.027 & $(0.058)$ & 0.057 & $(0.061)$ \\
\hline Caregiver & $0.417 * * *$ & $(0.058)$ & $0.327^{* * *}$ & $(0.060)$ & $0.191^{* * *}$ & $(0.055)$ & $0.133^{*}$ & $(0.067)$ \\
\hline Refugee & $-0.069 * * *$ & $(0.012)$ & $-0.090 * * *$ & $(0.012)$ & -0.023 & $(0.017)$ & $-0.041^{*}$ & $(0.020)$ \\
\hline Other & $-0.203^{* * *}$ & $(0.044)$ & $-0.219 * * *$ & $(0.044)$ & $-0.200 * * *$ & $(0.053)$ & $-0.202^{* * *}$ & $(0.052)$ \\
\hline Source Region & & & & & & & & \\
\hline United States & $-0.050^{* *}$ & $(0.018)$ & 0.009 & $(0.021)$ & $-0.062^{*}$ & $(0.026)$ & -0.034 & $(0.033)$ \\
\hline $\begin{array}{l}\text { Southern / Eastern } \\
\text { Europe }\end{array}$ & $0.113^{* * *}$ & $(0.013)$ & $0.066^{* * *}$ & $(0.017)$ & $0.234^{* * *}$ & $(0.019)$ & $0.220^{* * *}$ & $(0.024)$ \\
\hline Africa & $0.059^{* * *}$ & $(0.013)$ & 0.016 & $(0.016)$ & $0.084^{* * *}$ & $(0.020)$ & $0.068^{* *}$ & $(0.024)$ \\
\hline East Asia & 0.024 & $(0.014)$ & $-0.042^{*}$ & $(0.020)$ & 0.023 & $(0.019)$ & 0.006 & $(0.023)$ \\
\hline South Asia & $-0.037^{* *}$ & $(0.012)$ & $-0.091 * * *$ & $(0.017)$ & -0.006 & $(0.019)$ & -0.028 & $(0.026)$ \\
\hline Southeast Asia & $0.040^{* *}$ & $(0.013)$ & -0.016 & $(0.018)$ & $0.116^{* * *}$ & $(0.019)$ & $0.099 * * *$ & $(0.023)$ \\
\hline Other Asia & $0.045^{* *}$ & $(0.016)$ & -0.005 & $(0.020)$ & $0.173^{* * *}$ & $(0.025)$ & $0.151^{* * *}$ & $(0.031)$ \\
\hline Oceania & $0.100^{* * *}$ & $(0.027)$ & $0.089^{* *}$ & $(0.034)$ & $-0.108^{*}$ & $(0.049)$ & $-0.105^{*}$ & $(0.049)$ \\
\hline $\begin{array}{l}\text { Caribbean / South } \\
\text { America }\end{array}$ & $0.084^{* * *}$ & $(0.012)$ & $0.033^{*}$ & $(0.017)$ & $0.147^{* * *}$ & $(0.019)$ & $0.129^{* * *}$ & $(0.024)$ \\
\hline Other & $0.092^{* *}$ & $(0.029)$ & 0.042 & $(0.031)$ & 0.064 & $(0.036)$ & 0.056 & $(0.036)$ \\
\hline Initial Firn & & & & & & & & \\
\hline 20 - 99 Employees & -0.008 & $(0.007)$ & 0.000 & $(0.008)$ & 0.011 & $(0.010)$ & 0.016 & $(0.010)$ \\
\hline 100 - 500 Employees & -0.015 & $(0.008)$ & 0.001 & $(0.009)$ & 0.002 & $(0.010)$ & 0.013 & $(0.012)$ \\
\hline More than 500 & -0.003 & $(0.007)$ & $0.018^{*}$ & $(0.009)$ & $0.053^{* * *}$ & $(0.009)$ & $0.066^{* * *}$ & $(0.014)$ \\
\hline Constant & $0.386^{* * *}$ & $(0.062)$ & $0.567^{* * *}$ & $(0.070)$ & $-1.095^{* * *}$ & $(0.076)$ & $-0.978^{* * *}$ & $(0.116)$ \\
\hline Observations & \multicolumn{2}{|c|}{227,545} & \multicolumn{2}{|c|}{227,545} & \multicolumn{2}{|c|}{183,285} & \multicolumn{2}{|c|}{183,285} \\
\hline$R^{2}$ & \multicolumn{2}{|c|}{0.07} & \multicolumn{2}{|c|}{0.09} & \multicolumn{2}{|c|}{0.06} & \multicolumn{2}{|c|}{0.08} \\
\hline
\end{tabular}

Table C.4 reports the estimated coefficients from the parametric long-difference estimation in which the dependent variable is the difference between the log earnings in the sixth year and those in the first year since arrival; and the part-time PSE enrollment dummy is equal to 1 if the immigrant enrolls in PSE on a part-time basis at some point over the period from the 2nd to the 5th year since landing. Each model has a set of controls for occupation (9), industry (21), province/territory/major city of residence (13), first language spoken (6), marital status (2), year of landing (9), age at landing (1), age at landing squared divided by 100 (1). The sample includes those who had employment earnings and did not attend PSE on a part-time basis in 1st and 6th year since arrival. Those attending full-time PSE in any year are excluded. Robust standard errors are reported in parentheses. Significance levels are indicated by $* *$ and $* * *$ for $5 \%$ and $1 \%$, respectively. 
Table C.5: Earnings Return to Months of Full-Time PSE Investment of Immigrants Within the 6-Year Window Since Their Arrival

\begin{tabular}{|c|c|c|c|c|c|c|c|c|}
\hline \multirow{4}{*}{$\begin{array}{l}\text { Variable } \\
\text { Months of FT PSE } \\
\text { Enrollment } \\
\text { Initial Earnings }\end{array}$} & \multicolumn{4}{|c|}{ Men } & \multicolumn{4}{|c|}{ Women } \\
\hline & \multicolumn{2}{|c|}{ (1) } & \multicolumn{2}{|c|}{$(2)$} & \multicolumn{2}{|c|}{ (3) } & \multicolumn{2}{|c|}{ (4) } \\
\hline & $0.016^{* * *}$ & $(0.001)$ & $0.015^{* * *}$ & $(0.001)$ & $0.026^{* * *}$ & $(0.001)$ & $0.025^{* * *}$ & $(0.001)$ \\
\hline & & & $-0.000 * * *$ & $(0.000)$ & & & -0.000 & $(0.000)$ \\
\hline Ever a TFW & $-0.231^{* * *}$ & $(0.008)$ & $-0.123^{* * *}$ & $(0.024)$ & $-0.213^{* * *}$ & $(0.013)$ & $-0.146^{* *}$ & $(0.046)$ \\
\hline $\begin{array}{l}\text { Ever a Foreign Student } \\
\text { Education }\end{array}$ & 0.001 & $(0.012)$ & 0.009 & $(0.012)$ & $-0.038^{*}$ & $(0.017)$ & -0.019 & $(0.022)$ \\
\hline College Diploma & $0.083^{* * *}$ & $(0.007)$ & $0.080^{* * *}$ & $(0.007)$ & $0.059 * * *$ & $(0.009)$ & $0.058^{* * *}$ & $(0.009)$ \\
\hline Bachelor's Degree & $0.196^{* * *}$ & $(0.008)$ & $0.202^{* * *}$ & $(0.008)$ & $0.135^{* * *}$ & $(0.010)$ & $0.140 * * *$ & $(0.011)$ \\
\hline Graduate Degree & $0.212^{* * *}$ & $(0.010)$ & $0.234^{* * *}$ & $(0.011)$ & $0.124^{* * *}$ & $(0.013)$ & $0.144^{* * *}$ & $(0.022)$ \\
\hline $\begin{array}{l}\text { Admission Category } \\
\text { Spouse of Skilled Worker }\end{array}$ & $0.050^{* * *}$ & $(0.011)$ & $0.025^{*}$ & $(0.012)$ & $0.068^{* * *}$ & $(0.014)$ & $0.051^{* *}$ & $(0.018)$ \\
\hline Business Class & 0.040 & $(0.030)$ & -0.014 & $(0.031)$ & $0.111^{* * *}$ & $(0.030)$ & $0.089^{* *}$ & $(0.034)$ \\
\hline Family Class & $-0.108^{* * *}$ & $(0.010)$ & $-0.140 * * *$ & $(0.012)$ & $-0.107^{* * *}$ & $(0.015)$ & $-0.126^{* * *}$ & $(0.019)$ \\
\hline Provincial Nominee & 0.009 & $(0.046)$ & 0.051 & $(0.047)$ & 0.011 & $(0.058)$ & 0.041 & $(0.061)$ \\
\hline Caregiver & $0.399^{* * *}$ & $(0.059)$ & $0.309^{* * *}$ & $(0.061)$ & $0.184^{* * *}$ & $(0.055)$ & 0.125 & $(0.068)$ \\
\hline Refugee & $-0.065^{* * *}$ & $(0.012)$ & $-0.087^{* * *}$ & $(0.012)$ & -0.012 & $(0.017)$ & -0.030 & $(0.020)$ \\
\hline Other & $-0.173^{* * *}$ & $(0.045)$ & $-0.189^{* * *}$ & $(0.044)$ & $-0.182^{* * *}$ & $(0.053)$ & $-0.183^{* * *}$ & $(0.052)$ \\
\hline $\begin{array}{l}\text { Source Region } \\
\text { United States }\end{array}$ & & $(0.0$ & 0.1 & $(0.0$ & & $(0.1$ & -0.0 & $(0.034)$ \\
\hline $\begin{array}{l}\text { Southern / Eastern } \\
\text { Europe }\end{array}$ & 0.11 & $(0.013)$ & $0.071^{* * *}$ & $(0.017)$ & $0.243^{* * *}$ & $(0.020)$ & $0.229^{* * *}$ & $(0.025)$ \\
\hline Africa & $0.065^{* * *}$ & $(0.013)$ & 0.022 & $(0.017)$ & $0.093^{* * *}$ & $(0.020)$ & $0.077^{* *}$ & $(0.024)$ \\
\hline East Asia & $0.030^{*}$ & $(0.014)$ & -0.036 & $(0.020)$ & 0.031 & $(0.020)$ & 0.013 & $(0.024)$ \\
\hline South Asia & $-0.033^{* *}$ & $(0.013)$ & $-0.087 * * *$ & $(0.018)$ & 0.004 & $(0.019)$ & -0.018 & $(0.026)$ \\
\hline Southeast Asia & $0.045^{* * *}$ & $(0.013)$ & -0.010 & $(0.018)$ & $0.126^{* * *}$ & $(0.019)$ & $0.109^{* * *}$ & $(0.023)$ \\
\hline Other Asia & $0.051^{* *}$ & $(0.017)$ & 0.000 & $(0.020)$ & $0.186^{* * *}$ & $(0.026)$ & $0.164^{* * *}$ & $(0.031)$ \\
\hline Oceania & $0.111^{* * *}$ & $(0.027)$ & $0.098^{* *}$ & $(0.034)$ & -0.099 & $(0.051)$ & -0.095 & $(0.050)$ \\
\hline $\begin{array}{l}\text { Caribbean / South } \\
\text { America }\end{array}$ & $0.091^{* * *}$ & $(0.012)$ & $0.040^{*}$ & $(0.017)$ & $0.151^{* * *}$ & $(0.019)$ & $0.132^{* * *}$ & $(0.024)$ \\
\hline Other & $0.116^{* * *}$ & $(0.029)$ & $0.066^{*}$ & $(0.031)$ & 0.071 & $(0.037)$ & 0.064 & $(0.037)$ \\
\hline $\begin{array}{l}\text { Initial Firm } \\
20 \text { - } 99 \text { Employees }\end{array}$ & -0.009 & $(0.008)$ & -0.001 & $(0.008)$ & 0.011 & $(0.010)$ & 0.016 & $(0.010)$ \\
\hline 100 - 500 Employees & $-0.022^{* *}$ & $(0.008)$ & -0.007 & $(0.009)$ & 0.003 & $(0.010)$ & 0.014 & $(0.012)$ \\
\hline More than 500 & -0.011 & $(0.008)$ & 0.010 & $(0.009)$ & $0.053^{* * *}$ & $(0.009)$ & $0.065^{* * *}$ & $(0.013)$ \\
\hline Constant & $0.401^{* * *}$ & $(0.063)$ & $0.578^{* * *}$ & $(0.071)$ & $-1.036^{* * *}$ & $(0.076)$ & $-0.920^{* * *}$ & $(0.115)$ \\
\hline Observations & \multicolumn{2}{|c|}{226,770} & \multicolumn{2}{|c|}{226,770} & \multicolumn{2}{|c|}{185,195} & \multicolumn{2}{|c|}{185,195} \\
\hline$R^{2}$ & \multicolumn{2}{|c|}{0.07} & \multicolumn{2}{|c|}{0.09} & \multicolumn{2}{|c|}{0.07} & \multicolumn{2}{|c|}{0.08} \\
\hline
\end{tabular}

Table C.5 reports the estimated coefficients from the parametric long-difference estimation in which the dependent variable is the difference between the log earnings in the sixth year and those in the first year since arrival; and the full-time PSE enrollment variable is equal to the number of months of full-time PSE enrollment over the 2nd through 5th years since landing. Each model has a set of controls for occupation (9), industry (21), province/territory/major city of residence (13), first language spoken (6), marital status (2), year of landing (9), age at landing (1), age at landing squared divided by 100 (1). The sample includes those who had employment earnings and did not attend PSE on a full-time basis in 1st and 6th year since arrival. Those attending part-time PSE in any year are excluded. Specifications (2) and (4) include a control for log earnings in first full year in Canada. Robust standard errors are reported in parentheses. Significance levels are indicated by $* *$ and $* * *$ for $5 \%$ and $1 \%$, respectively. 
Table C.6: Earnings Return to Months of Part-Time PSE Investment of Immigrants Within the 6-Year Window Since Their Arrival

\begin{tabular}{|c|c|c|c|c|c|c|c|c|}
\hline \multirow{4}{*}{$\begin{array}{l}\text { Variable } \\
\text { Months of PT PSE } \\
\text { Enrollment } \\
\text { Initial Earnings }\end{array}$} & \multicolumn{4}{|c|}{ Men } & \multicolumn{4}{|c|}{ Women } \\
\hline & \multicolumn{2}{|c|}{ (1) } & \multicolumn{2}{|c|}{$(2)$} & \multicolumn{2}{|c|}{$(3)$} & \multicolumn{2}{|c|}{$(4)$} \\
\hline & $0.009^{* * *}$ & $(0.001)$ & $0.008^{* * *}$ & $(0.001)$ & $0.014^{* * *}$ & $(0.001)$ & $0.013^{* * *}$ & $(0.001)$ \\
\hline & & & $-0.000 * * *$ & $(0.000)$ & & & -0.000 & $(0.000)$ \\
\hline Ever a TFW & $-0.231^{* * *}$ & $(0.008)$ & $-0.123^{* * *}$ & $(0.023)$ & $-0.224^{* * *}$ & $(0.013)$ & $-0.156^{* * *}$ & $(0.046)$ \\
\hline $\begin{array}{l}\text { Ever a Foreign Student } \\
\text { Education }\end{array}$ & -0.008 & $(0.012)$ & 0.000 & $(0.012)$ & $-0.049 * *$ & $(0.016)$ & -0.029 & $(0.021)$ \\
\hline College Diploma & $0.082^{* * *}$ & $(0.007)$ & $0.079^{* * *}$ & $(0.007)$ & $0.058^{* * *}$ & $(0.009)$ & $0.058^{* * *}$ & $(0.009)$ \\
\hline Bachelor's Degree & $0.196^{* * *}$ & $(0.008)$ & $0.203^{* * *}$ & $(0.008)$ & $0.135^{* * *}$ & $(0.010)$ & $0.140^{* * *}$ & $(0.011)$ \\
\hline Graduate Degree & $0.216^{* * *}$ & $(0.010)$ & $0.238^{* * *}$ & $(0.011)$ & $0.130 * * *$ & $(0.013)$ & $0.150^{* * *}$ & $(0.022)$ \\
\hline $\begin{array}{l}\text { Admission Category } \\
\text { Spouse of Skilled Worker }\end{array}$ & $0.050^{* * *}$ & $(0.011)$ & $0.025^{*}$ & $(0.012)$ & $0.075^{* * *}$ & $(0.014)$ & $0.057^{* *}$ & $(0.018)$ \\
\hline Business Class & 0.034 & $(0.030)$ & -0.021 & $(0.031)$ & $0.100^{* *}$ & $(0.030)$ & $0.077^{*}$ & $(0.034)$ \\
\hline Family Class & $-0.098^{* * *}$ & $(0.010)$ & $-0.131^{* * *}$ & $(0.011)$ & $-0.109^{* * *}$ & $(0.014)$ & $-0.129^{* * *}$ & $(0.019)$ \\
\hline Provincial Nominee & 0.042 & $(0.046)$ & 0.084 & $(0.046)$ & 0.030 & $(0.058)$ & 0.060 & $(0.061)$ \\
\hline Caregiver & $0.420^{* * *}$ & $(0.058)$ & $0.330 * * *$ & $(0.060)$ & $0.197 * * *$ & $(0.055)$ & $0.138^{*}$ & $(0.067)$ \\
\hline Refugee & $-0.070 * * *$ & $(0.012)$ & $-0.091^{* * *}$ & $(0.012)$ & -0.025 & $(0.017)$ & $-0.042^{*}$ & $(0.020)$ \\
\hline Other & $-0.204^{* * *}$ & $(0.044)$ & $-0.220^{* * *}$ & $(0.044)$ & $-0.204^{* * *}$ & $(0.053)$ & $-0.206^{* * *}$ & $(0.052)$ \\
\hline Source Re & & & & & & & & \\
\hline United States & & $\begin{array}{l}(0.018) \\
(0.013)\end{array}$ & $\begin{array}{l}0.06 \\
0.06\end{array}$ & & & $\begin{array}{l}(0.026) \\
(0019)\end{array}$ & *** & \\
\hline $\begin{array}{l}\text { Southern / Eastern } \\
\text { Europe }\end{array}$ & 0 & $(0.013)$ & 0.06 & $(0.0$ & 0.23 & $(0.019)$ & & \\
\hline Africa & $0.060^{* * *}$ & $(0.013)$ & 0.017 & $(0.016)$ & $0.084^{* * *}$ & $(0.020)$ & $0.068^{* *}$ & $(0.024)$ \\
\hline East Asia & 0.025 & $(0.014)$ & $-0.041^{*}$ & $(0.020)$ & 0.024 & $(0.019)$ & 0.006 & $(0.023)$ \\
\hline South Asia & $-0.036^{* *}$ & $(0.012)$ & $-0.090 * * *$ & $(0.017)$ & -0.007 & $(0.019)$ & -0.029 & $(0.026)$ \\
\hline Southeast Asia & $0.040 * *$ & $(0.013)$ & -0.016 & $(0.018)$ & $0.116^{* * *}$ & $(0.019)$ & $0.099 * * *$ & $(0.023)$ \\
\hline Other Asia & $0.046^{* *}$ & $(0.016)$ & -0.004 & $(0.020)$ & $0.175^{* * *}$ & $(0.025)$ & $0.152^{* * *}$ & $(0.031)$ \\
\hline Oceania & $0.100^{* * *}$ & $(0.027)$ & $0.089^{* *}$ & $(0.034)$ & $-0.108^{*}$ & $(0.049)$ & $-0.105^{*}$ & $(0.049)$ \\
\hline $\begin{array}{l}\text { Caribbean / South } \\
\text { America }\end{array}$ & $0.085^{* * *}$ & $(0.012)$ & $0.034^{*}$ & $(0.017)$ & $0.149 * * *$ & $(0.019)$ & $0.130^{* * *}$ & $(0.024)$ \\
\hline Other & $0.092^{* *}$ & $(0.029)$ & 0.041 & $(0.031)$ & 0.063 & $(0.036)$ & 0.056 & $(0.036)$ \\
\hline Initial Firm & & & & & & & & \\
\hline 20 - 99 Employees & -0.008 & $(0.007)$ & 0.000 & $(0.008)$ & 0.011 & $(0.010)$ & 0.016 & $(0.010)$ \\
\hline 100 - 500 Employees & -0.015 & $(0.008)$ & 0.001 & $(0.009)$ & 0.002 & $(0.010)$ & 0.013 & $(0.012)$ \\
\hline More than 500 & -0.003 & $(0.007)$ & $0.018^{*}$ & $(0.009)$ & $0.053^{* * *}$ & $(0.009)$ & $0.066^{* * *}$ & $(0.014)$ \\
\hline Constant & $0.386^{* * *}$ & $(0.062)$ & $0.567^{* * *}$ & $(0.070)$ & $-1.092^{* * *}$ & $(0.076)$ & $-0.975^{* * *}$ & $(0.115)$ \\
\hline Observations & \multicolumn{2}{|c|}{227,545} & \multicolumn{2}{|c|}{227,545} & \multicolumn{2}{|c|}{183,285} & \multicolumn{2}{|c|}{183,285} \\
\hline$R^{2}$ & \multicolumn{2}{|c|}{0.07} & \multicolumn{2}{|c|}{0.09} & \multicolumn{2}{|c|}{0.06} & \multicolumn{2}{|c|}{0.08} \\
\hline
\end{tabular}

Table C.6 reports the estimated coefficients from the parametric long-difference estimation in which the dependent variable is the difference between the log earnings in the sixth year and those in the first year since arrival; and the part-time PSE enrollment variable is equal to the number of months of full-time PSE enrollment over the 2nd through 5th years since landing. Each model has a set of controls for occupation (9), industry (21), province/territory/major city of residence (13), first language spoken (6), marital status (2), year of landing (9), age at landing (1), age at landing squared divided by 100 (1). The sample includes those who had employment earnings and did not attend PSE on a part-time basis in 1st and 6th year since arrival. Those attending full-time PSE in any year are excluded. Specifications (2) and (4) include a control for log earnings in first full year in Canada. Robust standard errors are reported in parentheses. Significance levels are indicated by $* *$ and $* * *$ for $5 \%$ and $1 \%$, respectively. 
Table C.7: Determinants of Immigrant PSE Enrollment

Within the 6-Year Window Since Their Arrival, Linear Probability Model

\begin{tabular}{|c|c|c|c|c|c|c|c|c|}
\hline \multirow[b]{2}{*}{ Variable } & \multicolumn{4}{|c|}{ Men } & \multicolumn{4}{|c|}{ Women } \\
\hline & \multicolumn{2}{|c|}{ (1) } & \multicolumn{2}{|c|}{$(2)$} & \multicolumn{2}{|c|}{ (3) } & \multicolumn{2}{|c|}{ (4) } \\
\hline & \multicolumn{2}{|c|}{ FT PSE } & \multicolumn{2}{|c|}{ PT PSE } & \multicolumn{2}{|c|}{ FT PSE } & \multicolumn{2}{|c|}{ PT PSE } \\
\hline Age at Landing & $-0.015^{* * *}$ & $(0.001)$ & 0.001 & $(0.001)$ & $-0.017^{* * *}$ & $(0.001)$ & 0.001 & $(0.001)$ \\
\hline$\left((\text { Age at Landing })^{2}\right) / 100$ & $0.015^{* * *}$ & $(0.001)$ & $-0.005^{* * *}$ & $(0.001)$ & $0.016^{* * *}$ & $(0.001)$ & $-0.005^{* * *}$ & $(0.001)$ \\
\hline Ever a TFW & $-0.071^{* * *}$ & $(0.002)$ & $-0.051^{* * *}$ & $(0.002)$ & $-0.054^{* * *}$ & $(0.003)$ & $-0.035^{* * *}$ & $(0.003)$ \\
\hline Ever a Foreign Student & $0.085^{* * *}$ & $(0.003)$ & $0.015^{* * *}$ & $(0.003)$ & $0.045^{* * *}$ & $(0.004)$ & 0.006 & $(0.004)$ \\
\hline $\begin{array}{l}\text { Education } \\
\text { College Diploma }\end{array}$ & 0.05 & $(0.0$ & 0.04 & $(0.0$ & $0.056^{* * *}$ & $(0.0$ & $0.049^{* * *}$ & $(0.002)$ \\
\hline Bachelor's Degree & $0.085^{* * *}$ & $(0.002)$ & $0.093^{* * *}$ & $(0.002)$ & $0.076^{* * *}$ & $(0.002)$ & $0.092^{* * *}$ & $(0.002)$ \\
\hline Graduate Degree & $0.079^{* * *}$ & $(0.002)$ & $0.075^{* * *}$ & $(0.002)$ & $0.077^{* * *}$ & $(0.003)$ & $0.082^{* * *}$ & $(0.003)$ \\
\hline $\begin{array}{l}\text { on Category } \\
\text { f Skilled Worker }\end{array}$ & & & & & & & & \\
\hline Business Class & $-0.040^{* * *}$ & $(0.005)$ & $-0.049 * * *$ & $(0.004)$ & $-0.056^{* * *}$ & $(0.005)$ & $-0.070^{* * *}$ & $(0.004)$ \\
\hline Family Class & $-0.056^{* * *}$ & $(0.002)$ & $-0.047^{* * *}$ & $(0.002)$ & $-0.065^{* * *}$ & $(0.003)$ & $-0.058^{* * *}$ & $(0.003)$ \\
\hline Provincial Nominee & 0.001 & $(0.008)$ & $0.048^{* * *}$ & $(0.007)$ & 0.004 & $(0.011)$ & $0.059^{* * *}$ & $(0.009)$ \\
\hline Caregiver & $0.141^{* * *}$ & $(0.015)$ & $0.122^{* * *}$ & $(0.014)$ & $0.090^{* * *}$ & $(0.010)$ & $0.131^{* * *}$ & $(0.008)$ \\
\hline Refugee & $-0.046^{* * *}$ & $(0.003)$ & $-0.059 * * *$ & $(0.002)$ & $-0.035^{* * *}$ & $(0.004)$ & $-0.078^{* * *}$ & $(0.003)$ \\
\hline Other & $-0.058 * * *$ & $(0.008)$ & $-0.077 * * *$ & $(0.007)$ & $-0.068^{* * *}$ & $(0.010)$ & $-0.113^{* * *}$ & $(0.008)$ \\
\hline $\begin{array}{l}\text { Sourc } \\
\text { United }\end{array}$ & $023^{* * *}$ & $(0.004)$ & $0.013^{* * *}$ & $(0.004)$ & $0.024^{* * *}$ & $(0.005)$ & $-0.013 * * *$ & $(0.005)$ \\
\hline $\begin{array}{l}\text { Southern / Eastern } \\
\text { Europe }\end{array}$ & $0.034^{* * *}$ & $(0.003)$ & $0.022^{* * *}$ & $(0.003)$ & $0.126^{* * *}$ & $(0.004)$ & $0.082^{* * *}$ & $(0.004)$ \\
\hline Africa & $0.133^{* * *}$ & $(0.003)$ & $0.050^{* * *}$ & $(0.003)$ & $0.157^{* * *}$ & $(0.004)$ & $0.032^{* * *}$ & $(0.004)$ \\
\hline East Asia & $0.105^{* * *}$ & $(0.003)$ & $0.026^{* * *}$ & $(0.003)$ & $0.143^{* * *}$ & $(0.004)$ & $0.043^{* * *}$ & $(0.004)$ \\
\hline South Asia & $0.028^{* * *}$ & $(0.003)$ & $0.040^{* * *}$ & $(0.003)$ & $0.039 * * *$ & $(0.004)$ & -0.004 & $(0.004)$ \\
\hline Southeast Asia & $0.017^{* * *}$ & $(0.003)$ & $0.019^{* * *}$ & $(0.003)$ & $0.077^{* * *}$ & $(0.004)$ & $0.011^{* * *}$ & $(0.004)$ \\
\hline Other Asia & $0.073^{* * *}$ & $(0.004)$ & $0.049^{* * *}$ & $(0.003)$ & $0.113^{* * *}$ & $(0.005)$ & $0.040 * * *$ & $(0.005)$ \\
\hline Oceania & $0.053^{* * *}$ & $(0.006)$ & $0.033^{* * *}$ & $(0.006)$ & $0.015^{* *}$ & $(0.007)$ & 0.012 & $(0.008)$ \\
\hline $\begin{array}{l}\text { Caribbean / South } \\
\text { America }\end{array}$ & $0.083^{* * *}$ & $(0.003)$ & $0.060^{* * *}$ & $(0.003)$ & $0.130^{* * *}$ & $(0.004)$ & $0.065^{* * *}$ & $(0.004)$ \\
\hline Other & $0.061^{* * *}$ & $(0.008)$ & $0.033^{* * *}$ & $(0.008)$ & $0.089^{* * *}$ & $(0.009)$ & 0.003 & $(0.008)$ \\
\hline $\begin{array}{l}\text { Initial Firm } \\
20 \text { - } 99 \text { Employ }\end{array}$ & $0.026^{* * *}$ & $(0.002)$ & $0.010^{* * *}$ & $(0.002)$ & $0.017^{* * *}$ & $(0.002$ & $0.006^{* * *}$ & $(0.002)$ \\
\hline 100 - 500 Employees & $0.036^{* * *}$ & $(0.002)$ & $0.013^{* * *}$ & $(0.002)$ & $0.028^{* * *}$ & $(0.002)$ & $0.008^{* * *}$ & $(0.002)$ \\
\hline More than 500 & $0.055^{* * *}$ & $(0.002)$ & $0.017^{* * *}$ & $(0.002)$ & $0.048^{* * *}$ & $(0.002)$ & $0.011^{* * *}$ & $(0.002)$ \\
\hline Constant & $0.325^{* * *}$ & $(0.014)$ & $0.079^{* * *}$ & $(0.012)$ & $0.356^{* * *}$ & $(0.015)$ & $0.142^{* * *}$ & $(0.013)$ \\
\hline Observations & 380,9 & & 366,1 & & 327 & & 314,5 & \\
\hline$R^{2}$ & 0.1 & & 0.0 & & 0.08 & & 0.07 & \\
\hline
\end{tabular}

Table C.7 reports the estimated coefficients from the estimation of a linear probability model in which the dependent variable equals 1 if the immigrant enrolls in full-time or part-time PSE for at least one term over the period from the 2nd to the 5th year since landing in columns (1) and (3) and columns (2) and (4), respectively. Each model has a set of controls for occupation (9), industry (21), province/territory/major city of residence (13), first language spoken (6), marital status (2), year of landing (9). The sample includes those who had employment earnings and did not attend PSE on a full-time or part-time basis in 1st and 6 th year since arrival in columns (1) and (3) and columns (2) and (4), respectively. Robust standard errors are reported in parentheses. Significance levels are indicated by $* *$ and $* * *$ for $5 \%$ and $1 \%$, respectively. 
Table C.8: Propensity Score Matching Estimates for the Effect of Full-Time Study (Nearest Neighbour Matching Using the Euclidean Distance Metric)

\begin{tabular}{|c|c|c|c|c|c|c|c|c|}
\hline \multirow[b]{2}{*}{ Variable } & \multicolumn{4}{|c|}{ Men } & \multicolumn{4}{|c|}{ Women } \\
\hline & \multicolumn{2}{|c|}{ (1) } & \multicolumn{2}{|c|}{$(2)$} & \multicolumn{2}{|c|}{ (3) } & \multicolumn{2}{|c|}{ (4) } \\
\hline & & & Initial Ea & Control & & & Initial Es & Control \\
\hline ATT & $0.174^{* * *}$ & $(0.014)$ & $0.160^{* * *}$ & $(0.014)$ & $0.295^{* * *}$ & $(0.015)$ & $0.286^{* * *}$ & $(0.016)$ \\
\hline ATE & $0.111^{* * *}$ & $(0.014)$ & $0.084^{* * *}$ & $(0.014)$ & $0.236^{* * *}$ & $(0.016)$ & $0.210^{* * *}$ & $(0.016)$ \\
\hline Observations & \multicolumn{2}{|c|}{226,770} & \multicolumn{2}{|c|}{202,065} & \multicolumn{2}{|c|}{185,195} & \multicolumn{2}{|c|}{164,185} \\
\hline
\end{tabular}

Table C.8 reports the Average Treatment Effect on the Treated (ATT) and Average Treatment Effect (ATE) of full-time study. Abadie-Imbens (AI) standard errors are reported in parentheses. Significance levels are indicated by $* *$ and $* * *$ for $5 \%$ and $1 \%$, respectively.

Table C.9: Propensity Score Matching Estimates for the Effect of Part-Time Study (Nearest Neighbour Matching Using the Euclidean Distance Metric)

\begin{tabular}{|c|c|c|c|c|c|c|c|c|}
\hline \multirow[b]{2}{*}{ Variable } & \multicolumn{4}{|c|}{ Men } & \multicolumn{4}{|c|}{ Women } \\
\hline & \multicolumn{2}{|c|}{ (1) } & \multicolumn{2}{|c|}{ (2) } & \multicolumn{2}{|c|}{ (3) } & \multicolumn{2}{|c|}{ (4) } \\
\hline & & & Initial Ea & Control & & & Initial Ea & Control \\
\hline ATT & $0.072^{* * *}$ & $(0.011)$ & $0.058^{* * *}$ & $(0.012)$ & $0.166^{* * *}$ & $(0.014)$ & $0.181^{* * *}$ & $(0.016)$ \\
\hline ATE & $0.081^{* * *}$ & $(0.012)$ & $0.066^{* * *}$ & $(0.013)$ & $0.196^{* * *}$ & $(0.017)$ & $0.203^{* * *}$ & $(0.019)$ \\
\hline Observations & \multicolumn{2}{|c|}{227,545} & \multicolumn{2}{|c|}{201,690} & \multicolumn{2}{|c|}{183,285} & \multicolumn{2}{|c|}{160,665} \\
\hline
\end{tabular}

Table C.9 reports the Average Treatment Effect on the Treated (ATT) and Average Treatment Effect (ATE) of part-time study. Abadie-Imbens (AI) standard errors are reported in parentheses. Significance levels are indicated by $* *$ and $* * *$ for $5 \%$ and $1 \%$, respectively. 
Table C.10: Descriptive Statistics of Immigrant Characteristics

by Enrollment in Post-Secondary Education

(Sample Used for the Fixed Effects Estimation)

\begin{tabular}{|c|c|c|c|c|}
\hline & All & No PSE & PSE & Difference \\
\hline $\begin{array}{l}\text { Years-Since-Migration } \\
\text { Age in the Current Year } \\
\text { Age at Landing } \\
\text { Married at Landing } \\
\text { Indicator of Ever Being a Temporary Foreign Worker } \\
\text { Indicator of Ever Being a Foreign Student }\end{array}$ & $\begin{array}{c}5.861 \\
39.120 \\
32.555 \\
0.730 \\
0.090 \\
0.047 \\
\end{array}$ & $\begin{array}{c}5.257 \\
38.928 \\
32.915 \\
0.750 \\
0.096 \\
0.025 \\
\end{array}$ & $\begin{array}{c}7.384 \\
39.605 \\
31.647 \\
0.678 \\
0.074 \\
0.103 \\
\end{array}$ & $\begin{array}{l}-2.127^{* * *} \\
-0.677^{* * *} \\
1.268^{* * *} \\
0.072^{* * *} \\
0.022^{* * *} \\
-0.078^{* * *}\end{array}$ \\
\hline Province / Major CMA of Residence & All & No PSE & $\mathrm{PSE}$ & Difference \\
\hline $\begin{array}{l}\text { Toronto (default) } \\
\text { Newfoundland } \\
\text { PEI } \\
\text { Nova Scotia } \\
\text { New Brunswick } \\
\text { Quebec (Other) } \\
\text { Montreal } \\
\text { Ontario (Other) } \\
\text { Vancouver } \\
\text { Manitoba } \\
\text { Saskatchewan } \\
\text { Alberta } \\
\text { Other British Columbia } \\
\text { Territory }\end{array}$ & $\begin{array}{l}0.413 \\
0.001 \\
0.001 \\
0.005 \\
0.003 \\
0.022 \\
0.132 \\
0.097 \\
0.137 \\
0.026 \\
0.010 \\
0.118 \\
0.024 \\
0.001 \\
\end{array}$ & $\begin{array}{l}0.420 \\
0.001 \\
0.001 \\
0.005 \\
0.003 \\
0.019 \\
0.119 \\
0.095 \\
0.137 \\
0.028 \\
0.011 \\
0.120 \\
0.026 \\
0.001 \\
\end{array}$ & $\begin{array}{l}0.394 \\
0.001 \\
0.000 \\
0.004 \\
0.003 \\
0.027 \\
0.162 \\
0.101 \\
0.137 \\
0.021 \\
0.007 \\
0.112 \\
0.019 \\
0.001 \\
\end{array}$ & $\begin{array}{l}0.027^{* * *} \\
0.000^{* * *} \\
0.000^{* * *} \\
0.001^{* * *} \\
0.000^{* * *} \\
-0.007^{* * *} \\
-0.043^{* * *} \\
-0.006^{* * *} \\
0.000 \\
0.008^{* * *} \\
0.004^{* * *} \\
0.008^{* * *} \\
0.008^{* * *} \\
0.000^{* *} \\
\end{array}$ \\
\hline Mother Tongue and Official Language & All & No PSE & PSE & Difference \\
\hline $\begin{array}{l}\text { English Mother Tongue (default) } \\
\text { French Mother Tongue } \\
\text { English and French Mother Tongue } \\
\text { Other Mother Tongue, Speaks English } \\
\text { Other Mother Tongue, Speaks French } \\
\text { Other Mother Tongue, Speaks both English and French } \\
\text { Other Mother Tongue, Speaks neither English nor } \\
\text { French }\end{array}$ & $\begin{array}{l}0.092 \\
0.011 \\
0.022 \\
0.499 \\
0.041 \\
0.070 \\
0.265\end{array}$ & $\begin{array}{l}0.102 \\
0.011 \\
0.022 \\
0.489 \\
0.035 \\
0.057 \\
0.284\end{array}$ & $\begin{array}{l}0.066 \\
0.012 \\
0.023 \\
0.525 \\
0.056 \\
0.102 \\
0.216\end{array}$ & $\begin{array}{l}0.036^{* * *} \\
-0.001^{* * *} \\
-0.002^{* * *} \\
-0.036^{* * *} \\
-0.021^{* * *} \\
-0.045^{* * *} \\
0.069^{* * *}\end{array}$ \\
\hline Educational Attainment at Landing & All & No PSE & PSE & Difference \\
\hline $\begin{array}{l}\text { High School or Lower (default) } \\
\text { College Diploma } \\
\text { Bachelor's Degree } \\
\text { Graduate Degree }\end{array}$ & $\begin{array}{l}0.269 \\
0.238 \\
0.351 \\
0.141 \\
\end{array}$ & $\begin{array}{l}0.321 \\
0.237 \\
0.314 \\
0.128 \\
\end{array}$ & $\begin{array}{l}0.139 \\
0.241 \\
0.443 \\
0.176 \\
\end{array}$ & $\begin{array}{l}0.182^{* * *} \\
-0.004^{* * *} \\
-0.129^{* * *} \\
-0.048^{* * *}\end{array}$ \\
\hline
\end{tabular}


Table C.10: Descriptive Statistics of Immigrant Characteristics

by Enrollment in Post-Secondary Education

(Sample Used for the Fixed Effects Estimation), Cont.

\begin{tabular}{lcccc}
\hline \hline Immigration Class & All & No PSE & PSE & Difference \\
\hline Principal Skilled Worker (default) & 0.328 & 0.290 & 0.422 & $-0.132^{* * *}$ \\
Spouse of Skilled Worker & 0.194 & 0.183 & 0.221 & $-0.038^{* * *}$ \\
Provincial Nominee & 0.015 & 0.018 & 0.009 & $0.009^{* * *}$ \\
Caregiver & 0.027 & 0.025 & 0.031 & $-0.006^{* * *}$ \\
Business Class & 0.019 & 0.021 & 0.013 & $0.008^{* * *}$ \\
Family Class & 0.276 & 0.308 & 0.194 & $0.114^{* * *}$ \\
Refugee & 0.138 & 0.151 & 0.107 & $0.043^{* * *}$ \\
Other & 0.046 & 0.047 & 0.042 & $0.005^{* * *}$ \\
\hline Source Region & All & No PSE & PSE & Difference \\
\hline Northwest Europe (default) & & & & \\
Southern / Eastern Europe & 0.056 & 0.064 & 0.038 & $0.026^{* * *}$ \\
Africa & 0.132 & 0.125 & 0.151 & $-0.026^{* * *}$ \\
East Asia & 0.104 & 0.092 & 0.134 & $-0.042^{* * *}$ \\
South Asia & 0.188 & 0.170 & 0.234 & $-0.064^{* * *}$ \\
Southeast Asia & 0.222 & 0.242 & 0.171 & $0.071^{* * *}$ \\
Other Asia & 0.117 & 0.123 & 0.099 & $0.024^{* * *}$ \\
Oceania & 0.057 & 0.057 & 0.058 & $-0.001^{* * *}$ \\
Caribbean / South America & 0.004 & 0.005 & 0.002 & $0.003^{* * *}$ \\
Other & 0.099 & 0.099 & 0.099 & 0.000 \\
United States & 0.005 & 0.005 & 0.005 & $0.001^{* * *}$ \\
Observations & 0.016 & 0.019 & 0.010 & $0.009^{* * *}$ \\
\hline \hline
\end{tabular}

Table C.10 reports descriptive statistics of the characteristics of immigrants by enrollment in post-secondary education based on calculations using CEEDD as described in Section 3.3. Significance levels are indicated by $* *$ and $* * *$ for $5 \%$ and $1 \%$, respectively.

Table C.11: Descriptive Statistics (Variables Used in the Fixed Effects Estimation)

\begin{tabular}{|c|c|c|c|}
\hline & Men & Women & Difference \\
\hline Log earnings & 10.269 & 9.709 & $0.560^{* * *}$ \\
\hline $\begin{array}{l}\text { Indicator of ever participating in full-time post-secondary } \\
\text { education since landing }\end{array}$ & 0.199 & 0.232 & $-0.033^{* * *}$ \\
\hline $\begin{array}{l}\text { Indicator of ever participating in part-time post-secondary } \\
\text { education since landing }\end{array}$ & 0.195 & 0.215 & $-0.020 * * *$ \\
\hline Observations & $3,841,410$ & $3,657,520$ & \\
\hline
\end{tabular}

Table C.11 reports descriptive statistics of the key variables used in the fixed effects estimation.

Significance levels are indicated by $* *$ and $* * *$ for $5 \%$ and $1 \%$, respectively. 
Table C.12: Fixed Effects Estimation

of the Earnings Return to PSE Investment of Immigrants

\begin{tabular}{lccccccccc}
\hline \hline & \multicolumn{3}{c}{ Men } & \multicolumn{5}{c}{ Women } \\
\hline Variable & \multicolumn{1}{c}{$(\mathbf{1})$} & $\mathbf{( 2 )}$ & $\mathbf{( 3 )}$ & $\mathbf{( 4 )}$ \\
\hline FT PSE Enrollment & $0.219^{* * *}$ & $(0.007)$ & $0.215^{* * *}$ & $(0.007)$ & $0.328^{* * *}$ & $(0.007)$ & $0.326^{* * *}$ & $(0.008)$ \\
PT PSE Enrollment & $0.112^{* * *}$ & $(0.005)$ & $0.119^{* * *}$ & $(0.005)$ & $0.210^{* * *}$ & $(0.006)$ & $0.214^{* * *}$ & $(0.007)$ \\
YSM & $0.111^{* * *}$ & $(0.001)$ & $0.105^{* * *}$ & $(0.001)$ & $0.102^{* * *}$ & $(0.001)$ & $0.094^{* * *}$ & $(0.001)$ \\
$\left((\mathrm{YSM})^{2}\right) / 100$ & $-0.479^{* * *}$ & $(0.005)$ & $-0.480^{* * *}$ & $(0.005)$ & $-0.313^{* * *}$ & $(0.005)$ & $-0.333^{* * *}$ & $(0.006)$ \\
Constant & $9.741^{* * *}$ & $(0.004)$ & $9.832^{* * *}$ & $(0.004)$ & $9.118^{* * *}$ & $(0.005)$ & $9.283^{* * *}$ & $(0.006)$ \\
\hline Observations & $3,357,960$ & $2,733,105$ & $3,123,225$ & $2,251,590$ \\
$R^{2}$ & 0.06 & 0.05 & 0.06 & 0.05 \\
\hline \hline
\end{tabular}

Table C.12 reports the estimated coefficients from the fixed effects estimation in which the dependent variable is the log of earnings. The PSE enrollment dummy variables included in the estimation are equal to 1 if the immigrant ever enrolled in full-time or part-time PSE after landing, respectively. Each model has a set of controls for occupation (9), industry (21), province/territory/major city of residence (13), first language spoken (6), marital status (2), year of landing (9), age at landing (1), age at landing squared divided by 100 (1). Specifications (2) and (4) include a control for log earnings in first full year in Canada. Robust standard errors are reported in parentheses. Significance levels are indicated by $* *$ and $* * *$ for $5 \%$ and $1 \%$, respectively. 
Table C.13: Second Stage of the Fixed Effects Estimation

of the Earnings Return to PSE Investment of Immigrants

\begin{tabular}{|c|c|c|c|c|c|c|c|c|}
\hline \multirow{5}{*}{$\begin{array}{l}\text { Variable } \\
\text { Age at Landing } \\
\left((\text { Age at Landing })^{2}\right) / 100 \\
\text { Initial Earnings }\end{array}$} & \multicolumn{4}{|c|}{ Men } & \multicolumn{4}{|c|}{ Women } \\
\hline & \multicolumn{2}{|c|}{ (1) } & \multicolumn{2}{|c|}{$(2)$} & \multicolumn{2}{|c|}{ (3) } & \multicolumn{2}{|c|}{ (4) } \\
\hline & $0.022^{* * *}$ & $(0.000)$ & $0.012^{* * *}$ & $(0.001)$ & $0.025^{* * *}$ & $(0.000)$ & $0.016^{* * *}$ & $(0.001)$ \\
\hline & $-0.045^{* * *}$ & $(0.001)$ & $-0.029 * * *$ & $(0.001)$ & $-0.034^{* * *}$ & $(0.001)$ & $-0.018^{* * *}$ & $(0.001)$ \\
\hline & & & $0.000^{* * *}$ & $(0.000)$ & & & $0.000^{* * *}$ & $(0.000)$ \\
\hline Ever a TFW & $0.301^{* * *}$ & $(0.002)$ & $0.189^{* * *}$ & $(0.007)$ & $0.185^{* * *}$ & $(0.003)$ & $0.162^{* * *}$ & $(0.009)$ \\
\hline Ever a Foreign Student & $0.041^{* * *}$ & $(0.003)$ & $0.032^{* * *}$ & $(0.004)$ & $0.105^{* * *}$ & $(0.004)$ & $0.111^{* * *}$ & $(0.005)$ \\
\hline & & & & & & & & \\
\hline College Diploma & $0.053^{* * *}$ & $(0.002)$ & $0.055^{* * *}$ & $(0.002)$ & $0.047^{* * *}$ & $(0.002)$ & $0.033^{* * *}$ & $(0.002)$ \\
\hline Bachelor's Degree & $0.137^{* * *}$ & $(0.002)$ & $0.120^{* * *}$ & $(0.002)$ & $0.168^{* * *}$ & $(0.002)$ & $0.138^{* * *}$ & $(0.002)$ \\
\hline Graduate & $0.227 * * *$ & $(0.002)$ & $0.187^{* * *}$ & $(0.003)$ & $0.277^{* * *}$ & $(0.003)$ & $0.228^{* * *}$ & $(0.004)$ \\
\hline \multicolumn{9}{|l|}{ Admission Category } \\
\hline Spouse of Skill & $-0.075^{* * *}$ & $(0.003)$ & $-0.071^{* * *}$ & $(0.003)$ & $-0.110^{* * *}$ & $(0.003)$ & $-0.115^{* * *}$ & $(0.004)$ \\
\hline Business Class & $-0.286^{* * *}$ & $(0.006)$ & $-0.256^{* * *}$ & $(0.007)$ & $-0.222^{* * *}$ & $(0.005)$ & $-0.238^{* * *}$ & $(0.007)$ \\
\hline Family Class & $-0.186^{* * *}$ & $(0.002)$ & $-0.163^{* * *}$ & $(0.003)$ & $-0.206^{* * *}$ & $(0.003)$ & $-0.213^{* * *}$ & $(0.004)$ \\
\hline Provincial Nominee & $0.245^{* * *}$ & $(0.010)$ & $0.209^{* * *}$ & $(0.010)$ & $0.249^{* * *}$ & $(0.013)$ & $0.221^{* * *}$ & $(0.014)$ \\
\hline Caregiver & $-0.097^{* * *}$ & $(0.013)$ & -0.019 & $(0.015)$ & $-0.039^{* * *}$ & $(0.012)$ & $-0.040 * * *$ & $(0.015)$ \\
\hline Refugee & $-0.263^{* * *}$ & $(0.003)$ & $-0.232^{* * *}$ & $(0.003)$ & $-0.228^{* * *}$ & $(0.003)$ & $-0.227^{* * *}$ & $(0.004)$ \\
\hline Other & $-0.228^{* * *}$ & $(0.009)$ & $-0.209^{* * *}$ & $(0.009)$ & $-0.211^{* * *}$ & $(0.011)$ & $-0.205^{* * *}$ & $(0.012)$ \\
\hline \multicolumn{9}{|l|}{ Source Region } \\
\hline United States & $-0.077^{* * *}$ & $(0.005)$ & $-0.130 * * *$ & $(0.006)$ & $-0.075^{* * *}$ & $(0.006)$ & $-0.089^{* * *}$ & $(0.008)$ \\
\hline \multicolumn{9}{|c|}{ (2) } \\
\hline Africa & $-0.280^{* * *}$ & $(0.003)$ & $-0.256^{* * *}$ & $(0.0$ & $-0.210^{* * *}$ & $(0.1$ & $-0.214^{* * *}$ & $(0.1$ \\
\hline East Asia & $-0.421^{* * *}$ & $(0.003)$ & $-0.368^{* * *}$ & $(0.0$ & -0.10 & $(0.004)$ & $-0.146^{* * *}$ & $(0.0$ \\
\hline South Asia & $-0.317^{* * *}$ & $(0.003)$ & $-0.281^{* * *}$ & $(0.004)$ & $-0.212^{* * *}$ & $(0.004)$ & $-0.211^{* * *}$ & $(0.005)$ \\
\hline Southeast Asia & $-0.165^{* * *}$ & $(0.003)$ & $-0.125^{* * *}$ & $(0.005)$ & $0.068^{* * *}$ & $(0.004)$ & $0.043^{* * *}$ & $(0.005)$ \\
\hline Other Asia & $-0.386^{* * *}$ & $(0.004)$ & $-0.334^{* * *}$ & $(0.005)$ & $-0.246^{* * *}$ & $(0.005)$ & $-0.239 * * *$ & $(0.007)$ \\
\hline Oceania & $-0.063^{* * *}$ & $(0.007)$ & $-0.057 * * *$ & $(0.008)$ & $-0.030 * * *$ & $(0.012)$ & $-0.068^{* * *}$ & $(0.012)$ \\
\hline $\begin{array}{l}\text { Caribbean / South } \\
\text { America }\end{array}$ & $-0.215^{* * *}$ & $(0.003)$ & $-0.185^{* * *}$ & $(0.004)$ & $-0.114^{* * *}$ & $(0.004)$ & $-0.131^{* * *}$ & $(0.005)$ \\
\hline Other & $-0.111^{* * *}$ & $(0.007)$ & $-0.091^{* * *}$ & $(0.007)$ & $0.112^{* * *}$ & $(0.008)$ & $0.077^{* * *}$ & $(0.009)$ \\
\hline \multicolumn{9}{|c|}{ 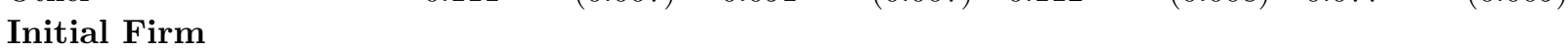 } \\
\hline $20-9$ & $0.073^{* * *}$ & $(0.002)$ & $0.063^{* * *}$ & $(0.002)$ & $0.041^{* * *}$ & $(0.002)$ & $0.033^{* * *}$ & $(0.002)$ \\
\hline 100 - 500 Employees & $0.107^{* * *}$ & $(0.002)$ & $0.093^{* * *}$ & $(0.002)$ & $0.078^{* * *}$ & $(0.002)$ & $0.065^{* * *}$ & $(0.003)$ \\
\hline More than 500 & $0.150 * * *$ & $(0.002)$ & $0.133^{* * *}$ & $(0.002)$ & $0.100 * * *$ & $(0.002)$ & $0.085^{* * *}$ & $(0.003)$ \\
\hline Obs & \multicolumn{2}{|c|}{$3,357,960$} & \multicolumn{2}{|c|}{$2,733,105$} & \multicolumn{2}{|c|}{$3,123,225$} & \multicolumn{2}{|c|}{$2,251,585$} \\
\hline$R^{2}$ & \multicolumn{2}{|c|}{0.20} & \multicolumn{2}{|c|}{0.24} & \multicolumn{2}{|c|}{0.15} & \multicolumn{2}{|c|}{0.17} \\
\hline
\end{tabular}

Table C.13 reports the estimated coefficients from the second stage regression of the first stage residuals of the estimations in Table C.12 on a set of non-time varying characteristics of individuals. Each model has a set of controls for occupation (9), industry (21), province/territory/major city of residence (13), first language spoken (6), marital status (2), year of landing (9), age at landing (1), age at landing squared divided by 100 (1). Specifications (2) and (4) include a control for log earnings in the first full year in Canada. Robust standard errors are reported in parentheses. Significance levels are indicated by $* *$ and $* * *$ for $5 \%$ and $1 \%$, respectively. 
Table C.14: Fixed Effects Estimation

of the Earnings Return to Months of PSE Investment of Immigrants

\begin{tabular}{|c|c|c|c|c|c|c|c|c|}
\hline \multirow{5}{*}{$\begin{array}{l}\text { Variable } \\
\text { Months of FT PSE } \\
\text { Enrollment } \\
\text { Months of PT PSE } \\
\text { Enrollment } \\
\text { YSM }\end{array}$} & \multicolumn{4}{|c|}{ Men } & \multicolumn{4}{|c|}{ Women } \\
\hline & \multicolumn{2}{|c|}{ (1) } & \multicolumn{2}{|c|}{$(2)$} & \multicolumn{2}{|c|}{ (3) } & \multicolumn{2}{|c|}{ (4) } \\
\hline & $0.032^{* * *}$ & $(0.001)$ & $0.031^{* * *}$ & $(0.001)$ & $0.041 * * *$ & $(0.001)$ & $0.040^{* * *}$ & $(0.001)$ \\
\hline & $0.016^{* * *}$ & $(0.001)$ & $0.018^{* * *}$ & $(0.001)$ & $0.023^{* * *}$ & $(0.001)$ & $0.024^{* * *}$ & $(0.001)$ \\
\hline & $0.110^{* * *}$ & $(0.001)$ & $0.103^{* * *}$ & $(0.001)$ & $0.101^{* * *}$ & $(0.001)$ & $0.092^{* * *}$ & $(0.001)$ \\
\hline$\left(\mathrm{YSM}^{2}\right) / 100$ & $-0.463^{* * *}$ & $(0.005)$ & $-0.463^{* * *}$ & $(0.005)$ & $-0.291 * * *$ & $(0.006)$ & $-0.309^{* * *}$ & $(0.006)$ \\
\hline Constant & $9.744^{* * *}$ & $(0.004)$ & $9.834^{* * *}$ & $(0.004)$ & $9.122^{* * *}$ & $(0.005)$ & $9.282^{* * *}$ & $(0.006)$ \\
\hline Observations & \multicolumn{2}{|c|}{$3,357,960$} & \multicolumn{2}{|c|}{$2,733,105$} & \multicolumn{2}{|c|}{$3,123,225$} & \multicolumn{2}{|c|}{$2,251,585$} \\
\hline$R^{2}$ & \multicolumn{2}{|c|}{0.06} & \multicolumn{2}{|c|}{0.05} & \multicolumn{2}{|c|}{0.06} & \multicolumn{2}{|c|}{0.05} \\
\hline
\end{tabular}

Table C.14 reports the estimated coefficients from the fixed effects estimation in which the dependent variable is the log of earnings. The PSE enrollment variables included in the estimation are equal to the number of months of full-time or part-time PSE enrollment after landing, respectively. Each model has a set of controls for occupation (9), industry (21), province/territory/major city of residence (13), first language spoken (6), marital status (2), year of landing (9), age at landing (1), age at landing squared divided by 100 (1). Specifications (2) and (4) include a control for log earnings in first full year in Canada. Robust standard errors are reported in parentheses. Significance levels are indicated by $* *$ and $* * *$ for $5 \%$ and $1 \%$, respectively. 
Table C.15: Fixed Effects Estimation

of the Earnings Return to PSE Investment of Immigrants by Admission Category

\begin{tabular}{|c|c|c|c|c|}
\hline \multirow{3}{*}{$\begin{array}{l}\text { Variable } \\
\text { Ever Studied FT }\end{array}$} & \multicolumn{2}{|c|}{ Men } & \multicolumn{2}{|c|}{ Women } \\
\hline & \multicolumn{2}{|c|}{$(1)$} & \multicolumn{2}{|c|}{$(2)$} \\
\hline & $0.278^{* * *}$ & $(0.010)$ & $0.338^{* * *}$ & $(0.018)$ \\
\hline Spouse of Skilled Worker $*$ FT PSE & $0.055^{* *}$ & $(0.022)$ & $0.094^{* * *}$ & $(0.022)$ \\
\hline Business Class * FT PSE & 0.043 & $(0.085)$ & 0.027 & $(0.057)$ \\
\hline Family Class $*$ FT PSE & $-0.215^{* * *}$ & $(0.017)$ & $-0.092^{* * *}$ & $(0.021)$ \\
\hline Provincial Nominee ${ }^{*}$ FT PSE & -0.252 & $(0.175)$ & 0.032 & $(0.156)$ \\
\hline Caregiver $*$ FT PSE & -0.084 & $(0.192)$ & -0.071 & $(0.148)$ \\
\hline Refugee $*$ FT PSE & $-0.129 * * *$ & $(0.020)$ & 0.041 & $(0.026)$ \\
\hline Other $*$ FT PSE & -0.021 & $(0.170)$ & -0.202 & $(0.147)$ \\
\hline Ever Studied PT & $0.164^{* * *}$ & $(0.007)$ & $0.150^{* * *}$ & $(0.011)$ \\
\hline Spouse of Skilled Worker $*$ PT PSE & 0.010 & $(0.017)$ & $0.219^{* * *}$ & $(0.015)$ \\
\hline Business Class * PT PSE & -0.014 & $(0.073)$ & 0.064 & $(0.063)$ \\
\hline Family Class $*$ PT PSE & $-0.218^{* * *}$ & $(0.015)$ & $-0.035^{* *}$ & $(0.017)$ \\
\hline Provincial Nominee ${ }^{*}$ PT PSE & $0.291^{* *}$ & $(0.127)$ & 0.127 & $(0.112)$ \\
\hline Caregiver $*$ PT PSE & $0.311^{* *}$ & $(0.141)$ & 0.100 & $(0.105)$ \\
\hline Refugee * PT PSE & $-0.179 * * *$ & $(0.023)$ & $0.060^{* *}$ & $(0.027)$ \\
\hline Other $*$ PT PSE & $-0.461^{* * *}$ & $(0.123)$ & $-0.287^{* * *}$ & $(0.104)$ \\
\hline YSM & $0.111^{* * *}$ & $(0.001)$ & $0.101^{* * *}$ & $(0.001)$ \\
\hline$\left((\mathrm{YSM})^{2}\right) / 100$ & $-0.478^{* * *}$ & $(0.005)$ & $-0.312^{* * *}$ & $(0.005)$ \\
\hline Constant & $9.741^{* * *}$ & $(0.004)$ & $9.118^{* * *}$ & $(0.005)$ \\
\hline Observations & \multicolumn{2}{|c|}{$3,357,960$} & \multicolumn{2}{|c|}{$3,123,225$} \\
\hline$R^{2}$ & \multicolumn{2}{|c|}{0.06} & \multicolumn{2}{|c|}{0.06} \\
\hline
\end{tabular}

Table C.15 reports the estimated coefficients from the fixed effects estimation in which the dependent variable is the log of earnings. The PSE enrollment dummy variables included in the estimation are equal to 1 if the immigrant ever enrolled in full-time or part-time PSE after landing, respectively. Each model has a set of controls for occupation (9), industry (21), province/territory/major city of residence (13), first language spoken (6), marital status (2), year of landing (9), age at landing (1), age at landing squared divided by $100(1)$. Robust standard errors are reported in parentheses. Significance levels are indicated by $* *$ and $* * *$ for $5 \%$ and $1 \%$, respectively. 
Table C.16: Fixed Effects Estimation

of the Earnings Return to PSE Investment of Immigrants by Source Region

\begin{tabular}{|c|c|c|c|c|}
\hline \multirow{3}{*}{$\begin{array}{l}\text { Variable } \\
\text { Ever Studied FT }\end{array}$} & \multicolumn{2}{|c|}{ Men } & \multicolumn{2}{|c|}{ Women } \\
\hline & \multicolumn{2}{|c|}{ (1) } & \multicolumn{2}{|c|}{$(2)$} \\
\hline & 0.006 & $(0.031)$ & $0.095^{* *}$ & $(0.047)$ \\
\hline United States * FT PSE & 0.057 & $(0.072)$ & -0.103 & $(0.090)$ \\
\hline Southern / Eastern Europe ${ }^{*}$ FT PSE & $0.263^{* * *}$ & $(0.037)$ & $0.388 * * *$ & $(0.051)$ \\
\hline Africa * FT PSE & $0.262^{* * *}$ & $(0.036)$ & $0.352^{* * *}$ & $(0.052)$ \\
\hline East Asia * FT PSE & $0.429 * * *$ & $(0.036)$ & $0.273^{* * *}$ & $(0.050)$ \\
\hline South Asia * FT PSE & 0.062 & $(0.034)$ & $0.108^{* *}$ & $(0.050)$ \\
\hline Southeast Asia * FT PSE & 0.027 & $(0.035)$ & 0.077 & $(0.050)$ \\
\hline Other Asia $*$ FT PSE & $0.301^{* * *}$ & $(0.044)$ & $0.365^{* * *}$ & $(0.058)$ \\
\hline Oceania $*$ FT PSE & 0.144 & $(0.109)$ & -0.108 & $(0.175)$ \\
\hline Caribbean / South America $*$ FT PSE & $0.232^{* * *}$ & $(0.037)$ & $0.270^{* * *}$ & $(0.051)$ \\
\hline Other $*$ FT PSE & 0.148 & $(0.083)$ & 0.154 & $(0.091)$ \\
\hline Ever Studied PT & -0.027 & $(0.022)$ & -0.027 & $(0.024)$ \\
\hline United States * PT PSE & -0.019 & $(0.055)$ & -0.067 & $(0.062)$ \\
\hline Southern / Eastern Europe $*$ PT PSE & $0.180^{* * *}$ & $(0.026)$ & $0.373^{* * *}$ & $(0.028)$ \\
\hline Africa $*$ PT PSE & $0.187^{* * *}$ & $(0.029)$ & $0.251^{* * *}$ & $(0.034)$ \\
\hline East Asia * PT PSE & $0.258^{* * *}$ & $(0.026)$ & $0.299^{* * *}$ & $(0.028)$ \\
\hline South Asia * PT PSE & $0.058^{* *}$ & $(0.024)$ & $0.236^{* * *}$ & $(0.028)$ \\
\hline Southeast Asia * PT PSE & $0.084^{* * *}$ & $(0.025)$ & $0.111^{* * *}$ & $(0.027)$ \\
\hline Other Asia $*$ PT PSE & $0.237^{* * *}$ & $(0.032)$ & $0.310^{* * *}$ & $(0.039)$ \\
\hline Oceania * PT PSE & -0.013 & $(0.064)$ & $-0.327^{* * *}$ & $(0.094)$ \\
\hline Caribbean / South America * PT PSE & $0.172^{* * *}$ & $(0.028)$ & $0.230^{* * *}$ & $(0.031)$ \\
\hline Other $*$ PT PSE & $0.179 * * *$ & $(0.063)$ & $0.196^{* *}$ & $(0.085)$ \\
\hline YSM & $0.111^{* * *}$ & $(0.001)$ & $0.102^{* * *}$ & $(0.001)$ \\
\hline$\left((\mathrm{YSM})^{2}\right) / 100$ & $-0.479 * * *$ & $(0.005)$ & $-0.313^{* * *}$ & $(0.005)$ \\
\hline Constant & $9.739^{* * *}$ & $(0.004)$ & $9.116^{* * *}$ & $(0.005)$ \\
\hline Observations & \multicolumn{2}{|c|}{$3,357,960$} & \multicolumn{2}{|c|}{$3,123,225$} \\
\hline$R^{2}$ & \multicolumn{2}{|c|}{0.06} & \multicolumn{2}{|c|}{0.06} \\
\hline
\end{tabular}

Table C.16 reports the estimated coefficients from the fixed effects estimation in which the dependent variable is the log of earnings. The PSE enrollment dummy variables included in the estimation are equal to 1 if the immigrant ever enrolled in full-time or part-time PSE after landing, respectively. Each model has a set of controls for occupation (9), industry (21), province/territory/major city of residence (13), first language spoken (6), marital status (2), year of landing (9), age at landing (1), age at landing squared divided by 100 (1). Robust standard errors are reported in parentheses. Significance levels are indicated by $* *$ and $* * *$ for $5 \%$ and $1 \%$, respectively. 
Table C.17: Fixed Effects Estimation

of the Earnings Return to PSE Investment of Immigrants by Education Level at Landing

\begin{tabular}{lcccc}
\hline \hline & \multicolumn{2}{c}{ Men } & \multicolumn{2}{c}{ Women } \\
\hline Variable & \multicolumn{2}{c}{$(\mathbf{1})$} & \multicolumn{2}{c}{$\mathbf{( 2 )}$} \\
\hline Ever Studied FT & $0.091^{* * *}$ & $(0.015)$ & $0.227^{* * *}$ & $(0.013)$ \\
College Diploma * FT PSE & $0.082^{* * *}$ & $(0.020)$ & $0.084^{* * *}$ & $(0.018)$ \\
Bachelor's Degree * FT PSE $_{\text {Graduate Degree * FT PSE }}$ & $0.185^{* * *}$ & $(0.019)$ & $0.169^{* * *}$ & $(0.018)$ \\
Ever Studied PT & $0.220^{* * *}$ & $(0.023)$ & $0.204^{* * *}$ & $(0.027)$ \\
College Diploma * PT PSE & $-0.079^{* * *}$ & $(0.016)$ & $0.093^{* * *}$ & $(0.016)$ \\
Bachelor's Degree * PT PSE & $0.111^{* * *}$ & $(0.020)$ & $0.097^{* * *}$ & $(0.020)$ \\
Graduate Degree * PT PSE & $0.235^{* * *}$ & $(0.018)$ & $0.155^{* * *}$ & $(0.018)$ \\
YSM & $0.273^{* * *}$ & $(0.020)$ & $0.156^{* * *}$ & $(0.022)$ \\
$\left((Y S M)^{2}\right) / 100$ & $0.111^{* * *}$ & $(0.001)$ & $0.101^{* * *}$ & $(0.001)$ \\
Constant & $-0.477^{* * *}$ & $(0.005)$ & $-0.310^{* * *}$ & $(0.005)$ \\
& $9.741^{* * *}$ & $(0.004)$ & $9.118^{* * *}$ & $(0.005)$ \\
\hline Observations & \multicolumn{2}{c}{$3,357,960$} & $3,123,225$ \\
$R^{2}$ & \multicolumn{2}{c}{0.06} & \multicolumn{2}{c}{0.06} \\
\hline \hline
\end{tabular}

The dependent variable of the fixed effects models reported in Table C.17 is the log of earnings. The PSE enrollment dummy variables included in the estimation are equal to 1 if the immigrant ever enrolled in full-time or part-time PSE after landing, respectively. Each model has a set of controls for occupation (9), industry (21), province/territory/major city of residence (13), first language spoken (6), marital status (2), year of landing (9), age at landing (1), age at landing squared divided by 100 (1). Robust standard errors are reported in parentheses. Significance levels are indicated by $* *$ and $* * *$ for $5 \%$ and $1 \%$, respectively.

Table C.18: Fixed Effects Estimation

of the Earnings Return to PSE Investment of Immigrants

- Including Immigrants Enrolled in Both Full-time and Part-time PSE

\begin{tabular}{|c|c|c|c|c|c|c|c|c|}
\hline \multirow{3}{*}{$\begin{array}{l}\text { Variable } \\
\text { FT PSE Enrollment }\end{array}$} & \multicolumn{4}{|c|}{ Men } & \multicolumn{4}{|c|}{ Women } \\
\hline & \multicolumn{2}{|c|}{ (1) } & \multicolumn{2}{|c|}{$(2)$} & \multicolumn{2}{|c|}{$(3)$} & \multicolumn{2}{|c|}{$(4)$} \\
\hline & $0.180^{* * *}$ & $(0.005)$ & $0.185^{* * *}$ & $(0.005)$ & $0.256^{* * *}$ & $(0.005)$ & $0.257^{* * *}$ & $(0.006)$ \\
\hline PT PSE Enrollment & $0.075^{* * *}$ & $(0.005)$ & $0.090^{* * *}$ & $(0.005)$ & $0.134^{* * *}$ & $(0.005)$ & $0.142^{* * *}$ & $(0.005)$ \\
\hline YSM & $0.111^{* * *}$ & $(0.001)$ & $0.105^{* * *}$ & $(0.001)$ & $0.101^{* * *}$ & $(0.001)$ & $0.093^{* * *}$ & $(0.001)$ \\
\hline$\left((\mathrm{YSM})^{2}\right) / 100$ & $-0.449 * * *$ & $(0.004)$ & $-0.463^{* * *}$ & $(0.005)$ & $-0.285^{* * *}$ & $(0.005)$ & $-0.306^{* * *}$ & $(0.006)$ \\
\hline Constant & $9.741^{* * *}$ & $(0.004)$ & $9.831^{* * *}$ & $(0.004)$ & $9.137 * * *$ & $(0.005)$ & $9.289 * * *$ & $(0.005)$ \\
\hline Observations & \multirow{2}{*}{\multicolumn{2}{|c|}{$\begin{array}{c}3,841,410 \\
0.06\end{array}$}} & \multirow{2}{*}{\multicolumn{2}{|c|}{$2,934,390$}} & \multicolumn{2}{|c|}{$3,657,520$} & \multirow{2}{*}{\multicolumn{2}{|c|}{$\begin{array}{c}2,457,455 \\
0,16\end{array}$}} \\
\hline$R^{2}$ & & & & & 0.1 & & & \\
\hline
\end{tabular}

The dependent variable of the fixed effects models reported in Table C.18 is the log of earnings. The PSE enrollment dummy variables included in the estimation are equal to 1 if the immigrant ever enrolled in full-time or part-time PSE after landing, respectively. Each model has a set of controls for occupation (9), industry (21), province/territory/major city of residence (13), first language spoken (6), marital status (2), year of landing (9), age at landing (1), age at landing squared divided by 100 (1). Specifications (2) and (4) include a control for log earnings in first full year in Canada. Robust standard errors are reported in parentheses. Significance levels are indicated by $* *$ and $* * *$ for $5 \%$ and $1 \%$, respectively. 
Table C.19: Fixed Effects Estimation

of the Earnings Return to PSE Investment of Immigrants

With Earnings Levels as the Outcome Variable

\begin{tabular}{|c|c|c|c|c|c|c|}
\hline \multirow[b]{2}{*}{ Variable } & \multicolumn{2}{|c|}{ Men } & \multicolumn{4}{|c|}{ Women } \\
\hline & (1) & $(2)$ & \multicolumn{2}{|l|}{$(3)$} & \multicolumn{2}{|l|}{$(4)$} \\
\hline $\begin{array}{l}\text { FT PSE } \\
\text { Enrollment }\end{array}$ & $1461.54^{* * *} \quad(390.14)$ & $1756.24^{* * *} \quad(442.59)$ & $3155.87^{* * *}$ & $(118.31)$ & $3432.05^{* * *}$ & $(130.74)$ \\
\hline $\begin{array}{l}\text { PT PSE } \\
\text { Enrollment }\end{array}$ & $3936.34^{* * *} \quad(402.72)$ & $4195.19^{* * *} \quad(460.23)$ & $4983.66^{* * *}$ & $(130.45)$ & $5300.28^{* * *}$ & $(144.36)$ \\
\hline YSM & $3916.71 * * * \quad(52.82)$ & $3782.11^{* * *} \quad(49.89)$ & $2154.10^{* * *}$ & $(20.62)$ & $2068.24^{* * *}$ & $(23.22)$ \\
\hline$\left((\mathrm{YSM})^{2}\right) / 100$ & $-13190.75^{* * *}(273.33)$ & $-13292.16^{* * *}(382.87)$ & $-5019.48^{* * *}$ & $(135.70)$ & $-5388.68^{* * *}$ & $(156.07)$ \\
\hline Constant & $25437.09^{* * *}(292.36)$ & $27587.62^{* * *}(321.94)$ & $14873.00^{* * *}$ & $(110.49)$ & $17122.28^{* * *}$ & $(125.94)$ \\
\hline Observations & $3,367,415$ & $2,738,840$ & $3,129,76$ & & $2,255,0^{\prime}$ & \\
\hline$R^{2}$ & 0.0017 & 0.0014 & 0.07 & & 0.06 & \\
\hline
\end{tabular}

The dependent variable of the fixed effects models reported in Table C.19 is the level of earnings. The PSE enrollment dummy variables included in the estimation are equal to 1 if the immigrant ever enrolled in full-time or part-time PSE after landing, respectively. Each model has a set of controls for occupation (9), industry (21), province/territory/major city of residence (13), first language spoken (6), marital status (2), year of landing (9), age at landing (1), age at landing squared divided by 100 (1). Specifications (2) and (4) include a control for the immigrant's level of earnings in their first full year in Canada. Robust standard errors are reported in parentheses. Significance levels are indicated by $* *$ and $* * *$ for $5 \%$ and $1 \%$, respectively.

Table C.20: Fixed Effects Estimation

of the Earnings Return to PSE Investment of Immigrants Including Immigrants Who Had Positive Earnings in Each of the First Full 8 Years Since Migration

\begin{tabular}{|c|c|c|c|c|c|c|c|c|}
\hline \multirow{3}{*}{$\begin{array}{l}\text { Variable } \\
\text { FT PSE Enrollment } \\
\text { PT PSE Enrollment } \\
\text { YSM } \\
\left((\mathrm{YSM})^{2}\right) / 100 \\
\text { Constant }\end{array}$} & \multicolumn{4}{|c|}{ Men } & \multicolumn{4}{|c|}{ Women } \\
\hline & \multicolumn{2}{|c|}{ (1) } & \multicolumn{2}{|c|}{ (2) } & \multicolumn{2}{|c|}{ (3) } & \multicolumn{2}{|c|}{ (4) } \\
\hline & $\begin{array}{l}0.222^{* * *} \\
0.116^{* * *} \\
0.111^{* * *} \\
-0.477^{* * *} \\
9.752^{* * *} \\
\end{array}$ & $\begin{array}{l}(0.008) \\
(0.006) \\
(0.001) \\
(0.005) \\
(0.004) \\
\end{array}$ & $\begin{array}{l}0.220^{* * *} \\
0.122^{* * *} \\
0.106^{* * *} \\
-0.486^{* * *} \\
9.840^{* * *}\end{array}$ & $\begin{array}{l}(0.008) \\
(0.006) \\
(0.001) \\
(0.005) \\
(0.005)\end{array}$ & $\begin{array}{l}0.330^{* * *} \\
0.214^{* * *} \\
0.105^{* * *} \\
-0.335^{* * *} \\
9.099^{* * *}\end{array}$ & $\begin{array}{l}(0.008) \\
(0.007) \\
(0.001) \\
(0.006) \\
(0.005)\end{array}$ & $\begin{array}{l}0.327^{* * *} \\
0.219^{* * *} \\
0.099^{* * *} \\
-0.366^{* * *} \\
9.264^{* * *}\end{array}$ & $\begin{array}{l}(0.008) \\
(0.007) \\
(0.001) \\
(0.007) \\
(0.006)\end{array}$ \\
\hline $\begin{array}{l}\text { Observations } \\
R^{2}\end{array}$ & $\begin{array}{r}2,704, \\
0.06\end{array}$ & 855 & $\begin{array}{r}2,180,7 \\
0.06\end{array}$ & $\begin{array}{l}775 \\
6\end{array}$ & $\begin{array}{r}2,509 \\
0.06\end{array}$ & & $\begin{array}{r}1,772, \\
0.06\end{array}$ & \\
\hline
\end{tabular}

The dependent variable of the fixed effects models reported in Table C.20 is the log of earnings. The PSE enrollment dummy variables included in the estimation are equal to 1 if the immigrant ever enrolled in full-time or part-time PSE after landing, respectively. Each model has a set of controls for occupation (9), industry (21), province/territory/major city of residence (13), first language spoken (6), marital status (2), year of landing (9), age at landing (1), age at landing squared divided by 100 (1). Specifications (2) and (4) include a control for log earnings in first full year in Canada. The sample used for the estimations is restricted to immigrants who had positive earnings in each of the first full 8 years since migration. Robust standard errors are reported in parentheses. Significance levels are indicated by $* *$ and $* * *$ for $5 \%$ and $1 \%$, respectively. 
Table C.21: Fixed Effects Estimation

of the Earnings Return to PSE Investment of Immigrants Including Immigrants Who Had Positive Earnings in Each of the First Full 8 Years Since Migration:

The Timing of the PSE Investment

\begin{tabular}{|c|c|c|c|c|c|c|c|c|}
\hline \multirow{3}{*}{$\begin{array}{l}\text { Variable } \\
\text { FT PSE }\end{array}$} & \multicolumn{4}{|c|}{ Men } & \multicolumn{4}{|c|}{ Women } \\
\hline & \multicolumn{2}{|c|}{ (1) } & \multicolumn{2}{|c|}{ (2) } & \multicolumn{2}{|c|}{ (3) } & \multicolumn{2}{|c|}{ (4) } \\
\hline & $0.268^{* * *}$ & $(0.008)$ & $0.264^{* * *}$ & $(0.009)$ & $0.379 * * *$ & $(0.009)$ & $0.373^{* * *}$ & $(0.009)$ \\
\hline $\begin{array}{l}\text { Study After 8th YSM } \\
* \text { FTPSE }\end{array}$ & $-0.295^{* * *}$ & $(0.020)$ & $-0.293^{* * *}$ & $(0.021)$ & $-0.260^{* * *}$ & $(0.020)$ & $-0.269^{* * *}$ & $(0.022)$ \\
\hline $\begin{array}{l}\text { PT PSE } \\
\text { Enrollment }\end{array}$ & $0.122^{* * *}$ & $(0.006)$ & $0.128^{* * *}$ & $(0.007)$ & $0.218^{* * *}$ & $(0.008)$ & $0.222^{* * *}$ & $(0.008)$ \\
\hline $\begin{array}{l}\text { Study After 8th YSM } \\
\text { * PTPSE }\end{array}$ & $-0.032^{* * *}$ & $(0.014)$ & $-0.031^{* * *}$ & $(0.014)$ & -0.014 & $(0.016)$ & -0.017 & $(0.017)$ \\
\hline YSM & $0.110^{* * *}$ & $(0.001)$ & $0.105^{* * *}$ & $(0.001)$ & $0.103^{* * *}$ & $(0.001)$ & $0.097^{* * *}$ & $(0.001)$ \\
\hline$\left((\mathrm{YSM})^{2}\right) / 100$ & $-0.468^{* * *}$ & $(0.005)$ & $-0.476^{* * *}$ & $(0.005)$ & $-0.322^{* * *}$ & $(0.006)$ & $-0.354^{* * *}$ & $(0.007)$ \\
\hline Constant & $9.752^{* * *}$ & $(0.004)$ & $9.842^{* * *}$ & $(0.005)$ & $9.100 * * *$ & $(0.005)$ & $9.266^{* * *}$ & $(0.006)$ \\
\hline Observations & 2,704, & 855 & 2,180 & 775 & 2,509, & 960 & $1,772,3$ & 335 \\
\hline$R^{2}$ & 0.06 & & 0.06 & & 0.06 & & 0.06 & \\
\hline
\end{tabular}

The dependent variable of the fixed effects models reported in Table C.21 is the log of earnings. The PSE enrollment dummy variables included in the estimation are equal to 1 if the immigrant ever enrolled in full-time or part-time PSE after landing, respectively. Each model has a set of controls for occupation (9), industry (21), province/territory/major city of residence (13), first language spoken (6), marital status (2), year of landing (9), age at landing (1), age at landing squared divided by 100 (1). Specifications (2) and (4) include a control for log earnings in first full year in Canada. The sample used for the estimations is restricted to immigrants who had positive earnings in each of the first full 8 years since migration. Each model includes interaction terms between a dummy variable for studying after the first 8 years in which positive earnings were received and indicator variables for whether the immigrant participated in full-time or part-time post-secondary education. Robust standard errors are reported in parentheses. Significance levels are indicated by $* *$ and $* * *$ for $5 \%$ and $1 \%$, respectively. 
Table C.22: Fixed Effects Estimation

of the Earnings Return to PSE Investment of Immigrants:

The Non-Linear Effects of Post-Migration Education

\begin{tabular}{|c|c|c|c|c|c|c|c|c|}
\hline \multirow{3}{*}{$\begin{array}{l}\text { Variable } \\
\text { FT PSE Enrollment }\end{array}$} & \multicolumn{4}{|c|}{ Men } & \multicolumn{4}{|c|}{ Women } \\
\hline & \multicolumn{2}{|c|}{ (1) } & \multicolumn{2}{|c|}{$(2)$} & \multicolumn{2}{|c|}{$(3)$} & \multicolumn{2}{|l|}{$(4)$} \\
\hline & $0.044^{* * *}$ & $(0.007)$ & $0.027^{* * *}$ & $(0.008)$ & $0.205^{* * *}$ & $(0.007)$ & $0.172^{* * *}$ & $(0.008)$ \\
\hline Second Year Since FT PSE & $0.190^{* * *}$ & $(0.005)$ & $0.185^{* * *}$ & $(0.007)$ & $0.159^{* * *}$ & $(0.005)$ & $0.166^{* * *}$ & $(0.008)$ \\
\hline Third Year Since FT PSE & $0.254^{* * *}$ & $(0.006)$ & $0.252^{* * *}$ & $(0.008)$ & $0.188^{* * *}$ & $(0.006)$ & $0.216^{* * *}$ & $(0.009)$ \\
\hline $\begin{array}{l}\text { Fourth Years or more Since } \\
\text { FT PSE }\end{array}$ & $0.336^{* * *}$ & $(0.006)$ & $0.360^{* * *}$ & $(0.008)$ & $0.229^{* * *}$ & $(0.006)$ & $0.293^{* * *}$ & $(0.009)$ \\
\hline PT PSE Enrollment & $0.103^{* * *}$ & $(0.006)$ & $0.094^{* * *}$ & $(0.006)$ & $0.200^{* * *}$ & $(0.006)$ & $0.192^{* * *}$ & $(0.007)$ \\
\hline Second Year Since PT PSE & $0.020 * * *$ & $(0.004)$ & $0.019 * * *$ & $(0.005)$ & $0.016^{* * *}$ & $(0.005)$ & 0.010 & $(0.007)$ \\
\hline Third Year Since PT PSE & $0.031^{* * *}$ & $(0.005)$ & $0.035^{* * *}$ & $(0.006)$ & $0.032^{* * *}$ & $(0.006)$ & $0.040^{* * *}$ & $(0.008)$ \\
\hline $\begin{array}{l}\text { Fourth Years or more Since } \\
\text { PT PSE }\end{array}$ & $0.043^{* * *}$ & $(0.005)$ & $0.069 * * *$ & $(0.006)$ & $0.045^{* * *}$ & $(0.006)$ & $0.073^{* * *}$ & $(0.008)$ \\
\hline YSM & $0.111^{* * *}$ & $(0.001)$ & $0.106^{* * *}$ & $(0.001)$ & $0.101^{* * *}$ & $(0.001)$ & $0.095^{* * *}$ & $(0.001)$ \\
\hline$\left((\mathrm{YSM})^{2}\right) / 100$ & $-0.491^{* * *}$ & $(0.005)$ & $-0.500 * * *$ & $(0.005)$ & $-0.321^{* * *}$ & $(0.006)$ & $-0.355^{* * *}$ & $(0.006)$ \\
\hline Constant & $9.745^{* * *}$ & $(0.004)$ & $9.833^{* * *}$ & $(0.004)$ & $9.122^{* * *}$ & $(0.005)$ & $9.282^{* * *}$ & $(0.006)$ \\
\hline Observations & \multicolumn{2}{|c|}{$3,357,960$} & \multicolumn{2}{|c|}{$2,733,105$} & \multicolumn{2}{|c|}{$3,123,225$} & \multicolumn{2}{|c|}{$2,251,585$} \\
\hline$R^{2}$ & \multicolumn{2}{|c|}{0.06} & \multicolumn{2}{|c|}{0.06} & \multicolumn{2}{|c|}{0.06} & \multicolumn{2}{|c|}{0.05} \\
\hline
\end{tabular}

The dependent variable of the fixed effects models reported in Table C.22 is the log of earnings. The PSE enrollment dummy variables included in the estimation are equal to 1 if the immigrant ever enrolled in full-time or part-time PSE after landing, respectively. Each model has a set of controls for occupation (9), industry (21), province/territory/major city of residence (13), first language spoken (6), marital status (2), year of landing (9), age at landing (1), age at landing squared divided by 100 (1). Specifications (2) and (4) include a control for log earnings in first full year in Canada. Each model includes interaction terms between a dummy variable for the period after the most recent study year and indicator variables for whether the immigrant participated in full-time or part-time post-secondary education. Robust standard errors are reported in parentheses. Significance levels are indicated by $* *$ and $* * *$ for $5 \%$ and $1 \%$, respectively. 
Table C.23: Shares of Immigrants Absent from the Tax Records by Landing Cohort

\begin{tabular}{ccccccccccccc}
\hline \hline \multirow{2}{*}{ Landing Year } & \multicolumn{1}{c}{ Share of Landing Cohort } & \multicolumn{1}{c}{ Absent } \\
& 5 & 6 & 7 & 8 & 9 & 10 & 11 & 12 & 13 & 14 \\
\hline \multirow{2}{*}{1998} & $0.00 \%$ & $0.11 \%$ & $0.25 \%$ & $0.50 \%$ & $0.77 \%$ & $1.06 \%$ & $1.42 \%$ & $1.78 \%$ & $2.18 \%$ & $2.57 \%$ \\
1999 & $0.00 \%$ & $0.11 \%$ & $0.24 \%$ & $0.44 \%$ & $0.71 \%$ & $1.01 \%$ & $1.33 \%$ & $1.71 \%$ & $2.13 \%$ & $2.52 \%$ \\
2000 & $0.00 \%$ & $0.09 \%$ & $0.24 \%$ & $0.46 \%$ & $0.69 \%$ & $0.98 \%$ & $1.31 \%$ & $1.68 \%$ & $2.08 \%$ & - \\
2001 & $0.00 \%$ & $0.10 \%$ & $0.23 \%$ & $0.42 \%$ & $0.65 \%$ & $0.92 \%$ & $1.26 \%$ & $1.63 \%$ & - & - \\
2002 & $0.00 \%$ & $0.08 \%$ & $0.19 \%$ & $0.36 \%$ & $0.61 \%$ & $0.90 \%$ & $1.22 \%$ & - & - & - \\
2003 & $0.00 \%$ & $0.07 \%$ & $0.19 \%$ & $0.37 \%$ & $0.61 \%$ & $0.89 \%$ & - & - & - & - \\
2004 & $0.00 \%$ & $0.10 \%$ & $0.23 \%$ & $0.40 \%$ & $0.65 \%$ & - & - & - & - & - \\
2005 & $0.00 \%$ & $0.08 \%$ & $0.21 \%$ & $0.37 \%$ & - & - & - & - & - & - \\
2006 & $0.00 \%$ & $0.09 \%$ & $0.21 \%$ & - & - & - & - & - & - & - \\
2007 & $0.00 \%$ & $0.08 \%$ & - & - & - & - & - & - & - & - \\
2008 & $0.00 \%$ & - & - & - & - & - & - & - & - & - \\
\hline \hline
\end{tabular}

Table C.23 reports the shares of immigrants in each landing cohort who had been absent from the tax records for a period of four consecutive years or more by each year since migration (YSM) commencing from the 5 th to 14 th year since migration. A '-' implies that the landing cohort had not been present in Canada for the associated number of years since migration. 
Table C.24: Probit Estimation for the Incidence of Male Immigrants Being Absent from the Tax Records for Four or More Consecutive Years

\begin{tabular}{|c|c|c|c|c|c|c|}
\hline \multirow{2}{*}{$\begin{array}{l}\text { Variable } \\
\text { FT PSE Enrollment }\end{array}$} & \multicolumn{2}{|c|}{ (1) } & \multicolumn{2}{|c|}{$(2)$} & \multicolumn{2}{|c|}{ (3) } \\
\hline & $-0.00125^{* * *}$ & $(0.00021)$ & $-0.00136^{* * *}$ & $(0.00024)$ & $-0.00084^{* * *}$ & $(0.00020)$ \\
\hline PT PSE Enrollment & $-0.00441^{* * *}$ & $(0.00023)$ & $-0.00504^{* * *}$ & $(0.00027)$ & $-0.00337^{* * *}$ & $(0.00023)$ \\
\hline Age at Landing & $-0.00062^{* * *}$ & $(0.00011)$ & $-0.00068^{* * *}$ & $(0.00012)$ & $-0.00051^{* * *}$ & $(0.00010)$ \\
\hline$\left((\text { Age at Landing })^{2}\right) / 100$ & $0.00062^{* * *}$ & $(0.00015)$ & $0.00068^{* * *}$ & $(0.00018)$ & $0.00045^{* * *}$ & $(0.00015)$ \\
\hline YSM & $-0.00215^{* * *}$ & $(0.00003)$ & $-0.00248^{* * *}$ & $(0.00004)$ & $-0.00216^{* * *}$ & $(0.00003)$ \\
\hline$\left((\mathrm{YSM})^{2}\right) / 100$ & $0.00841^{* * *}$ & $(0.00018)$ & $0.00973^{* * *}$ & $(0.00020)$ & $0.01215^{* * *}$ & $(0.00019)$ \\
\hline Ever a TFW & $0.00123^{* * *}$ & $(0.00033)$ & $0.00143^{* * *}$ & $(0.00038)$ & $0.00138^{* * *}$ & $(0.00032)$ \\
\hline Ever a Foreign Student & $0.00250^{* * *}$ & $(0.00034)$ & $0.00289^{* * *}$ & $(0.00040)$ & $0.00069^{* * *}$ & $(0.00032)$ \\
\hline Married (at Landing) & $-0.00227^{* * *}$ & $(0.00021)$ & $-0.00261^{* * *}$ & $(0.00024)$ & $-0.00201^{* * *}$ & $(0.00020)$ \\
\hline Divorced & $0.00180^{* * *}$ & $(0.00056)$ & $0.00211^{* * *}$ & $(0.00064)$ & $0.00225^{* * *}$ & $(0.00054)$ \\
\hline \multicolumn{7}{|l|}{ Education } \\
\hline College Diploma & 0.00023 & $(0.00024)$ & 0.00029 & $(0.00028)$ & 0.00018 & $(0.00023)$ \\
\hline Bachelor's Degree & 0.00016 & $(0.00027)$ & 0.00018 & $(0.00031)$ & -0.00034 & $(0.00026)$ \\
\hline Graduate Degree & $0.00073^{* * *}$ & $(0.00032)$ & $0.00086^{* * *}$ & $(0.00037)$ & 0.00010 & $(0.00030)$ \\
\hline \multicolumn{7}{|l|}{ Admission Category } \\
\hline Spouse of Skilled Worker & -0.00025 & $(0.00039)$ & -0.00026 & $(0.00045)$ & $-0.00101^{* * *}$ & $(0.00040)$ \\
\hline Business Class & 0.00088 & $(0.00058)$ & $0.00113^{* *}$ & $(0.00067)$ & $0.00109^{* * *}$ & $(0.00055)$ \\
\hline Family Class & 0.00032 & $(0.00034)$ & 0.00033 & $(0.00039)$ & 0.00032 & $(0.00033)$ \\
\hline Provincial Nominee & -0.00188 & $(0.00134)$ & -0.00237 & $(0.00168)$ & $-0.01563^{* * *}$ & $(0.00128)$ \\
\hline Caregiver & -0.00529 & $(0.00469)$ & -0.00583 & $(0.00543)$ & $-0.01349^{* * *}$ & $(0.00437)$ \\
\hline Refugee & $0.00148^{* * *}$ & $(0.00034)$ & $0.00160^{* * *}$ & $(0.00039)$ & $0.00102^{* * *}$ & $(0.00034)$ \\
\hline Other & $0.00227^{* * *}$ & $(0.00086)$ & $0.00258^{* * *}$ & $(0.00099)$ & $0.00676^{* * *}$ & $(0.00085)$ \\
\hline \multicolumn{7}{|l|}{ Source Region } \\
\hline United States & 0.00099 & $(0.00068)$ & 0.00127 & $(0.00080)$ & 0.00006 & $(0.00065)$ \\
\hline $\begin{array}{l}\text { Southern / Eastern } \\
\text { Europe }\end{array}$ & $-0.00095^{* * *}$ & $(0.00048)$ & $-0.00093^{* *}$ & $(0.00056)$ & 0.00003 & $(0.00047)$ \\
\hline Africa & $0.00279^{* * *}$ & $(0.00045)$ & $0.00334^{* * *}$ & $(0.00052)$ & $0.00278^{* * *}$ & $(0.00043)$ \\
\hline East Asia & $-0.00183^{* * *}$ & $(0.00048)$ & $-0.00198^{* * *}$ & $(0.00056)$ & $-0.00149^{* * *}$ & $(0.00047)$ \\
\hline South Asia & $-0.00182^{* * *}$ & $(0.00046)$ & $-0.00190^{* * *}$ & $(0.00054)$ & $-0.00171^{* * *}$ & $(0.00045)$ \\
\hline Southeast Asia & $-0.00506^{* * *}$ & $(0.00062)$ & $-0.00561^{* * *}$ & $(0.00072)$ & $-0.00522^{* * *}$ & $(0.00060)$ \\
\hline Other Asia & $0.00234^{* * *}$ & $(0.00049)$ & $0.00287^{* * *}$ & $(0.00057)$ & $0.00241^{* * *}$ & $(0.00047)$ \\
\hline Oceania & $0.00234^{* * *}$ & $(0.00104)$ & $0.00284^{* * *}$ & $(0.00121)$ & 0.00112 & $(0.00100)$ \\
\hline $\begin{array}{l}\text { Caribbean / South } \\
\text { America }\end{array}$ & $0.00246^{* * *}$ & $(0.00046)$ & $0.00294^{* * *}$ & $(0.00053)$ & $0.00139^{* * *}$ & $(0.00044)$ \\
\hline Other & -0.00092 & $(0.00134)$ & -0.00100 & $(0.00156)$ & -0.00035 & $(0.00129)$ \\
\hline \multicolumn{7}{|l|}{ Mother Tongue and } \\
\hline French Mother Tongue & -0.00065 & $(0.00077)$ & -0.00064 & $(0.00089)$ & -0.00051 & $(0.00073)$ \\
\hline $\begin{array}{l}\text { English and French } \\
\text { Mother Tongue }\end{array}$ & -0.00091 & $(0.00064)$ & -0.00093 & $(0.00075)$ & $-0.00293^{* * *}$ & $(0.00061)$ \\
\hline $\begin{array}{l}\text { Other Mother Tongue, } \\
\text { Speaks English }\end{array}$ & -0.00026 & $(0.00034)$ & -0.00027 & $(0.00039)$ & $-0.00066^{* * *}$ & $(0.00033)$ \\
\hline $\begin{array}{l}\text { Other Mother Tongue, } \\
\text { Speaks French }\end{array}$ & $-0.00176^{* * *}$ & $(0.00052)$ & $-0.00191^{* * *}$ & $(0.00060)$ & $-0.00194^{* * *}$ & $(0.00051)$ \\
\hline $\begin{array}{l}\text { Other Mother Tongue, } \\
\text { Speaks both English and } \\
\text { French }\end{array}$ & $-0.00154^{* * *}$ & $(0.00047)$ & $-0.00176^{* * *}$ & $(0.00055)$ & $-0.00412^{* * *}$ & $(0.00046)$ \\
\hline $\begin{array}{l}\text { Other Mother Tongue, } \\
\text { Speaks neither English } \\
\text { nor French }\end{array}$ & $-0.00323^{* * *}$ & $(0.00039)$ & $-0.00363^{* * *}$ & $(0.00045)$ & $-0.00286^{* * *}$ & $(0.00038)$ \\
\hline
\end{tabular}


Table C.24: Probit Estimation for the Incidence of Male Immigrants Being Absent from the Tax Records for Four or More Consecutive Years, Cont.

\begin{tabular}{|c|c|c|c|c|c|}
\hline Variable & \multicolumn{2}{|c|}{$(1)$} & \multicolumn{2}{|c|}{$(2)$} & (3) \\
\hline \multicolumn{6}{|c|}{ Landing Year } \\
\hline 1999 & 0.00075 & $(0.00058)$ & 0.00071 & $(0.00055)$ & \\
\hline 2000 & $-0.00228 * * *$ & $(0.00054)$ & $-0.00215^{* * *}$ & $(0.00051)$ & \\
\hline 2001 & $-0.00552^{* * *}$ & $(0.00051)$ & $-0.00521^{* * *}$ & $(0.00048)$ & \\
\hline 2002 & $-0.00780 * * *$ & $(0.00049)$ & $-0.00735^{* * *}$ & $(0.00046)$ & \\
\hline 2003 & $-0.01048 * * *$ & $(0.00047)$ & $-0.00986^{* * *}$ & $(0.00044)$ & \\
\hline 2004 & $-0.01249 * * *$ & $(0.00045)$ & $-0.01173^{* * *}$ & $(0.00042)$ & \\
\hline 2005 & $-0.01370 * * *$ & $(0.00044)$ & $-0.01285^{* * *}$ & $(0.00041)$ & \\
\hline 2006 & $-0.01453^{* * *}$ & $(0.00043)$ & & & \\
\hline 2007 & $-0.01494^{* * *}$ & $(0.00043)$ & & & \\
\hline Observations & \multicolumn{2}{|c|}{$5,437,315$} & \multicolumn{2}{|c|}{$4,683,525$} & $5,731,555$ \\
\hline Groups & \multicolumn{2}{|c|}{614,615} & \multirow{2}{*}{\multicolumn{2}{|c|}{486,645}} & 678,645 \\
\hline Pseudo $R^{2}$ & \multicolumn{2}{|c|}{0.10} & & & 0.04 \\
\hline
\end{tabular}

Table C.24 reports the estimated average marginal effects of the variables in the probit model estimations for the incidence of an immigrant leaving Canada by the 14th year since migration. The dependent variable is a dummy variable equal to 1 if the immigrant had at least one absence from the tax records of four or more consecutive years by the 14 th year since migration and the value 0 otherwise. The PSE enrollment dummy variables included in the estimation are equal to 1 if the immigrant ever enrolled in full-time or part-time PSE after landing at any time prior to out-migrating, respectively. Each model has a set of controls for province/territory/major city of residence (13). Specification (2) is estimated excluding cohorts arriving from 2006 to 2008 while specification (3) is estimated without cohort dummies.

Delta-method standard errors are reported in parentheses. Significance levels are indicated by $* *$ and $* * *$ for $5 \%$ and $1 \%$, respectively. 
Table C.25: Probit Estimation for the Incidence of Female Immigrants Being Absent from the Tax Records for Four or More Consecutive Years

\begin{tabular}{|c|c|c|c|c|c|c|}
\hline Variable & \multicolumn{2}{|c|}{$(1)$} & \multicolumn{2}{|c|}{$(2)$} & \multicolumn{2}{|c|}{$(3)$} \\
\hline FT PSE Enrollment & $-0.001430^{* * *}$ & $(0.000157)$ & $-0.001615^{* * *}$ & $(0.000183)$ & $-0.001138^{* * *}$ & $(0.000152)$ \\
\hline PT PSE Enrollment & $-0.002760^{* * *}$ & $(0.000175)$ & $-0.003148^{* * *}$ & $(0.000203)$ & $-0.001998^{* * *}$ & $(0.000168)$ \\
\hline Age at Landing & $-0.000533^{* * *}$ & $(0.000080)$ & $-0.000612^{* * *}$ & $(0.000094)$ & $-0.000354^{* * *}$ & $(0.000077)$ \\
\hline$\left((\text { Age at Landing })^{2}\right) / 100$ & $0.000722^{* * *}$ & $(0.000118)$ & $0.000829^{* * *}$ & $(0.000138)$ & $0.000446^{* * *}$ & $(0.000113)$ \\
\hline YSM & $-0.001488^{* * *}$ & $(0.000024)$ & $-0.001725^{* * *}$ & $(0.000028)$ & $-0.001478^{* * *}$ & $(0.000023)$ \\
\hline$\left((\mathrm{YSM})^{2}\right) / 100$ & $0.005772^{* * *}$ & $(0.000139)$ & $0.006710^{* * *}$ & $(0.000162)$ & $0.008296^{* * *}$ & $(0.000147)$ \\
\hline Ever a TFW & $0.001133^{* * *}$ & $(0.000271)$ & $0.001297^{* * *}$ & $(0.000319)$ & $0.000860^{* * *}$ & $(0.000259)$ \\
\hline Ever a Foreign Student & $0.002465^{* * *}$ & $(0.000271)$ & $0.002775^{* * *}$ & $(0.000322)$ & $0.001265^{* * *}$ & $(0.000258)$ \\
\hline Married (at Landing) & $-0.001281^{* * *}$ & $(0.000182)$ & $-0.001487^{* * *}$ & $(0.000212)$ & $-0.001304^{* * *}$ & $(0.000175)$ \\
\hline Divorced & -0.000086 & $(0.000371)$ & -0.000049 & $(0.000430)$ & 0.000357 & $(0.000359)$ \\
\hline \multicolumn{7}{|l|}{ Education } \\
\hline College Diploma & $0.001004^{* * *}$ & $(0.000176)$ & $0.001181^{* * *}$ & $(0.000206)$ & $0.000815^{* * *}$ & $(0.000169)$ \\
\hline Bachelor's Degree & $0.001341^{* * *}$ & $(0.000185)$ & $0.001553^{* * *}$ & $(0.000217)$ & $0.000673^{* * *}$ & $(0.000177)$ \\
\hline Graduate Degree & $0.001111^{* * *}$ & $(0.000253)$ & $0.001365^{* * *}$ & $(0.000295)$ & 0.000264 & $(0.000242)$ \\
\hline \multicolumn{7}{|l|}{ Admission Category } \\
\hline Spouse of Skilled Worker & -0.000020 & $(0.000267)$ & 0.000002 & $(0.000310)$ & 0.000371 & $(0.000267)$ \\
\hline Business Class & 0.000474 & $(0.000388)$ & 0.000585 & $(0.000451)$ & $0.001074^{* * *}$ & $(0.000380)$ \\
\hline Family Class & 0.000200 & $(0.000271)$ & 0.000197 & $(0.000315)$ & 0.000275 & $(0.000272)$ \\
\hline Provincial Nominee & $-0.002609^{* *}$ & $(0.001508)$ & -0.002884 & $(0.001944)$ & $-0.011020^{* * *}$ & $(0.001449)$ \\
\hline Caregiver & $-0.005275^{* * *}$ & $(0.000978)$ & $-0.006088^{* * *}$ & $(0.001132)$ & $-0.008361^{* * *}$ & $(0.000973)$ \\
\hline Refugee & $-0.000750^{* * *}$ & $(0.000311)$ & $-0.000850^{* * *}$ & $(0.000362)$ & $-0.001261^{* * *}$ & $(0.000310)$ \\
\hline Other & $0.002288^{* * *}$ & $(0.000800)$ & $0.002626^{* * *}$ & $(0.000919)$ & $0.005004^{* * *}$ & $(0.000787)$ \\
\hline \multicolumn{7}{|c|}{ ) } \\
\hline United States & $0.000947^{* *}$ & $(0.000485)$ & $0.001053^{* *}$ & $(0.000573)$ & 0.000436 & $(0.000452)$ \\
\hline $\begin{array}{l}\text { Southern / Eastern } \\
\text { Europe }\end{array}$ & $-0.000950^{* * *}$ & $(0.000377)$ & $-0.001103^{* * *}$ & $(0.000442)$ & $-0.000648^{* *}$ & $(0.000364)$ \\
\hline Africa & $0.000758^{* * *}$ & $(0.000368)$ & $0.000920^{* * *}$ & $(0.000432)$ & 0.000402 & $(0.000352)$ \\
\hline East Asia & $-0.000989^{* * *}$ & $(0.000367)$ & $-0.001095^{* * *}$ & $(0.000429)$ & $-0.001173^{* * *}$ & $(0.000356)$ \\
\hline South Asia & $-0.001471^{* * *}$ & $(0.000371)$ & $-0.001654^{* * *}$ & $(0.000435)$ & $-0.001658^{* * *}$ & $(0.000359)$ \\
\hline Southeast Asia & $-0.003400 * * *$ & $(0.000436)$ & $-0.003875^{* * *}$ & $(0.000511)$ & $-0.003751^{* * *}$ & $(0.000422)$ \\
\hline Other Asia & $0.001245^{* * *}$ & $(0.000387)$ & $0.001448^{* * *}$ & $(0.000454)$ & $0.000972^{* * *}$ & $(0.000373)$ \\
\hline Oceania & $0.001801^{* * *}$ & $(0.000857)$ & $0.002004^{* * *}$ & $(0.001017)$ & $0.001417^{* *}$ & $(0.000824)$ \\
\hline $\begin{array}{l}\text { Caribbean / South } \\
\text { America }\end{array}$ & 0.000102 & $(0.000370)$ & 0.000188 & $(0.000434)$ & -0.000510 & $(0.000351)$ \\
\hline Other & -0.000588 & $(0.001006)$ & -0.000627 & $(0.001175)$ & -0.000478 & $(0.000972)$ \\
\hline \multicolumn{7}{|l|}{$\begin{array}{l}\text { Mother Tongue and } \\
\text { Official Language }\end{array}$} \\
\hline French Mother Tongue & -0.000450 & $(0.000677)$ & -0.000570 & $(0.000795)$ & -0.000686 & $(0.000637)$ \\
\hline $\begin{array}{l}\text { English and French } \\
\text { Mother Tongue }\end{array}$ & -0.000473 & $(0.000545)$ & -0.000641 & $(0.000646)$ & $-0.001764^{* * *}$ & $(0.000512)$ \\
\hline $\begin{array}{l}\text { Other Mother Tongue, } \\
\text { Speaks English }\end{array}$ & 0.000221 & $(0.000277)$ & 0.000278 & $(0.000322)$ & -0.000214 & $(0.000268)$ \\
\hline $\begin{array}{l}\text { Other Mother Tongue, } \\
\text { Speaks French }\end{array}$ & $-0.001516^{* * *}$ & $(0.000442)$ & $-0.001783^{* * *}$ & $(0.000516)$ & $-0.001945^{* * *}$ & $(0.000429)$ \\
\hline $\begin{array}{l}\text { Other Mother Tongue, } \\
\text { Speaks both English and } \\
\text { French }\end{array}$ & $-0.000975^{* * *}$ & $(0.000392)$ & $-0.001083^{* * *}$ & $(0.000459)$ & $-0.002842^{* * *}$ & $(0.000381)$ \\
\hline $\begin{array}{l}\text { Other Mother Tongue, } \\
\text { Speaks neither English } \\
\text { nor French }\end{array}$ & $-0.001682^{* * *}$ & $(0.000299)$ & $-0.001919 * * *$ & $(0.000348)$ & $-0.001309^{* * *}$ & $(0.000290)$ \\
\hline
\end{tabular}


Table C.25: Probit Estimation for the Incidence of Female Immigrants Being Absent from the Tax Records for Four or More Consecutive Years, Cont.

\begin{tabular}{|c|c|c|c|}
\hline Variable & (1) & $(2)$ & (3) \\
\hline \multicolumn{4}{|c|}{ Landing Year } \\
\hline 1999 & $(0.000462)$ & $(0.000437)$ & \\
\hline 2000 & $-0.001226^{* * *}(0.000427)$ & $-0.001171^{* * *}(0.000404)$ & \\
\hline 2001 & $-0.003666^{* * *}(0.000397)$ & $-0.003475 * * *(0.000375)$ & \\
\hline 2002 & $-0.005570^{* * *}(0.000383)$ & $-0.005268^{* * *}(0.000361)$ & \\
\hline 2003 & $-0.007152^{* * *}(0.000366)$ & $-0.006749 * * *(0.000345)$ & \\
\hline 2004 & $-0.008272^{* * *}(0.000352)$ & $-0.007798^{* * *}(0.000331)$ & \\
\hline 2005 & $-0.009418^{* * *}(0.000342)$ & $-0.008865^{* * *}(0.000321)$ & \\
\hline 2006 & $-0.009817^{* * *}(0.000338)$ & & \\
\hline 2007 & $-0.010152^{* * *}(0.000336)$ & & \\
\hline Observations & $6,118,555$ & $5,240,035$ & $6,467,625$ \\
\hline Groups & 675,275 & 528,900 & 750,170 \\
\hline Pseudo $R^{2}$ & 0.09 & 0.07 & 0.03 \\
\hline
\end{tabular}

Table C.25 reports the estimated average marginal effects of the variables in the probit model estimations for the incidence of an immigrant leaving Canada by the 14th year since migration. The dependent variable is a dummy variable equal to 1 if the immigrant had at least one absence from the tax records of four or more consecutive years by the 14th year since migration and the value 0 otherwise. The PSE enrollment dummy variables included in the estimation are equal to 1 if the immigrant ever enrolled in full-time or part-time PSE after landing at any time prior to out-migrating, respectively. Each model has a set of controls for province/territory/major city of residence (13), and first language spoken (6). Specification (2) is estimated excluding cohorts arriving from 2006 to 2008 while specification (3) is estimated without cohort dummies. Delta-method standard errors are reported in parentheses. Significance levels are indicated by $* *$ and $* * *$ for $5 \%$ and $1 \%$, respectively. 
Table C.26: Fixed Effects Estimation of the Earnings Return to PSE Investment of Immigrants Excluding Immigrants Who Were Ever Absent

\begin{tabular}{|c|c|c|c|c|c|c|c|c|}
\hline \multirow{3}{*}{$\begin{array}{l}\text { Variable } \\
\text { FT PSE Enrollment }\end{array}$} & \multicolumn{4}{|c|}{ Men } & \multicolumn{4}{|c|}{ Women } \\
\hline & \multicolumn{2}{|c|}{$(1)$} & \multicolumn{2}{|c|}{$(2)$} & \multicolumn{2}{|c|}{$(3)$} & \multicolumn{2}{|c|}{$(4)$} \\
\hline & $0.219^{* * *}$ & $(0.007)$ & $0.215^{* * *}$ & $(0.007)$ & $0.328^{* * *}$ & $(0.007)$ & $0.326^{* * *}$ & $(0.008)$ \\
\hline PT PSE Enrollment & $0.112^{* * *}$ & $(0.005)$ & $0.119 * * *$ & $(0.005)$ & $0.210^{* * *}$ & $(0.006)$ & $0.214^{* * *}$ & $(0.007)$ \\
\hline YSM & $0.111^{* * *}$ & $(0.001)$ & $0.105^{* * *}$ & $(0.001)$ & $0.102^{* * *}$ & $(0.001)$ & $0.094^{* * *}$ & $(0.001)$ \\
\hline$\left((\mathrm{YSM})^{2}\right) / 100$ & $-0.479^{* * *}$ & $(0.005)$ & $-0.480^{* * *}$ & $(0.005)$ & $-0.313^{* * *}$ & $(0.005)$ & $-0.333^{* * *}$ & $(0.006)$ \\
\hline Constant & $9.741^{* * *}$ & $(0.004)$ & $9.832^{* * *}$ & $(0.004)$ & $9.118^{* * *}$ & $(0.005)$ & $9.282^{* * *}$ & $(0.006)$ \\
\hline Observations & \multicolumn{2}{|c|}{$3,356,765$} & \multicolumn{2}{|c|}{$2,731,910$} & \multicolumn{2}{|c|}{$3,122,160$} & \multicolumn{2}{|c|}{$2,250,520$} \\
\hline$R^{2}$ & \multicolumn{2}{|c|}{0.06} & \multicolumn{2}{|c|}{0.05} & \multicolumn{2}{|c|}{0.06} & \multicolumn{2}{|c|}{0.05} \\
\hline
\end{tabular}

Table C.26 reports the estimated coefficients from the fixed effects estimation in which the dependent variable is the log of earnings. The PSE enrollment dummy variables included in the estimation are equal to 1 if the immigrant ever enrolled in full-time or part-time PSE after landing, respectively. Each model has a set of controls for occupation (9), industry (21), province/territory/major city of residence (13), first language spoken (6), marital status (2), year of landing (9), age at landing (1), age at landing squared divided by 100 (1). Specifications (2) and (4) include a control for log earnings in first full year in Canada. The sample used for the estimations is restricted to immigrants who were never absent from the tax records for a period of four consecutive years or more by each year since migration commencing from the 5th to 14th year since migration. Robust standard errors are reported in parentheses. Significance levels are indicated by $* *$ and $* * *$ for $5 \%$ and $1 \%$, respectively. 


\section{References}

Abadie, A. and G. W. Imbens (2006). Large Sample Properties of Matching Estimators for Average Treatment Effects. Econometrica 74, 235 - 267.

Adamuti-Trache, M. (2011). First 4 Years in Canada: Post-Secondary Education Pathways of Highly Educated Immigrants. International Migration and Integration 12, 61 - 83.

Aguir, A., F. Lakhal, N. Lakhal, and A. Malek (2015, May). Do Women on Boards and in Top Management Reduce Earnings Management? Evidence in France. Journal of Applied Business Research 31(3), $1107-1118$.

Anker, A. L., S. J. Freeman, K. K. Reed, and M. Tschirhart (2008). Is the Grass Greener? Sector Shifting and Choice of Sector by MPA and MBA Graduates. Nonprofit and Voluntary Sector Quarterly 37(4), $668-688$.

Aydemir, A. and C. Robinson (2008). Global Labour Markets, Return, and Onward Migration. Canadian Journal of Economics 41(4), 1285 - 1311.

Aydemir, A. and M. Skuterud (2005). Explaining the Deteriorating Entry Earnings of Canada's Immigrant Cohorts, 1966 - 2000. Canadian Journal of Economics 38(2), 641 647. 
Baker, M. and D. Benjamin (1994). The Performance of Immigrants in the Canadian Labour Market. Journal of Labor Economics 12(3), 369 - 405.

Banerjee, R., A. Verma, and T. Zhang (2018). Brain Gain or Brain Waste? Horizontal, Vertical, and Full Job-Education Mismatch and Wage Progression among Skilled Immigrant Men in Canada. International Migration Review 53(3), 646 - 670.

Barber, B. M. and T. Odean (2001). Boys Will Be Boys: Gender, Overconfidence, and Common Stock Investment. Quarterly Journal of Economics, 261 - 292.

Bargain, O. and B. Melly (2008). Public Sector Pay Gap in France: New Evidence Using Panel Data. Discussion Paper 3427.

Bartik, T. J. (1991). Who benefits from state and local economic development policies? Kalamazoo, MI: W.E. Upjohn Institute for Employment Research.

Bergstresser, D. and T. Philippon (2006). CEO Incentives and Earnings Management. Journal of Financial Econometrics 80, 511 - 529.

Bernile, G., V. Bhagwat, and S. E. Yonker (2016, June). Board Diversity, Firm Risk, and Corporate Policies.

Bertrand, M. (2009). CEOs. Annual Review of Economics 1, $1.1-1.29$.

Bertrand, M. (2018). Coase Lecture - The Glass Ceiling. Economica 85, $205-231$.

Bisson, A., A. Chakma, J. Côté, C. Dodds, L. Smith, and D. Wright (2012). International Education: A Key Driver of Canada's Future Prosperity. Technical report. 
Blinder, A. S. (1973). Wage Discrimination: Reduced Form and Structural Estimates. Journal of Human Resources 8(4), $436-455$.

Bollinger, C. R. and A. Chandra (2005, April). Iatrogenic Specification Error: A Cautionary Tale of Cleaning Data. Journal of Labor Economics 23(2), 235 - 257.

Bonikowska, A. and F. Hou (2015). The Earnings Advantage of Landed Immigrants who were Previously Temporary Residents in Canada. Analytical studies branch research paper series, catalogue no. 11f0019m - no. 370 .

Borjas, G. J. and B. Bratsberg (1996). Who Leaves? The Outmigration of the Foreign-Born. The Review of Economics and Statistics 78(1), 165 - 176.

Boyd, M. (2013). Wanted and Welcome?, Chapter Accreditation and the Labor Market Integration of Internationally Trained Engineers and Physicians in Canada, pp. 165 - 197. Springer New York.

Bratsberg, B. and J. F. Ragan Jr. (2002). The Impact of Host-Country Schooling on Earnings: A Study of Male Immigrants in the United States. Journal of Human Resources 13(1), $63-105$.

Byrne, K. A. and D. A. Worthy (2015). Gender Differences in Reward Sensitivity and Information Processing During Decision-Making. Journal of Risk Uncertainty 50, 55 - 71.

Cai, L. and A. Y. C. Liu (2011). Public-Private Sector Wage Gap in Australia: Variation Along the Distribution. British Journal of Industrial Relations 49(2), 362 - 390.

Campos, M. M. and M. Centeno (2012). Public-Private Wage Gaps in the Period Prior to 
the Adoption of the Euro: An Application Based on Longitudinal Data. Working Paper WP $1 / 2012$.

Card, D. (2001). Immigrant Inflows, Native Outflows, and the Local Labor Market Impacts of Higher Immigration. Journal of Labour Economics 19(1), 22 - 64.

Cheng, Q., T. Warfield, and M. Ye (2011, April). Equity Incentives and Earnings Management: Evidence from the Banking Industry. Journal of Accounting, Auditing \& Finance 26(2), $317-349$.

Chiswick, B. R. (1978). The Effect of Americanization on the Earnings of Foreign-born Men. Journal of Political Economy 86, 8.

Chiswick, B. R. and P. W. Miller (1994). The Determinants of Post-Immigration Investments in Education. Economics of Education Review 13(2), 163 - 177.

Ci, W., J. Galdo, M. Voia, and C. Worswick (2015). Wage Returns to Mid-Career Investments in Job Training Through Employer Supported Course Enrollment: Evidence for Canada. Discussion Paper 9007.

Ci, W., M. Laing, M. Voia, and C. Worswick (2020). Immigrant Earnings Returns to Post-Migration Education: Evidence for Canada, 1999-2013. Canadian Journal of Economics. forthcoming.

Cobb-Clark, D. T., M. Connolly, and C. Worswick (2005). Post-Migration Investments in Education and Job Search: A Family Perspective. Journal of Population Economics 18, $663-690$. 
Croson, R. and U. Gneezy (2009). Gender Differences in Preferences. Journal of Economic Literature $47(2), 448-474$.

Dechow, Patricia M. \& Dichev, I. D. (2002). The Quality of Accruals and Earnings: The Role of Accrual Estimation Errors. The Accounting Review 77, 35 - 59.

Dechow, P. M. (1994). Accounting Earnings and Cash Flows as Measures of Firm Performance: The Role of Aaccounting Accruals. Journal of Accounting and Economics 18(1), $3-42$.

Dechow, P. M., R. G. Sloan, and A. P. Sweeney (1995, April). Detecting Earnings Management. The Accounting Review 70(2), 193 - 225.

DeVoretz, D. J. and J. Ma (2002). Triangular Human Capital Flows between Sending, Entrepot and the Rest of the World Regions. Special Issue on Migration and Globalization, Canadian Studies in Population 29(1), 53 - 69.

Di Matteo, L. (2015, June). An Analysis of Public and Private Sector Employment Trends in Canada, 1990 - 2013. Technical report.

Disney, R. and A. Gosling (1998). Does It Pay to Work in the Public Sector? Fiscal Studies 19(4), $347-374$.

Dohmen, G. B., A. Falk, D. Huffman, U. Sunde, and G. G. Wagner (2011). Individual Risk Attitudes: Measurement, Determinants, and Behavioral Consequences. Journal of the European Economic Association 9(3), 522 - 550.

Dormady, N. C., R. T. Greenbaum, and K. A. Young (2017). Sex, Gender, and Disasters: 
Experimental Evidence on the Decision to Invest in Resilience. International Journal of Disaster Risk Reduction 24, $439-450$.

Dostie, B. and P. T. Leger (2014). Firm-Sponsored Classroom Training: Is It Worth It for Older Workers? Canadian Public Policy 40(4), 377 - 390.

Duleep, H. O. and M. Regets (1997). Measuring Immigrant Wage Growth Using Matched CPS Files. Demography 34(2), $239-249$.

Duleep, H. O. and M. Regets (1999). Immigrants and Human-Capital Investment. American Economic Review 89(2), 186 - 191.

Duong, L. and J. Evans (2015). CFO Compensation: Evidence from Australia. Pasific-Basin Finance Journal 35, 425 - 443.

Dustmann, C. and A. van Soest (1998). Public and Private Sector Wages of Male Workers in Germany. European Economic Review 42(8), 1417-1441.

Easton, P. and M. Zmijewski (1989). Cross - Sectional Variation in the Stock Market Response to Accounting Earnings Announcements. Journal of Accounting and Economics 11(2-3), $117-141$.

Erkut, S., A. M. Konrad, and V. W. Kramer (2008). Critical Mass: hy Three or More Women Enhance Governance. Organizational Dynamics 37(2), 145 - 164.

Federation of Canadian Municipalities (2013). Canada's Aging Population: The Municipal Role in Canada's Demographic Shift. Ottawa, Canada. 
Fehr-Duda, H., M. De Gennaro, and R. Schubert (2006). Gender, Financial Risk, and Probability Weights. Theory and Decision 60, $283-313$.

Ferrer, A. and W. C. Riddell (2008, February). Education, Credentials, and Immigrant Earnings. Canadian Journal of Economics 41(1), 186 - 216.

Flory, J. A., A. Leibbrandt, and J. A. List (2015). Do Competitive Workplaces Deter Female Workers? A Large-scale Natural Field Experiment on Job Entry Decisions. Review of Economic Studies 82(1), $122-155$.

Francis, B., I. Hasan, J. Chool Park, and Q. Wu (2015). Gender Differences in Financial Reporting Decision Making: Evidence from Accounting Conservatism. Contemporary Accounting Research 32(3), 1285 - 1318.

Friedberg, R. M. (2000). You Can't Take It With You? Immigrant Assimilation and the Portability of Human Capital. Journal of Labor Economics 18(2), 221 - 251.

Gassen, J. and G. Markarian (2009, September). Investor Fear and Earnings Management: VIX-based Evidence. First Draft.

Goldmann, G., A. Sweetman, and C. Warman (2015). The Portability of New Immigrants' Human Capital: Language, Education, and Occupational Skills. Canadian Public Policy 41, S64 - S79.

Goldsmith-Pinkham, P., I. Sorkin, and H. Swift (2020). Bartik Instruments: What, When, Why, and How. American Economic Review 110(8), 2586 - 2624.

Graham, J. F., M. J. Graham, J. K. Myers, and E. J. Stendardi Jr. (2002). Gender Differences 
in Investment Strategies: An Information Processing Perspective. International Journal of Bank Marketing 20(1), $17-26$.

Graham, J. R., C. R. Harvey, and M. Puri (2013). Managerial Attitudes and Corporate Actions. Journal of Financial Economics (109), 103 - 121.

Green, D. and C. Worswick (2012). Immigrant Earnings Profiles in the Presence of Human Capital Investment: Measuring Cohort and Macro Effects. Labour Economics 19(2), 241 $-259$.

Guay, W. R., S. P. Kothari, and R. L. Watts (1996). A Market - Based Evaluation of Discretionary Accrual Models. Journal of Accounting Research 34, 83 - 105.

Gul, F. A., B. Srinidhi, and J. Tsui (2011). Female Directors and Earnings Quality. Contemporary Accounting Research 28(5), 1610 - 1644.

Gunderson, M. (1979). Earnings Differentials between the Public and Private Sectors. Canadian Journal of Economics 12(2), 228 - 242.

Gunderson, M., D. Hyatt, and C. Riddell (2000). Pay Differences between the Government and Private Sectors: Labour Force Survey and Census Estimates. CPRN Discussion Paper W-10, Ottawa, ON, Canada.

Gyapong, E., F. Hu, and R. Monem (2016). Do Women and Ethnic Minority Directors Influence Firm Value? Evidence from an Emerging Market with a History of Legal Racial Segregation. Journal of Business Finance \& Accounting 43(3 - 4), 370 - 413. 
Hambrick, D. C. and P. A. Mason (1984). Upper Echelons: The Organization as a Reflection of its Top Managers. Academy of Management Review 9(2), 193 - 206.

Hartog, J. and H. Oosterbeek (1993). Public and Private Sector Wages in the Netherlands. European Economic Review 37(1), 97 - 114.

Heckman, J., L. Lochner, and C. Taber (1998). Tax Policy and Human-Capital Formation. American Economic Review Papers and Proceedings 88, 293 - 297.

Heitmueller, A. (2004). Public-Private Sector Wage Differentials in Scotland: An Endogenous Switching Model. IZA Discussion Paper 992.

Hermalin, B. E. and M. S. Weisbach (1998). Endogenously Chosen Boards of Directors and Their Monitoring of the CEO. American Economic Review 88(1), 96 - 118.

Hou, F. and Y. Lu (2017). International Students, Immigration and Earnings Growth: The Effect of a Pre-immigration Host-Country University Education. Analytical studies branch research paper series, catalogue no. 11f0019m - no. 395.

Hou, F., Y. Lu, and C. Schimmele (2019). Recent Trends in Over-education by Immigration Status. Analytical Studies Branch Research Paper Catalogue No. 11F0019M - No. 436.

Hui, S. and J. Smith (2003). The Labour Market Impacts of Adult Education and Training in Canada. Education, Skills and Learning Research Paper Catalogue no. 81-595-MIE2003008.

Imbens, G. (2014, March). Matching Methods in Practice: Three Examples. Working Paper 19959. 
Isidro, H. and M. Sobral (2015). The Effects of Women on Corporate Boards on Firm Value, Financial Performance, and Ethical and Social Compliance. Journal of Business Ethics 132, 1 - 19.

Jaeger, D. A., J. Ruist, and J. Stuhler (2018, January). Shift-Share Instruments and the Impact of Immigration. Discussion Paper 11307, IZA.

Jann, B. (2008). The Blinder-Oaxaca Decomposition for Linear Regression Models. The Stata Journal 8(4), $453-479$.

Jiang, J. X., K. R. Petroni, and I. Y. Wang (2010). CFOs and CEOs: Who Have the Most Influence on Earnings Management? Journal of Financial Economics 96, 513 - 526.

Jones, J. J. (1991). Earnings Management During Import Relief Investigations. Journal of Accounting Research 29(2), 193 - 228.

Kaplan, S. N. and M. Sorensen (2017, September). Are CEOs Different? Charateristics of Top Managers. Working Paper 23832.

Kasznik, R. (1999). On the Association Between Voluntary Disclosure and Earnings Management. Journal of Accounting Research 37(1), 57 - 81.

Khan, A. H. (1997). Post-Migration Investment in Education by Immigrants in the United States. Quarterly Review of Economics and Finance 37, 285 - 313.

Kim, D. and Y. Qi (2010). Accruals Quality, Stock Returns, and Macroeconomic Conditions. The Accounting Review 85(3), 937 - 978. 
Konrad, A. M. and V. W. Kramer (2006, December). How Many Women Do Boards Need? Harvard Business Review.

Kormendi, R. and R. Lipe (1987). Earnings Innovations, Earnings Persistence and Stock Returns. Journal of Business 60(3), $323-345$.

Kothari, S. P., A. J. Leone, and C. E. Wasley (2005). Performance Matched Discretionary Accrual Measures. Journal of Accounting and Economics 39(1), 163 - 197.

Lange, F. (2007). The Speed of Employer Learning. Journal of Labor Economics 25(1), 1 35.

Lee, B. B. and W. Vetter (2015). Critical Evaluation of Accrual Models in Earnings Management Studies. Journal of Accounting and Finance 15(1), $62-71$.

Li, C., G. Gervais, and A. Duval (2006). The Dynamics of Overqualification: Canada's Underemployed University Graduates. Analysis in Brief 11-621-MIE, Statistics Canada.

Loukil, N. and O. Yousfi (2016). Does Gender Diversity on Corporate Boards Increase Risk - Taking? Canadian Journal of Administrative Sciences 33, 66 - 81.

Lucifora, C. and D. Meurs (2006). The Public Sector Pay Gap in France, Great Britain and Italy. Review of Income and Wealth 52(1), $43-59$.

Mallett, T. and Q. Wong (2008, December). Wage Watch. Technical report.

McDonald, J. T. and C. Worswick (1998). The Earnings of Immigrant Men in Canada: Job Tenure, Cohort, and Macroeconomic Conditions. Industrial and Labor Relations Review $51(3), 465-482$. 
McInturff, K. and P. Tulloch (2014, October). Narrowing the Gap: The Difference That Public Sector Wages Make. Technical report.

McNichols, M. F. (2002). The Quality of Accruals and Earnings: The Role of Accrual Estimation Errors: Discussion. The Accounting Review 7r(4), 61 - 69.

Mincer, J. A. (1974). The Human Capital Earnings Function, Chapter Schooling, Experience, and Earnings, pp. $83-96$. NBER.

Morissette, R., P. C. W. Chan, and Y. Lu (2015). Wages, Youth Employment, and School Enrollment: Recent Evidence from Increases in World Oil Prices. Journal of Human Resources 50(1), $222-253$.

Mueller, R. E. (2000). Public- and Private-Sector Wage Differentials in Canada Revisited. Industrial Relations 39(3), $375-400$.

Nickell, S. (1981). Biases in Dynamic Models with Fixed Effects. Econometrica 49(6), 1417 $-1426$.

Oaxaca, R. (1973). Male - Female Wage Differentials in Urban Labor Markets. International Economic Review 14(3), $693-709$.

Orr, M. and D. M. West (2007). Race, Gender, and Communications in Natural Disasters. The Policy Studies Journal 35(4), 569 - 586.

Pae, J. (2005). Expected Accrual Models: The Impact of Operating Cash Flows and Reversals of Accruals. Review of Quantitative Finance and Accounting 24, 5-22. 
Parent, D. (2003). Employer-Supported Training in Canada and its Impact on Mobility and Wages. Empirical Economics 28, $431-459$.

Parotta, P. and N. Smith (2013). Female - Led Firms: Performance and Risk Attitudes. Discussion Paper 7613.

Penman, S. and X. Zhang (2002). Accounting Conservatism, the Quality of Earnings, and Stock Returns. The Accounting Review rr(2), 237 - 264.

Picot, G. and P. Piraino (2013). Immigrant Earnings Growth: Selection Bias or Real Progress? Canadian Journal of Economics 46(4), 1510 - 1536.

Postel-Vinay, F. (2015). Does it Pay to be a Public-Sector Employee? Technical Report 156.

Prescott, D. and B. Wandschneider (1999). Public / Private Sector Wage Differentials in Canada - Evidence from the 1991 and 1982 Surveys of Consumer Finance. Applied Economics 31(6), $723-731$.

Richardson, S., R. Sloan, M. Soliman, and I. Tuna (2005). Accrual Reliability, Earnings Persistence and Stock Prices. Journal of Accounting and Economics 39(3), 437 - 485.

Robinson, C. (1995). Union Incidence in the Public and Private Sectors. Canadian Journal of Economics 28(4b), 1056 - 1076.

Robinson, C. and N. Tomes (1984). Union Wage Differentials in the Public and Private Sectors: A Simultaneous Equations Specification. Journal of Labour Economics 2(1), 106 $-127$. 
Rollin, A. M. (2011). The Income of Immigrants Who Pursue Post-Secondary Education in Canada. Perspectives on Labour and Income 23(3).

Rosenbaum, P. and D. Rubin (1983). The Central Role of the Propensity Score in Observational Studies For Causal Effects. Biometrika 70(1), 33 - 38.

Rosenbaum, P. R. and D. B. Rubin (1985). Constructing a Control Group Using Multivariate Matched Sampling Methods That Incorporate the Propensity Score. The American Statistician 39(1), $33-38$.

Shapiro, D. M. and M. Stelcner (1989). Canadian Public-Private Sector Earnings Differentials, 1970 - 1980. Industrial Relations 28(1), 72 - 81.

Simpson, W. (1985). The Impact of Unions on the Structure of Canadian Wages: An Empirical Analysis with Microdata. Canadian Journal of Economics 18(1), 164 - 181.

Skuterud, M. and Z. J. Chen (2017). Relative Labour Market Performance of Former International Students: Evidence from the National Graduates Survey. Canadian Public Policy 44(3), $207-225$.

Smith, S. P. (1976a). Government Wage Differentials by Sex. Journal of Human Resources 11(2), $185-199$.

Smith, S. P. (1976b). Pay Differentials between Federal Government and Private Sector Workers. ILR Review 29(2), 179 - 197.

Status of Women Canada (2016, November). Increasing the Representation of Women on Canadian Boards. Technical report. 
Stein, L. C. D. and C. C. Y. Wang (2016). Economic Uncertainty and Earnings Management. Working Paper 16 - 103.

Tiagi, R. (2010). Public Sector Wage Premium in Canada: Evidence from Labour Force Survey. Labour 24(4), $456-473$.

Warman, C. and C. Worswick (2015). Technological Change and Declining Immigrant Outcomes, Implications for Income Inequality in Canada. Canadian Journal of Economics 48, $736-772$.

Webb, M. D. (2019). Finish It and It's Free: An Evaluation of College Graduation Subsidies. Carleton Economic Papers CEP 19-08, Carleton University. 